\title{
Immunomodulatory roles of endotoxin and glutaraldehyde in the development of latex allergy
}

\author{
Michael D. Howell \\ West Virginia University
}

Follow this and additional works at: https://researchrepository.wvu.edu/etd

\section{Recommended Citation}

Howell, Michael D., "Immunomodulatory roles of endotoxin and glutaraldehyde in the development of latex allergy" (2002). Graduate Theses, Dissertations, and Problem Reports. 1676.

https://researchrepository.wvu.edu/etd/1676

This Dissertation is protected by copyright and/or related rights. It has been brought to you by the The Research Repository @ WVU with permission from the rights-holder(s). You are free to use this Dissertation in any way that is permitted by the copyright and related rights legislation that applies to your use. For other uses you must obtain permission from the rights-holder(s) directly, unless additional rights are indicated by a Creative Commons license in the record and/ or on the work itself. This Dissertation has been accepted for inclusion in WVU Graduate Theses, Dissertations, and Problem Reports collection by an authorized administrator of The Research Repository @ WVU.

For more information, please contact researchrepository@mail.wvu.edu. 
Immunomodulatory Roles of Endotoxin and Glutaraldehyde in the Development of Latex Allergy

\author{
Michael D. Howell
}

A dissertation submitted to the School of Medicine at West Virginia University in partial fulfillment of the requirements for the degree of

\author{
Doctor of Philosophy \\ in \\ Microbiology, Immunology, and Cell Biology \\ B. Jean Meade, D.V.M., Ph.D., Chair \\ Christopher Cuff, Ph.D. \\ Daniel Lewis, Ph.D. \\ Albert Munson, Ph.D. \\ Rosana Schafer, Ph.D.
}

Department of Microbiology, Immunology, and Cell Biology

\author{
Morgantown, West Virginia \\ 2002
}

Keywords: Latex, Allergy, Sensitization, Airway Hyper-reactivity, Endotoxin, Glutaraldehyde, Concurrent Exposure

Copyright (C) 2002 Michael D. Howell 


\title{
ABSTRACT \\ Immunomodulatory Roles of Endotoxin and Glutaraldehyde in the Development of Latex Allergy
}

\author{
Michael D. Howell
}

Although much data has been obtained related to the clinical manifestations of latex allergy and the characterization of the protein allergens, little is known regarding the natural history of the disease. These studies were undertaken to demonstrate the immunological relevance of both dermal and respiratory exposure in the development of latex allergy and to investigate the role of co-exposure by these routes to other agents in the health care environment on the development of NRL sensitization.

An initial study in female BALB/c mice demonstrated comparable rates of induction of latex specific IgE following dermal and respiratory latex exposure, demonstrating the importance of both routes in the development of latex allergy. Upon further investigation using whole body plethysmography, non-specific airway hyperreactivity to methacholine was observed in mice following both dermal and intratracheal sensitization with latex proteins. In contrast, at these exposure levels latex specific airway hyper-reactivity was only observed in dermally sensitized mice.

Endotoxin, a common contaminant of powdered gloves, and glutaraldehyde, a frequently used cold sterilant, were chosen to investigate the immunomodulatory effects of other agents in the health care setting on the development of latex allergy. In comparison with mice exposed to latex alone, mice concurrently exposed to latex and increasing concentrations of endotoxin demonstrated $\sim 50 \%$ lower levels of latex specific IgE and a decrease in latex specific airway hyper-reactivity and mucin production. The same animals demonstrated increased levels of latex specific IgG2a and IgA, cellular infiltration (i.e. macrophages and neutrophils) into the peribronchial and perivascular regions of the lung, messenger IFN- $\gamma$ and IL-12 levels in the draining mediastinal lymph nodes, and non-specific airway hyper-reactivity upon respiratory challenge with methacholine. Upon concurrent dermal exposure to latex and concentrations of glutaraldehyde surrounding the permissible exposure limit, mice demonstrated a dose responsive increase in latex specific $\operatorname{IgE}$ levels through an as yet undetermined mechanism.

These studies demonstrate the potential for mixed exposures in the health care environment to diversely modulate the development of $\operatorname{IgE}$ mediated responses to NRL proteins underscoring the importance of environmental factors in the development of allergies to foreign antigens. 


\section{ACKNOWLEDGEMENTS}

To my advisor, mentor and friend, Dr. Barbara Jean Meade, for her knowledge, support, discipline, motivation and persistence in helping me grow as a scientist.

To Dr. Albert E. Munson for always stimulating the mind to understand both the question and answer in all of science and life.

To Drs. Christopher Cuff, Daniel Lewis, and Rosana Schafer for supporting me through out the course of my training and offering valuable insight into my research.

To my predecessors, Drs. Michael Woolhiser, Scott Manetz, and Ben Hayes, for their direction, assistance, patience and advice during my early years in the laboratory.

To friends along the way who have helped mold me both scientifically and personally throughout my stay in Morgantown. To Kurt Brumbaugh for his friendship, support through life experiences, and constant nagging about proper statistical analysis. To Melanie Flint (Crazy Brit) for both scientific stimulation and comic relief. To Kim Klink for scientific discussion, analysis of artificial precipitation, and humor. To Ashley Murray for being by my side, supporting me, and helping me maintain my sanity through the final stages of my dissertation and experiences ahead.

To all of the staff at NIOSH who assisted me during the course of my education and research with special thanks to Leon Butterworth, Shahla Azadi, Beverly Fragale, Kim Collins, and the Pathology group.

And most importantly, to my family, not only because they gave birth to me, but also because they have always told me to shoot for the stars and have supported me every step

of the way. 


\section{TABLE OF CONTENTS}

\section{Page}

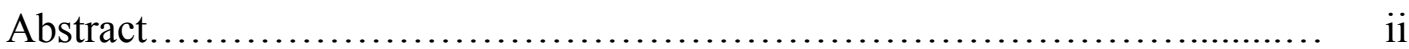

List of Tables....................................................... ix

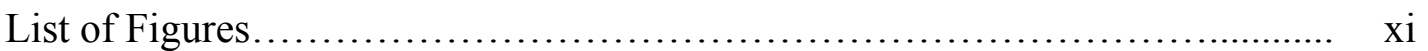

List of Abbreviations.............................................. xiv

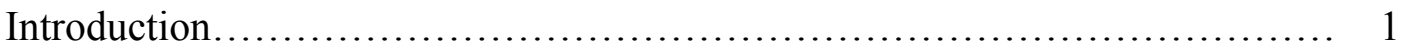

\section{Literature Review}

Natural Rubber Latex............................................. 4

Overview of the IgE Mediated Allergic Response.................... 12

The "Skin Immune System", .................................. 17

Glutaraldehyde.............................................. 21

Endotoxin .................................................. 26

Materials and Methods

Animals

Mice.

Guinea Pigs........................................... 31

Rabbits............................................. 32

Test Articles.................................................... 32

Latex Protein Preparation and Quantification..................... 33

Radiolabeled Materials........................................... 37 
Murine Exposures

Dermal Exposures....................................... 37

Intranasal Exposures.................................. 38

Intratracheal Exposures................................... 39

Subcutaneous Exposures................................. 39

Guinea Pig Exposures......................................... 39

Total IgE ELISA ................................................. 40

Latex Specific ELISA........................................ 41

Anti-NAL Antibody Generation

Murine Anti-NAL Antibody Generation.................... 43

Rabbit Anti-NAL Antibody Generation........................ 43

Phenotypic Analysis

Antibodies.............................................. 44

Flow Cytometry Procedure................................. 45

Whole Body Plethysmography

Methacholine Challenge $\ldots . \ldots \ldots \ldots \ldots \ldots \ldots \ldots \ldots \ldots \ldots \ldots . . \ldots, 46$

NAL Challenge......................................... 47

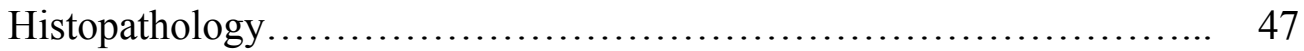

Dermal Penetration Experiments

Radiolabeling of Latex Proteins........................... 48

Penetration Apparatus.................................... 49

Harvesting Skin for In Vitro Penetration Studies.............. 50

In Vitro Percutaneous Penetration Assay...................... 51 
Skin Barrier Test....................................... 51

Radiolabeled Latex Protein Penetration Studies................. 52

SDS-PAGE and Phosphoimaging........................... 54

Immunohistochemical Evaluation of HGP Skin Sections.......... 54

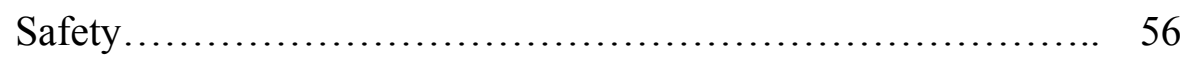

RNA Isolation.................................................... 59

In Vitro Transcription.................................................. 61

Real-Time Quantitative Polymerase Chain Reaction.................. 62

Epidermal Sheet Preparation and Staining........................... 64

Statistics........................................................... 65

Results

General Observations and Body Weights........................... 67

Comparison of Sensitization Routes

Total IgE Response ....................................... 67

Latex Specific IgE Response................................ 68

NAL Sensitization and Airway Hyper-Reactivity

Total IgE Levels......................................... $\quad 72$

Latex Specific Antibody Responses......................... $\quad 73$

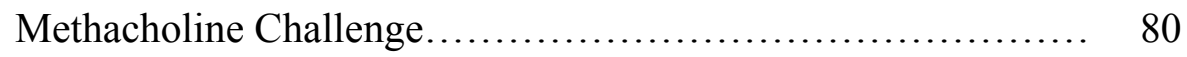

NAL Specific Challenge .................................... 81

Immunomodulatory Effect of Endotoxin on the Development of an IgE Mediated Hypersensitivity Response to Latex Proteins

Total IgE Response........................................... 85

Latex Specific Response................................... 86 
Characterization of the Immunomodulatory Response

Total IgE Response $\ldots \ldots \ldots \ldots \ldots \ldots \ldots \ldots \ldots \ldots \ldots \ldots \ldots \ldots \ldots . \ldots 4$

Latex Specific Antibody Response....................... 95

Non-Specific Airway Hyper-reactivity ..................... 95

Antigen Specific Airway Hyper-reactivity................... 96

Histopathological Evaluation of the Lung Following

Concurrent Exposure to Latex and Endotoxin................. 96

Cytokine Evaluation................................... 106

Correlation between Class Switch and Cytokine Response

Latex Specific IgG2a Antibodies.......................... 109

Th1 Cytokine Message Levels............................ 111

Immunomodulatory Role of Glutaraldehyde in the Development

of an IgE Mediated Hypersensitivity Response to Latex Proteins

Serum IgE Response..$\ldots \ldots \ldots \ldots \ldots \ldots \ldots \ldots \ldots \ldots \ldots \ldots \ldots \ldots$

Potential Role for Barrier Disruption

In Vitro Percutaneous Penetration of Latex Proteins

Barrier Integrity in Mice Concurrently Exposed to Latex and Glutaraldehyde.

Investigations of the Mechanisms Leading to the Augmented IgE Response in Mice Concurrently Exposed to Latex and Glutaraldehyde

Serum IgE Response.

Cytokine Micro-Environment in the Draining Lymph Node. ...

Expression of Cell Surface Markers and Co-Stimulatory Molecules

Discussion. 
Appendix

Appendix 1: Components of One Liter of HBHSS

182

Appendix 2: Body Weights of Mice Exposed to Latex Proteins.........

Vita.

193 


\section{LIST OF TABLES}

Table

Page

1. Major Allergens of Natural Rubber Latex ......................... 11

2. Lipopolysaccharide and Endotoxin Content in Bacterial Strains ......... 32

3. Reverse Transcription Reaction for cDNA in RT-PCR Analysis......... 61

4. Thermocycler Setting for Reverse Transcription Reaction............. 62

5. PCR Reaction Mix for GADPH Controls.......................... 63

6. PCR Reaction Mix for Cytokines................................ 64

7. RT-PCR Settings for Thermocycler............................ 64

8. Histopathological Analysis of the Lung Following Concurrent Exposure to Latex and Increasing Concentrations of Endotoxin from $S$. tyhpimurium.

9. Penetration of Latex Protein through Hairless Guinea Pig Skin Previously Exposed to 0.75 ppm Glutaraldehyde. . .

10. Percutaneous Penetration of Latex Protein through Hairless Guinea Pig Skin Previously Exposed to 1ppm Glutaraldehyde.

11. Modulation of B Cell Markers Upon Concurrent Exposure to Latex and Glutaraldehyde.

12. Modulation of MHC Class II Expression and T Cell Markers Upon Concurrent Exposure to Latex and Glutaraldehyde....

13. Time Course of DLN Cell Counts in Mice Concurrently Exposed to Latex and Glutaraldehyde...

14. Time Course of B220 Expression in DLN Cells of Mice Following Concurrent Exposure to Latex and Glutaraldehyde.

15. Time Course of IgE Expression on B Cells in the DLN of Mice Concurrently Exposed to Latex and Glutaraldehyde.

16. Time Course of CD86 Expression on B Cells in Mice Concurrently Exposed to Latex and Glutaraldehyde. 
17. Time Course of CD40 Expressing B Cells in the DLN of Mice Concurrently Exposed to Latex and Glutaraldehyde.....................

18. Time Course of CD4+ T Cells in the DLN of Mice Concurrently Exposed to Latex and Glutaraldehyde.

19. Time Course of CD28+ Expressing CD4+ T Cells in Mice Concurrently Exposed to Latex and Glutaraldehyde............................... 140

20. Time Course of DLN Cells Expressing MHC Class II I Mice Concurrently Exposed to Latex and Glutaraldehyde..... 


\section{LIST OF FIGURES}

Figure

Page

1. Overview of the IgE Mediated Allergic Response .................... 16

2. Illustration of the Different Layers of the Skin.................... 20

3. $10 \%$ SDS-PAGE of Endotoxin from Salmonella tyhpimurium and NAL Proteins .............................................. 35

4. $10 \%$ SDS-PAGE of Glutaraldehyde and NAL Proteins................. 36

5. In Vitro Flow Through Diffusion Cell Apparatus..................... 57

6. Representative Graph of Temperature and Humidity Readings in Hairless Guinea Pig In Vitro Percutaneous Penetration Experiments ............ 58

7. Total Serum IgE Levels in Mice Exposed to $50 \mu \mathrm{g}$ of Latex Proteins by Different Routes of Administration.

8. Latex Specific Serum Immunoglobulin Levels in Mice Exposed to $50 \mu \mathrm{g}$ of Latex Proteins by Several Routes.

9. Time Course of Total Serum IgE Production in Mice Dermally, Intranasally, or Intratracheally Exposed to Latex Proteins............. 75

10. Final Total Serum IgE Levels in Latex Exposed Mice................. 76

11. Latex Specific Serum Antibody Levels on Day 93 in Dermally Exposed Mice.

12. Latex Specific Serum Antibody Levels on Day 51 in Intranasally Exposed Mice

13. Latex Specific Serum Antibody Levels on Day 79 in Intratracheally Exposed Mice.

14. Non-Specific Airway Hyper-reactivity in Previously Sensitized Mice....

15. Latex Specific Airway Hyper-reactivity in Previously Sensitized Mice... 84

16. Total IgE Levels in Mice Intranasally Exposed to NAL and Endotoxin from Salmonella typhimurium

17. Total IgE Response in Mice Concurrently Exposed to NAL and Different Strains of Bacterial Endotoxin. 
18. Latex Specific Serum Antibody Response in Mice Intranasally Exposed to NAL and 5000-50,000 EU of Endotoxin from Salmonella typhimurium

19. Latex Specific Serum Antibody Response in Mice Intranasally Exposed to NAL and Endotoxin from Salmonella typhimurium

20. Latex Specific Serum Antibody Response in Mice Intranasally Exposed to NAL and Endotoxin from Salmonella typhosa ........................

21. Latex Specific Serum Antibody Response in Mice Intranasally Exposed to NAL and Endotoxin from Escherichia coli...

22. Total IgE Levels in Mice Intratracheally Exposed to NAL and Endotoxin from Salmonella typhimurium.

23. Latex Specific Serum Response in Mice Intratracheally Exposed to NAL and Endotoxin from Salmonella typhimurium....

24. Levels of Non-Specific Airway Hyper-Reactivity in Mice Exposed to Latex and Increasing Concentrations of Endotoxin.

25. Latex Specific Airway Hyper-Reactivity in Mice Exposed to Latex and Increasing Concentrations of Endotoxin.

26. Histopathological Evaluation of Cellular Infiltration Following Concurrent Respiratory Exposure to Latex and Endotoxin from S. typhimurium...... 104

27. Mucin Production in Mice Following Concurrent Exposure to Latex and Endotoxin from S. typhimurium

28. Th2 Cytokine Message Levels in Mice Exposed to Latex and Increasing Concentrations of Endotoxin from S. typhimurium.

29. Th1 Cytokine Message Levels in Mice Exposed to Latex and Increasing Concentrations of Endotoxin from $S$. typhimurium

30. Time Course of Latex Specific Serum IgG2a Levels in Mice Exposed to Latex and 2500 EU of Salmonella typhimurium.

31. Latex Specific Serum IgG2a Levels on Day 16 in Mice Exposed to Latex and Increasing Concentrations of Endotoxin....

32. Th1 Cytokine Message Levels in Mice Exposed to Latex and Endotoxin for 16 Days 
33. Total and Latex Specific Serum IgE Levels in Mice Concurrently Exposed to Latex and Glutaraldehyde for 72 Days............................. 115

34. Serum and Latex Specific Serum IgE Levels in Mice Concurrently Exposed to Latex and Glutaraldehyde for 65 Days............................ 118

35. Serum and Latex Specific Serum IgE Levels in Mice Concurrently Exposed to Latex and Glutaraldehyde for 86 Days............................... 119

36. Latex Protein Penetration in Hairless Guinea Pig Skin Exposed to 0.75ppm Glutaraldehyde....

37. Latex Protein Penetration in Hairless Guinea Pig Skin Exposed to 1ppm Glutaraldehyde.

38. Barrier Integrity in Skin Previously Exposed to Latex and Increasing Concentrations of Glutaraldehyde.

39. Total and Latex Specific Serum IgE Levels in Mice Exposed to Latex and Glutaraldehyde on the Ears

40. Cytokine Message Levels in Mice Exposed to Latex and Glutaraldehyde for 86 Days

41. Time Course Evaluation of MHC Class II Expressing Langerhans' Cell Numbers in Mice Concurrently Exposed to Latex and Glutaraldehyde .... 


\section{LIST OF ABBREVIATIONS}

ACGIH

ANOVA

APC

AP

ASTM

BBS

$\mathrm{cc}$

CD

CDC

cDNA

DNA

DNP

DPM

DTH

EDTA

ELISA

EU

FACS

FBS

FDA

FITC
American Conference for Government Industrial Hygienists

One-Way Analysis of Variance

Antigen Presenting Cell

Alkaline Phosphatase

American Society for Testing and Materials

Borate Buffered Saline

Cubic Centimeters

Clusters of Differentiation

Center for Disease Control and Prevention

Complementary DNA

Deoxyribonucleic Acid

Dinitrophenyl

Decays Per Minute

Delayed Type Hypersensitivity

Ethylenediaminetetraacetic Acid

Enzyme Linked Immunosorbent Assay

Endotoxin Units

Fluorescence Activated Cell Sorter

Fetal Bovine Serum

Food and Drug Administration

Fluorescein Isothiocyanate 


\begin{tabular}{|c|c|}
\hline GM-CSF & Granulocyte Macrophage - Colony Stimulating Factor \\
\hline $\mathrm{HCW}$ & Health Care Workers \\
\hline HELD & Health Effects Laboratory Division \\
\hline HRP & Horseradish Peroxidase \\
\hline i.n. & Intranasal \\
\hline i.t. & Intratracheal \\
\hline IFN- $\gamma$ & Interferon-gamma \\
\hline $\operatorname{Ig}$ & Immunoglobulin \\
\hline IL & Interleukin \\
\hline $\mathrm{kD}$ & Kilodalton \\
\hline LAL & Limulus Amebocyte Assay \\
\hline LPS & Lipopolysaccharide \\
\hline $\mathrm{MCH}$ & Methacholine \\
\hline MDI & Diphenylmethane-4,4'-Diisocyanate \\
\hline $\mathrm{mg}$ & Milligram \\
\hline MHC & Major Histocompatibility Complex \\
\hline $\mathrm{ml}$ & Milliliter \\
\hline mRNA & Messenger RNA \\
\hline$\mu \mathrm{g}$ & Microgram \\
\hline$\mu l$ & Microliter \\
\hline$\mu \mathrm{m}$ & Micrometer \\
\hline NAL & Non-ammoniated Latex \\
\hline $\mathrm{NIH}$ & National Institute of Health \\
\hline
\end{tabular}




\begin{tabular}{|c|c|}
\hline NIOSH & National Institute for Occupational Safety and Health \\
\hline NK & Natural Killer \\
\hline NRL & Natural Rubber Latex \\
\hline OSHA & Occupational Safety and Health Administration \\
\hline OVA & Ovalbumin \\
\hline PAGE & Polyacrylamide Gel Electrophoresis \\
\hline PBS & Phosphate Buffered Saline \\
\hline PCR & Polymerase Chain Reaction \\
\hline PE & Phycoerythrin \\
\hline PEF & Peak Expiratory Flow \\
\hline PenH & Enhanced Pause \\
\hline PIF & Peak Inspiratory Flow \\
\hline PMN & Polymorphonuclear \\
\hline ppm & Parts Per Million \\
\hline $\mathrm{rcf}$ & Relative Centrifugal Force \\
\hline RNA & Ribonucleic Acid \\
\hline RRIM & Rubber Research Institute of Malaysia \\
\hline RT & Relaxation Time \\
\hline s.c. & Subcutaneous \\
\hline SDS & Sodium dodecylsulfate \\
\hline SE & Standard error \\
\hline TCA & Trichloroacetic Acid \\
\hline TCR & T Cell Receptor \\
\hline
\end{tabular}


Te

TGF

Th

TMA

TNF

$\mathrm{VH}$
Time of Expiration

Transforming Growth Factor

T Helper Cell

Trimellitic Anhydride

Tumor Necrosis Factor

Vehicle 


\section{INTRODUCTION}

Despite efforts to reduce protein and allergen content in natural rubber latex gloves, latex allergy continues to pose a serious health risk to those occupationally exposed to natural rubber latex products. Exposure to latex proteins in natural rubber latex products has been shown to induce an IgE mediated response (Czuppon et al., 1993) which upon subsequent exposure may elicit urticaria, rhinitis, or anaphylactic shock (Sussman et al., 1991; Tomazic et al., 1992; Alenius et al., 1994; Kagy and Blaiss, 1998; Kelso, 1998; Tomei et al., 2000). While the prevalence of latex allergy among the general population is believed to be less than 1\% (Liss and Sussman, 1999), approximately $5-17 \%$ of health care workers have been reported to have serum $\operatorname{IgE}$ specific for NRL allergens (Turjanmaa, 1987; Arellano et al., 1992; Lagier et al., 1992; Grzybowski et al., 1996; Liss et al., 1997; Liss and Sussman, 1999; Sinha and Harrison, 1999).

Other adverse reactions to natural rubber latex products include irritant dermatitis and allergic contact dermatitis. Irritant dermatitis is the most frequently observed manifestation among health care workers due to occlusion and the frequent donning and removal of gloves (Sussman and Beezhold, 1995; Alessio et al., 1997). Additionally,

chemicals added to latex gloves have been shown to induce contact dermatitis (Turjanmaa et al., 1988; Stingeni et al., 1995; Turjanmaa, 1997) which has been suggested as a predisposing factor in the development of an $\operatorname{IgE}$ mediated hypersensitivity response (Turjanmaa et al., 1996). 
The increased prevalence in latex allergy observed among health care workers has predominantly been associated with an increase in exposure resulting from an increase in glove usage in employees following the recommendations for barrier protection to prevent blood borne pathogen transmission (CDC, 1987; CDC, 1988; CDC, 1989). In addition to increased exposure, other factors may be responsible for the increased prevalence of latex allergy. Health care workers are concurrently exposed to multiple chemicals and/or contaminants in the health care environment in addition to latex products. Endotoxin, a common contaminant in the health care environment, is a known B cell mitogen which has previously been shown to modulate the development of $\operatorname{IgE}$ mediated hypersensitivity responses to allergen (Danneman and Michael, 1976; Mizoguchi et al., 1986; Slater et al., 1998). Studies have shown that endotoxin is a contaminant of latex gloves (Tomazic et al., 1994; Williams and Halsey, 1997) and, upon donning and removing gloves, health care workers may potentially be exposed to endotoxin in the glove powder (Swanson et al., 1994).

Glutaraldehyde is another immunologically active chemical frequently encountered due to its extensive use in the sterilization of surgical instruments in medical facilities. Concentrations of glutaraldehyde in sterilant solutions range between $1-5 \%$, and have been shown to induce numerous adverse reactions such as irritation and contact dermatitis (Benson, 1984; Jachuck et al., 1989; Fisher, 1990; Vyas et al., 2000). While the permissible exposure limit is $0.8 \mathrm{mg} / \mathrm{m}^{3}(0.2 \mathrm{ppm})$, aerosolization of the sterilant solutions has been shown to result in an exposure of up to $2.6 \mathrm{mg} / \mathrm{m}^{3}$ (Gannon et al., 
1995) which is sufficient to induce both respiratory and cutaneous irritation (Corrado et al., 1986; Norback, 1988).

Given that studies have demonstrated the ability of other agents (i.e. diesel exhaust particles, proteolytically active dust mite allergen, polystyrene particles) to augment the development of allergen specific IgE responses (Suzuki et al., 1996; Lovik et al., 1997; Miyabara et al., 1998; Wang et al., 1999; Gough et al., 2001; Granum et al., 2001; Heo et al., 2001); it was hypothesized that concurrent exposure to other agents with latex proteins would modulate the induction of $\operatorname{IgE}$ and the elicitation of symptoms associated with latex allergy. 


\section{LITERATURE REVIEW}

\section{Natural Rubber Latex}

Numerous reviews have covered the history of natural rubber latex allergy (Sussman et al., 1991; Slater, 1994; Sussman and Beezhold, 1995; Germolec et al., 1999; Tomei et al., 2000; Toraason et al., 2000; Meade et al., 2002). Natural rubber latex (NRL) is recovered from the lacticiferous cells of the Hevea brasiliensis rubber tree grown primarily in Southeast Asia, but also found in South America and West Africa. Analysis of the collected latex product has demonstrated the presence of rubber particles (cis-1,4-polyisoprene units), carbohydrates, lipids, and proteins (Levy et al., 1992; Jacob et al., 1993; Slater, 1994; Landwehr and Boguniewicz, 1996; Warshaw, 1998). In 1993 Czuppon demonstrated that these latex proteins induce IgE mediated hypersensitivity responses (Czuppon et al., 1993). Due to the severity of the reactions associated with latex protein exposure, numerous studies have since focused on the identification and characterization of the allergenic Hevea brasiliensis proteins. To date, eleven allergenic latex proteins (Hev b $1-11)$ have been identified, cloned or purified, and named by the International Union of Immunological Societies (Table 1) (reviewed in) (Meade et al., 2002).

Natural rubber latex is collected by tapping the Hevea brasiliensis tree and collecting the latex product in a container. Immediately following collection of the latex, 
chemicals, such as ammonia, formaldehyde or zinc oxide, are often added to prevent coagulation, degradation, and bacterial growth (Jacob et al., 1993). To separate the rubber particle fraction from the aqueous latex serum, the latex product is centrifuged and concentrated to approximately $60 \%$ latex. During product manufacturing, chemicals including accelerators (e.g., mercaptobenzothiazole, thiurams, and carbamates) and antioxidants (e.g., p-phenylenediamine) are added. For the production of dipped latex products, porcelain or ceramic molds are first coated with coagulants and then immersed into the compounded rubber solutions, leached, vulcanized (dried in ovens), and leached again. Following the final leaching step, lubricants may be added to the glove to ease donning and removal. During the vulcanization process, proteins migrate to the surface of the latex product and therefore, upon inversion when stripped from the mold, permits direct skin contact with potentially allergenic latex proteins (Beezhold et al., 1994). Dipped latex products are available for both medical (latex gloves, intratracheal tubing, anesthesia masks, etc.) and commercial use (balloons, rubber bands, condoms, etc.) (DHHS, 1997; Kelso, 1998; Tomei et al., 2000).

While natural rubber latex has been in use since the early 1500's (Coates, 1987), the first reported case of an adverse reaction due to latex exposure was not until 1927 when an allergic reaction was observed in a woman using a dental plate (Stern, 1927). Despite the continued exposure of individuals to latex products, another adverse reaction to latex was not reported until 1979 when a housewife developed contact urticaria following exposure to rubber gloves (Nutter, 1979). Increased medical awareness and diagnosis of adverse reactions to NRL proteins resulted in an increase in the number of 
reported cases of immediate hypersensitivity to latex products in the literature (Forstrom, 1980; Kleinhans, 1984; Meding and Fregert, 1984; Carrillo et al., 1986; Frosch et al., 1986; Axelsson et al., 1987; Spaner et al., 1989). Between the years of 1988 and 1992, over 1,100 cases of allergic responses and 15 cases of anaphylactic related deaths due to latex exposure were reported to the Food and Drug Administration (Slater, 1994). This trend continued from 1992 - 1997 as an additional 1,200 allergic responses and 13 anaphylactic related deaths were reported in 1998 by Dr. Gawchik at the National Latex Allergy Conference in San Antonio, TX (Gawchik, 1998).

Several factors may be responsible for the dramatic increase in the number of reported cases of latex allergy. In the late 1980's the Center for Disease Control and Prevention issued a set of "Universal Precautions" recommending the use of latex gloves as a protective barrier in the handling of bloodborne pathogens (CDC, 1987; CDC, 1988; CDC, 1989). These recommendations stimulated an increase in glove usage among health care workers, as well as individuals employed in non-health care occupations. To address the increased usage, there was an increase in the worldwide manufacturing of latex gloves as well as a rise in the importation of latex gloves into the US from less than 1 billion gloves a year in the late 1980's to approximately 11 billion gloves a year in 1992 (Warshaw, 1998), followed by a rise to approximately 20 billion gloves a year in 1996 (DHHS, 1999). Other additional factors have been proposed to account for the drastic increase in the number of reported allergic responses to latex proteins. Due to the increased demand for barrier protection, numerous new latex manufacturers entered the industry, each attempting to keep up with product demand by altering the manufacturing 
process (i.e. decreased washes, removal of final leaching step, etc.) for increased turnaround. A recent study demonstrated that removal of the final leaching step from the manufacturing process resulted in higher levels of protein and allergen when compared to another glove of the same brand that underwent the whole process (Brehler et al., 2002).

Adverse reactions to natural rubber latex products can manifest themselves clinically as irritant dermatitis, allergic contact dermatitis (delayed type hypersensitivity [DTH], T cell mediated hypersensitivity), and, most importantly, immediate type hypersensitivity (IgE mediated hypersensitivity) (Kelso, 1998; McCracken, 1999). Irritant dermatitis is characterized by dry, cracked skin that is often attributable to chemical additives in the latex products or friction associated with latex glove usage (Sussman and Beezhold, 1995; Alessio et al., 1997). Allergic contact dermatitis to latex products is characterized by erythema and edema, cracked or blistered skin, and sometimes thickening of the skin (Charous et al., 1994; Stingeni et al., 1995; Tomei et al., 2000). T cell mediated dermatological responses are thought to be predominantly generated against the rubber additives (i.e. thiuram mix, carbamates, phenylene diamine, mercapto compounds) (Cohen et al., 1998; Tomei et al., 2000). Several cases have described the development of contact hypersensitivity reactions following exposure to latex products. In 1993, Conde-Salazar et al. reported positive patch tests to at least one rubber additive in greater than $14 \%$ of 4360 hospital patients from non-medical occupations (Conde-Salazar et al., 1993). Recently, Nettis et al. demonstrated a positive patch test response to rubber related chemicals in 31 out of 295 health care workers with contact dermatitis (10.5\%) (Nettis et al., 2002). While it is the least frequently observed 
adverse reaction, IgE mediated hypersensitivity comprises the most severe immunological response following latex exposure. An IgE mediated hypersensitivity response to latex products can occur within minutes of exposure in a sensitized individual and can manifest itself as urticaria, rhinitis, asthma, or potentially fatal anaphylaxis (Sussman et al., 1991; Tomazic et al., 1992; Alenius et al., 1994; Kagy and Blaiss, 1998; Kelso, 1998; Tomei et al., 2000).

Due to the frequent use of natural rubber latex (NRL) gloves by health care workers in medical facilities, primary concern has been given to the dermal and inhalation routes of exposure (Kujala and Reijula, 1995; Phillips et al., 1999; Zak et al., 2000). During the manufacturing of latex gloves, lubricating powders (i.e. corn starch, dextran) are often added in an effort to ease the donning and removal process. These powders have been shown to bind to latex proteins and therefore permit the aerosolization of latex proteins (Jaeger et al., 1992; Tomazic et al., 1994; Vandenplas, 1995; Crippa and Pasolini, 1997; Edelstam et al., 2002). The frequent donning and removal of powdered latex gloves creates an environment rich with respirable latex proteins within the health care setting. Several studies have demonstrated elevated levels of latex aeroallergen in medical facilities. Swanson et al. (Swanson et al., 1994) demonstrated airborne latex protein concentrations of up to $1000 \mathrm{ng} / \mathrm{m}^{3}$ in areas of high powdered glove usage. A year later Baur et al. (Baur et al., 1995) found levels of latex aeroallergen as high as $205 \mathrm{ng} / \mathrm{m}^{3}$ in non-ventilated hospital rooms where powdered latex gloves were used. Elevated latex specific antibody levels were observed in individuals employed in rooms with latex aeroallergen levels as low as $0.6 \mathrm{ng} / \mathrm{m}^{3}$ (Baur et al., 1998). 
In addition to serving as a carrier molecule for latex proteins, corn starch may serve as a source of nutrients facilitating the growth of bacteria in powder slurries. Studies have demonstrated significant levels of endotoxin in powdered surgical and exam gloves (Peiro, 1990; Williams and Halsey, 1997). Endotoxin may stimulate an early inflammatory reaction that modulates the development of immunological responses (Danneman and Michael, 1976; Mizoguchi et al., 1986), including IgE responses to latex proteins (Slater et al., 1998).

Several case studies have also demonstrated the potential for the development of IgE mediated hypersensitivity responses (i.e. urticaria) following dermal exposure to latex proteins (Forstrom, 1980; Meding and Fregert, 1984; Carrillo et al., 1986; Turjanmaa et al., 1988; Turjanmaa, 1997). Latex gloves have been shown to contain as much as $181.1 \mu \mathrm{g}$ of protein per gram of glove (Beezhold et al., 1996; Howell et al., 2002b). Using a fingerprint assay, Beezhold et al. (Beezhold et al., 1994) demonstrated a significant transfer of proteins from latex gloves to the skin. Hamilton and Adkinson confirmed the elicitation of an allergic cutaneous reaction to latex proteins by dermally exposing an individual wearing eye protection and a non-latex respirator (Hamilton and Adkinson, 1996). Recent studies have also demonstrated that latex proteins can penetrate through intact and abraded skin and may potentially enter the systemic circulation (Hayes et al., 2000) resulting in the induction of an IgE mediated hypersensitivity response.

Two populations at higher risk of developing latex allergy have been identified. It is currently estimated that the prevalence of latex allergy among the general public is less 
than 1\% (Turjanmaa, 1987; Liss and Sussman, 1999), while the reported prevalence among health care workers (physicians, nurses, dentists, etc.) and children undergoing multiple surgeries (i.e. spina bifida patients) ranges between $5-17 \%$ and $25-70 \%$, respectively (Grzybowski et al., 1996; Liss et al., 1997; Cremer et al., 1998; Sussman et al., 1998; Kattan et al., 1999; Liss and Sussman, 1999; Sinha and Harrison, 1999; Galobardes et al., 2001; Garabrant et al., 2001). The increased prevalence among health care workers is predominantly attributed to the increased inhalation and dermal exposure due to the frequent use of latex gloves (Kujala and Reijula, 1995; Phillips et al., 1999; Zak et al., 2000). In contrast, children undergoing multiple surgeries are additionally exposed to latex proteins through mucosal and direct tissue contact with natural rubber latex products (i.e. gloves, medical devices) (Chen et al., 1997; Szepfalusi et al., 1999; Buck et al., 2000). 
Table 1. Major Allergens of Natural Rubber Latex

\begin{tabular}{|c|c|c|}
\hline Nomenclature & Protein Identification & Approximate Size (kD) \\
\hline Hev b 1 & Rubber elongation factor & 14.6 \\
\hline Hev b 2 & $\beta$-1,3-glucanase & 35 \\
\hline Hev b 3 & Rubber particle protein & $22-27$ \\
\hline Hev b 4 & Microhelix protein & 100 \\
\hline Hev b 5 & Acidic protein & 16 \\
\hline Hev b 6.01 & Prohevein & 20 \\
\hline Hev b 6.02 & Hevein & 4.7 \\
\hline Hev b 6.03 & Prohevein & 14 \\
\hline Hev b 7 & Patatin-like protein & $43-46$ \\
\hline Hev b 8 & Profiling & 14 \\
\hline Hev b 9 & Enolase protein & 47.6 \\
\hline $\mathrm{Hev}$ b 10 & $\begin{array}{l}\text { Manganese superoxide } \\
\text { dismutase like protein }\end{array}$ & 26 \\
\hline Hev b 11 & Chitinase & 33 \\
\hline
\end{tabular}

Data reviewed in Meade et al. (Meade et al., 2002). 


\section{Overview of the IgE Mediated Allergic Response}

IgE mediated hypersensitivity responses are comprised of two immunological phases: the induction or sensitization phase and the elicitation phase (Galli and Lantz, 1999). The events within these two phases are summarized briefly in the following paragraphs and in Figure 1.

Upon initial exposure, antigen presenting cells (APC; i.e. Langerhans cells, macrophages, dendritic cells) take up allergen into a phagolysosome where the allergen is then degraded into peptide fragments due to a drop in the $\mathrm{pH}$. Upon fusion with another lysosome containing preformed major histocompatibility complex (MHC) class II molecules, allergenic peptide fragments bind to the variable cleft region of the $\mathrm{MHC}$ class II molecule. During this process the APC migrates from the exposed tissue to the T cell rich regions of the local, draining lymph node. Once in the $\mathrm{T}$ cell region of the draining lymph node the MHC class II molecule expressing antigenic peptide is escorted to the surface of the APC and presented to CD4+ T helper cells. The antigen presenting process is initiated when the MHC class II:peptide complex on the APC is recognized by the $\mathrm{T}$ cell receptor $(\mathrm{TCR})$ on $\mathrm{CD} 4+\mathrm{T}$ cells. $\mathrm{T}$ cell activation and proliferation is induced during the antigen presentation process by the interaction between the co-stimulatory molecules CD86 (B7.2) on the APC and CD28 on the T cell. T cells release IL-2 and upregulate their expression of CD25 (IL-2R $\alpha$ ) to facilitate activation. During the activation process, APC and T cells release cytokines which aid in the differentiation of CD4+ T cells into either Th1 or Th2 subsets. In the event of a Th2 response, T cells up-regulate 
the expression of CD40 ligand and migrate to the B cell rich areas of the draining lymph node. Cytokines important in the development of a humoral response (IL-4, IL-5, IL-6, IL-10 and IL-13) are secreted by Th2 cells while Th1 cells produce IFN- $\gamma$, IL-12 and TGF- $\beta$ that play a role in the development of cell-mediated responses. Although these cytokine profiles have been well characterized; the initial signals triggering the differentiation into the specific $\mathrm{CD} 4+\mathrm{T}$ cell subsets are not completely understood. It has been hypothesized that early sources of IL-4 are required for the induction of an $\operatorname{IgE}$ mediated allergic response, and while several possible sources have been suggested (NK1.1+CD4+ cells, naive CD4+ cells, mast cells, basophils and eosinophils), the source of this "Early IL-4" remains unclear (Galli and Lantz, 1999; Haas et al., 1999).

The induction of an $\operatorname{IgE}$ mediated allergic response also requires the direct involvement of B lymphocytes. B cells bind to and internalize allergen through the B cell receptor. Upon internalization, the antigen is processed and presented to activated Th2 cells via MHC class II molecules. Upon recognition of the MHC class II molecule by the $\mathrm{T}$ cell receptor (TCR), activated $\mathrm{T}$ cells provide two costimulatory signals important for the development of IgE antibodies: 1) secretion of IL-4 and IL-13, and 2) expression of CD40 ligand to maintain the required physical interaction with B cells via CD40 (Hermes et al., 1997; Jeppson et al., 1998). These signals initiate the proliferation of B cells and differentiation into antibody secreting plasma cells.

Following secretion from plasma cells, IgE antibodies enter the systemic circulation and bind to a variety of cells expressing the high and low affinity IgE 
receptors, Fc $\in$ RI and Fc $\in$ RII (CD23), respectively. FceRI receptors are important in the activation of the signal transduction cascade leading to the release of preformed mediators. While they have been shown to be expressed at high levels on mast cells and basophils, low levels of Fc $\in$ RI expression have been observed on human Langerhans' cells and eosinophils. Studies have demonstrated a larger role for FceRII/CD23 in the regulation of IgE synthesis as mice deficient in $\mathrm{CD} 23$ exhibit increased levels of serum IgE in comparison with wild type mice following allergen exposure (Dasic et al., 1999; Riffo-Vasquez et al., 2000). While studies have evaluated the role of CD23 in IgE regulation, the mechanism remains unclear as contradicting roles have been suggested. Whereas one study demonstrated a down regulation of IgE production by soluble CD23 inhibiting the interaction between $\operatorname{IgE}$ and FceRI (Kelly et al., 1998), another study suggested an additional B cell activation mechanism through the interaction of soluble CD23 and CD21 (Payet and Conrad, 1999).

Upon subsequent allergen exposure, IgE antibodies bound to FceRI on mast cells and basophils are cross-linked, activating tyrosine kinases and thereby initiating an intracellular signaling cascade. Phosphorylation events result in the activation of phospholipase $\mathrm{C}$ which enzymatically cleaves phosphotidylinositol 4,5-bisphophate into diacylglycerol and inositol 1,4,5-triphosphate. These both activate protein kinase C (PKC), triggering the release of calcium from the endoplasmic reticulum. Upon the interaction between PKC and calcium, preformed secretory granules are exocytosed and their contents (i.e. histamine, proteases) released. The release of these preformed 
mediators initiates a local immediate allergic response by inducing vasodilation, smooth muscle contraction, and vascular permeability.

In addition to an immediate allergic response, a late phase allergic response can occur up to 24 hours following allergen exposure. The late phase response is characterized by the secretion of prostaglandins, leukotrienes and cytokines. Increased intracellular calcium levels, due to cleavage of phosphotidylinositol 4,5-bisphosphate and release of calcium from the endoplasmic reticulum, activate phospholipase $\mathrm{A}_{2}$ to cleave phosphytidylcholine and initiate the arachidonic acid pathway. Prostaglandins and leukotrienes are mediators involved in the late phase allergic response that are synthesized from arachidonic acid via the cyclooxygenase-2 and lipoxygenase pathways, respectively. Additionally, cytokine message and protein secretion are upregulated through the Ras/MAP kinase pathway and contribute to the development of a late phase allergic response (Galli and Lantz, 1999). 
Figure 1. Overview of the IgE Mediated Allergic Response

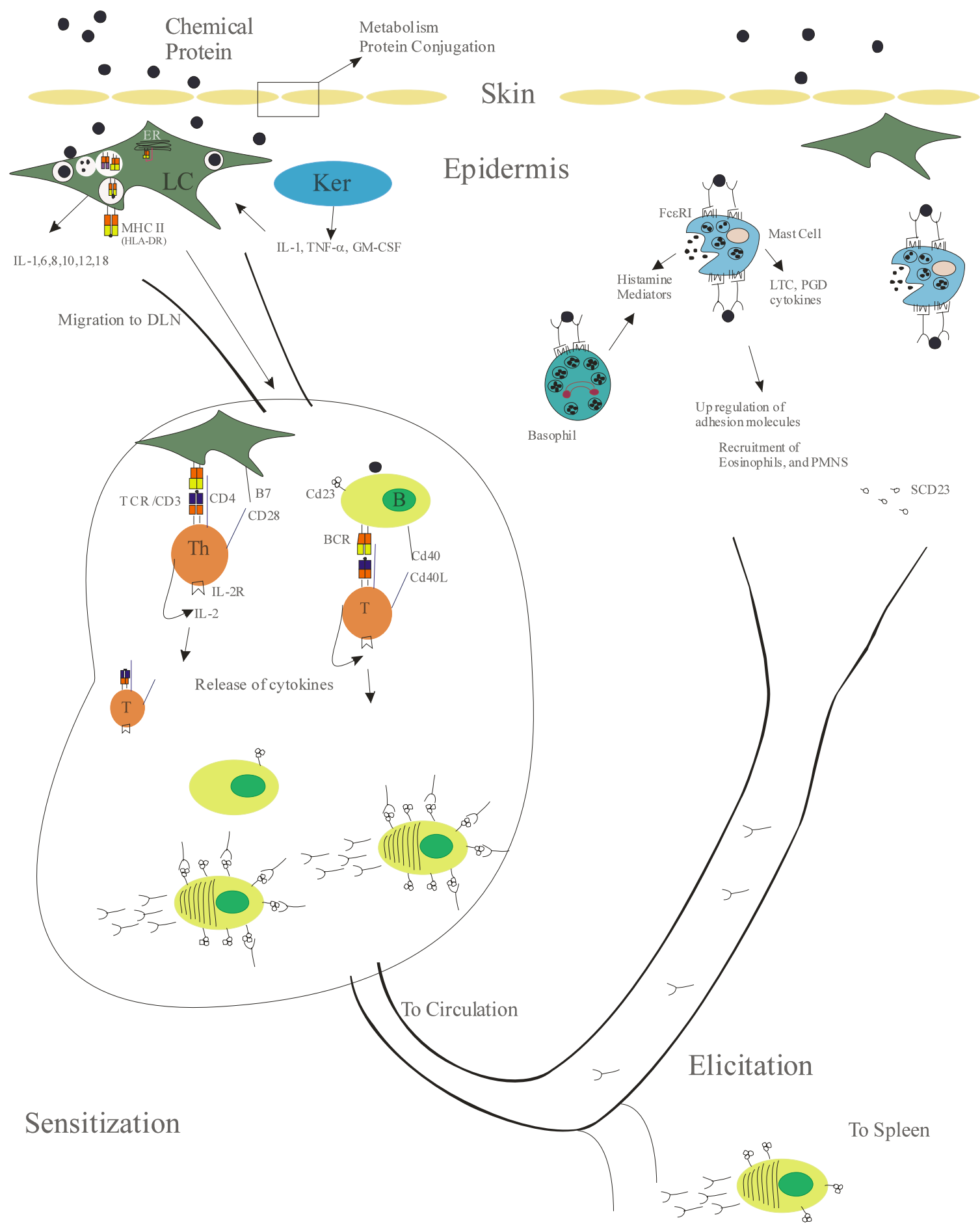

Modified from figure in Galli and Lantz (Galli and Lantz, 1999). 


\section{The "Skin Immune System"}

The skin is the largest bodily organ and is comprised of 3 separate layers: the epidermis, the dermis, and the subcutaneous tissue (Figure 2). Each of these layers is distinct in its composition and cellular makeup. The subcutaneous layer of the skin is composed of adipose tissue while the dermis is comprised of connective tissue and an extracellular matrix of collagen and elastin. The microvasculature, which supplies the epidermis with blood and nutrients, as well as connective tissue mast cells and macrophages are located within the dermis (Elmets et al., 1994).

The epidermis is an immunologically rich layer of skin comprised largely of keratinocytes (greater than $90 \%$ of cells), as well as melanocytes, Langerhans' cells, and Merkel cells. It is within the epidermis that basal keratinocytes morphometrically differentiate into anucleate cells and form the stratum corneum. Skin pigmentation is provided by the melanocyte-produced melanin. Merkel cells are neuroendocrine cells thought to function as mechanoreceptors for tactile responses. Langerhans cells are bone marrow derived antigen presenting cells that serve to endocytose antigen for processing and presentation to $\mathrm{T}$ cells in the draining lymph node (Bos and Kapsenberg, 1993; Elmets et al., 1994).

In the early 1990's the term "skin immune system" was coined in reference to the number of immunological components identified within the skin. These components are described by Bos and Kapsenberg, each playing a role in the first line of defense to 
foreign particles and the development of hypersensitivity responses (Bos and Kapsenberg, 1993). Upon antigenic exposure, keratinocytes within the epidermis have been shown to produce IL-1 $\beta$ and TNF- $\alpha$, thereby inducing the mobilization and migration of the Langerhans' cells into the draining lymph nodes (reviewed in Cumberbatch et al., 2000). Additionally, GM-CSF secreted by keratinocytes stimulates the maturation of Langerhans' cells which subsequently allows for increased antigen processing and presentation to T cells in the draining lymph node (Burnham et al., 2000). The interaction between antigen presenting cells and $\mathrm{T}$ cell in the draining lymph node initiates the activation of $\mathrm{T}$ cells and subsequent secretion of cytokines which drives the proliferation and differentiation of the T cells towards either a Th1 or Th2 phenotype. In the case of a cell-mediated hypersensitivity response, activated $\mathrm{T}$ cells migrate to the skin under the direction of chemokines and adhesion molecules to contribute to the hypersensitivity response (Akdis et al., 1997; Akdis et al., 1999). In IgE mediated allergic responses, $\mathrm{T}$ cells interact with $\mathrm{B}$ cells resulting in the activation of $\mathrm{B}$ cells and subsequent differentiation and clonal expansion into $\operatorname{IgE}$ secreting plasma cells. Circulating IgE, secreted by the plasma cells, binds to the high affinity Fc\&RI expressed on mast cells and basophils and, upon subsequent exposure and cross-linking of antibody, release mediators that initiate cutaneous allergic responses (Elmets et al., 1994).

Until recently, the prevailing hypothesis in allergic responses has been that cutaneous exposure to allergens and xenobiotics results in skin reactions while inhalation exposure leads to respiratory responses. Numerous studies have been reported in which animals were cutaneously sensitized to low molecular weight chemicals and upon 
respiratory challenge, demonstrated increased airway hyper-reactivity. Guinea pig models have been used to demonstrate the development of bronchoconstriction following cutaneous exposure to trimellitic anhydride (TMA) (Hayes et al., 1992), diphenylmethane-4,4'-diisocyanate (MDI) (Pauluhn and Mohr, 1994; Rattray et al., 1994), or 3 - carene (Lastbom et al., 2000). Using a murine model, Arts et al. (Arts et al., 1998) and Cui et al. (Cui et al., 1997) demonstrated that cutaneous exposure to TMA induces elevated serum $\operatorname{IgE}$ levels and bronchoconstriction upon subsequent chemical respiratory challenge. Additionally, similar responses have been observed in mice dermally exposed to proteins. Spergel et al. (Spergel et al., 1998) observed elevated serum OVA specific serum IgE levels in mice epicutaneously sensitized and increased non-specific airway hyper-reactivity upon subsequent methacholine challenge. Similarly, Woolhiser et al. (Woolhiser et al., 2000) demonstrated that dermal application of latex proteins induces elevated total serum $\operatorname{IgE}$ levels and, upon subsequent latex specific respiratory challenge, bronchoconstriction. These studies indicate the importance of the skin immune system in the development of IgE mediated allergic responses. 
Figure 2. Illustration of the Different Layers of the Skin

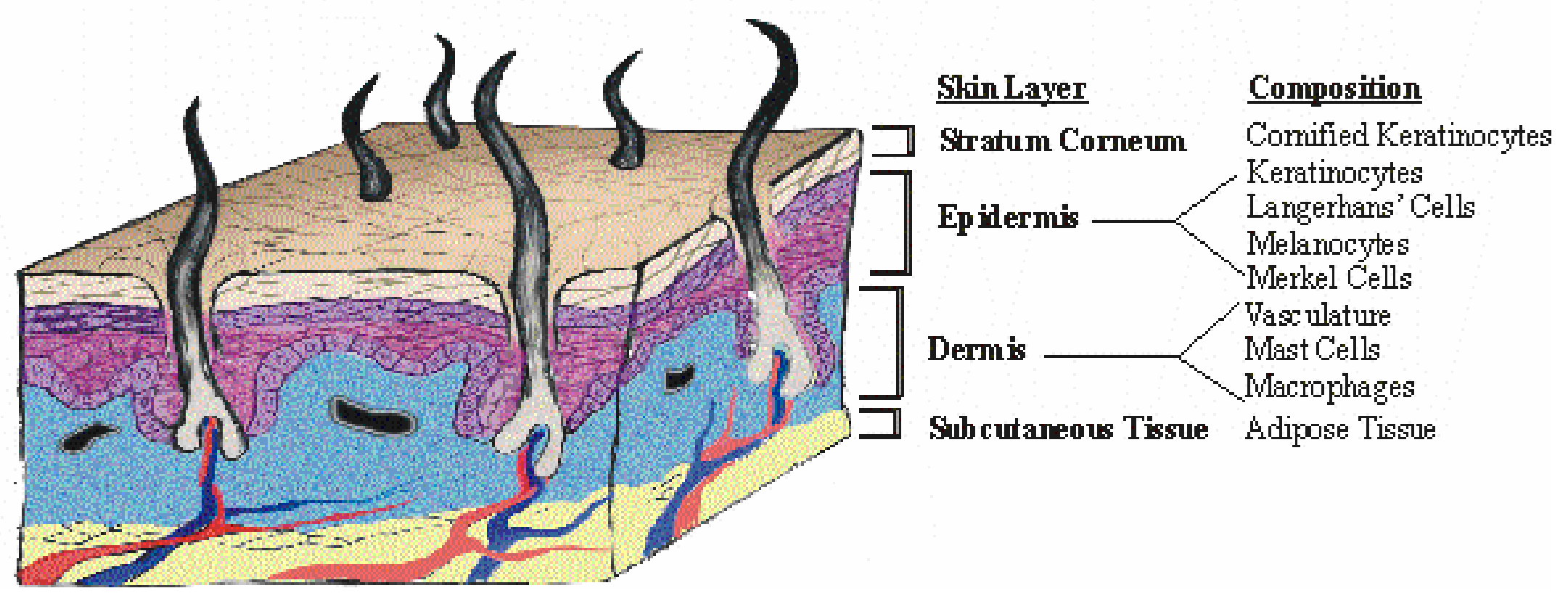




\section{Glutaraldehyde}

Glutaraldehyde (1,5-pentanedial) is a low molecular weight chemical that was first synthesized in 1908 by Harries and Tank (Harries and Tank, 1908). Synthesized from glutaric acid, glutaraldehyde is a five-carbon aldehyde with a molecular weight of 100.13. The two-aldehyde groups have been shown to be readily reactive with proteins (Bowes and Cater, 1968; Hopwood et al., 1970). In 1968, Richards \& Knowles (Richards and Knowles, 1968) demonstrated the presence of $\alpha, \beta$ unsaturated aldehydes that were highly capable of cross-linking. In its purest form, glutaraldehyde emits a single peak at $280 \mathrm{~nm}$, however changes in temperature and $\mathrm{pH}$ can induce conformational changes that result in the addition or reduction of free aldehyde groups (Gorman and Scott, 1980). These changes have been shown to drastically affect the fungicidal and bacteriocidal activity of glutaraldehyde (Beauchamp et al., 1992). It has also been shown that storage of alkaline solutions of glutaraldehyde for extended periods of time will result in a decrease in bactericidal activity and overall glutaraldehyde concentration (Gorman and Scott, 1980).

Glutaraldehyde is used in many occupational settings as a leather-tanning agent, tissue fixative for electron microscopy, medical treatment for warts, cold sterilant for surgical equipment, as well as its commercial use in many cosmetic products. While numerous occupations have employed the use of glutaraldehyde, it is extensively used in the health care setting due to the increasing concern over exposure to pathogens such as human immunodeficiency virus and hepatitis (Fowler, 1989). The ability of 
glutaraldehyde to cross-link proteins is the mechanism behind its use as a biocide, tanning agent and tissue fixative.

While most commercial preparations of glutaraldehyde range in concentration from $1-50 \%$, exposures to glutaraldehyde exist on two different spectrums. Alkaline sterilization solutions are typically comprised of approximately $2 \%$ glutaraldehyde. Lower levels of glutaraldehyde are observed in the ambient air of sterilization rooms where concentrations of glutaraldehyde are measured in parts per million (ppm). Exposure at both high (sterilant concentrations) and low levels (aerosol concentrations) have been shown to induce adverse effects on the eyes, throat, and nasal passages (Norback, 1988; Burge, 1989; Abbott, 1995; Gannon et al., 1995). Due to the irritant nature of this chemical, the Occupational Safety and Health Administration (OSHA) and the American Conference for Government Industrial Hygienists (ACGIH) have suggested personal exposure limits (PEL) and relative exposure limits (REL) of $0.2 \mathrm{ppm}$ and 0.05 ppm, respectively, but these have not been established as federal standards (Weinert, 1996). The development of both contact and IgE-mediated hypersensitivity reactions has been documented at concentrations lower than those suggested by OSHA (Norback, 1988; Jachuck et al., 1989; Leinster et al., 1993; Gannon et al., 1995; Pisaniello et al., 1997).

Health care workers comprise the population with the highest reported prevalence of hypersensitivity to glutaraldehyde. Glutaraldehyde is extensively used to disinfect endoscopes, bronchoscopes, and surgical instruments, resulting in increased exposure for 
individuals employed in areas where these instruments are sterilized. Numerous case reports have described the development of adverse reactions to glutaraldehyde. In 1994 a study of health care workers in an Italian hospital demonstrated that 1 out of 14 employees had either irritant or allergic contact dermatitis due to glutaraldehyde exposure (Stingeni et al., 1995). Glutaraldehyde exposure was also found to be responsible for the development of hand dermatitis in 13 health care workers in a Toronto medical facility (Nethercott et al., 1988). Allergic contact dermatitis has been identified in numerous endoscopy workers exposed to glutaraldehyde sterilization solutions (Goncalo et al., 1984; Fisher, 1990). A study of 348 current and 18 ex-nurses from 59 endoscopy units in the United Kingdom demonstrated that approximately $44 \%$ of workers experience glutaraldehyde-related contact dermatitis (Vyas et al., 2000). Another study investigating glutaraldehyde exposure in an endoscopy unit at Newcastle General Hospital in the United Kingdom revealed that 8 of the 9 staff members tested complained of symptoms (dermatitis, rhinitis, shortness of breath) associated with glutaraldehyde exposure (Jachuck et al., 1989). In addition to occupational exposures, exposure to glutaraldehyde in commercially available products (i.e. hair conditioner) and medical treatments has been shown to induce contact hypersensitivity (Jaworsky et al., 1987; Martin et al., 1997).

While glutaraldehyde exposure has been shown to induce dermatitis, several cases have arisen implicating glutaraldehyde exposure in the development of occupational asthma. The breathing rates of a nurse employed in an endoscopy unit were monitored over a period of two weeks following complaints of shortness of breath. Pulmonary 
reactivity was monitored while using a glutaraldehyde solution for a week and another detergent solution (Dettox) for the second week. Upon evaluation, it was determined that she had developed occupational asthma to glutaraldehyde (Benson, 1984). Another study of the employees in 19 endoscopy and x-ray departments demonstrated a decrease in the forced expiratory volume of 7 out of 8 subjects tested for airway hyper-reactivity at 2 hour increments throughout the period of a normal day. Upon further evaluation, levels of glutaraldehyde within the endoscopy unit were determined to be $0.94 \mathrm{mg} / \mathrm{m}^{3}$, well above the permissible exposure limit (Gannon et al., 1995).

A majority of individuals working with glutaraldehyde solutions utilize natural rubber latex gloves as protection from the deleterious effects of glutaraldehyde (Jordan et al., 1996). While latex gloves have been shown to be effective in reducing the potential for adverse chemical exposure, several studies have demonstrated that latex gloves were less effective than other glove materials in preventing glutaraldehyde penetration (Mellstrom et al., 1992; Lehman et al., 1994; Jordan et al., 1996). Using diffusion cells and a ${ }^{3} \mathrm{H}$-water barrier integrity test, glutaraldehyde solutions were shown to induce greater levels of permeability in latex gloves when compared with tactylon gloves (Lehman et al., 1994). Another study on 3 different glove materials (latex, vinyl, and polyethylene) demonstrated greater barrier protection from glutaraldehyde by vinyl and polyethylene gloves (Mellstrom et al., 1992). It was shown by Jordan et al. that solutions containing $2 \%$ and $50 \%$ glutaraldehyde penetrate through latex gloves in less than 1 hour (Jordan et al., 1996). The ineffective barrier protection of latex gloves against 
glutaraldehyde penetration allows for concurrent exposure to latex proteins and glutaraldehyde solutions.

Several studies have demonstrated the potential in health care workers for dual sensitization to glutaraldehyde and latex proteins. A study in Australia of 336 nurses and 18 ex-nurses demonstrated $44 \%$ skin prick test reactivity to glutaraldehyde and $6 \%$ skin prick reactivity to latex proteins. Upon further serological analysis, it was determined that $4.1 \%$ sero-recognized latex proteins (Vyas et al., 2000). In another study evaluating 44 latex allergic health care workers, nine (20.1\%) also patch tested positively for glutaraldehyde (Taylor and Praditsuwan, 1996).

Animal studies have been conducted to investigate the effects of glutaraldehyde in the development of $\mathrm{T}$ cell mediated and IgE mediated hypersensitivity responses. Using the murine local lymph node assay (LLNA), it has been shown that concentrations of glutaraldehyde as low as $0.006 \mathrm{M}$ induce significant elevations (threefold increase over controls) in cellular proliferation (Hilton et al., 1998). Further analysis of the interleukin (IL)-4, IL-10, and interferon (IFN)- $\gamma$ levels in the draining lymph node cells from mice treated with solutions containing greater than $1 \%$ glutaraldehyde, revealed a Th2-like cytokine profile indicative of an IgE mediated hypersensitivity response (Dearman et al., 1999). B6C3F1 mice and Hartley guinea pigs demonstrated a dose dependent cell mediated hypersensitivity response upon induction with 0.3 , 1 , and $3 \%$ glutaraldehyde solutions and subsequent challenge with a $10 \%$ glutaraldehyde solution (Stern et al., 1989). Additionally, inhalation studies have demonstrated that concentrations of 
glutaraldehyde as low as $0.3 \mathrm{ppb}$ induce lesions and metaplasia in the upper respiratory tract of exposed mice (Gross et al., 1994; Zissu et al., 1994; Zissu et al., 1998).

\section{Endotoxin}

Lipopolysaccharide (LPS), or endotoxin, is a cell wall component of gramnegative bacteria that can be found ubiquitously as a contaminant in the environment (Becker et al., 1996) and house dust (Michel et al., 1991; Michel et al., 1996). Numerous reviews have been written describing the history, composition, and activities of endotoxin (Morrison and Ryan, 1979; Morrison and Ryan, 1987; Burrell, 1990; Doran, 1992; Rietschel et al., 1994; Rietschel et al., 1996). Bacterial endotoxins were first identified in the by Pfeiffer in the late $19^{\text {th }}$ century; however, the components of endotoxin were not identified until the early $20^{\text {th }}$ century when it was determined that the active portion of endotoxin was comprised of lipids, polysaccharides and protein, resulting in the term lipopolysaccharide (LPS) (Boivin and Mesrobeanu, 1935). Several reviews further describe the components of LPS in three major regions: O-specific antigens, core polysaccharides, and lipid A (reviewed in (Morrison and Ryan, 1979; Doran, 1992; Rietschel et al., 1996)). O-antigens are chains of monosaccharides that are unique to each bacterial strain. The core polysaccharides are separated into inner and outer core regions. The outer core polysaccharides are composed of D-glucose, D-galactose, and Nacetyl-D-glucosamine while the inner core is composed of 2-keto-3-deoxyoctonic acid and heptose. Lipid A is the most conserved portion of the LPS and has been shown to consist of a phosphorylated glucosamine-disaccharide backbone attached to chains of 
fatty acids. Early demonstrations that the lipid A portion of endotoxin was able to induce inflammation (Galanos et al., 1984; Kotani et al., 1984) led to an influx of lipid A related research (Kiener et al., 1988; Henricson et al., 1990; Mattern et al., 1994; Salkowski et al., 1997).

The immunomodulatory effects of endotoxin have been investigated for decades with volumes of literature available on the subject. Numerous studies have described B cell mitogenic activity upon exposure, or the addition of LPS, to in vivo and in vitro systems (Melchers et al., 1975; Wetzel and Kettman, 1981; Bessler et al., 1985). A report by Peavy et al. (Peavy et al., 1970) in 1970 demonstrated the ability of Salmonella endotoxin to stimulate the proliferation of murine splenocytes. Additionally, lymphocytes isolated from $\mathrm{CBA} / \mathrm{J}$ and $\mathrm{C} 3 \mathrm{H} / \mathrm{HeJ}$ (endotoxin resistant) mice were later shown to proliferate in the presence of endotoxin (Sultzer and Goodman, 1976). Other studies have also demonstrated the ability of endotoxin to induce proliferation of T cells (Milner et al., 1983; Vogel et al., 1983; Mattern et al., 1994). In 1973, Andersson et al. (Andersson et al., 1973) compared the mitogenic activity of several smooth and rough LPS mutants and determined that the mitogenic activity of LPS was contained within the lipid A portion.

Lipopolysaccharide exposure has been shown to induce the production of numerous cytokines (Luheshi and Rothwell, 1996). Increased levels of IFN- $\gamma$ and the pro-inflammatory cytokines IL-1 and TNF- $\alpha$ have been identified in the supernatants following LPS addition to lymphoid cell cultures (Friedman et al., 1987) and in the serum 
following intravenous injection in mice (Kiener et al., 1988). Upon interacting with alveolar macrophages in the lung, endotoxin binds to CD14 and lipopolysaccharide binding protein (LBP) stimulating the activation of macrophages and inducing cytokine production (TNF, IL-1, IL-6, IL-8) (Ulevitch and Tobias, 1995; Tobias et al., 1999). A study by Salkowski et al. (Salkowski et al., 1997) demonstrated elevated levels of the Th1 cytokines, IL-12 and IFN- $\gamma$, in murine macrophages and lymphocytes upon exposure to LPS.

Slurries of dextran used to powder latex gloves have been shown to serve as rich media sources for the growth of gram-negative bacteria and several reports have demonstrated endotoxin contamination in natural rubber latex gloves. In 1990, the levels of endotoxin in powdered surgical gloves were determined to be sufficient to induce fever in an exposed individual (Peiro, 1990). In 1997, a study by Williams and Halsey demonstrated levels of endotoxin ranging from $0.09 \mathrm{ng} / \mathrm{g}$ to greater than $2800 \mathrm{ng} / \mathrm{g}$ of glove material (Williams and Halsey, 1997).

Lubricating powders carrying latex proteins and endotoxin may potentially expose health care workers via inhalation. Inhalation of endotoxin has been shown to initiate immunological activity in the lungs resulting, in some cases, in the development of respiratory complications. In 1985, Lantz et al. (Lantz et al., 1985) demonstrated a decrease in lung volume and an increase in endothelial vesicles upon inhalation exposure to LPS in hamsters. Ginanni et al. (Ginanni et al., 1991) demonstrated several years later, that inhalation of LPS induced non-specific bronchoconstriction in both non-atopic 
and atopic patients. In 1995, a study of fiberglass manufacturing employees demonstrated the development of flu-like symptoms and asthma in individuals exposed to high concentrations of endotoxin in a washwater mist (Milton et al., 1995).

Several immunological factors are thought to contribute to the morphological changes and the development of non-specific bronchoconstriction observed following endotoxin inhalation. In 1987, Rylander and Beijer (Rylander and Beijer, 1987) exposed guinea pigs to endotoxin via inhalation and observed an increase in the production of platelet activating factor. Platelet activating factor is a potent inducer of inflammation and bronchoconstriction, as well as a chemotactic factor for neutrophil migration. Yanagihara et al. (Yanagihara et al., 2001) demonstrated that a single intratracheal instillation of endotoxin in mice induced increased mucous production and neutrophil recruitment. Similar observations were reported in mice receiving intratracheal instillations of endotoxin, twice weekly for 12 weeks (Vernooy et al., 2002). Mucous production has been shown to be associated with increased non-specific airway hyperreactivity (Walter et al., 2001).

Several studies have suggested that endotoxin may serve as an adjuvant in the development of an IgE mediated hypersensitivity response. It has previously been shown that pre-exposure of mice to airborne endotoxin will augment the development of an OVA specific serum IgE response (Wan et al., 2000). Slater et al. (Slater et al., 1998) demonstrated augmented allergen specific IgE levels in mice intranasally exposed to LPS 
and Hev b 5. In 1986, Mizoguchi et al. (Mizoguchi et al., 1986) exposed mice via inhalation to $50 \mathrm{mg}$ of OVA with or without $1 \mathrm{mg}$ of LPS for up to 10 weeks. Mice concurrently exposed to OVA and LPS demonstrated significant elevations in OVA specific serum IgE levels. Using a different exposure regimen, it was recently reported that mice systemically exposed to endotoxin prior to OVA sensitization demonstrate suppressed OVA specific serum IgE levels but increased non-specific airway hyperreactivity (Gerhold et al., 2002). 


\section{MATERIALS AND METHODS}

\section{Animals}

Mice. Female BALB/c mice were purchased from Harlan Sprague Dawley, Inc. (Indianapolis, IN) or Taconic Farms (Germantown, NY) and were received between 6-12 weeks of age. Upon their arrival, mice were maintained under conditions specified within NIH guidelines (NRC, 1996) and quarantined for at least one-week prior to use. Mice were housed in polycarbonate "shoebox" cages with hardwood bedding and provided tap water and Agway Prolab Animal Diet (5\% fat) ad libitum. Animal rooms were maintained between $18-26^{\circ} \mathrm{C}$ and $20-70 \%$ relative humidity with light/dark cycles of 12-hour intervals. To prevent latex contamination, nitrile gloves were worn while handling mice during study procedures.

Guinea Pigs. Male hairless guinea pigs (CrL: IAF/HA (hr/hr)) were obtained from a previously established breeding colony at the West Virginia University animal facility. To establish the breeding colony, 6 male and 6 female hairless guinea pigs were purchased from Charles River Laboratories, Inc. (Wilmington, MA), paired randomly and housed in large polycarbonate cages in an environment regulated at approximately $25^{\circ} \mathrm{C}$ and $60 \%$ relative humidity. Three weeks following birth, pups were removed from the parents and litters were placed in polycarbonate cages until they attained sexual maturity, at which time they were separated by sex and paired for use in breeding. Guinea pigs 
between the ages of $4-12$ months were used in penetration studies. All guinea pigs were provided TekLab Guinea Pig Chow (Harlan, Indianapolis, IN) and water ad libitum.

Rabbits. New Zealand white rabbits were purchased from Harlan Sprague Dawley (Oxford, MI). All rabbits were housed under specific pathogen-free conditions at the West Virginia University in an environment regulated at approximately $25^{\circ} \mathrm{C}$ and $60 \%$ relative humidity. All rabbits were provided Rabbit Chow (Harlan, Indianapolis, IN) and water ad libitum and were used for antibody production when they reached approximately 6 to 8 kilograms.

\section{Test Articles}

Glutaraldehyde (Cas No. 111-30-8, M.W. 100.1) and lipopolysaccharide (TCA extracted from Salmonella typhimurium; Salmonella typhosa; and Escherichia coli) were purchased from Sigma Chemical Co. (St. Louis, MO). The lot numbers and endotoxin content of each strain of lipopolysaccharide (LPS) are listed in Table 2. Nonammoniated latex (NAL) was generously provided by Dr. Che Hasma Hashim of the Rubber Research Institute of Malaysia (RRIM).

Table 2. Lipopolysaccharide and Endotoxin Content in Bacterial Strains

\begin{tabular}{|lcc|}
\hline Bacterial Strain & Lot Number(s) & Endotoxin Content (EU/mg) \\
\hline Salmonella typhimurium & $68 \mathrm{H} 4041$ & $3 * 10^{6}$ \\
& $69 \mathrm{H} 4060$ & $1 * 10^{6}$ \\
Salmonella typhosa & $78 \mathrm{H} 4059$ & $5 * 10^{6}$ \\
Escherichia coli O111:B4 & 684091 & $3 * 10^{6}$ \\
\hline
\end{tabular}


Mice were concurrently exposed to NAL and either endotoxin or glutaraldehyde in numerous studies. Analysis of the NAL protein profile by $10 \%$ SDS-PAGE methodology revealed that while endotoxin did not affect the overall protein profile, concentrations of glutaraldehyde greater than $1 \mathrm{ppm}$ caused significant alteration of the proteins (Figures 3 and 4). Therefore, glutaraldehyde dosing solutions were prepared separately and applied to the site of exposure first, followed by exposure to the NAL dosing solution. Studies evaluating concurrent exposure to NAL and endotoxin utilized the preparation of a single dosing solution since endotoxin failed to visibly alter NAL proteins.

\section{Latex Protein Preparation and Quantification}

Raw latex was collected from rubber trees in Malaysia and diluted with a 50\% glycerol $/ 67 \mathrm{mM} \mathrm{NaHCO} / 2 \mathrm{mM} \mathrm{L-cysteine} \mathrm{buffer} \mathrm{(Goodyear} \mathrm{Preservative).} \mathrm{Upon} \mathrm{receipt,}$ an aqueous protein extract was prepared as described by the RRIM. The latex suspension was centrifuged for 40 minutes at 14,400 relative centrifugal force (rcf) to separate the rubber fraction from the aqueous protein phase. Using a 10-cc syringe and an 18-gauge needle, the aqueous layer was removed from underneath the rubber fraction and centrifuged for two additional 1-hour spins at 40,000 rcf. The final protein extract was filtered through a $0.45 \mu \mathrm{m}$ bottle top filter, aliquoted into $50 \mathrm{ml}$ conical tubes and stored at $-80^{\circ} \mathrm{C}$. As needed, NAL was thawed, aliquoted into eppendorf vials and stored at $20^{\circ} \mathrm{C}$ for daily use. Using a modified Lowry Assay (ASTM D5712), the total protein concentration of the latex extract was determined to be approximately $7 \mathrm{mg} / \mathrm{ml}$. The 
protein profile of the NAL extract, as separated on a $10 \%$ SDS-PAGE gel, is illustrated in Figure 3 (lane A). Using the Limulus Amebocyte Lysate (LAL) assay (Jacobs, 1997), the endotoxin content in the NAL extract was determined to be $87 \mathrm{EU} / \mathrm{ml}$ by Mike Whitmer of the Analytical Services Branch at NIOSH. 


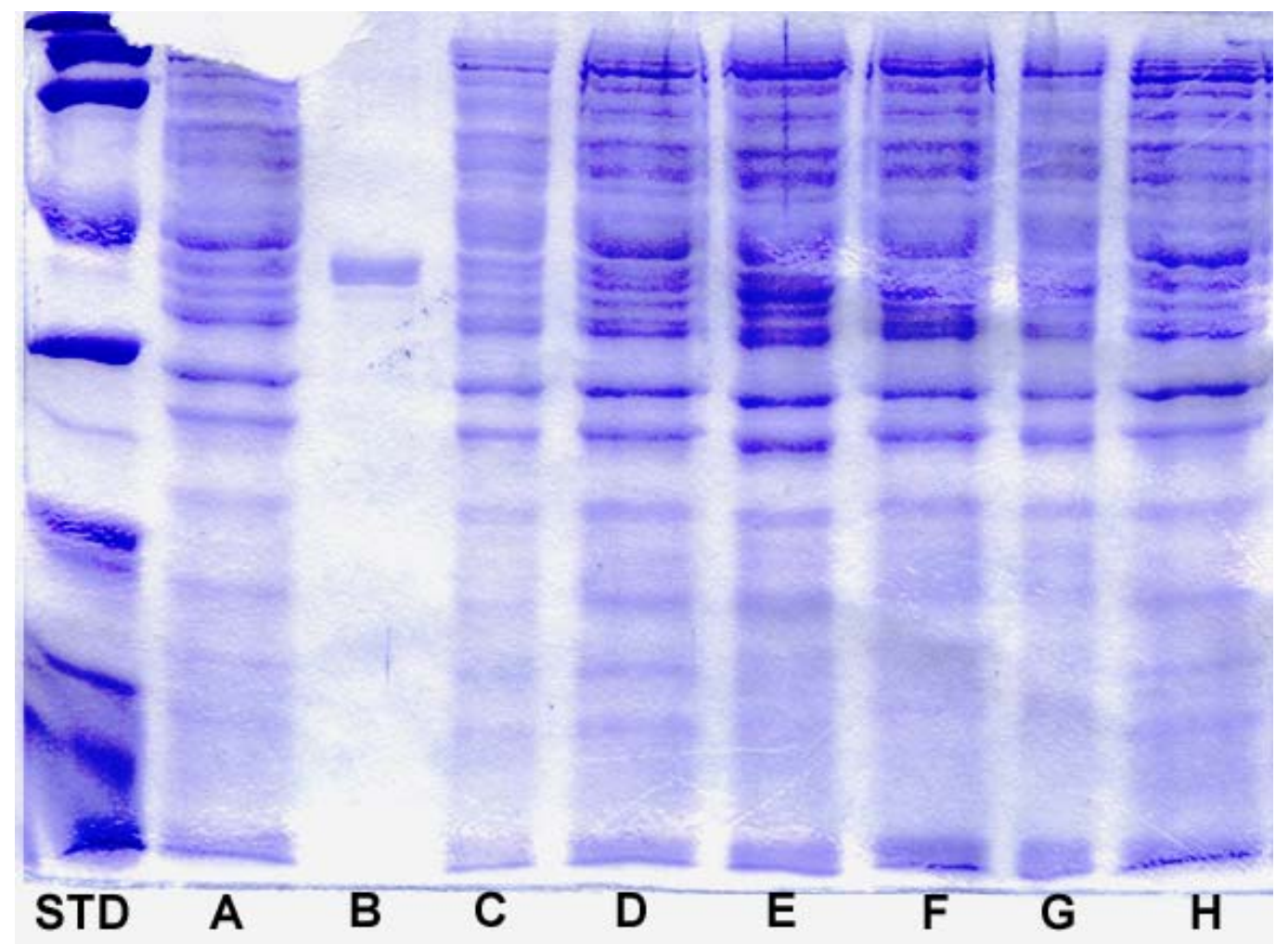

Figure 3. 10\% SDS-PAGE of Endotoxin from Salmonella tyhpimurium and NAL Proteins. 10\% SDS-PAGE gel of STD) broad range standard, A) $25 \mu \mathrm{g}$ NAL proteins in PBS, B) 25,000 EU; remaining columns $25 \mu \mathrm{g}$ with C) $50 \mathrm{EU}, \mathrm{D}) 500 \mathrm{EU}, \mathrm{E}) 1,250 \mathrm{EU}$, F) 2,500 EU, G) 5,000 EU, and H) 25,000 EU 


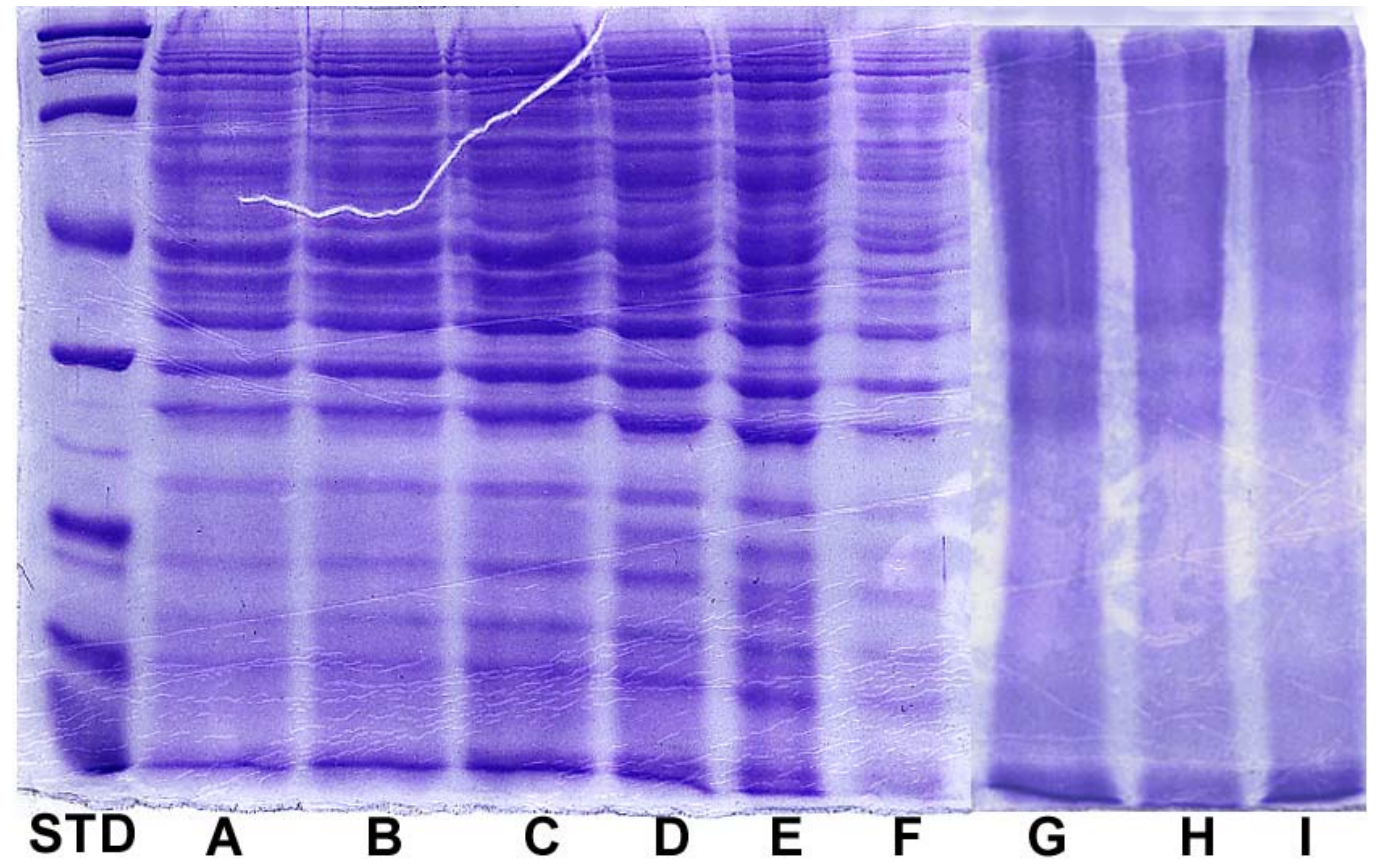

Figure 4. 10\% SDS-PAGE of Glutaraldehyde and NAL Proteins. 10\% SDS-PAGE gel of STD) broad range standard, A) $25 \mu \mathrm{g}$ NAL proteins in acetone; remaining columns 25 $\mu \mathrm{g}$ with B) 0.05ppm, C) 0.2ppm, D) 0.5ppm, E) 0.75ppm, F) $1 \mathrm{ppm}, \mathrm{G}) 0.1 \%$, H) $0.5 \%$, and I) $1 \%$ glutaraldehyde. 


\section{Radiolabeled Materials}

$\left[{ }^{3} \mathrm{H}\right]-\mathrm{H}_{2} \mathrm{O}$ (M.W.=18.0), specific activity of $1 \mathrm{mCi} / \mathrm{g}$, was obtained from $\mathrm{New}$ England Nuclear (NEN, Boston, MA). Carrier-free $\mathrm{Na}^{125}$ Iodine was purchased fresh (within two weeks of new commercial lot preparation) from NEN for each custom labeling experiment and had a theoretical specific activity of $17.4 \mathrm{Ci} / \mathrm{mg}$ upon arrival. All radioactive materials were stored in compliance with the Radiation Safety Office at NIOSH.

\section{Murine Exposures}

Prior to the initial exposure, mice were weighed and assigned to homogenous weight groups $(\mathrm{n} \geq 5)$. To monitor antibody levels in time course studies, mice were tail bled prior to initial exposure and weekly/bi-weekly thereafter.

Dermal Exposures. Prior to initial exposure and weekly thereafter, the dorsal thorax of all mice was clipped to remove hair from the site of application. In some murine studies the depilatory agent Nair $^{\circledR}$ was applied to remove remaining hair from the exposure site. Nair ${ }^{\circledR}$ was applied to the clipped dorsal thorax region for up to one minute and removed using gauze dampened with tap water. In studies where skin was abraded, the exposure site was tape stripped once a week with ten (10) $22 \mathrm{~mm}$ stripping discs (DSquame $^{\circledR}$ Stripping Discs, CuDerm Corp., Dallas, TX). Hayes et al. previously demonstrated that tape stripping with 10 discs will effectively remove the stratum corneum (Hayes et al., 2000). Mice were dermally exposed by applying $50 \mu$ of vehicle 
or test article to the dorsal thorax region either every $5^{\text {th }}$ day or 5 days a week. In studies where mice were exposed on the dorsal surface of the ear, $12.5 \mu 1$ of vehicle or test article was applied to each ear 5 days a week for up to 14 weeks. NAL dosing solutions were first prepared in Goodyear preservative and then diluted 1:1 in acetone. Analysis using a $10 \%$ tris-HCL gel demonstrated that the NAL protein profile is unaffected by acetone (see Figure 4, lane A). Concentrations of test articles used in these studies ranged from 0 $-25 \mu \mathrm{g}$ of NAL proteins and $0.05-1 \mathrm{ppm}$ and $0.1-1 \%$ of glutaraldehyde.

Intranasal Exposures. Mice were manually restrained in a supine position while $10 \mu \mathrm{l}$ of vehicle or test article was applied to the external openings of both nares (5 $\mu \mathrm{l} / \mathrm{nare})$. Mice were exposed either every $5^{\text {th }}$ day or 5 days a week for up to 72 days. All dosing solutions were prepared in Goodyear Preservative and diluted 1:7 in PBS. Concentrations of test articles used in these studies ranged from $0-25 \mu \mathrm{g}$ of NAL protein and $50-50,000 \mathrm{EU}$ of LPS. To reduce the number of animals, a single vehicle $(n=10)$ and latex alone $(n=10)$ exposure group was used for the studies evaluating the different strains of bacterial endotoxin.

Robinson et al. demonstrated that intranasal instillation of dosing solutions to mice may result in both an upper respiratory and oral exposure (Robinson et al., 1996). To determine the distribution of the exposure, $10 \mu \mathrm{l}$ of Evans blue dye was instilled into the nares of mice followed 10 minutes later by dissection. Following instillation, there were no signs of infiltration into the lung, but instead into the stomach. 
Intratracheal Exposures. Intratracheal aspirations were performed on mice to localize the respiratory tract exposure to the trachea and lung. Mice were anesthetized via Isoflurane (Abbott Laboratories, Chicago, IL) inhalation using a Bell jar and then restrained in a vertical position on a Plexiglas stand by the upper and lower teeth. While withdrawing the tongue using forceps to prevent swallowing the solution, $50 \mu 1$ of the dosing solution was pipetted into the back of the oral cavity. The tongue was held withdrawn until the dose was inhaled into the trachea and subsequently the lungs. Mice were dosed every $5^{\text {th }}$ day for up to 72 days with $0-25 \mu \mathrm{g}$ of NAL proteins and/or $50-$ 25,000 EU of LPS.

I.t aspirations of $50 \mu \mathrm{l}$ of $0.5 \%$ Evans blue were conducted to demonstrate the distribution of dosing solutions throughout the lungs. Within 10 minutes of i.t. aspiration, Evans Blue was visible in the trachea and all lobes of the lung.

$\underline{\text { Subcutaneous Exposures. }}$ Mice were injected with $50 \mu \mathrm{g}(100 \mu \mathrm{l})$ of latex proteins in the dorsal thorax region every $5^{\text {th }}$ day for up to 52 days. All dosing solutions were prepared in Goodyear Preservative and diluted 1:7 in PBS.

\section{Guinea Pig Exposures}

The potential for glutaraldehyde to induce alterations in the barrier integrity was evaluated by dermally exposing male hairless guinea pigs between the ages of $4-12$ months 5 days a week for up to 15 weeks. Eight dosing regions, each approximately 30 $\mathrm{mm}$ in diameter, were identified on the dorsal region of the animals prior to the initial 
exposure. Four dosing areas were designated for acetone (vehicle) exposure and four designated for glutaraldehyde exposure. Animals were exposed by applying $50 \mu \mathrm{l}$ of either acetone (vehicle for glutaraldehyde) or glutaraldehyde $(0.75,1 \mathrm{ppm})$ to each dosing area. At the end of the exposure period, animals were sacrificed via carbon dioxide asphyxiation and used for in vitro percutaneous penetration studies.

\section{Total IgE ELISA}

Total IgE serum levels were measured using methodology described by Manetz and Meade (Manetz and Meade, 1999). Immulon-2 (Dynex, Chantilly, VA), 96-well flat bottom plates were coated overnight $\left(4^{\circ} \mathrm{C}\right)$ with $20 \mu \mathrm{g} / \mathrm{ml} \mathrm{B} 1 \mathrm{E} 3$ rat anti-mouse $\operatorname{IgE}$ prepared in boric acid buffered saline (BBS; $60 \mu 1 /$ well). The B1E3 coated plates were blocked the following morning for 1 hour using a $0.05 \%$ Tween-20/PBS/2\% FBS buffer containing $10 \mathrm{mM}$ Hepes and $0.05 \%$ sodium azide. Using separate u-bottom, 96-well plates, 12 two-fold serial dilutions of IgE standard were prepared starting at $500 \mathrm{ng} / \mathrm{ml}$. The IgE standard was a mouse anti-DNP IgE purified from a hybridoma prepared following hyper-immunization of mice using DNP-Ascaris (Liu et al., 1980). Serum samples from exposed mice were added to the first well beginning with a 1:10 or 1:20 dilution. Serially diluted IgE standards and serum samples were transferred from the ubottom dilution plates to the blocked Immulon-2 plates and incubated for 2 hours at $37^{\circ} \mathrm{C}$. Plates were washed and $60 \mu \mathrm{l}$ of $10 \mu \mathrm{g} / \mathrm{ml}$ of R1E4 (rat anti-mouse IgE) conjugated with biotin (EZ-Link ${ }^{\mathrm{TM}}$ Sulfo-NHS-Biotin, Pierce, Rockford, IL) or $60 \mu \mathrm{l}$ of 2 $\mu \mathrm{g} / \mathrm{ml}$ of R35-118 biotinylated rat anti-mouse $\operatorname{IgE}$ (Pharmingen, San Diego, CA) was 
added for 2 hours at $37^{\circ} \mathrm{C}$. Subsequently, $1 \mu \mathrm{g} / \mathrm{ml}$ streptavidin-alkaline phosphatase (Sigma Chemical Co., St. Louis, MO) was added for an additional hour at $37^{\circ} \mathrm{C}$. Following the final wash step, p-Nitrophenyl phosphate (Sigma Chemical Co., St. Louis, MO) diluted to a $1 \mathrm{mg} / \mathrm{ml}$ concentration in substrate buffer $(\mathrm{pH}$ 9.8; 50\% Diethanolamine $/ 200 \mu \mathrm{g} / \mathrm{ml} \mathrm{MgCl}_{2} / 400 \mu \mathrm{g} / \mathrm{ml} \mathrm{NaN}_{3}$ ) was added and plate absorbance determined by a Spectramax Vmax plate reader (Molecular Devices Co., Sunnyvale, CA) within 30 minutes at $405 \mathrm{~nm}$. All standard and sample absorbance were analyzed using Softmax Pro (Molecular Devices Co., Sunnyvale, CA). A plot of the IgE standard curve was created using a log-log plot. Data points determined to be beyond the linear portion of the curve were "masked"; at least one point from each edited standard curve had an absorbency of greater than 0.5 optical density. The resulting curves had slopes ranging from $0.7-1.1$ and correlation coefficients greater than 0.98 . IgE concentrations for each serum sample dilution were interpolated from the standard curve and the $\operatorname{IgE}$ concentration for each mouse was determined using a multipoint analysis. The B1E3, R1E4, and IgE standard antibodies were purified from hybridoma cell lines that were generously provided by Dr. Daniel Conrad (Medical College of Virginia/Virginia Commonwealth University, Richmond, VA).

\section{Latex Specific ELISA.}

Latex specific serum immunoglobulin levels were measured using a modified sandwich ELISA. Wells of Immulon-2 plates (Dynex, Chantilly, VA) were coated with $100 \mu \mathrm{l}$ of $5 \mu \mathrm{g} / \mathrm{ml}$ rat anti-mouse $\operatorname{IgE}$ (R1E4), $2 \mu \mathrm{g} / \mathrm{ml}$ rat anti-mouse IgG1 (A85-3; 
Pharmingen, San Diego, CA), $2 \mu \mathrm{g} / \mathrm{ml}$ rat anti-mouse IgG2a (Igh-1a; Pharmingen, San Diego, CA), or $2 \mu \mathrm{g} / \mathrm{ml}$ rat anti-mouse IgA (C10-3; Pharmingen, San Diego, CA) in BBS overnight at $4{ }^{\circ} \mathrm{C}$. The following morning, plates were blocked for one hour with $3 \%$ dry milk freshly prepared in PBS/Tween $0.05 \%$. Serum samples were added beginning with either a 1:10 (for IgE, IgA) or 1:1,000 (for IgG1, IgG2a) dilution $(100 \mu 1 /$ well) and incubated for 2 hours at $37^{\circ} \mathrm{C}$. Plates were washed and NAL (precipitated and stored in a 3:1 $\mathrm{H}_{2} \mathrm{PO}_{4}: \mathrm{NaOH}$ buffer) was diluted to $25 \mu \mathrm{g} / \mathrm{ml}$ and $100 \mu \mathrm{l}$ was added to each well for 2 hours at $37^{\circ} \mathrm{C}$. Following the 2-hour incubation period, a polyclonal rabbit anti-NAL antibody (see Anti-NAL Antibody Generation) was diluted 1:16,000 and $100 \mu \mathrm{l} /$ well was added for 2 hours at $37^{\circ} \mathrm{C}$. A horseradish peroxidase (HRP) conjugated donkey antirabbit IgG antibody (Jackson Laboratories, Bar Harbor, ME) was diluted 1:2,500 and 100 $\mu \mathrm{l}$ was added to the wells for 1 hour at $37^{\circ} \mathrm{C}$. O-phenylenediamine substrate was prepared at $1 \mathrm{mg} / \mathrm{ml}$ and added at $100 \mu \mathrm{l} /$ well. Approximately 20 minutes following the addition of the substrate, $50 \mu 1$ of $4 \mathrm{~N}$ sulfuric acid was added to the plates to stop the colorimetric reaction and the optical densities were read by a Spectramax Vmax plate reader (Molecular Devices Co., Sunnyvale, CA) at $490 \mathrm{~nm}$. Sample absorbances were analyzed using Softmax Pro 3.1 (Molecular Devices Co., Sunnyvale, CA). Serum with high total IgE levels ( $>1500 \mathrm{ng} / \mathrm{ml}$ ) obtained from mice exposed to toluene di-isocyanate was used as a negative control. Serum from mice with elevated total $\operatorname{IgE}$ serum levels ( $>$ $10,000 \mathrm{ng} / \mathrm{ml}$, see Anti-NAL Antibody Generation) was used as a positive control. Arbitrary units (AU) for the neat sera were determined by multiplying the dilution for each sample by the optical density. Average AU values were calculated for each mouse 
and then used to determine the overall mean $\mathrm{AU} \pm$ standard error $(\mathrm{SE})$ for each exposure group.

\section{Anti-NAL Antibody Generation}

Sera containing antibodies to latex proteins is not currently available commercially. In order to assay the development of latex specific serum antibodies, latex was injected into animals to generate latex specific polyclonal antibody development. These antibodies were subsequently used as positive control sera in ELISA or as secondary reagents in the latex specific ELISA and immunohistochemistry.

Murine Anti-NAL Antibody Generation. Female BALB/c mice received weekly subcutaneous injections of NAL in the dorsal thorax region for up to 8 weeks. Mice were injected with $25 \mu \mathrm{g}$ of NAL proteins diluted in PBS to a final volume of $100 \mu \mathrm{l}$. All injections were administred using one-cc tuberculin syringes with latex-free plungers fitted with 25 gauge needles. Following 4 weeks of exposure, weekly tail bleeds were conducted to monitor total serum IgE levels until levels were greater than 10,000 ng/ml. Once total serum IgE levels were greater than $10,000 \mathrm{ng} / \mathrm{ml}$, mice were sacrificed, blood was collected via cardiac puncture, and serum pooled to serve as positive control antiNAL serum for the latex specific ELISA and immunoblots. All serum was stored at $20^{\circ} \mathrm{C}$ until use.

Rabbit Anti-NAL Antibody Generation. Rabbits were immunized by injection with $200 \mu \mathrm{g}$ of non-ammoniated latex emulsified with Freund's Complete Adjuvant on 
the first day of sensitization. Subsequent immunizations used $200 \mu \mathrm{g}$ in incomplete Freund's adjuvant. Rabbits were injected at five time points on days $0,3,5,8$, and 10 . One week following the final injection weekly bleeds were conducted to determine the titer of the antiserum. Titers of rabbit anti-NAL serum were determined using a Latex ELISA for Antigenic Proteins (LEAP) as previously described (Beezhold, 1992). The titer was then determined using dilution values with an optical density of 1.5. All sera was stored at $-20^{\circ} \mathrm{C}$ until use. This sera was used for the latex specific ELISA and immunohistochemistry.

Before use in immunohistochemistry experiments, it was necessary to reduce the amount of immunoglobulins that could potentially cross-react with skin proteins. Using previously described methods (Hayes et al., 2000), rabbit anti-NAL sera (500 $\mu \mathrm{l})$ was incubated for 48 hours at $4^{\circ} \mathrm{C}$ with $15 \mathrm{mg}$ of stratum corneum scrapings obtained from the dorsal lumbar region of hairless guinea pigs. Antibodies were then passed through a $0.45 \mu \mathrm{m}$ filter and further absorbed against normal guinea pig serum for 1 hour. The absorbed rabbit anti-NAL sera was then stored at $-20^{\circ} \mathrm{C}$ until use in immunohistochemistry.

\section{Phenotypic Analysis}

Antibodies. Monoclonal antibodies against CD16/CD32 (Fc Block ${ }^{\circledR}$, clone 2.4G2), CD45R/B220 (clone RA3-6B2), IgE (clone R-35-72), CD4 (clone RM4-4), CD40 (clone 3/23), CD23 (clone B3B4), I-A/I-E (MHC class II, clone 2G9), CD152 
(CTLA-4, clone 9H10), CD86 (B7.2, clone GL1), CD28 (clone 37.51) and isotype controls conjugated to either fluorescein isothiocyanate (FITC) or phycoerythrin (PE) labels were purchased from Pharmingen (San Diego, CA.).

Flow Cytometry Procedure. Phenotypic analysis of draining lymph node cells was performed according to methods described by Manetz and Meade (Manetz and Meade, 1999). Draining cervical lymph nodes were excised from individual mice, collected in tubes containing PBS, and placed on ice. Single cell suspensions were prepared by dissociating lymphoid tissue using frosted microscope slides. Cell counts were determined using a Z2 Coulter ${ }^{\circledR}$ Counter (Hialeah, FL) and approximately $1 \times 10^{6}$ cells per sample were added to the wells of 96 well u-bottom plates. A volume of $100 \mu 1$ was used on all following steps. The cells were washed with a PBS staining buffer containing $1.0 \%$ BSA (bovine serum albumin) and $0.1 \%$ sodium azide, and then incubated with $1.0 \mu \mathrm{g}$ of $\mathrm{Fc}$ Block ${ }^{\circledR}$ for 5 minutes at $4^{\circ} \mathrm{C}$. Antibodies were then added at a 1:100 dilution in staining buffer and samples were incubated for approximately 45 minutes in the dark at $4^{\circ} \mathrm{C}$. After washing, cells were incubated with $10 \mu \mathrm{g} / \mathrm{ml}$ of propidium iodide (PI) in the dark at $4^{\circ} \mathrm{C}$ for five minutes. Cells were washed, resuspended in staining buffer, and analyzed on a Becton Dickinson FACSCalibur or FACSVantage flow cytometer. A PBS sample sheath lacking chelators was used as the interaction between IgE and surface CD23 (FceRII) is calcium dependent. Using the propidium iodide stain as well as the forward and side scatter profiles; cells were gated on viability and size to exclude dead cells and red blood cells. Approximately 10,000 
viable events were collected for each sample and analysis was performed on gated cell populations.

\section{Whole Body Plethysmography}

To determine pulmonary reactivity following sensitization, enhanced pause (PenH), an indicator of bronchoconstriction (Drazen et al., 1999), was evaluated in mice using whole body plethysmography (Buxco Electronics, Sharon, CT). Following sensitization with latex proteins, mice were challenged via inhalation with methacholine $(\mathrm{MCH})$ or i.t. aspiration with NAL protein and pulmonary responses recorded. Prior to all respiratory challenges, mice were placed into plethysmography chambers and monitored for five minutes to establish baseline PenH values. PenH was calculated as (expiratory time/relaxation time -1$) *$ (peak expiratory flow/peak inspiratory flow) (Drazen et al., 1999).

Methacholine Challenge. Increasing concentrations of $\mathrm{MCH}(10,25$, and 50 $\mathrm{mg} / \mathrm{ml}$ ) were used for non-specific challenge and were delivered to the mice while in the plethysmography chambers using a nebulizer (DeVilbiss HealthCare Inc., Somerset, PA). Mice were exposed to each concentration of $\mathrm{MCH}$ for 3 minutes followed by exposure to dry air for 2 additional minutes. PenH measurements were calculated and recorded every 30 seconds for a total of 5 minutes for each concentration of $\mathrm{MCH}$. For each animal, the percent increase in PenH values over baseline was plotted against time for each 
concentration of $\mathrm{MCH}$ and averaged to determine the mean $\pm \mathrm{SE}$ for each exposure group.

NAL Challenge. Following the five-minute baseline monitoring period, mice were removed from the plethysmograph chambers and briefly anesthetized (Isoflurane, Schering Plough, NY) to allow for i.t. aspiration of $300 \mu \mathrm{g}$ of NAL in $50 \mu \mathrm{lBS}$. Following NAL challenge, mice were returned to the Buxco chambers within 1 minute. PenH values were collected every minute for 25 minutes and percent over baseline calculated as described for the methacholine challenge.

\section{Histopathology}

Within 24 hours of the i.t. challenge with latex proteins, mice were sacrificed and the lungs were collected for histopathology. Anesthetized $\left(\mathrm{CO}_{2}\right)$ mice were exsanguinated by transecting the abdominal region of the aorta; the organs of the thoracic cavity were removed and the lungs were inflated via intratracheal instillation with $\sim 1 \mathrm{ml}$ of $10 \%$ buffered formalin prior to submersion into $15 \mathrm{ml}$ of formalin. Tissues underwent a series of alcohol washes followed by immersion in xylene and embedding in paraffin. Following embedding, tissues were cut in $5 \mu \mathrm{m}$ sections and stained for pathological evaluation. All tissues were stained with Hematoxylin and Eosin. Eosinophilia was evaluated by staining tissue sections with $0.5 \%$ Chromotrop $2 \mathrm{R}$. Additionally, Alcian blue and periodic acid-Schiff stains were used to visualize the production of polysaccharides and mucoproteins. Slide preparation and staining were performed by the 
Pathology Laboratory at the Health Effects Laboratory Division, NIOSH. The left lungs of all animals were evaluated for pathological changes.

\section{Dermal Penetration Experiments}

$\underline{\text { Radiolabeling of Latex Proteins. }}$. To reduce the potential interference of glycerol in the radiolabeling process, NAL was precipitated according to the American Society for Testing and Materials' protocol D5712 (ASTM 1995) using 72\% phosphotungstic acid and $72 \%$ trichloroacetic acid. The precipitates were resolubilized in a $3: 1$ phosphate buffered saline $(100 \mathrm{mM}$ PBS $) / 0.1 \mathrm{~N} \mathrm{NaOH}(\mathrm{pH}=7.0)$ solution and stored at $-20^{\circ} \mathrm{C}$ until use. Concentrations of NAL preparations were determined by the modified Lowry assay (ASTM D5712) and diluted with $100 \mathrm{mM}$ PBS $(\mathrm{pH}=7.0)$ to $1 \mathrm{mg} / \mathrm{ml}$ for radiolabeling.

Non-ammoniated latex proteins used in all in vitro penetration studies were radiolabeled with ${ }^{125}$ Iodine (NEN, Boston, MA) using Markwell's methodology (Markwell, 1982) with minor modifications. To reduce the potential for radioactivity exposure, the entire radiolabeling procedure was carried out in a Class IIB hood. In an Eppendorf tube, carrier-free $\mathrm{Na}^{125} \mathrm{I}(500 \mu \mathrm{Ci})$ was added to $250 \mu \mathrm{l}$ of $100 \mathrm{mM}$ PBS $(\mathrm{pH}=7.0)$ to prevent volatilization of free Iodine. Prior to the addition of NAL proteins, Iodo-Beads ${ }^{\circledR}$ (Pierce, Rockford, IL) were added to serve as a catalyst for the radiolabeling reaction. NAL proteins were then added and the reaction was allowed to proceed for 25 minutes at which time the Iodo-Beads ${ }^{\circledR}$ (Pierce, Rockford, IL) were removed to stop the reaction. The radioactive solution was immediately placed into 
dialysis tubing with a molecular weight cut off of 1,000 Da (Spectrum Laboratories Inc., Rancho Dominguez, CA). To remove any unincorporated label, the tubing was placed in

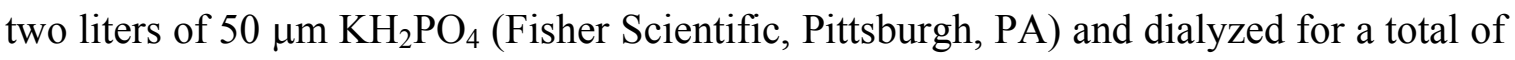
48 hours at $4^{\circ} \mathrm{C}$. The buffer was changed every 12 hours to increase the concentration gradient and continue the diffusion of un-incorporated label. After dialyzing, the radioactive protein solution was removed and refrigerated in a lead peg until used.

Penetration Apparatus. Percutaneous penetration of compounds was measured using a previously described one-compartment, flow-through diffusion cell system (Figure 5) (Hayes et al., 2000). In-line, Teflon diffusion cells (Permegear, Inc, Riegesville, PA) with an exposure area of $0.64 \mathrm{~cm}^{2}$ and reservoir of $0.26 \mathrm{ml}$ of receptor fluid beneath the skin surface were used for all studies. Aluminum cell warmers securely held the diffusion cells in place while flow through tubing was setup to dispense directly into corresponding scintillation vials held in an Isco Retriever $\mathrm{IV}^{\mathrm{TM}}$ fraction collector (Fisher Scientific, Pittsburgh, PA). In order to maintain a consistent skin temperature of $32^{\circ} \mathrm{C}$ for each cell, a Neslab water circulating bath was connected to the aluminum cell warmers. Receptor fluid was stored in a 2 liter reservoir and was delivered to the flowthrough diffusion via a 16-cartridge peristaltic pump (Ismatec Inc., Zurich, Switzerland) with a 14 outlet manifold. Tygon tubing (Fisher Scientific, Pittsburgh, PA) was used to connect the pump to each diffusion cell. To maintain consistent exposure conditions, the diffusion cells were enclosed in a Plexiglas chamber and connected to a temperaturehumidity control system (Miller-Nelson Research, Inc., Monterey, CA) set at $26.7^{\circ} \mathrm{C}$ and $50 \%$ (temperature and humidity, respectively). The exact temperature and humidity was 
monitored by a sensor that was placed above the cells inside the chamber. The sensor gathered twenty readings of the humidity and temperature in five-second intervals, and the overall mean \pm standard deviation was calculated for each parameter during the entire exposure period using the LabView software package (National Instruments, Austin, TX). The environmental chamber was built by Aliakbar Afshari of the Engineering and Control Technology Branch, NIOSH. Figure 6 illustrates a computer generated line graph for the humidity and temperature readings from a representative study.

Harvesting Skin for In Vitro Penetration Studies. At designated time points post exposure, hairless guinea pigs were euthanized by carbon dioxide asphyxiation and fullthickness skin was removed from the dorsal thorax and lumbar areas. Following excision, the skin was washed with a $10 \%$ soap solution, rinsed with water, and dried using paper towels. To remove the remaining subcutaneous and connective tissue, the skin was mounted epidermis side down on Styrofoam blocks and the tissue trimmed using forceps and surgical scissors. Skin was then turned over so that the epidermis side was up and secured to the Styrofoam blocks using $90^{\circ}$ bent needles. Using an electric dermatome (Padgett Instruments, Kansas City, MO), a $250 \mu \mathrm{m}$ thickness of skin was excised which included the entire epidermis and a portion of the upper papillary dermis. Using a steel punch (McMaster-Carr, Inc., New Brunswick, NJ), $12.7 \mathrm{~mm}$ (0.5 in) circular punches were taken of acetone and glutaraldehyde exposed skin. In each experiment, the entire procedure was accomplished within 2 hours following removal of skin from the euthanized animals. 


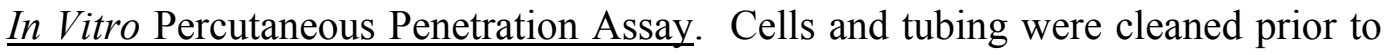
each penetration assay by flushing the system with $70 \%$ ethanol. To prevent fluid from leaking out of the diffusion cells, transparency paper punches were placed in the cells. HEPES-balanced Hank's salt solution (HBHSS, Gibco, Grand Island, NY) was prepared fresh for each penetration experiment, adjusted to $\mathrm{pH} 7.4$, filtered $(0.22 \mu \mathrm{m})$, and pumped through the cells to displace the alcohol solution. The HBHSS solution was selected for use in penetration studies due to its ability to maintain skin viability for greater than 24 hours (Collier, 1989). A complete listing of the components in the HBHSS solution can be found in Appendix 1. Once the system was cleaned (with 70\% ethanol) and following HBHSS addition, dermatomed punches of the skin samples were placed in each diffusion cell epidermis side up and clamped down securely.

Throughout the course of the experimental process, the HBHSS (receptor fluid) was pumped by the peristaltic pump at a flow rate of $1.8 \mathrm{ml} / \mathrm{hr}$. The receptor fluid was pumped through the flow through diffusion cells and collected in polypropylene scintillation vials using the fraction collector.

Skin Barrier Test. Prior to evaluating the in vitro percutaneous penetration of latex proteins, the barrier integrity of all skin samples receiving radioactive test compounds was verified using a 20 minute ${ }^{3} \mathrm{H}_{2} 0$ penetration assay (Bronaugh and Collier, 1991). Briefly, $200 \mu \mathrm{l}$ of ${ }^{3} \mathrm{H}_{2} \mathrm{O}$ was applied to the skin sample covering the entire exposed surface area. Twenty minutes following application, the solution was removed and the skin was blotted dry with cotton-tipped applicators (Fisher Scientific, Pittsburgh, 
PA). Each skin sample was rinsed once with $300 \mu \mathrm{dH}_{2} 0$ to reduce remaining radioactivity and then dried again with cotton tipped applicators. Receptor effluent was collected for an additional 60 minutes (total of 80 minutes). Finally, $10 \mathrm{ml}$ of Scintisafe Plus $^{\mathrm{TM}} 50 \%$ scintillation cocktail (Fisher Scientific, Pittsburgh, PA) was added to each collection tube and the radioactivity quantified via a Packard Tri-Carb 2500TR beta liquid scintillation counter (Downers Grove, IL). A $200 \mu 1$ sample of the dosing solution was counted in duplicate and averaged. The percent ${ }^{3} \mathrm{H}_{2} 0$ penetration for each cell was calculated by the following formula:

[effluent dpm $(80 \mathrm{~min}) \div$ dosing solution (avg dpm) $\times 100=\%$ penetrated] Bronaugh and Collier (Bronaugh and Collier, 1991) previously established that greater than $0.35 \%$ penetration was indicative of abraded skin based on comparing the results of the barrier test with calculated permeability constant values $\left(\mathrm{K}_{\mathrm{p}}\right)$ from the same skin samples. Therefore, only skin samples that passed the test $\left(<0.35 \%{ }^{3} \mathrm{H}_{2} 0\right.$ penetration $)$ were used for intact skin analysis and only cells failing the test were used as abraded samples.

Radiolabeled Latex Protein Penetration Studies. Following the barrier test, approximately $100 \mu \mathrm{g}$ of the radiolabeled latex protein mixture (100 $\mu \mathrm{l})$ was applied to the skin samples covering the entire exposed surface area $\left(0.64 \mathrm{~cm}^{2}\right)$. To prevent evaporation of the radiolabeled NAL protein solution, skin samples were occluded with a Teflon plug. 
Following 24 hours of exposure, the remaining radiolabeled NAL protein solution was removed from the skin surface and, the skin samples were washed with $10 \%$ soap and water using cotton tip applicators. Washes were continued, usually $9-11$ washes, until less than $0.1 \%$ of the original radiolabeled NAL protein solution was detectable by gamma counting (Cobra II gamma counter, Packard, Downers Grove, IL). In order to quantify latex protein penetration, as well as calculate mass balance, in the skin and that which penetrated through the skin; radioactive counts were obtained for each of the skin samples, as well as $500 \mu \mathrm{l}$ aliquots of receptor effluent for each time point $(6,12,18,24$ hr). Mass balance was calculated as a percentage of the originally applied dosing solution by adding together the counts from the soap and water washes, skin samples, and the receptor fluid and dividing by the radioactive counts obtained for the original dosing solution. The remaining receptor fluid for each diffusion cell was combined into one 50 $\mathrm{ml}$ conical and freeze-dried (LabConco Corporation, Kansas City, MO). Following the lyophilization process, the remaining product was resuspended in $1 \mathrm{ml} \mathrm{10 \%} \mathrm{formic} \mathrm{acid}$ and, upon combining samples from each exposure group (acetone or glutaraldehyde), dialyzed in tubing with a 1,000 mw cutoff (Spectrum Laboratories Inc., Rancho Dominguez, $\mathrm{CA})$ against $4 \mathrm{~L} \mathrm{d \textrm {H } _ { 2 }} 0\left(48 \mathrm{hr}, 4^{\circ} \mathrm{C}\right)$ to remove the salts and the formic acid. The dialyzed solution was lyophilized again and resuspended in $250 \mu 1$ of 1x sample buffer for subsequent protein separation using gel electrophoresis. For each penetration study, two skin samples (one intact and one abraded) were exposed to non-radioactive latex proteins under identical conditions as those used for radiolabeled samples for immunohistochemical analysis. The non-radioactive skin samples were fixed in $10 \%$ 
buffered formalin overnight, processed, and embedded in paraffin wax by Patsy Willard of the Pathology and Physiology Branch at NIOSH.

SDS-PAGE and Phosphoimaging. Latex proteins were separated using SDSpolyacrylamide gel electrophoresis (PAGE) according to previously described methods (Laemmli, 1970; Hoefer, 1994). All samples were diluted in electrophoresis running buffer and boiled for 2 minutes prior to loading on gels. Samples were pipetted into wells of a $10 \%$ polyacrylamide gel and separated at a constant voltage of $200 \mathrm{~V}$ for approximately 1 hour (Mini Protean II Cell; Bio-Rad, Hercules, CA). Broad range, molecular weight protein markers (7.4-202 kDa, Bio-Rad, Hercules, CA) were run concurrently with the samples for molecular weight estimation. Coomassie brilliant blue (Sigma, St. Louis, MO) was used to visualize proteins followed by drying with a Savant SGD2000 slab gel dryer. In order to visualize the radiolabeled proteins in the dosing solution and receptor effluents, dried gels were placed in a storage cassette and exposed to a Phosphor screen for approximately 1 hour followed by a scan for gamma radiation using a PhosphorImager 445 SI (Molecular Dynamics, Inc., Sunnyvale, CA).

Immunohistochemical Evaluation of HGP skin sections. Paraffin-embedded NAL exposed samples were cut at $5 \mu \mathrm{m}$ and placed on Superfrost Plus Gold microscope slides. Using xylene and a series of alcohol to $\mathrm{dH}_{2} \mathrm{O}$ washes, slides were first de-paraffinized and then re-hydrated. In order to retrieve masked antigens, tissue sections were immersed in a $0.01 \mathrm{M}$ citrate buffer $(\mathrm{pH}=6)$ and microwaved for approximately 2 minutes. Slides were then immersed for 20 minutes in a $1: 1$ solution of $3 \% \mathrm{H}_{2} \mathrm{O}_{2}$ and 
methanol (Sigma Chemical Co., St. Louis, MO) to block endogenous peroxidase followed by a $\mathrm{dH}_{2} \mathrm{O}$ wash and placement on Sequenza chamber racks (Shandon Inc., Pittsburgh, PA). Following a 5-minute wash with Cadenza buffer (Shandon Inc., Pittsburgh, PA), endogenous biotin in the skin was blocked by incubating slides for 30 minutes in solutions containing $0.1 \%$ avidin (DAKO, Carpinteria, CA) and $0.01 \%$ biotin (DAKO, Carpinteria, CA). Slides were then coated with $500 \mu 1$ 10\% BSA/PBS block buffer (Sigma, St. Louis, MO) for $1 \mathrm{hr}$ at room temperature (RT). Following the blocking step, $160 \mu \mathrm{l}$ of the adsorbed rabbit polyclonal anti-latex antibody (1:200; See Rabbit anti-NAL antibody generation) was added and the slides were incubated overnight at $4^{\circ} \mathrm{C}$. Twelve to eighteen hours later, the skin sections were washed with Cadenza buffer and $160 \mu$ of biotinylated swine, anti-rabbit $\mathrm{F}(\mathrm{ab}$ ')2 fragment (1:300, DAKO, Carpinteria, CA) was added to the chambers for 30 minutes at room temperature. Slides were washed three more times with Cadenza buffer and the slides were incubated for 30 minutes at room temperature with $160 \mu \mathrm{l}$ of streptavidin-horseradish peroxidase conjugate solution (NEN, 1:100). The slides were again washed with Cadenza buffer and developed for 5 minutes with liquid 3-amino-9-ethylcarbazole (DAKO, Carpinteria, CA). Following one wash with $\mathrm{dH}_{2} 0$, the skin sections were counter stained with Mayer's hematoxylin (5 minutes). Finally, the slides were mounted using Crystal/mount, ovendried, cover-slipped, and examined under light microscopy. Under the guidance of Lyndell Millechia (Pathology and Physiology Research Branch, NIOSH), photomicrographs were taken of representative skin sections. 


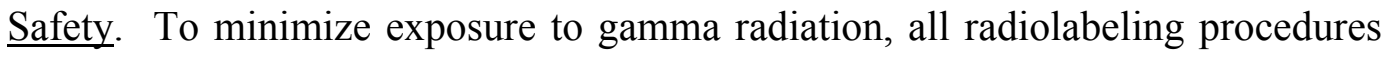
were performed in a Class IIB hood and radiolabeled protein solutions were stored in lead pegs. Radiation exposure was monitored by the use of lapel and ring badges which were worn during the use of unbound $\mathrm{Na}^{125} \mathrm{I}$. To further monitor exposure to unbound $\mathrm{Na}^{125} \mathrm{I}$, thyroid scans were obtained within 72 hours of each radiolabeling procedure by the Nuclear Medicine department at Ruby Memorial Hospital (Morgantown, WV). Radioactive waste was collected and disposed of by the Radiation Safety Office at NIOSH. Following experimentation, the non-radioactive skin samples were placed in bio-hazard bags and disposed of by incineration through the safety office at NIOSH. 


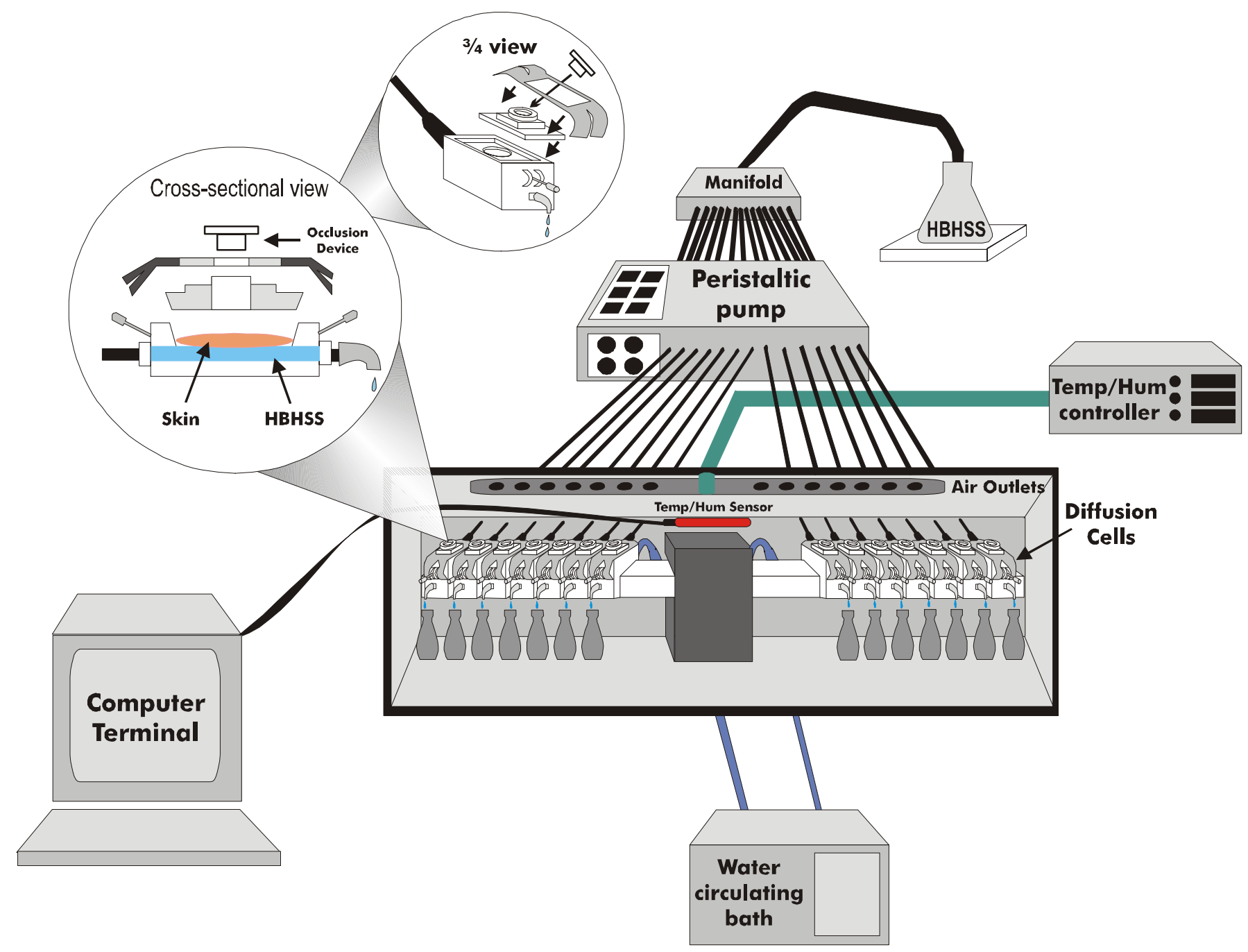

Figure 5. In Vitro Flow Through Diffusion Cell Apparatus 


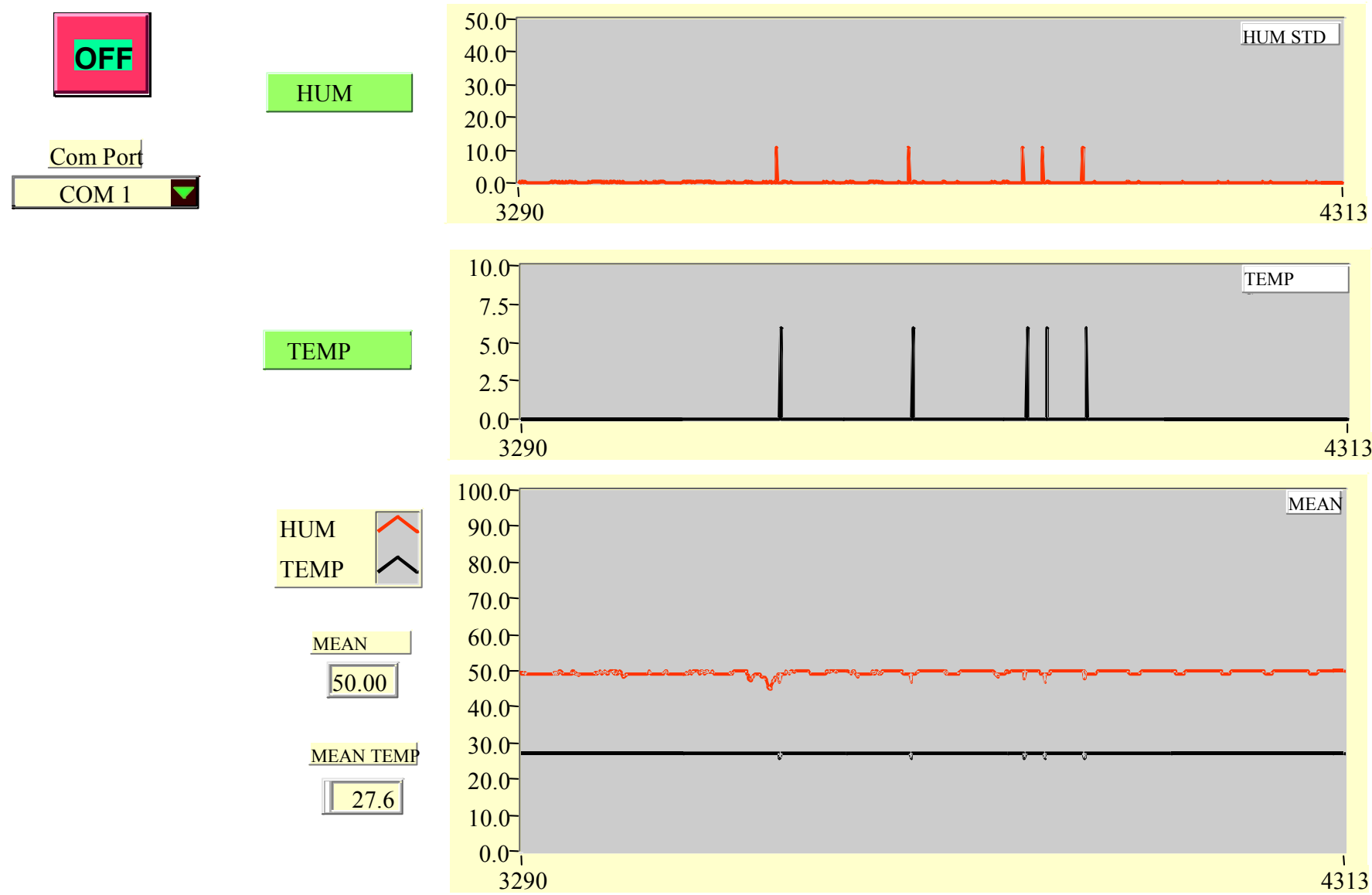

Figure 6. Representative Graph of Temperature and Humidity Readings in Hairless Guinea Pig In Vitro Percutaneous Penetration Experiments. The lower panel represents the mean for humidity (black line) and temperature (red line) and the upper panels are the standard deviations for twenty readings used to generate each point on the line. 


\section{RNA Isolation}

RNA was isolated from the mediastinal (intratracheally exposed mice) or cervical (dermally exposed mice) draining lymph nodes following the manufacturer's recommendation for the RNeasy ${ }^{\circledR}$ and QiaShredder ${ }^{\mathrm{TM}}$ Kits (Qiagen, Valencia, CA). Upon excision, tissue was either snap frozen in liquid nitrogen and stored at $-80^{\circ} \mathrm{C}$ until isolation or collected in $600 \mu \mathrm{l}$ of RNAlater ${ }^{\mathrm{TM}}$ (Ambion, Houston, TX) and stored at $4^{\circ} \mathrm{C}$ until isolation. Prior to isolation, $\beta$-mercaptoethanol was added to the RLT Buffer according to the manufacturer's guideline giving a $1.0 \% \beta$-mercaptoethanol solution. A DNase I stock solution was also prepared by dissolving the lyophilized powder in $550 \mu \mathrm{l}$ of RNase free water. This DNase I stock solution was further diluted for experimental use by adding $10 \mu \mathrm{l}$ of the stock solution with $70 \mu \mathrm{l}$ of RDD Buffer and storing at $4^{\circ} \mathrm{C}$ until use. To isolate the RNA, tissue was transferred to a RNase free $1.5 \mathrm{ml}$ eppendorf tube containing $600 \mu \mathrm{l}$ of RLT buffer and dissociated using a rotor-stator hand held homogenizer. To prevent degradation of RNA, samples were placed on ice until the next step in the isolation process. Once samples had been completely dissociated, each sample suspension was added to a QiaShredder ${ }^{\mathrm{TM}}$ spin column and centrifuged at 20,800 rcf for 2 minutes. To further pellet any debris that may have passed through the column, caps were placed on the collection tubes and cell lysates were spun for an additional 3 minutes at 20,800 rcf. Following centrifugation, the supernatant was transferred to a new $1.5 \mathrm{ml}$ eppendorf tube containing $600 \mu \mathrm{l}$ of $70 \%$ ethanol and mixed by pipetting. For each sample, $600 \mu \mathrm{l}$ was added to the RNeasy ${ }^{\circledR}$ columns and centrifuged for 15 seconds at 20,800 rcf. The supernatant was removed and again added to the spin column and 
centrifuged to maximize purification. The remaining supernatant was discarded and this step was repeated with the remaining sample volume. Once the entire sample had been added and run through the RNeasy ${ }^{\circledR}$ column, $350 \mu$ of RW1 Buffer was added to the column and the spin columns centrifuged at 20,800 rcf. The flow through was discarded and $80 \mu \mathrm{l}$ of a diluted DNase I solution was added to the spin columns for a 15 -minute incubation at room temperature. Following the incubation, an additional $350 \mu 1$ of RW1 Buffer was added to the spin column and the tubes were spun for 15 seconds at 20,800 rcf. The columns were placed in new $2.0 \mathrm{ml}$ collection tubes and $500 \mu \mathrm{l}$ of RPE Buffer was added to each column. The spin columns were centrifuged for 15 seconds at 20,800 rcf, followed by the addition of another $500 \mu \mathrm{l}$ of RPE Buffer and centrifugation (15 seconds, 20,800 rcf). The spin columns were transferred to a new snap cap eppendorf tube and centrifuged for 1 minute at 20,800 rcf to dry the column. To release the RNA from the column, $30 \mu \mathrm{l}$ of RNAse free water was added to the column followed by a 1minute spin at 20,800 rcf. The supernatant was removed from the collection tube and again added to the column for an additional spin. Following the final spin the tubes were closed and stored at $-80^{\circ} \mathrm{C}$ until RNA quantification.

To determine the quantity and purity of the isolated RNA, samples were thawed and diluted 1:50 in RNAse free water and analyzed using the Beckman DU650 spectrophotometer (Beckman Coulter, Fullerton, CA). Optical density values were obtained at wavelengths of 260 and $280 \mathrm{~nm}$ for each sample and were used to calculate the quantity (optical density at $260 \mathrm{~nm} * 40 *$ dilution $=\mu \mathrm{g}$ RNA) and purity (optical 
density at $260 \mathrm{~nm} /$ optical density at $280 \mathrm{~nm}=$ purity). Target purity ratios ranged between 1.5 and 2.0 .

\section{In Vitro Transcription}

DNA complementary to the RNA for each sample was generated using TaqMan ${ }^{\circledR}$ reverse transcription reagents (Applied Biosystems, Branchburg, NJ). Samples were prepared in $0.2 \mathrm{ml}$ MicroAmp PCR tubes (Perkin Elmer, Norwalk, CT) with a total volume of $50 \mu \mathrm{l}$ as outlined in table 3 . Each sample was prepared with $2 \mu \mathrm{g}$ of total RNA (as determined by RNA quantification) and reverse transcription was carried out on the GeneAmp PCR system 6700 thermocycler (Applied Biosystems, Branchburg, NJ) with settings outlined in table 4 .

Table 3. Reverse Transcription Reaction for cDNA in RT-PCR Analysis

\begin{tabular}{ccc}
\hline Component & Volume/Tube $(\mu \mathrm{L})$ & Final Concentration \\
\hline 10X TaqMan RT Buffer & 5.00 & $1 \mathrm{x}$ \\
25mM MgCl 2 & 11.00 & $5.5 \mathrm{mM}$ \\
10mM dNTP Mix & 10.00 & $500 \mu \mathrm{M}$ each \\
Random Hexamers & 2.50 & $2.5 \mu \mathrm{M}$ \\
RNase Inhibitor & 1.00 & $0.4 \mathrm{U} / \mu \mathrm{L}$ \\
MultiScribe Reverse Transcriptase & 1.25 & $1.25 \mathrm{U} / \mu \mathrm{L}$ \\
RNA & Variable & $2 \mu \mathrm{g} / \mathrm{sample}$ \\
Rnase free Water & $\#$ & ---- \\
\hline
\end{tabular}

\# RNase free water was added to bring total volume of reaction up to $50 \mu \mathrm{L}$. 
Table 4. Thermocycler Setting for Reverse Transcription Reaction

\begin{tabular}{c|ccc}
\hline Step & Incubation & RT & RT inactivation \\
\hline & HOLD & HOLD & HOLD \\
Time & $10 \mathrm{~min}$ & $60 \mathrm{~min}$ & $5 \mathrm{~min}$ \\
Temp & $25^{\circ} \mathrm{C}$ & $48^{\circ} \mathrm{C}$ & $95^{\circ} \mathrm{C}$ \\
\hline
\end{tabular}

\section{Real-Time Quantitative Polymerase Chain Reaction}

Individual cytokine message levels were evaluated following amplification using real-time, semi-quantitative PCR. This procedure utilizes fluorescently labeled primers and probes in detecting the level of endogenous control (GAPDH) and cytokine target (IL-4, IL-10, IL-12, IFN- $\gamma$ ) message. Each sample was prepared using cDNA from the previous amplification step, a PCR master mix (Applied Biosystems, Branchburg, NJ) and commercially available probe/primer kits (Applied Biosystems, Branchburg, NJ). Samples were prepared for endogenous control detection as outlined in table 5 and cytokine target detection as outlined in table 6 . Samples were then added to 96 well BioRad iCycler iQ plates, centrifuged for 1 minute at $200 \mathrm{rcf}$, and loaded on the iCycler iQ (Bio-Rad, Hercules, CA). The settings for the real-time PCR are outlined in table 7. A threshold was determined by calculating the mean fluorescent intensity following the annealing/extending portions of cycles $2-10$. This threshold was subtracted from each data point and was used to determine the adjusted threshold intensity. The threshold was averaged for all samples and the cycle threshold calculated as: $10 *$ standard deviation of the threshold. The relative quantification of the target gene was determined based on the relative expression of the target gene compared to GAPDH. In brief, a cycle threshold was determined for both the endogenous control and target genes based on nuclease 
degradation and the subsequent release of fluorescence. These cycle thresholds were then used to calculate the relative expression of the target gene using the following formula (Giulietti et al., 2001; Pfaffi, 2001): $2^{-\Delta \Delta \mathrm{Ct}} . \quad \Delta \Delta \mathrm{Ct}=\Delta \mathrm{Ct}($ Sample) $\Delta \mathrm{Ct}($ Vehicle $) . \Delta \mathrm{Ct}=\mathrm{Ct}(\mathrm{GAPDH})-\mathrm{Ct}($ target $)$.

The efficiency of the thermocycler was calculated as described by the manufacturer. Briefly, sample mRNA was serially diluted and added to corresponding tubes containing PCR master mix, GAPDH primers and probes. Samples were run as previously described to determine the cycle thresholds for each sample. The efficiency was calculated by graphing the logarithm of the amount of mRNA versus the cycle threshold. Efficiencies within these studies were within the range specified by the manufacturer.

Table 5. PCR Reaction Mix for GAPDH Controls

\begin{tabular}{ccc}
\hline Component & Volume/Tube $(\mu \mathrm{l})$ & Final Concentration \\
\hline 2X PCR Master Mix & 10.0 & $1 \mathrm{X}$ \\
Forward Primer & 0.2 & $100 \mathrm{nM}$ \\
Reverse Primer & 0.2 & $100 \mathrm{nM}$ \\
Probe & 0.2 & $200 \mathrm{nM}$ \\
cDNA & $4.0^{\ddagger}$ & -- \\
RNase Free Water & 5.4 & -- \\
Total & 20.0 & -- \\
\hline
\end{tabular}

${ }^{*} 0.16 \mu \mathrm{g}$ of cDNA was used for each experiment 
Table 6. PCR Reaction Mix for Cytokines

\begin{tabular}{ccc}
\hline Component & Volume/Tube $(\mu \mathrm{l})$ & Final Concentration \\
\hline 2X PCR Master Mix & 10.0 & $1 \mathrm{X}$ \\
20X Probe/Primer Mix* & 1.0 & $1 \mathrm{X}$ \\
cDNA & $4.0^{\ddagger}$ & -- \\
RNase Free Water & 5.0 & -- \\
Total & 20.0 & -- \\
\hline
\end{tabular}

* All cytokines from Applied Biosystem come in a master mix containing probe, forward and reverse primers, with a constant concentration between kits of 20X.

${ }^{\ddagger} 0.16 \mu \mathrm{g}$ of cDNA was used for each experiment

Table 7. RT-PCR Settings for Thermocycler

\begin{tabular}{ccccc}
\hline \multirow{2}{*}{ Stage } & \multirow{2}{*}{ UNG Incubation } & $\begin{array}{c}\text { AmpliTaq } \\
\text { Activation }\end{array}$ & \multicolumn{2}{c}{ PCR (60 cycles) } \\
\hline \multirow{2}{*}{ Temperature } & Hold & Hold & Denature & Anneal $/$ Extend \\
Time & $50.0^{\circ} \mathrm{C}$ & $95.0^{\circ} \mathrm{C}$ & $95.0^{\circ} \mathrm{C}$ & $60.0^{\circ} \mathrm{C}$ \\
\hline
\end{tabular}

\section{Epidermal Sheet Preparation and Staining}

In order to visualize the activation of antigen presenting cells, mice were exposed to vehicle or test articles on the dorsal surface of the ear pinna. Upon sacrifice, the dorsal and ventral regions of ears of mice exposed to NAL alone or concurrently with glutaraldehyde were separated using forceps. The dorsal region of the ear was then placed into $5 \mathrm{ml}$ of $0.02 \mathrm{M}$ EDTA $(\mathrm{pH} 8.0)$ and incubated for 30 minutes at $37^{\circ} \mathrm{C}$. Using forceps, the epidermal sheets were separated and placed on a microscope slide. The epidermal sheets were then washed with PBS and fixed with acetone at $-20^{\circ} \mathrm{C}$ for 20 minutes. Following a 5 minute PBS wash, FITC labeled anti-mouse I-A/I-E (2G9, Pharmingen, San Diego, CA) was added to the slides at a 1:100 dilution and incubated 
for 1 hour at $25^{\circ} \mathrm{C}$. Slides were washed, mounted with ProLong (Molecular Probes, Eugene, OR), and sealed with nail polish. Confocal microscopy was used to visualize the expression of cell surface molecules and capture images for analysis. Under the guidance of Lyndell Millechia (Pathology and Physiology Research Branch, NIOSH), at least three representative images were collected for each epidermal sheet from the ears of exposed mice.

Images obtained from the confocal microscope were analyzed for Langerhans' cell numbers by counting the number of fluorescing cells in a $40 \mathrm{~mm}^{2}$ field of focus. Data are presented as the percent increase in MHC class II expressing Langerhans' cell over vehicle. This value was determined for each mouse by first calculating the average number of cells per field for vehicle exposed animals and then using the following calculation:

$\%$ Increase over Vehicle $=\underline{(\text { Count }(\text { exposed animal })-\text { Count }(\text { vehicle average }))}$

Count (vehicle average)

\section{Statistics}

All statistical analysis was conducted using Graph Pad Prism, version 3.01 (San Diego, CA). Body weights, serum immunoglobulin levels, phenotypic analysis and PenH data from vehicle and test article exposed mice were analyzed by one-way analysis of variance (ANOVA). When significant differences were detected ( $p>0.05$ ), test groups were compared to the controls using a Dunnett's test. Dose responsive relationships were

determined using linear regression. A one-tailed, unpaired t-test was used to perform pair 
wise comparisons between skin samples exposed to acetone or glutaraldehyde in the dermal penetration experiments. 


\section{RESULTS}

\section{Clinical Observations and Systemic Toxicity}

With the exception of erythema induced by high concentrations of glutaraldehyde $(1 \%)$ at the site of exposure, all mice appeared clinically normal throughout the course of the study. There were no exposure related changes in body weight in any of the studies (See Appendix 2). The only unscheduled deaths occurred due to respiratory complications during intratracheal administration of test article while under isoflurane anesthesia.

\section{Comparison of Sensitization Routes}

An initial study was conducted to evaluate the induction of sensitization following exposure to NAL proteins via the dermal, intranasal (i.n.), intratracheal (i.t.), and subcutaneous (s.c.) routes. All mice were exposed to $50 \mu \mathrm{g}$ of NAL proteins every $5^{\text {th }}$ day for 52 days. As tape stripping was used to prepare the site for dermal application, an additional set of control animals was included in this testing battery to account for changes due to inflammation resulting from the disruption of the stratum corneum as well as a response to chemicals present in the adhesive of the tape strips.

Total IgE Response. Elevations in total serum IgE levels were observed as early as day 16 in mice exposed via s.c. injection reaching $\sim 20,000 \mathrm{ng} / \mathrm{ml}(\mathrm{p}<0.01)$ by day 23 
(Figure 7A). However, 23 and 37 days of exposure were required before significantly elevated serum IgE levels were observed in mice exposed via the dermal $(\mathrm{p}<0.05)$ or i.t. $(\mathrm{p}<0.01)$ routes, respectively. Total serum IgE production in s.c. and i.t. exposed mice appeared to plateau with levels of $\sim 30,000 \mathrm{ng} / \mathrm{ml}$ by day 23 and $\sim 10,000 \mathrm{ng} / \mathrm{ml}$ by day 37, respectively. In mice exposed dermally to NAL proteins, levels of IgE reached a maximum of $\sim 6000 \mathrm{ng} / \mathrm{ml}$ on day 23 . No significant elevations in total serum IgE were observed in mice i.n. exposed to NAL by day 52 of the study (Figure 7B). No elevations in total serum IgE levels were observed in the naïve, vehicle or tape strip control groups throughout the course of the study (data not shown).

Latex Specific Immunoglobulin Response. Levels of NAL specific serum IgE were evaluated throughout the study using a modified sandwich ELISA. Mice exposed via s.c. injection of NAL proteins demonstrated significant $(\mathrm{p}<0.01)$ elevations in NAL specific serum IgE as early as day 16 (Figure $8 \mathrm{~A}$ ) while significant elevations were not observed until day 23 in mice exposed via i.t. aspiration. On the final day of the study (day 52), the levels of NAL specific serum IgG2a and IgA were additionally measured in exposed animals. Whereas animals exposed dermally to NAL proteins demonstrated a significant $(p<0.01)$ increase in NAL specific serum IgE on day 52 when compared to vehicle-exposed animals, no significant elevation in the levels of NAL specific IgG2a or IgA was observed in these same animals (Figures 8B-D). Slight increases in NAL specific IgE were observed in intranasally exposed mice (Figure 8B). However these mice demonstrated greater than 1000-fold and 40-fold increases over vehicle exposed animals in NAL specific IgG2a and IgA, respectively (Figures 8C \& D). In comparison 
with mice exposed to vehicle alone, mice exposed via the s.c. and i.t routes demonstrated approximately 5,000-fold and 3,000-fold increases, respectively, in NAL specific IgG2a levels (Figure 8C). Additionally, mice exposed via i.t. aspiration also demonstrated significantly higher levels ( $\sim 150$-fold) of NAL specific IgA than vehicle exposed mice (Figure 8D). No elevations in NAL specific serum IgE, IgG2a or IgA levels were observed in the naïve, vehicle and tape strip control groups throughout the course of the study (data not shown). 


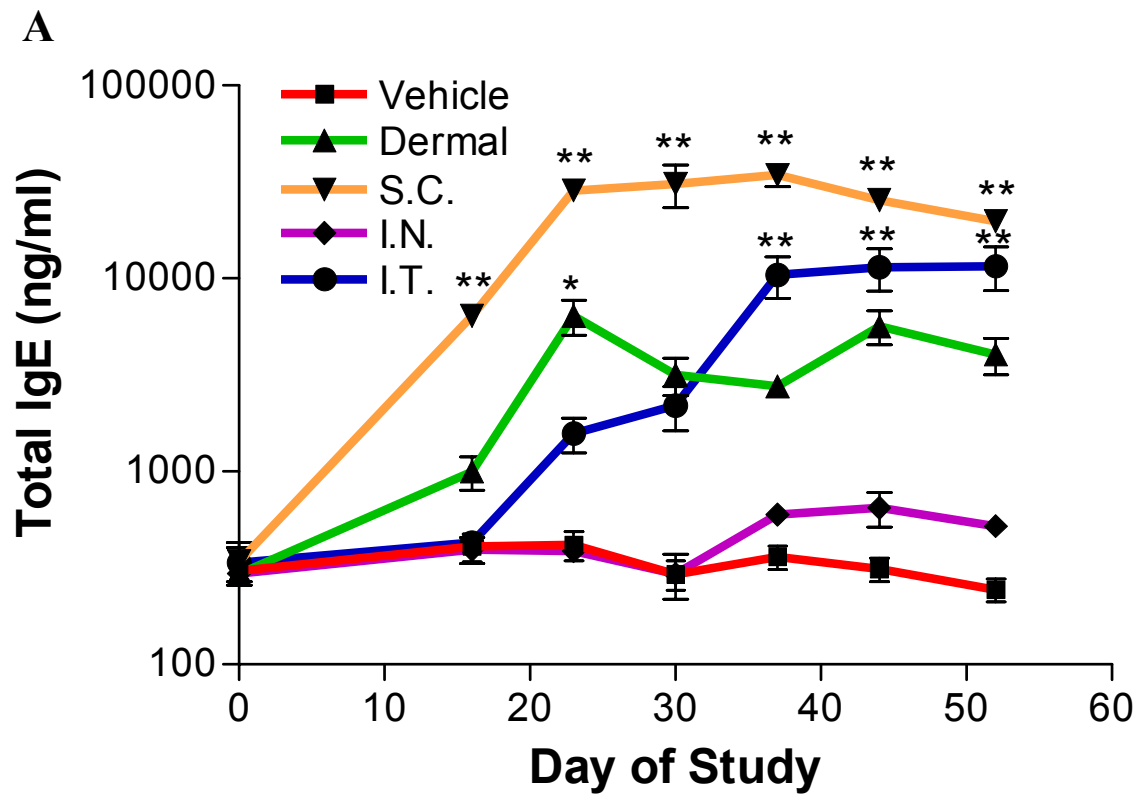

B

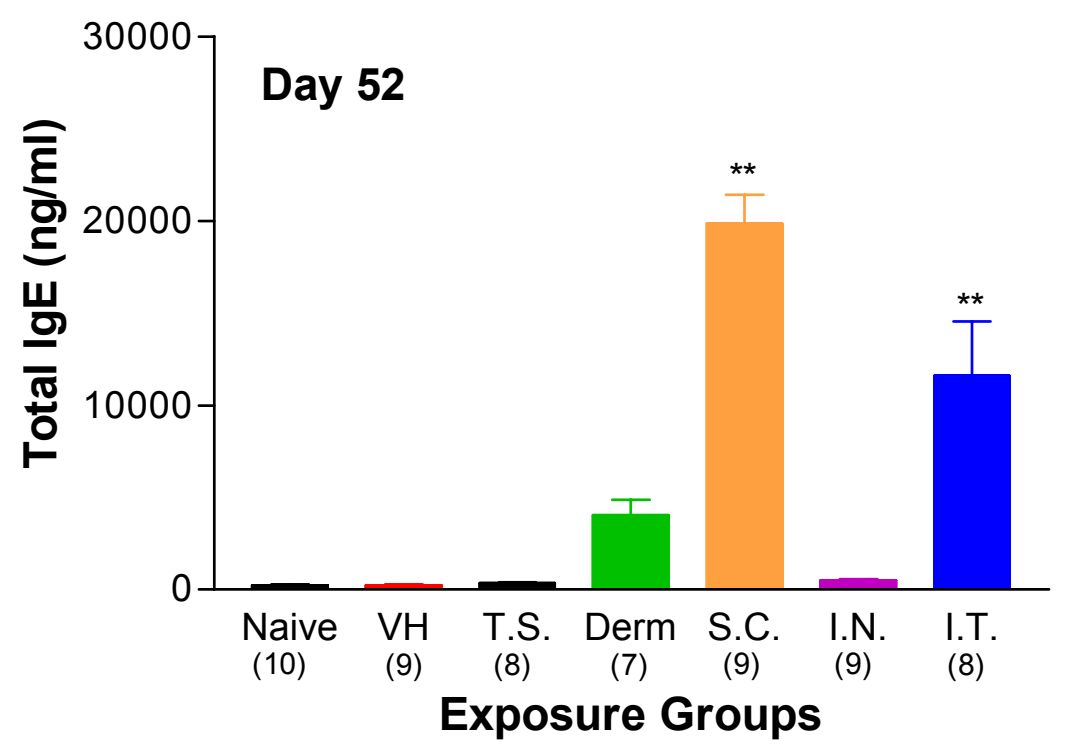

Figure 7. Total Serum IgE Levels in Mice Exposed to $50 \mu \mathrm{g}$ of Latex Proteins by Different Routes of Administration. Time course (A) and day 52 (B) total serum IgE levels were determined in mice exposed to $50 \mu \mathrm{g}$ of NAL proteins. Points and bars represent means \pm standard error for each group. The number of animals in each exposure group is indicated in parenthesis. Significance from vehicle (VH) was determined using a Dunnett's t test and is indicated by * $(\mathrm{p}<0.05)$ and $* *(\mathrm{p}<0.01)$. 

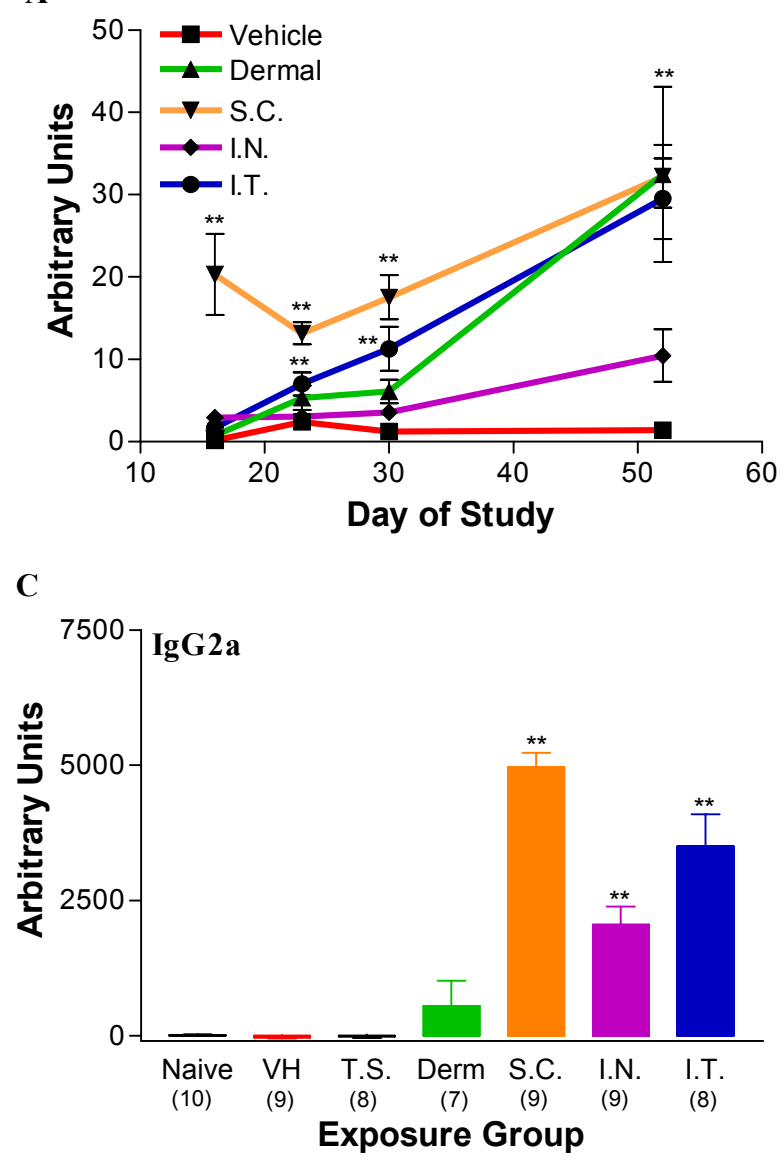

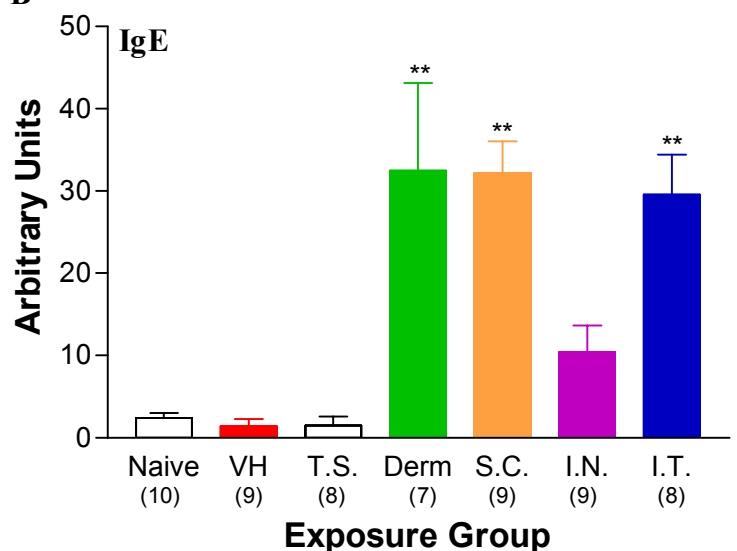

D

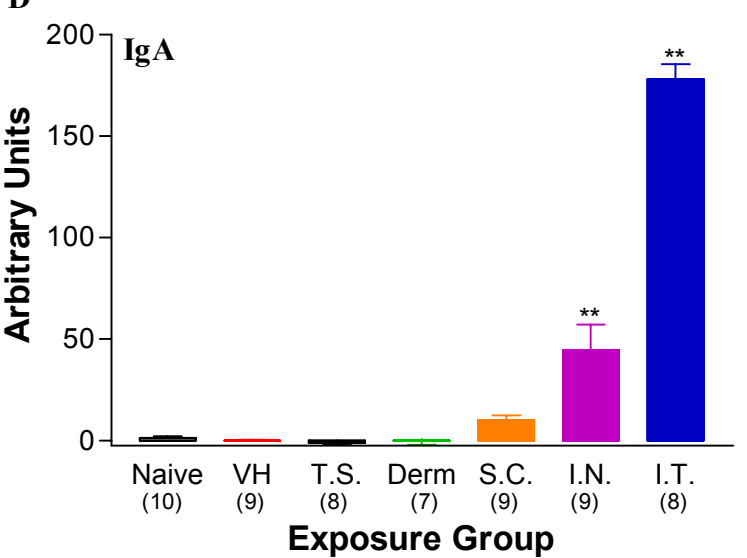

Figure 8. Latex Specific Serum Immunoglobulin Levels in Mice Exposed to $50 \mu \mathrm{g}$ of Latex Proteins by Several Routes. Time course NAL specific $\operatorname{IgE}(A)$ and day 52 NAL specific serum $\operatorname{IgE}(\mathrm{B}), \operatorname{IgG} 2 \mathrm{a}(\mathrm{C})$, and $\operatorname{IgA}(\mathrm{D})$ levels were determined in mice exposed to 50 $\mu \mathrm{g}$ of NAL proteins. Points and bars represent means \pm standard error for each group. The number of animals in each exposure group is indicated in parenthesis. Significance from vehicle $(\mathrm{VH})$ was determined using a Dunnett's $t$ test and is indicated by ** $(\mathrm{p}<0.01)$. 


\section{NAL Sensitization and Airway Hyper-reactivity}

The previous study demonstrated that NAL proteins have the potential to induce allergen specific IgE upon dermal, s.c., i.n., and i.t. exposure. To further investigate the development of NAL specific IgE and the relationship between IgE induction and airway hyper-reactivity; mice were dermally, i.n., or i.t. exposed to increasing concentrations of NAL proteins $(6.25,12.5$, and $25 \mu \mathrm{g})$ until elevations in total IgE were observed. Airway hyper-reactivity was then evaluated following methacholine or NAL respiratory challenge.

$\underline{\text { Total IgE Levels. }}$ Elevated levels of serum IgE were observed as early as day 58 (>3000ng/ml, p<0.05), $44(\sim 1000 \mathrm{ng} / \mathrm{ml}, \mathrm{p}<0.05)$, and $37(>4000 \mathrm{ng} / \mathrm{ml}, \mathrm{p}<0.05)$ in mice exposed to $25 \mu \mathrm{g}$ of NAL proteins via dermal, i.n., and i.t. routes, respectively (Figure 9). Whereas exposure to 6.25 or $12.5 \mu \mathrm{g}$ of NAL proteins via i.n. and i.t. routes failed to induce significant elevations in serum $\operatorname{IgE}$ by days 51 and 79 , respectively, significant elevations $(\mathrm{p}<0.05)$ were observed on day 93 in mice exposed to $12.5 \mu \mathrm{g}$ of NAL proteins dermally (Figure 10).

In mice exposed via the i.n. and i.t. routes, levels of total serum IgE increased in mice exposed to increasing concentrations of NAL reaching significant elevations in mice exposed to $25 \mu \mathrm{g}$ of NAL. Levels of serum IgE in mice dermally exposed to $25 \mu \mathrm{g}$ of NAL peaked at day 58 and decreased throughout the remainder of the study to $\sim 2000$ 
$\mathrm{ng} / \mathrm{ml}$ while levels of IgE in mice exposed to $12.5 \mu \mathrm{g}$ of NAL peaked at $\sim 3000 \mathrm{ng} / \mathrm{ml}$ on day 93 (Figure 10A).

Latex Specific Antibody Responses. Latex specific antibodies (IgE, IgA, IgG1, IgG2a) were measured in the serum of mice exposed to NAL via the dermal, i.n., and i.t. routes on the final day of the studies. Mice dermally exposed to $12.5 \mu \mathrm{g}$ of NAL proteins demonstrated significantly $(\mathrm{p}<0.05)$ elevated levels of NAL specific serum IgE with a greater than 6-fold increase over the vehicle-exposed animals (Figure 11A). When compared to mice exposed to vehicles alone, mice exposed to either 6.25 or $25 \mu \mathrm{g}$ of NAL proteins demonstrated at least a 50-fold increase in IgG1 (Figure 11B) and approximately a 2-fold increase in IgG2a (Figure 11C). Less than a 2.5-fold increase in IgA levels was observed in mice exposed to 6.25 or $25 \mu \mathrm{g}$ of NAL proteins (Figure 11D).

Intranasal exposure of mice to increasing concentrations of NAL proteins resulted in a dose-responsive increase in latex specific serum antibodies $(p<0.05$ for all subclasses). Significant increases in latex specific serum $\operatorname{IgE}(\mathrm{p}<0.01), \operatorname{IgG} 1(\mathrm{p}<0.01)$, $\operatorname{IgG} 2 \mathrm{a}(\mathrm{p}<0.05)$, and $\operatorname{IgA}(\mathrm{p}<0.01)$ were observed in mice exposed to as little as 12.5 $\mu \mathrm{g}$ of NAL proteins. Mice exposed to $25 \mu \mathrm{g}$ of NAL proteins demonstrated greater than $10,50,300$, and 1,500-fold increases over vehicle levels of $\operatorname{IgE}, \operatorname{IgA}, \operatorname{IgG} 2 \mathrm{a}$, and $\operatorname{IgG} 1$, respectively (Figure 12).

Intratracheal exposure to NAL proteins induced significant increases in all subclasses of latex specific antibody evaluated. Latex specific serum IgE levels reached 
significant $(\mathrm{p}<0.01)$ elevations in mice exposed to $25 \mu \mathrm{g}$ of NAL proteins (Figure 13A). A dose responsive increase $(\mathrm{p}<0.05)$ in latex specific serum IgG1 levels was observed in mice exposed to increasing concentrations of NAL reaching greater than a 50 -fold increase over vehicle exposed animals (Figure 13B). Greater than 500-fold increases in IgG2a (Figure 13C) and IgA (Figure 13D) were observed in animals exposed to 12.5 or $25 \mu \mathrm{g}$ of NAL. 
A

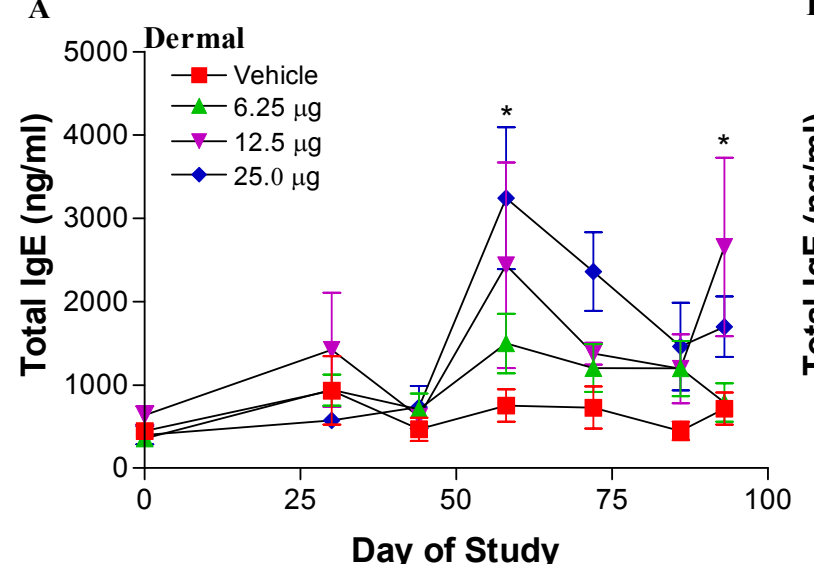

Day of Study

C
B

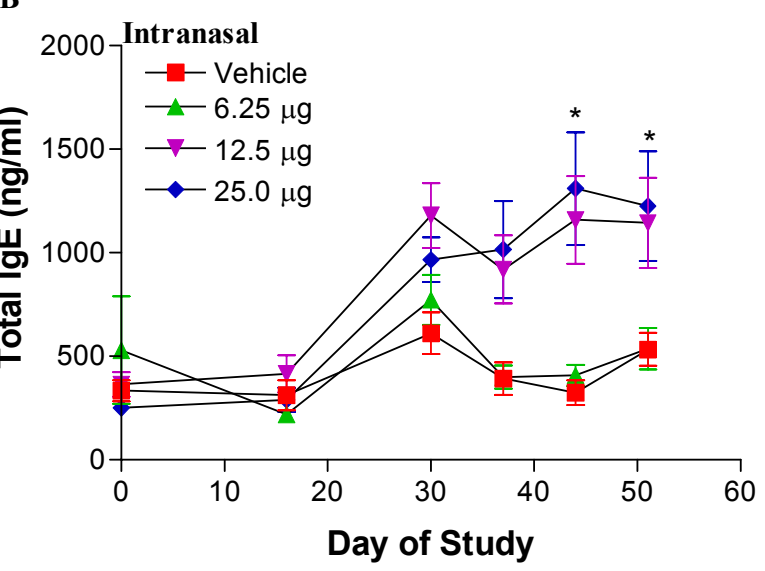

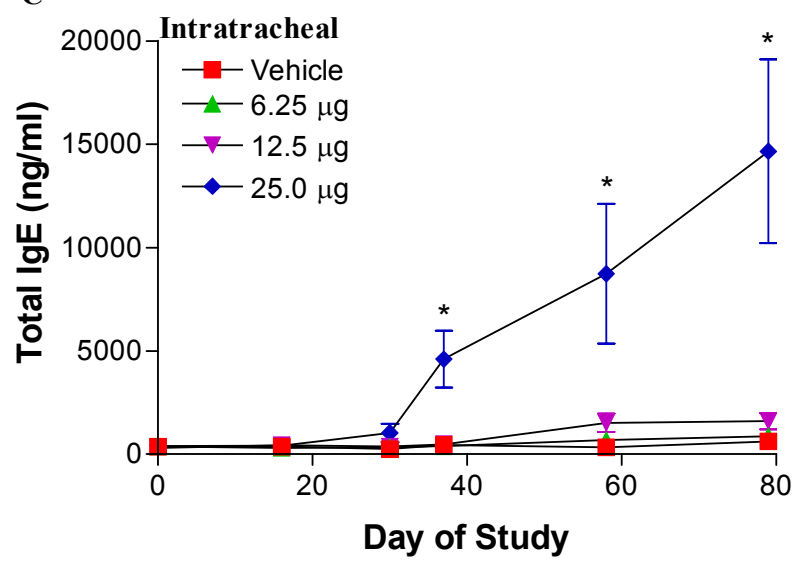

Figure 9. Time Course of Total Serum IgE Production in Mice Dermally, Intranasally, or Intratracheally Exposed to Latex Proteins. Time course of total serum IgE levels in mice exposed to NAL proteins via the dermal (A), i.n. (B), and i.t. (C) routes. Points represent means \pm standard error for each group. $n=5$ for all exposure groups except for the vehicle in intratracheally exposed animals where the $n=4$. Significance from vehicle $(\mathrm{VH})$ was determined using a Dunnett's $t$ test and is indicated by $*(p<0.05)$. 

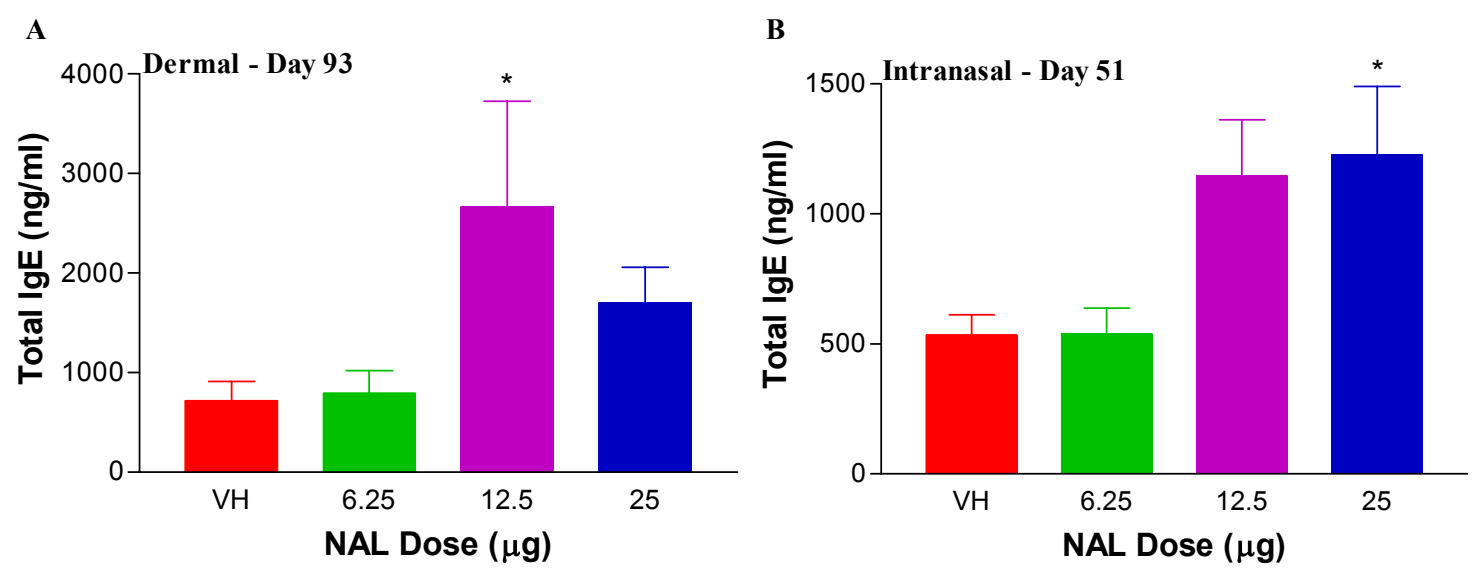

C

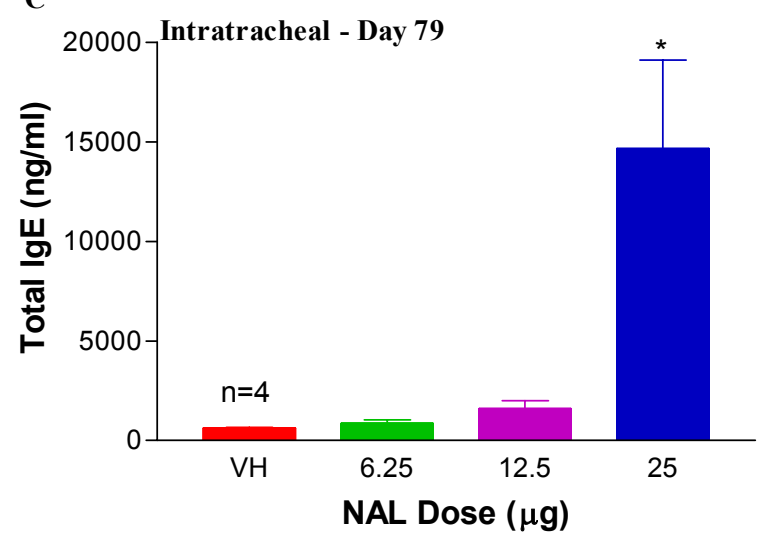

Figure 10. Final Total Serum IgE Levels in Latex Exposed Mice. Total serum IgE levels on days 93, 51, and 79 in mice exposed to NAL proteins via the dermal (A), i.n. (B), and i.t. (C) routes, respectively. Bars represent means \pm standard error for each group. $\mathrm{n}=5$ for all exposure groups except where noted. Significance from vehicle (VH) was determined using a Dunnett's t test and significance is indicated by $*(\mathrm{p}<0.05)$. 
A

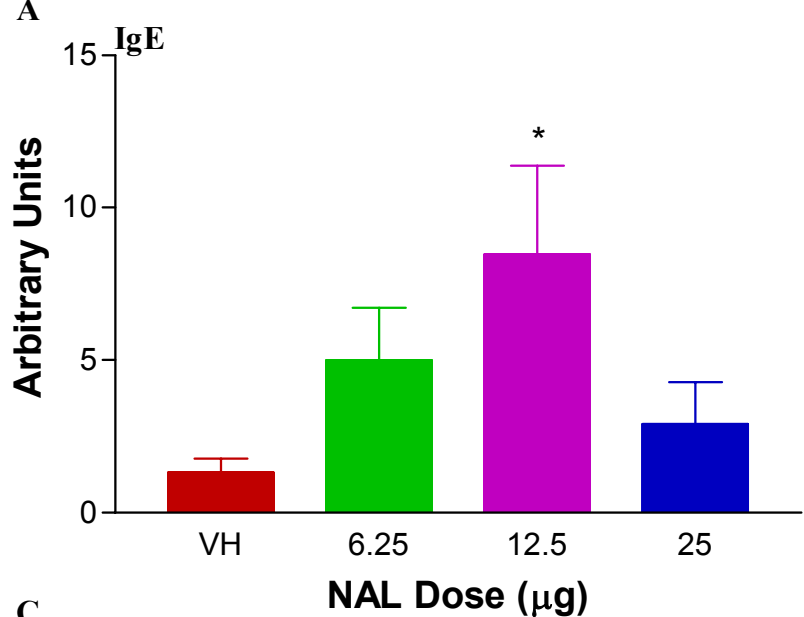

C

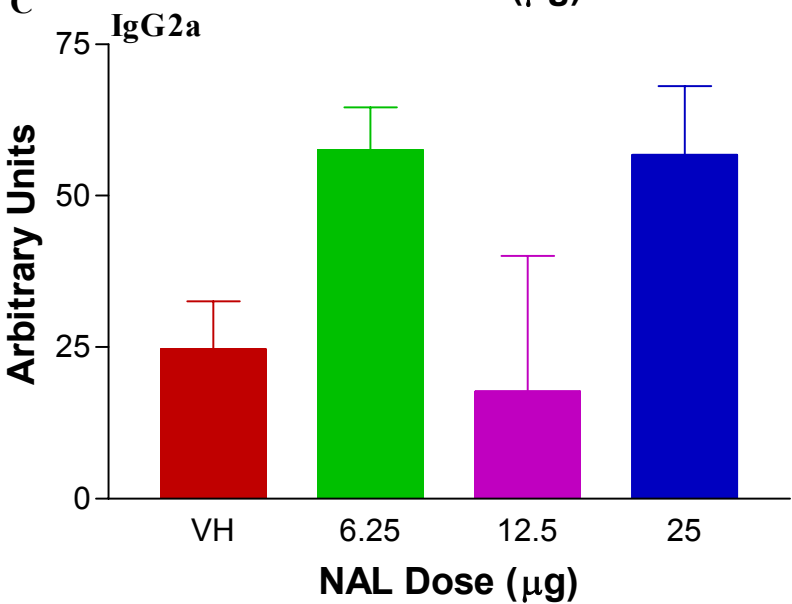

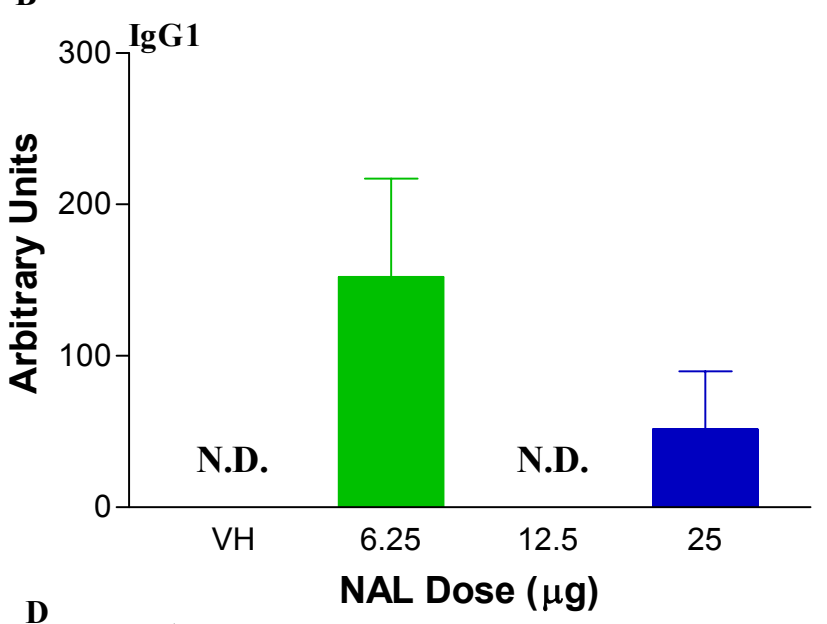

D

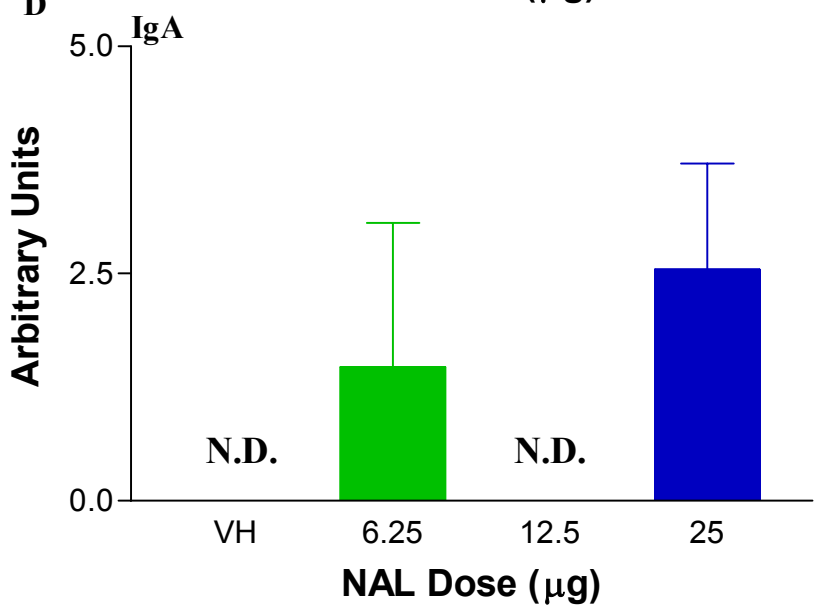

Figure 11. Latex Specific Serum Antibody Levels on Day 93 in Dermally Exposed Mice. Levels of latex specific IgE (A), IgG1 (B), IgG2a (C), and IgA (D) were evaluated in serum obtained from mice on the final day of the study (day 93). Bars represent the means $\pm \mathrm{SE}$ for each exposure group. N.D. represents non-detectable levels. $\mathrm{n}=5$ for all exposure groups. Significance from vehicle (VH) was determined using a Dunnett's $t$ test and is indicated by * $(\mathrm{p}<0.05)$. 
A
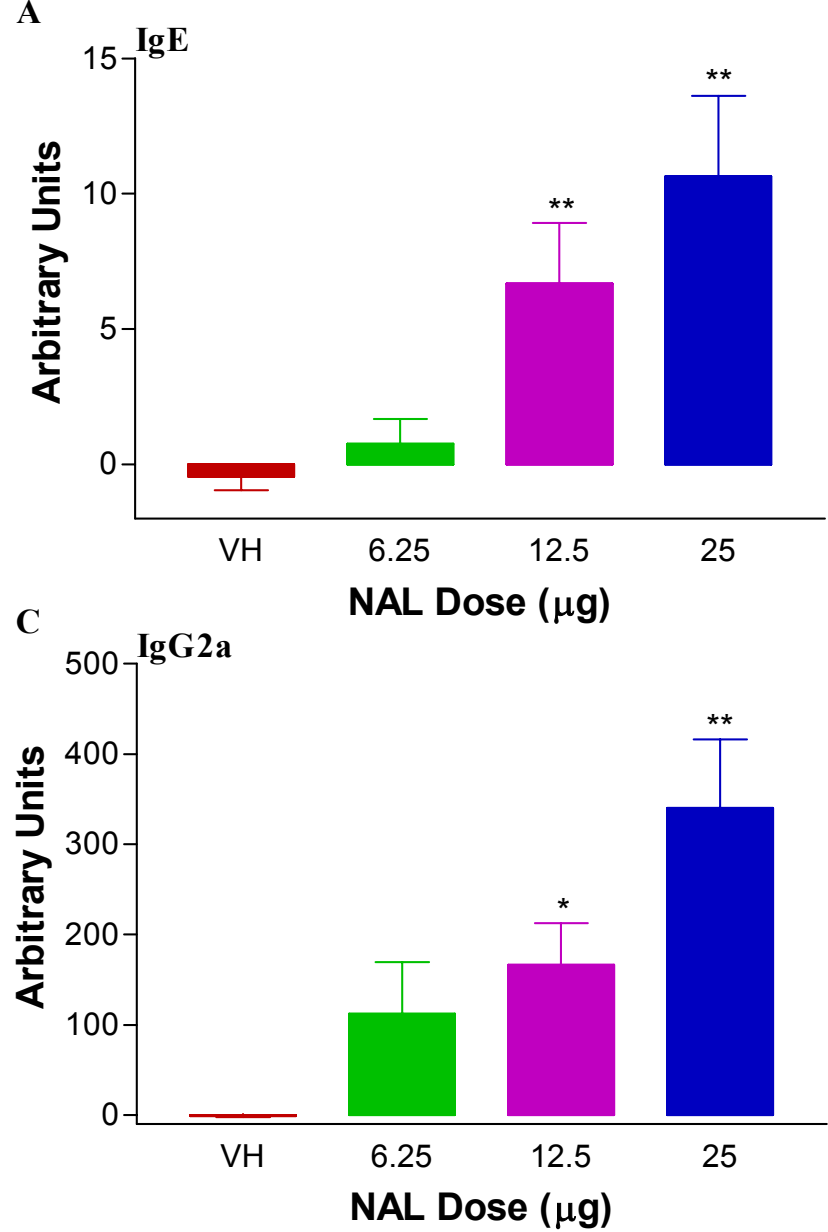

B
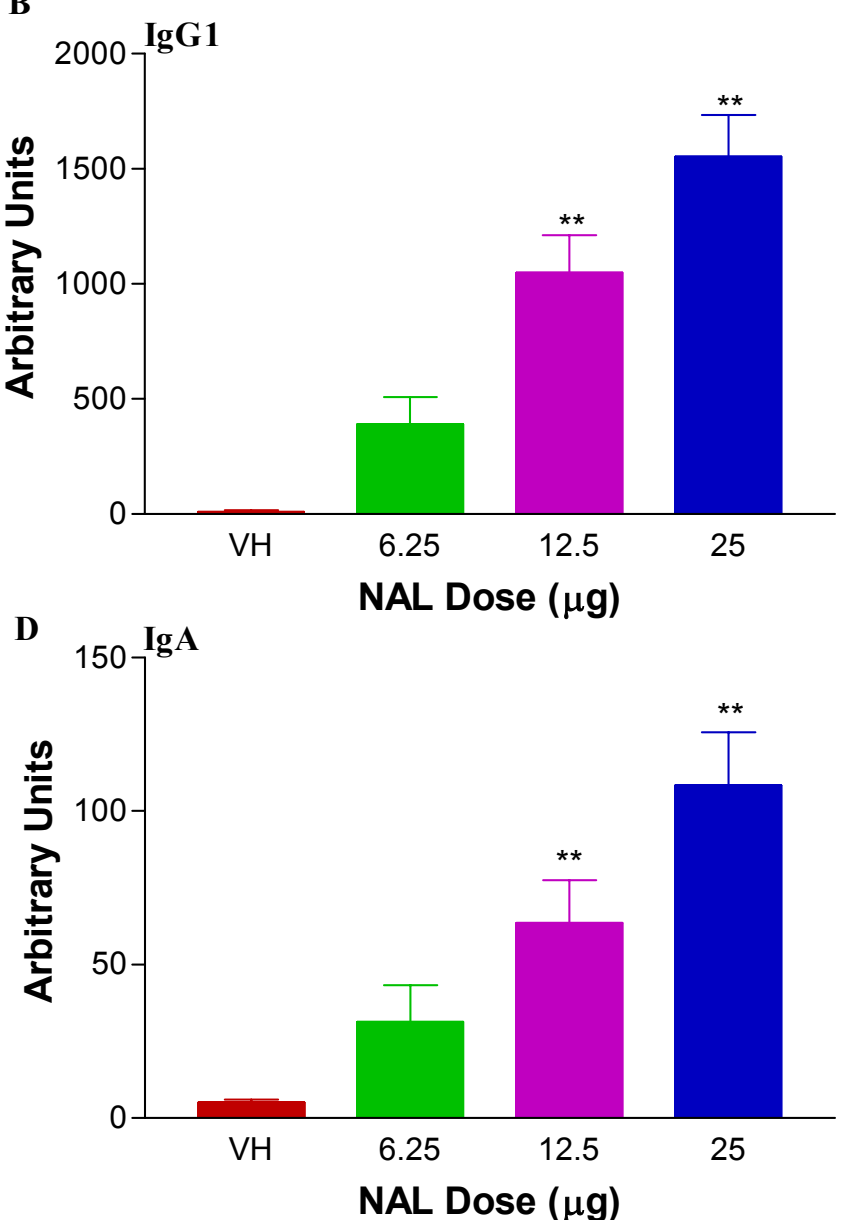

Figure 12. Latex Specific Serum Antibody Levels on Day 51 in Intranasally Exposed Mice. Levels of latex specific IgE (A), IgG1 (B), IgG2a (C), and IgA (D) were evaluated in serum obtained from mice on the final day of the study (day 51). Bars represent the means \pm SE for each exposure group. $n=5$ for all exposure groups. Significance from vehicle (VH) was determined using a Dunnett's $\mathrm{t}$ test and is indicated by $*(\mathrm{p}<0.05)$ and $* *(\mathrm{p}<0.01)$. 
A

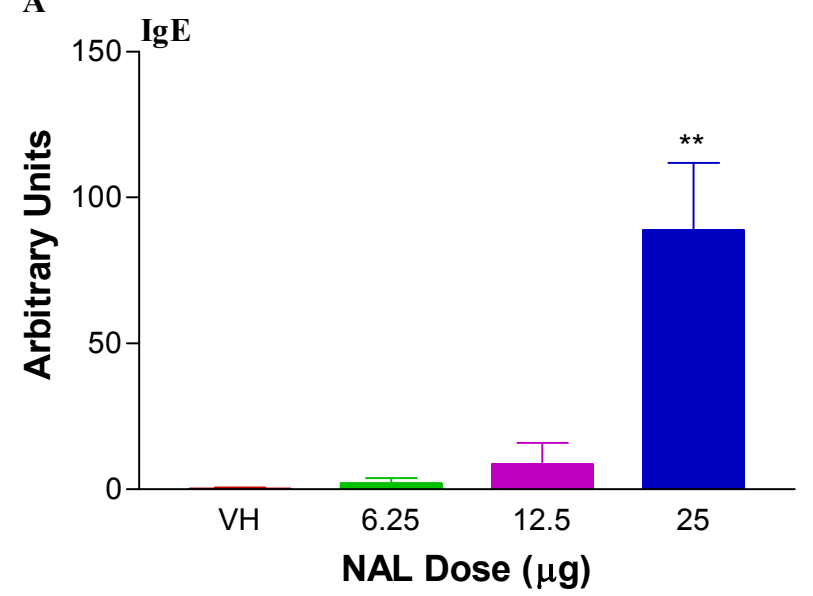

C

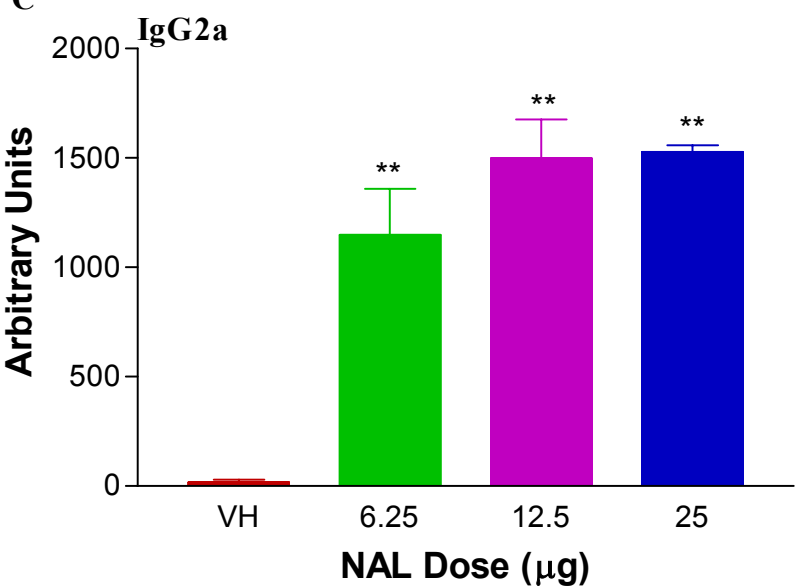

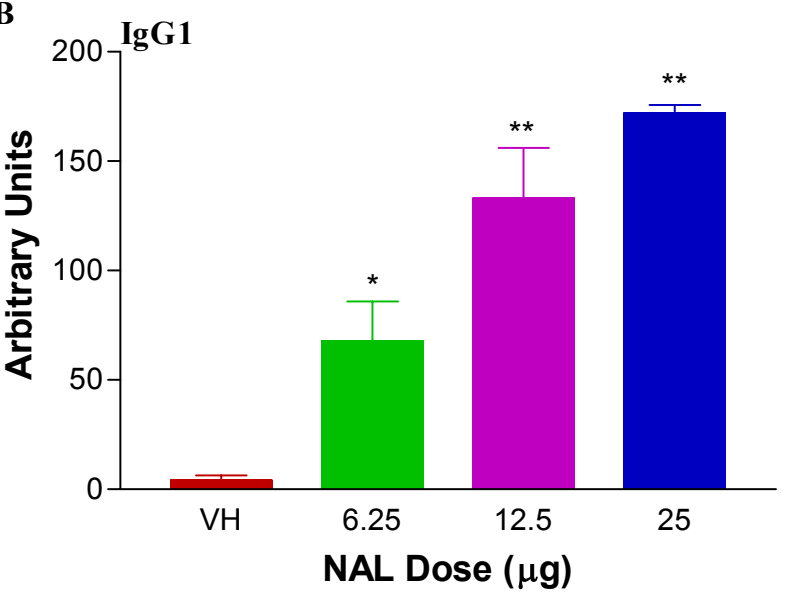

D

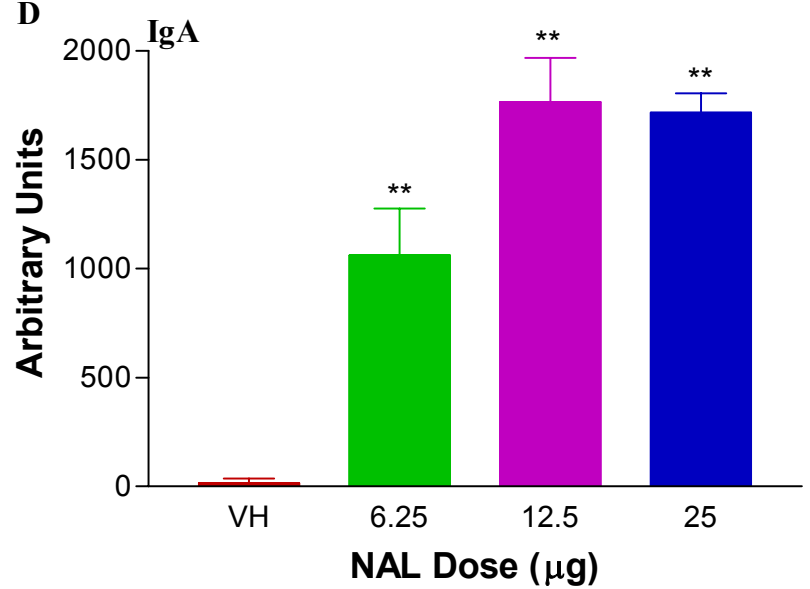

Figure 13. Latex Specific Serum Antibody Levels on Day 79 in Intratracheally Exposed Mice. Levels of latex specific IgE (A), IgG1 (B), IgG2a (C), and IgA (D) were evaluated in serum obtained from mice on the final day of the study (day 79). Bars represent the means $\pm \mathrm{SE}$ for each exposure group. $\mathrm{n}=5$ for all exposure groups except the vehicle where $\mathrm{n}=4$. Significance from vehicle $(\mathrm{VH})$ was determined using a Dunnett's $t$ test and is indicated by * $(\mathrm{p}<0.05)$ and $* *(p<0.01)$. 
Methacholine Challenge. Methacholine was used to assess the development of non-specific airway hyper-reactivity in mice exposed to NAL proteins via the dermal, i.n., and i.t. routes. Previous studies conducted in our laboratory have demonstrated different time requirements for the development of a latex specific $\operatorname{IgE}$ response following different routes of exposure to latex proteins. To determine the proper timepoint to assess the airway hyper-reactivity of previously sensitized mice, levels of total serum IgE were monitored. When the serum IgE levels of the high dose group reached statistical significance from vehicle exposed animals, mice were non-specifically challenged with methacholine. On days 60 (dermal), 44 (i.n.), and 47 (i.t.) following initial exposure, mice were placed into whole body plethysmography chambers and challenged with nebulized methacholine. Modulation of airway hyper-reactivity was evaluated by comparing the percent increase in PenH over baseline between animals previously exposed to vehicle and animals previously exposed to NAL at each methacholine challenge dose. Dose-responsive relationships within each exposure group were determined using linear regression.

Upon comparing the degree of airway hyper-reactivity between exposed animals for each methacholine challenge dose, mice previously sensitized via dermal exposure to 12.5 or $25 \mu \mathrm{g}$ of NAL proteins demonstrated significant elevations $(\mathrm{p}<0.01)$ in airway hyper-reactivity upon respiratory challenge with either $25 \mathrm{or} 50 \mathrm{mg} / \mathrm{ml}$ of methacholine, reaching greater than $400 \%$ increase over baseline values (Figure 14A). Additionally, mice intratracheally sensitized with 12.5 and $25 \mu \mathrm{g}$ of NAL proteins demonstrated significant $(\mathrm{p}<0.01)$ increases in airway hyper-reactivity with greater than $350 \%$ and 
$400 \%$ increases, respectively, over baseline values (Figure 14C). Since no significant differences in airway hyper-reactivity were observed between mice intranasally exposed to vehicle or the high dose group ( $25 \mu \mathrm{g}$ of NAL), other exposure groups were excluded from the non-specific airway challenge (Figure 14B). Using linear regression, a dose responsive relationship $(\mathrm{p}<0.01)$ was observed between the level of airway hyperreactivity and methacholine challenge dose $(10,25$ and $50 \mathrm{mg} / \mathrm{ml})$ for all exposure groups in mice dermally or intratracheally exposed to NAL proteins (Figures 14A and 14C).

NAL Specific Challenge. Following the non-specific methacholine challenge, mice remained on study and continued to be exposed to NAL proteins as previously described. On days 93 (dermal), 51 (i.n.), and 76 (i.t.) following initial test article exposure, the development of a latex specific airway hyper-reactivity response was evaluated in previously sensitized mice by administering $300 \mu \mathrm{g}$ of NAL proteins via i.t. aspiration and monitoring PenH values over a 25 minute period.

While mice dermally exposed to 6.25 or $25 \mu \mathrm{g}$ of NAL proteins failed to demonstrate significant increases in the level of latex specific airway hyper-reactivity; mice previously exposed via dermal application to $12.5 \mu \mathrm{g}$ of NAL proteins demonstrated greater than 1000 -fold increase $(\mathrm{p}<0.01)$ over baseline PenH values (Figure 15A). Upon respiratory challenge, mice previously intranasally exposed to NAL proteins failed to demonstrate elevations in the levels of airway hyper-reactivity (Figure 15B). Despite inducing elevations in non-specific airway hyper-reactivity, mice intratracheally exposed to NAL proteins did not exhibit an elevation in enhanced pause in this study (Figure 
15C). This lack of significance may be due in part to the elevated baseline level of airway hyper-reactivity in mice intratracheally exposed to vehicle (PBS). While levels of antigen specific airway hyper-reactivity in vehicle mice exposed by the dermal and i.n. routes were $\sim 200 \%$ over baseline, levels in mice i.t. exposed were $\sim 1,800 \%$ over baseline. Similar studies described later evaluating i.t. exposure to NAL proteins demonstrated $\sim 1,000 \%$ increase over baseline in vehicle exposed mice. 


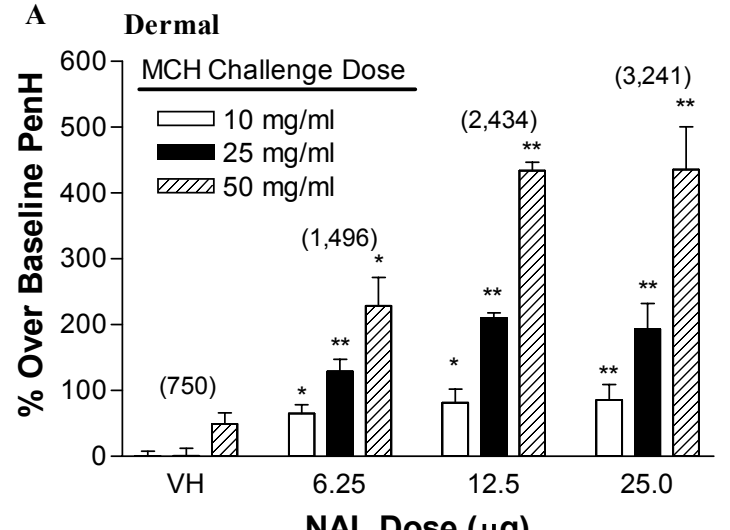

B Intranasal
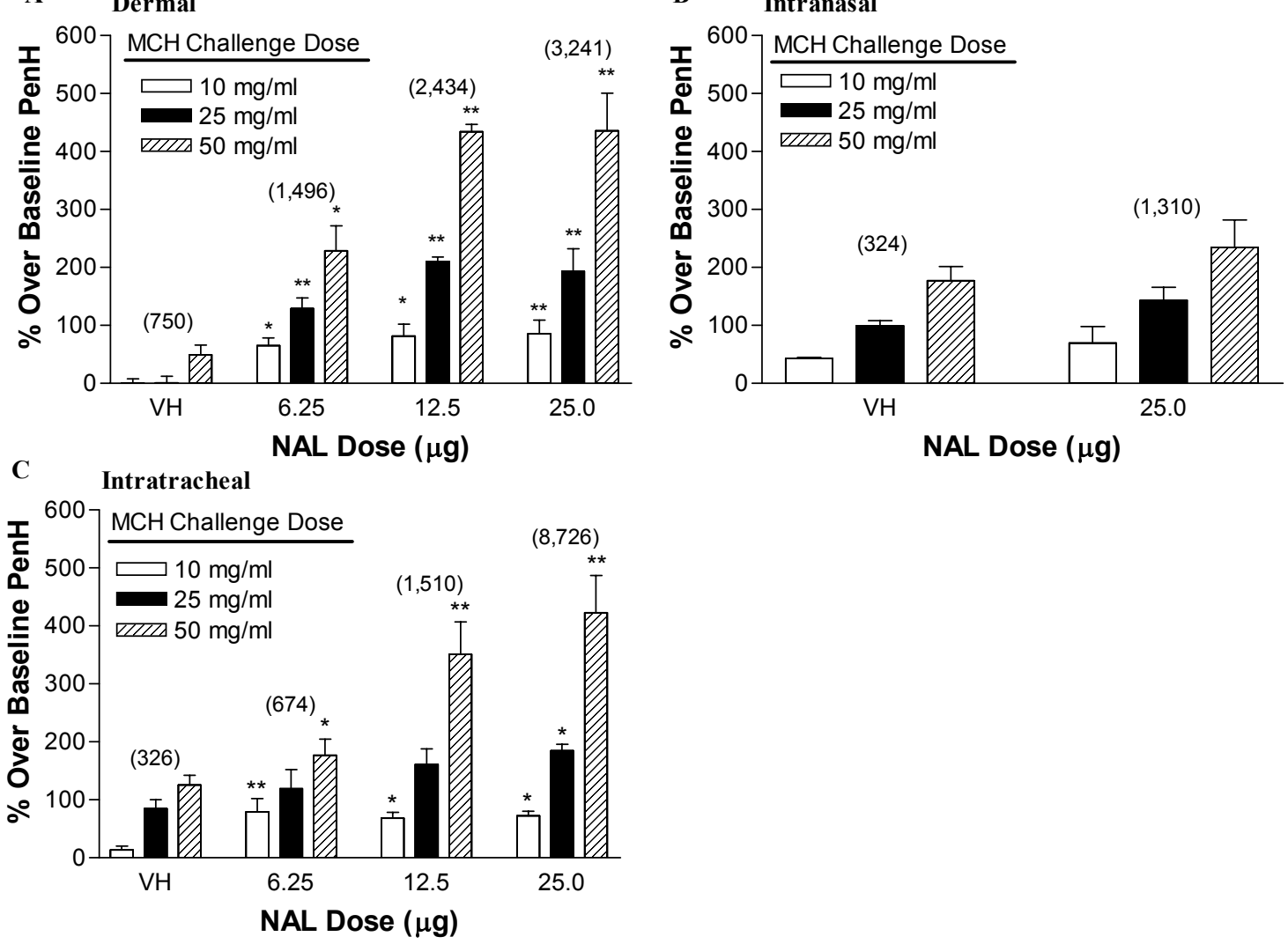

NAL Dose $(\mu \mathrm{g})$

Figure 14. Non-Specific Airway Hyper-reactivity in Previously Sensitized Mice. Mice previously exposed via the dermal (A), i.n. (B), or i.t. (C) routes were evaluated for the development of airway hyper-reactivity following methacholine challenge. Numbers in parenthesis represent the mean total serum IgE levels $(\mathrm{ng} / \mathrm{ml})$ on day 58 (dermal), day 44 (i.n.), and day 58 (i.t.) for each corresponding exposure group. Bars represent means \pm standard error for each group. $\mathrm{n}=5$ for all exposure groups except for the vehicle in intratracheally exposed animals where the $n=4$. For each challenge dose of $\mathrm{MCH}$, mice exposed to NAL were compared to vehicle animals and statistical significance was determined using a Dunnett's $t$ test. Significance is indicated by $*(p<0.05)$ and $* *$ $(\mathrm{p}<0.01)$. 
A

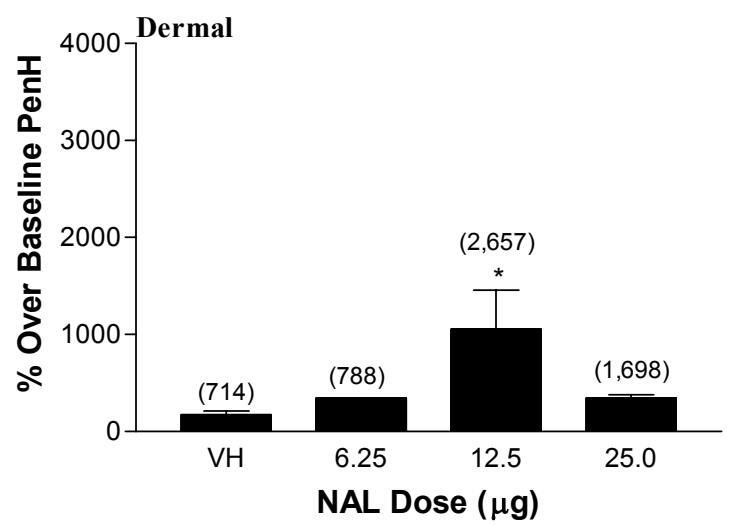

C

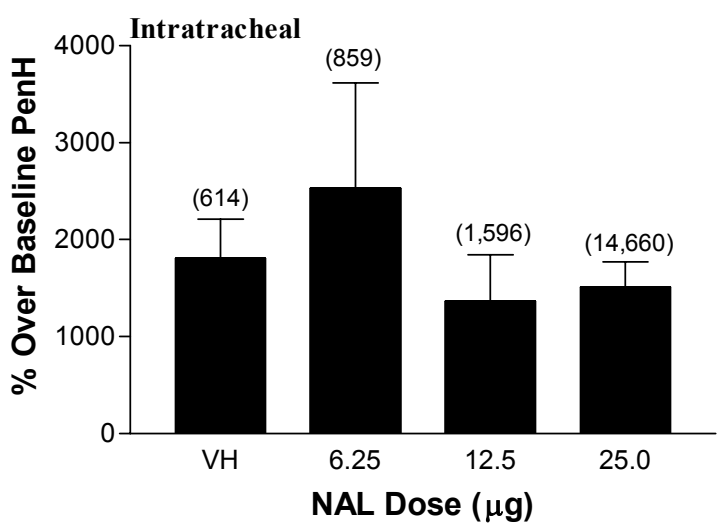

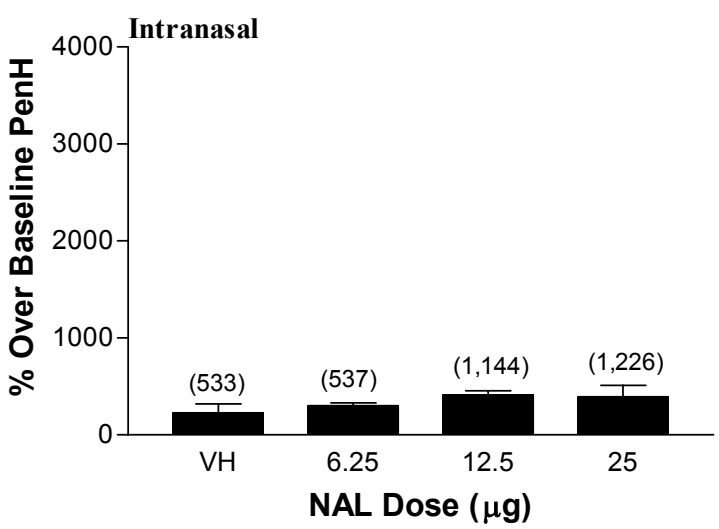

Figure 15. Latex Specific Airway Hyper-reactivity in Previously Sensitized Mice. Mice previously exposed via the dermal (A), i.n. (B), and i.t. (C) routes were evaluated for the antigen specific airway hyper-reactivity following latex challenge. Numbers in parenthesis represent the mean total serum $\operatorname{IgE}$ levels $(\mathrm{ng} / \mathrm{ml})$ on day 93 (dermal), day 51 (i.n.), and day 79 (i.t.) for each corresponding exposure group. Bars represent means \pm standard error for each group. $n=5$ for all exposure groups except for the vehicle in intratracheally exposed animals where the $n=4$. For the NAL challenge, significance was determined by comparing mice dermally exposed to NAL to dermally exposed vehicle animals using a Dunnett's t test. Significance is indicated by $*(p<0.05)$. 


\section{Immunomodulatory Effect of Endotoxin on the Development of an IgE Mediated Hypersensitivity Response to Latex Proteins}

Previous studies validated dermal and respiratory exposure in evaluating the induction of latex specific IgE. Individuals within the health care environment are exposed to numerous agents in addition to latex proteins. Endotoxin is a common contaminant in the health care environment that has been shown to induce numerous inflammatory responses upon inhalation. It was hypothesized that concurrent respiratory tract exposure to endotoxin with latex would modulate the development of an $\operatorname{IgE}$ mediated hypersensitivity response to latex proteins.

Total IgE Response. Initial studies were conducted to demonstrate the immunomodulatory effect of LPS on the levels of total serum IgE in mice exposed to latex proteins. Total serum IgE levels were monitored in mice exposed i.n. to NAL proteins and increasing concentrations of endotoxin from Salmonella typhimurium via i.n. instillation for up to 72 days. Exposure of mice to NAL proteins alone resulted in a time dependent increase in total $\operatorname{IgE}$ with a peak on day 58 at greater than 1,500 ng/ml (Figure 16). In contrast, mice concurrently exposed to NAL and concentrations of endotoxin ranging from 5,000 - 50,000 EU demonstrated levels of total serum IgE similar to those observed for vehicle-exposed mice (Figure 16B).

A second study was conducted to evaluate the effect of lower concentrations (5025,000 EU) of endotoxin on the total serum $\operatorname{IgE}$ response. Additionally, a strain comparison study was conducted using endotoxin from Salmonella typhimurium, 
Salmonella typhosa, and Escherichia coli. To conserve the number of animals, a single group of vehicle $(\mathrm{n}=10)$ and NAL $(\mathrm{n}=10)$ exposed mice were used as controls for the strain comparison studies. As in the previous study, mice exposed to NAL alone demonstrated significantly elevated levels of total serum IgE, reaching greater than 1,500 $\mathrm{ng} / \mathrm{ml}$ (Figure 17). Co-administration of NAL proteins with as little as $50 \mathrm{EU}$ of endotoxin from Salmonella typhimurium, Salmonella typhosa, or Escherichia coli resulted in significantly lower levels of total serum IgE when compared to those observed in mice exposed to NAL alone (Figure 17). Despite using lower concentrations of endotoxin (50 - 25,000 EU), no dose responsive relationship was observed in the levels of total serum IgE in mice concurrently exposed.

Latex Specific Response. On the final day of the study, blood was obtained from mice via cardiac puncture and serum collected for analysis of NAL specific antibodies. Sera from exposed mice were analyzed for the presence of NAL specific IgE, IgG2a, and IgA antibodies using a modified sandwich ELISA. In the initial study evaluating concurrent exposure to NAL and concentrations of Salmonella typhimurium endotoxin between 5,000 and 50,000 EU, mice exposed to NAL alone demonstrated significant elevations $(\mathrm{p}<0.01)$ in latex specific serum IgE, IgG2a, and IgA antibodies (Figure 18). While concurrent exposure to NAL and endotoxin resulted in greater than a $50 \%$ reduction of latex specific IgE production (Figure 18A), levels of IgG2a and IgA were elevated approximately 2 -fold $(\mathrm{p}<0.01$ ) over mice exposed to NAL alone (Figure $18 \mathrm{~B}$, C). 
Similar results were observed in the subsequent study evaluating lower concentrations of endotoxin (50 - 25,000 EU) from Salmonella typhimurium, Salmonella typhosa, or Escherichia coli. While mice exposed concurrently to NAL and S. typhimurium endotoxin demonstrated lower latex specific serum IgE production when compared to levels in mice exposed to NAL alone (Figure 19A), a dose-responsive increase in latex specific IgG2a antibodies was observed (Figure 19B). Although not dose responsive, concurrent exposure to NAL and concentrations of endotoxin greater than $1,250 \mathrm{EU}$ resulted in a significant $(\mathrm{p}<0.05)$ increase in latex specific IgA antibody levels when compared to mice exposed to NAL alone (Figure 19C). Following a similar trend as S. typhimurium, concurrent exposure to NAL and endotoxin from S. typhosa resulted in a decrease in latex specific IgE levels by approximately 50\% (Figure 20A), a dose-responsive increase in IgG2a levels with greater than a 2-fold increase over NAL exposed mice (Figure 20B), and significantly $(\mathrm{p}<0.01)$ elevated levels of $\operatorname{IgA}$ upon concurrent exposure with as little as $500 \mathrm{EU}$ (Figure 20C). Mice exposed concurrently to NAL and increasing concentrations of endotoxin from E. coli demonstrated a decrease in latex specific serum IgE production, although this reduction was not statistically significant from mice exposed to NAL alone (Figure 21A). However, levels of latex specific IgG2a antibodies were dose responsively increased in these mice with greater than a 2-fold increase over levels in mice exposed to NAL alone (Figure 21B). Concurrent exposure to NAL and greater than 5,000 EU from E. coli strains resulted in significantly higher latex specific IgA levels when compared to mice exposed to NAL alone (Figure 21C). 

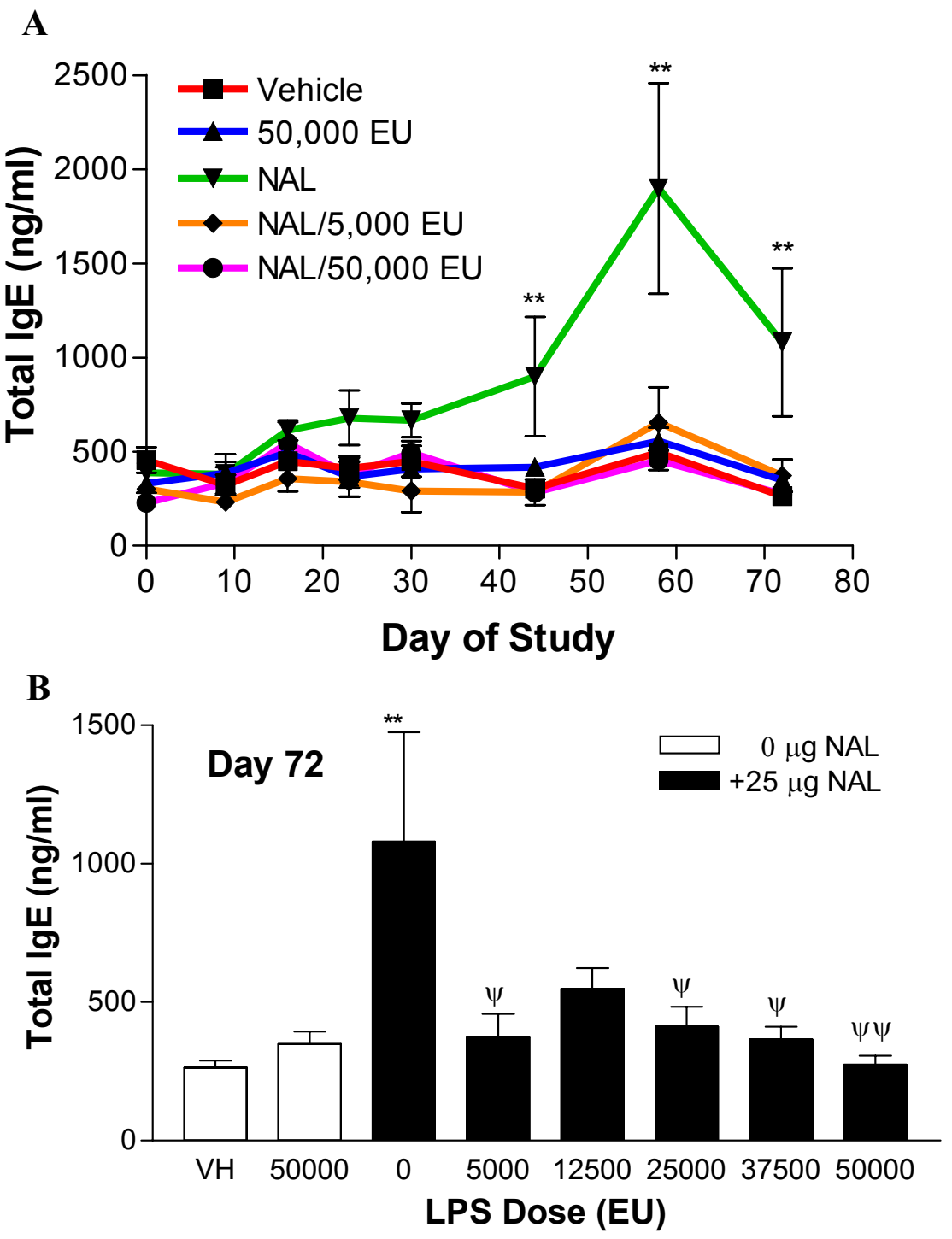

Figure 16: Total IgE Levels in Mice Intratranasally Exposed to NAL and Endotoxin from Salmonella typhimurium. Time course (A) and day 72 (B) total IgE levels were evaluated in mice concurrently exposed to NAL and concentrations of endotoxin ranging from 5,000-50,000 EU. Points and bars represent means \pm SE for each exposure group. $\mathrm{n}=5$ for all exposure groups. Statistical significance was determined using a Dunnett's $\mathrm{t}$ test. ** represents $\mathrm{p}<0.01$ as compared to vehicle alone. $\psi$ and $\psi \psi$ represent $\mathrm{p}<0.05$ and $\mathrm{p}<0.01$, respectively, as compared to NAL alone. 

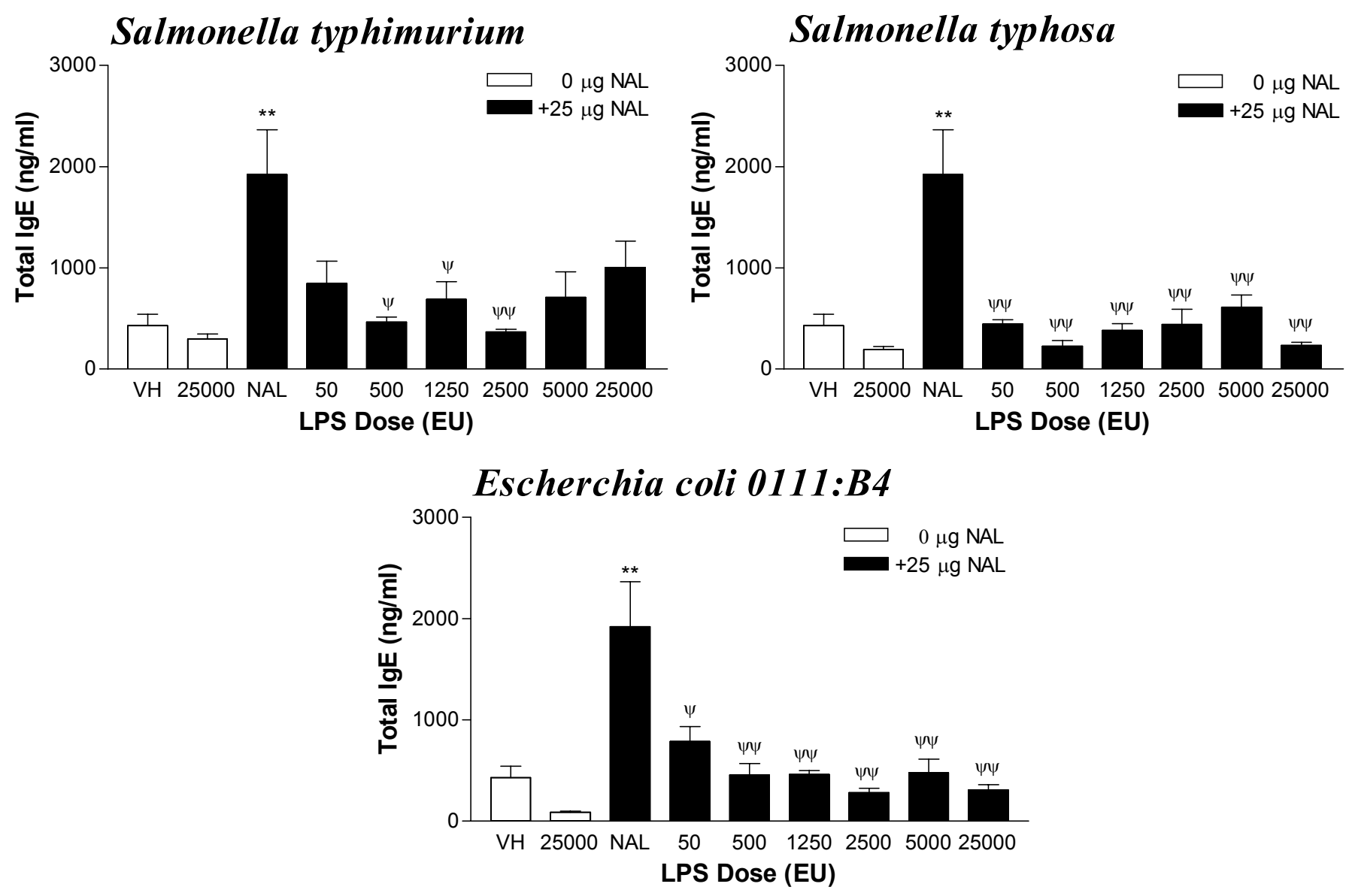

Figure 17. Total IgE Response in Mice Concurrently Intranasally Exposed to NAL and Different Strains of Bacterial Endotoxin. Mice were exposed to NAL and endotoxin (50 - 25,000 EU) from Salmonella typhimurium, Salmonella typhosa, or Escherichia coli. Serum was collected following sacrifice on day $65 . \mathrm{n}=5$ for all exposure groups except for the vehicle and NAL alone groups where $\mathrm{n}=10$. ** represents $\mathrm{p}<0.01$ as compared to vehicle alone. $\psi$ and $\psi \psi$ represent $\mathrm{p}<0.05$ and $\mathrm{p}<0.01$, respectively, as compared to NAL alone. 

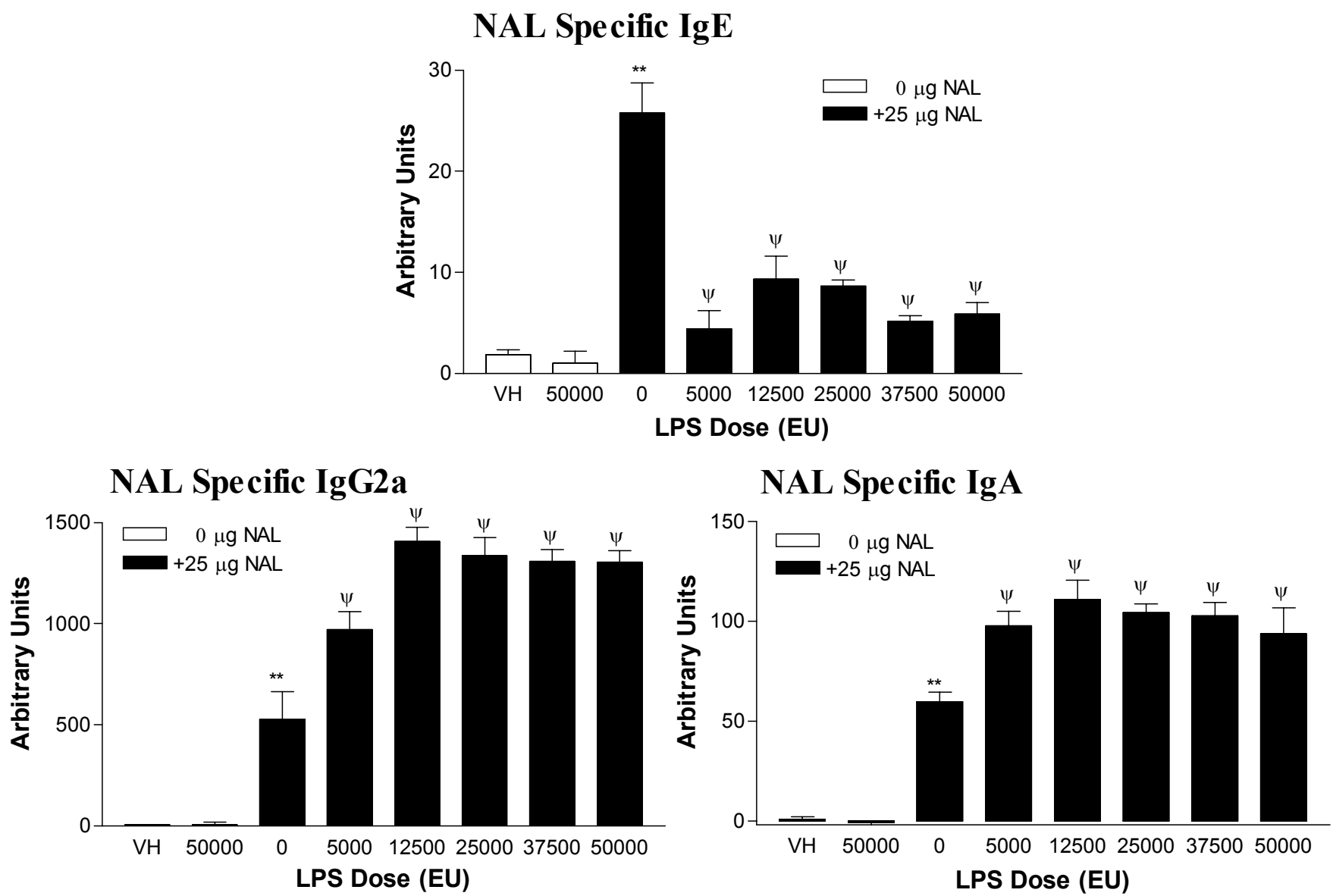

Figure 18. Latex Specific Serum Antibody Response in Mice Intranasally Exposed to NAL and 5,000 - 50,000 EU of Endotoxin from Salmonella typhimurium. Levels of latex specific $\operatorname{IgE}(\mathrm{A}), \operatorname{IgG} 2 \mathrm{a}(\mathrm{B})$, and $\operatorname{IgA}(\mathrm{C})$ were evaluated in serum obtained from mice on the final day of the study (day 72). Bars represent the means $\pm \mathrm{SE}$ for each exposure group. $\mathrm{n}=5$ for all exposure groups except the vehicle and NAL alone groups where $\mathrm{n}=10 . * *$ represents $\mathrm{p}<0.01$ as compared to vehicle alone. $\psi$ represents $\mathrm{p}<0.05$ as compared to NAL alone. 

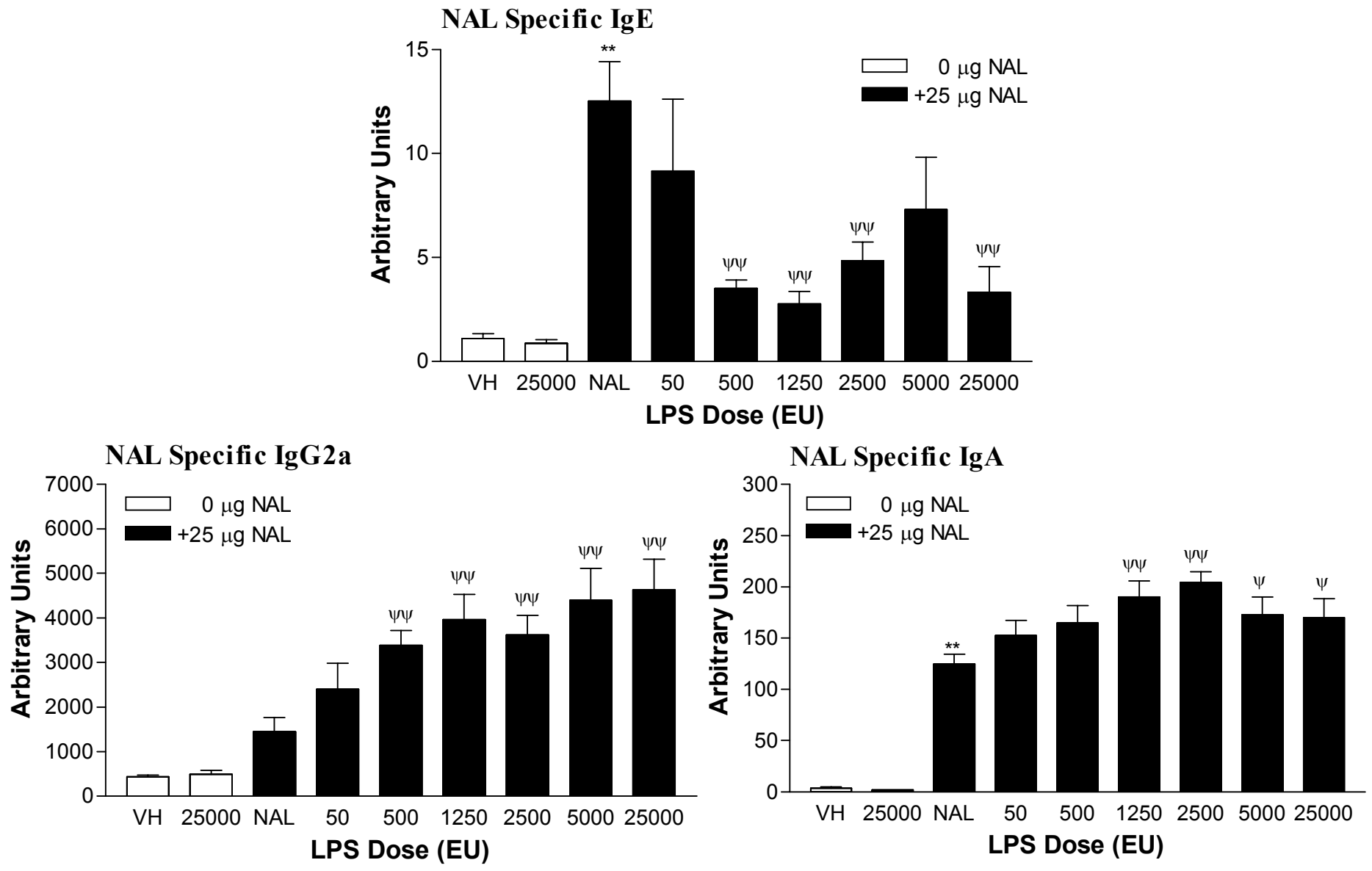

Figure 19. Latex Specific Serum Antibody Response in Mice Intranasally Exposed to NAL and Endotoxin from Salmonella typhimurium. Levels of latex specific $\operatorname{IgE}(\mathrm{A}), \operatorname{IgG} 2 \mathrm{a}(\mathrm{B})$, and $\operatorname{IgA}(\mathrm{C})$ were evaluated in serum obtained from mice on the final day of the study (day 65). Bars represent the means \pm SE for each exposure group. $n=5$ for all exposure groups except the vehicle and NAL alone groups where $\mathrm{n}=10$. $* *$ represents $\mathrm{p}<0.01$ as compared to vehicle alone. $\psi$ and $\psi \psi$ represent $\mathrm{p}<0.05$ and $\mathrm{p}<0.01$, respectively, as compared to NAL alone. 

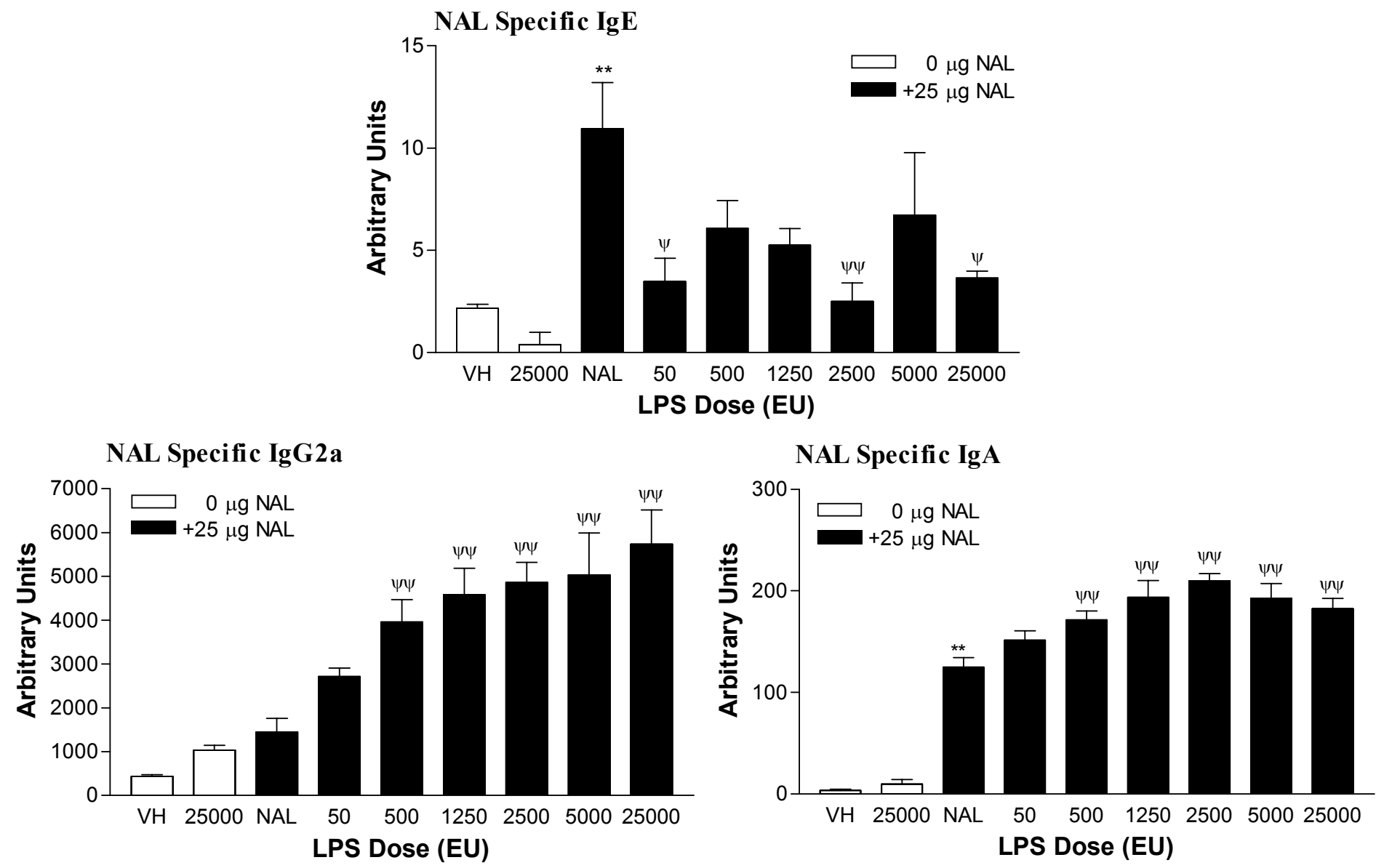

Figure 20. Latex Specific Serum Antibody Response in Mice Intranasally Exposed to NAL and Endotoxin from Salmonella typhosa. Levels of latex specific $\operatorname{IgE}(\mathrm{A}), \operatorname{IgG} 2 \mathrm{a}(\mathrm{B})$, and $\operatorname{IgA}(\mathrm{C})$ were evaluated in serum obtained from mice on the final day of the study (day 65). Bars represent the means $\pm \mathrm{SE}$ for each exposure group. $\mathrm{n}=5$ for all exposure groups except the vehicle and NAL alone groups where $\mathrm{n}=10$. $* *$ represents $\mathrm{p}<0.01$ as compared to vehicle alone. $\psi$ and $\psi \psi$ represent $\mathrm{p}<0.05$ and $\mathrm{p}<0.01$, respectively, as compared to NAL alone. 

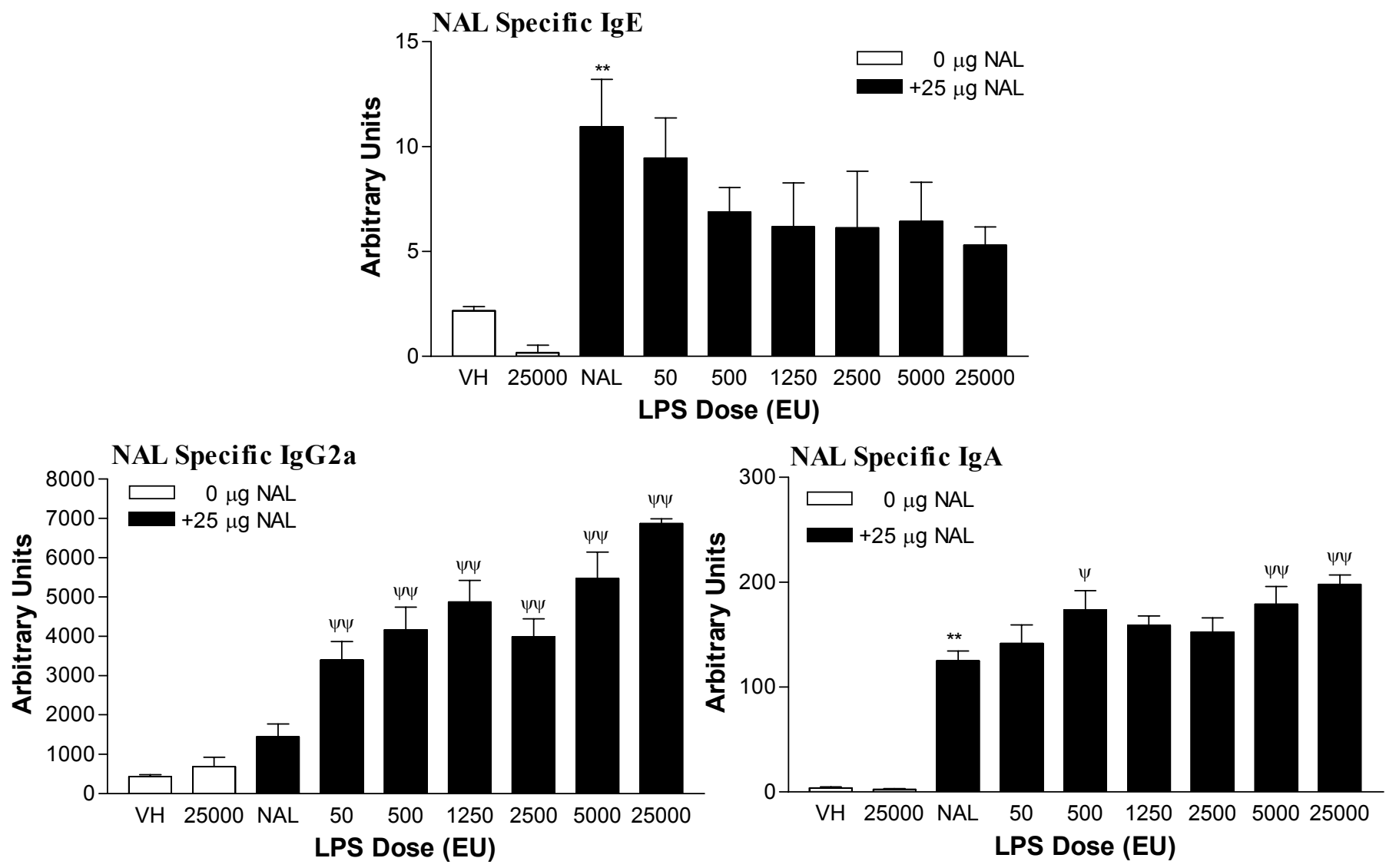

Figure 21. Latex Specific Serum Antibody Response in Mice Intranasally Exposed to NAL and Endotoxin from Escherichia coli. Levels of latex specific $\operatorname{IgE}(\mathrm{A}), \operatorname{IgG} 2 \mathrm{a}(\mathrm{B})$, and $\operatorname{IgA}(\mathrm{C})$ were evaluated in serum obtained from mice on the final day of the study (day 65). Bars represent the means $\pm \mathrm{SE}$ for each exposure group. $\mathrm{n}=5$ for all exposure groups except the vehicle and NAL alone groups where $\mathrm{n}=10$. $\quad * *$ represents $\mathrm{p}<0.01$ as compared to vehicle alone. $\psi$ and $\psi \psi$ represent $\mathrm{p}<0.05$ and $\mathrm{p}<0.01$, respectively, as compared to NAL alone. 


\section{Characterization of the Immunomodulatory Response}

The previous studies demonstrated the potential for endotoxin to down-regulate the induction of IgE. Further investigation was necessary to elucidate the potential mechanisms by which endotoxin altered the immune response. Due to the complex lymphoid drainage system of the nasopharyngeal region, mice in the subsequent studies were exposed via i.t. aspiration in order to evaluate the immune response in the lung associated lymph nodes.

Total IgE Response. An initial time and dose response study was conducted to confirm that i.t. endotoxin exposure had the same effect on the total and latex specific

serum IgE levels as observed in the previous studies. Mice were exposed every $5^{\text {th }}$ day to NAL and/or concentrations of $S$. typhimurium endotoxin from $50-5,000$ EU. Peak serum IgE production in mice exposed to NAL alone occurred on day 58 when levels reached greater than $20,000 \mathrm{ng} / \mathrm{ml}$, however, significant elevations $(\mathrm{p}<0.01)$ were observed as early as day 37 (Figure 22A). On day 58, levels of total serum IgE in mice concurrently exposed to NAL and increasing amounts of endotoxin (50 - 5,000 EU) were approximately $50-70 \%$ less than those observed in mice exposed to NAL alone (Figure 22B). Intratracheal exposure to NAL and increasing concentrations of endotoxin was shown to induce a trend of $\operatorname{IgE}$ production in mice similar to those observed in previous i.n. exposure studies. 
Latex Specific Antibody Response. Sera obtained from mice on the final day of the study were analyzed for latex specific antibodies using an ELISA. As seen in mice exposed by the i.n. route, mice i.t. exposed to NAL proteins alone demonstrated significant increases $(p<0.01)$ in latex specific $\operatorname{IgE}, \operatorname{IgG} 2 \mathrm{a}$, and $\operatorname{Ig} \mathrm{A}$. Whereas the latex specific serum IgE levels were significantly lower in all mice concurrently exposed to NAL and endotoxin (Figure 23A), both IgG2a (Figure 23B) and IgA (Figure 23C) levels in mice concurrently exposed to NAL and as little as $500 \mathrm{EU}$ reached greater than 2-fold increases over the levels in animals exposed to NAL alone.

Non-Specific Airway Hyper-reactivity. Forty-seven (47) days following initial exposure, mice were challenged with increasing concentrations of methacholine to assess non-specific airway hyper-reactivity. For each methacholine challenge dose, the levels of airway hyper-reactivity (percent increase in PenH over baseline) in mice exposed to NAL and/or endotoxin were compared to levels in vehicle control group for significance.

Within each exposure group, the dose responsive relationship between airway hyper-reactivity and methacholine challenge dose was evaluated by linear regression. While mice previously exposed to 5,000 EU of endotoxin alone demonstrated a dose responsive $(\mathrm{p}<0.01)$ increase in airway hyper-reactivity, no other exposure groups demonstrated a significant dose responsive relationship between the methacholine challenge dose and the levels of airway hyper-reactivity (Figure 24). Previous exposure to NAL and 5,000 EU of endotoxin resulted in a significant $(\mathrm{p}<0.05)$ increase in airway hyper-reactivity upon challenge with 25 and $50 \mathrm{mg} / \mathrm{ml}$ of methacholine as compared to 
levels of airway hyper-reactivity in vehicle-exposed mice challenged with the same concentration of methacholine. Although not reaching statistical significance, levels of airway hyper-reactivity in mice exposed to 5,000 $\mathrm{EU}$ of endotoxin alone were similar to those observed for mice concurrently exposed to NAL and 5,000 EU of endotoxin (Figure 24). No significant elevations in airway hyper-reactivity were observed in mice exposed to NAL alone or concurrently to NAL and either 50 or 1,250 EU of endotoxin.

Antigen Specific Airway Hyper-reactivity. Following methacholine challenge, mice were dosed for an additional 19 days. On day 66 following initial exposure, the development of a latex specific airway hyper-reactivity response was evaluated in previously sensitized mice as previously described. Although levels failed to reach statistical significance from vehicle exposed animals, a 2-fold increase in airway hyperreactivity was observed in mice exposed to NAL alone (Figure 25). Despite an increase in non-specific airway hyper-reactivity, mice exposed to 5,000 EU of endotoxin alone did not exhibit increased levels of latex specific airway hyper-reactivity. Mice concurrently exposed to NAL and increasing concentrations $(50,1,250$, or 5,000 EU) of endotoxin demonstrated decreases in airway hyper-reactivity with levels dropping to approximately $50 \%$ of those observed in mice exposed to NAL alone (Figure 25).

Histopathological Evaluation of the Lung Following Concurrent Exposure to Latex and Endotoxin. Twenty-four hours following the latex specific challenge, animals were sacrificed, lungs were perfused with formalin and removed for histopathological evaluation. Lungs were processed and stained with: 1) hematoxylin and eosin to 
visualize cellular infiltration, 2) $0.5 \%$ Chromotrop $2 \mathrm{R}$ to visualize eosinophils, and 3) Alcian blue-periodic acid-Schiff to visualize mucin (polysaccharides and mucoproteins) production.

Sections of tissue from the left lobe of the lung were analyzed for the degree of cellular and eosinophil infiltration and mucin production. All vehicle animals demonstrated low levels of peribronchial histocytic alveolitis which is suspected to be due to repeated i.t. exposure to PBS. Mice exposed to endotoxin alone exhibited perivascular and peribronchial alveolitis with increased numbers of macrophages over controls. Latex exposure resulted in multifocal peribronchial and perivascular alveolitis. For animals exposed concurrently to NAL and endotoxin, the severity of the pathology appeared to increase with increasing concentrations of endotoxin with animals exposed to 5,000 EU and NAL demonstrating severe diffuse alveolitis with large numbers of macrophages (Table 8 and Figure 26). Pathological changes were confirmed by a board certified veterinary pathologist.

Whereas exposure to NAL and endotoxin resulted in the cellular infiltration of macrophages, lymphocytes, and neutrophils, eosinophilia was not observed in mice from any of the exposure groups. Differential mucin responses were observed between exposure groups. Lung sections from mice were scored based on the degree of mucin production in the bronchial epithelium and the severity of the responses \{scored as "(Figure 27F), '+' (Figure 27B\&E), '++' (Figure 27D), '+++' (Figure 27C)\} are summarized in Table 8 . While sections from 3 out of 4 and 3 out of 5 mice exposed to 
vehicle (Figure 27A) and endotoxin alone (Figure 27B), respectively, demonstrated low levels of mucin staining, increased production of mucin was observed in mice exposed to NAL alone as evidenced by scoring of ' ++ ' or ' +++ ' in all mice of the exposure group (Figure 27C). Mice concurrently exposed to $50 \mathrm{EU}$ of endotoxin with latex demonstrated a decrease in the severity of the response as scores for mucin production were '-' to '++' (Figure 27D). Upon co-exposure with increasing amounts of endotoxin, the mucin production further decreased as scores of '-' to '+' were recorded for mice exposed to NAL and 1,250 EU (Figure 27E) and only one mouse stained positively (+) for mucin production in mice exposed to NAL and 5,000 EU (Figure 27F). 
A

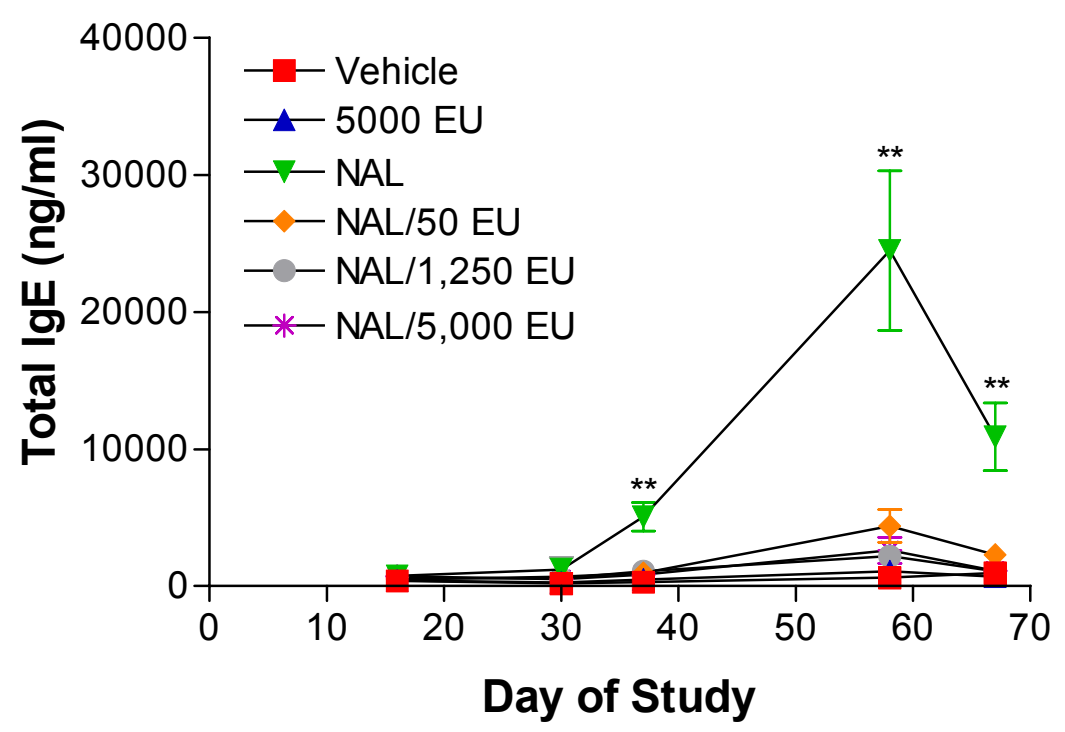

B

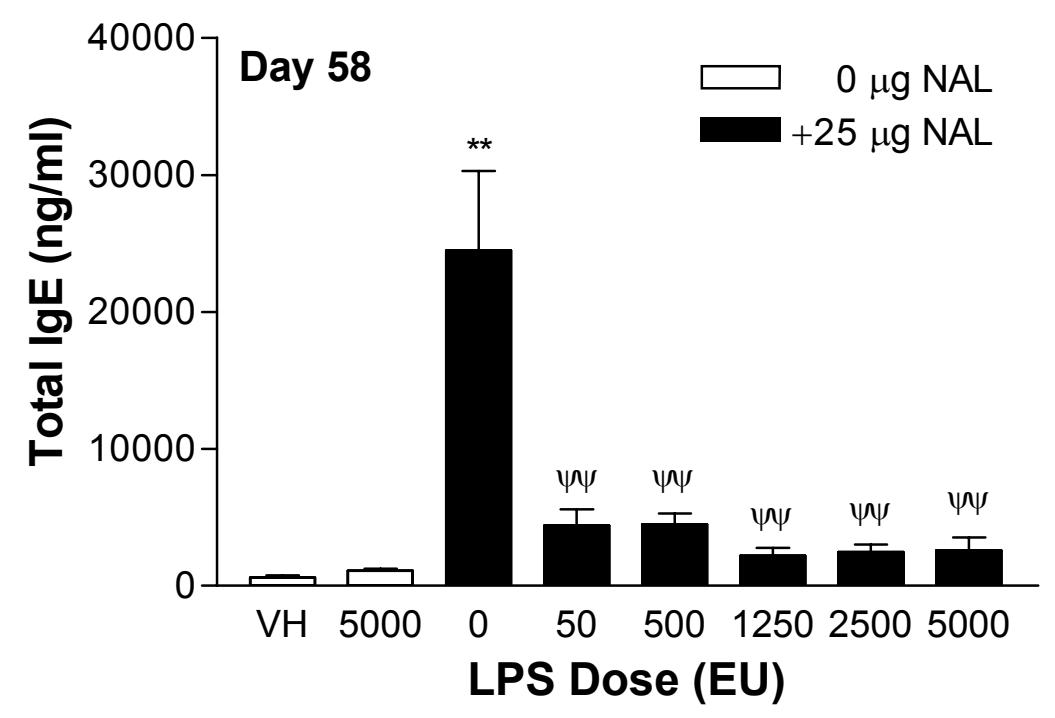

Figure 22: Total IgE Levels in Mice Intratracheally Exposed to NAL and Endotoxin from Salmonella typhimurium. Time course (A) and day 58 (B) total IgE levels were evaluated in mice concurrently exposed to NAL and concentrations of endotoxin ranging from $50-5000$ EU. Points and bars represent means \pm SE for each exposure group. $n=5$ for all exposure groups except the vehicle where $n=4$. Statistical significance was determined using a Dunnett's $t$ test. $* *$ represents $\mathrm{p}<0.01$ as compared to vehicle alone. $\psi$ and $\psi \psi$ represent $\mathrm{p}<0.05$ and $\mathrm{p}<0.01$, respectively, as compared to NAL alone. 

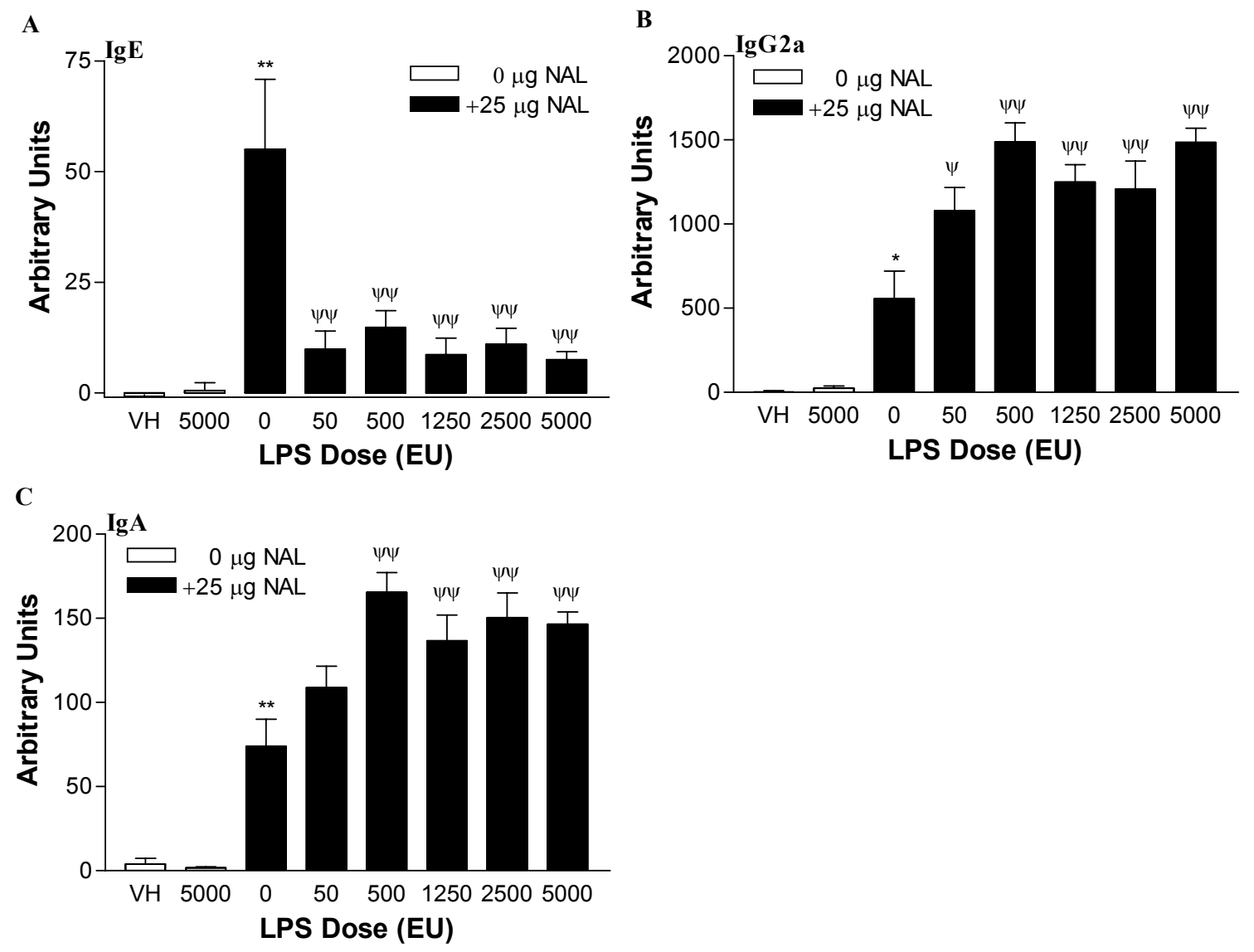

Figure 23. Latex Specific Serum Response in Mice Intratracheally Exposed to NAL and Endotoxin from Salmonella typhimurium. Levels of latex specific $\operatorname{IgE}(\mathrm{A}), \operatorname{IgG} 2 \mathrm{a}(\mathrm{B})$, and $\operatorname{IgA}(\mathrm{C})$ were evaluated in serum obtained from mice on the final day of the study (day 67). Bars represent the means $\pm \mathrm{SE}$ for each exposure group. $\mathrm{n}=5$ for all exposure groups except the vehicle where $n=4$. Statistical significance was determined using a Dunnett's t test. ${ }^{*}$ and ${ }^{* *}$ represent $\mathrm{p}<0.05$ and $\mathrm{p}<0.01$, respectively, as compared to vehicle alone. $\psi$ and $\psi \psi$ represent $\mathrm{p}<0.05$ and $\mathrm{p}<0.01$, respectively, as compared to NAL alone. 


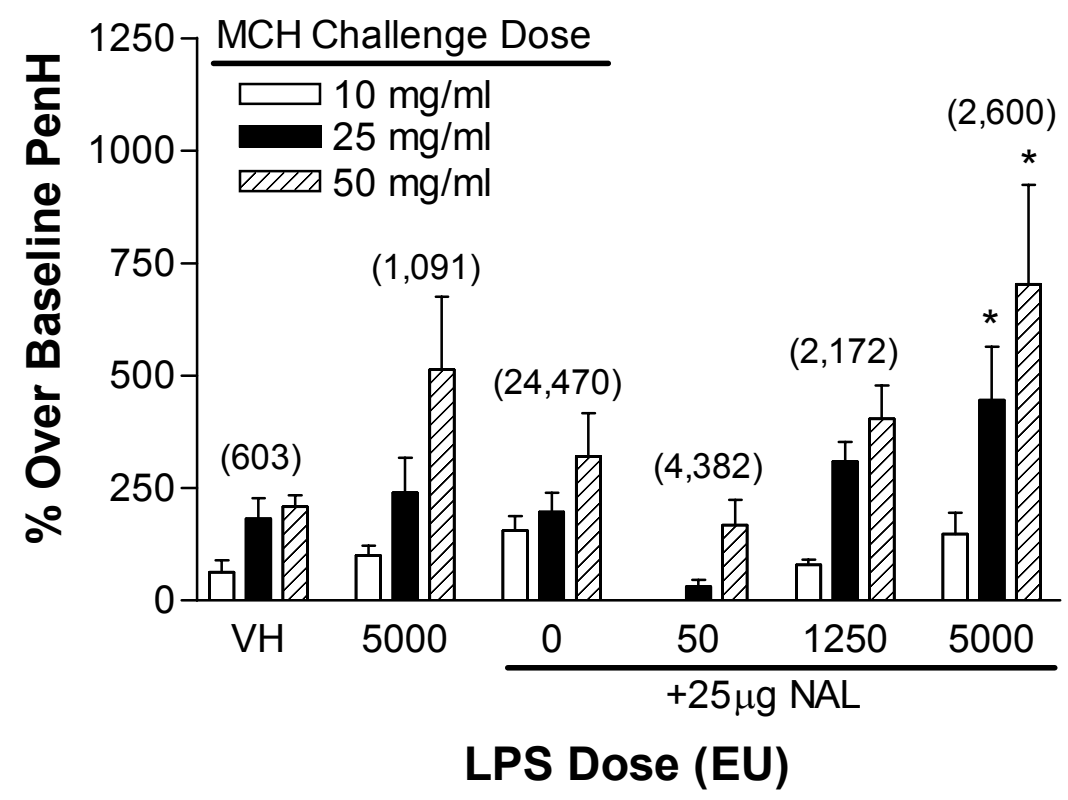

Figure 24. Levels of Non-Specific Airway Hyper-Reactivity in Mice Exposed to Latex and Increasing Concentrations of Endotoxin. Numbers in parenthesis represent the mean total serum IgE levels on day 47 for each corresponding exposure group. Bars represent means \pm SE for each group. $n=5$ for all exposure groups except the vehicle where $n=4$. For each challenge dose of methacholine, exposed mice were compared to vehicle animals and statistical significance was determined using a Dunnett's t test. Significance is indicated by $*(\mathrm{p}<0.05)$. Within each exposure group, dose responsive trends were determined using linear regression. 


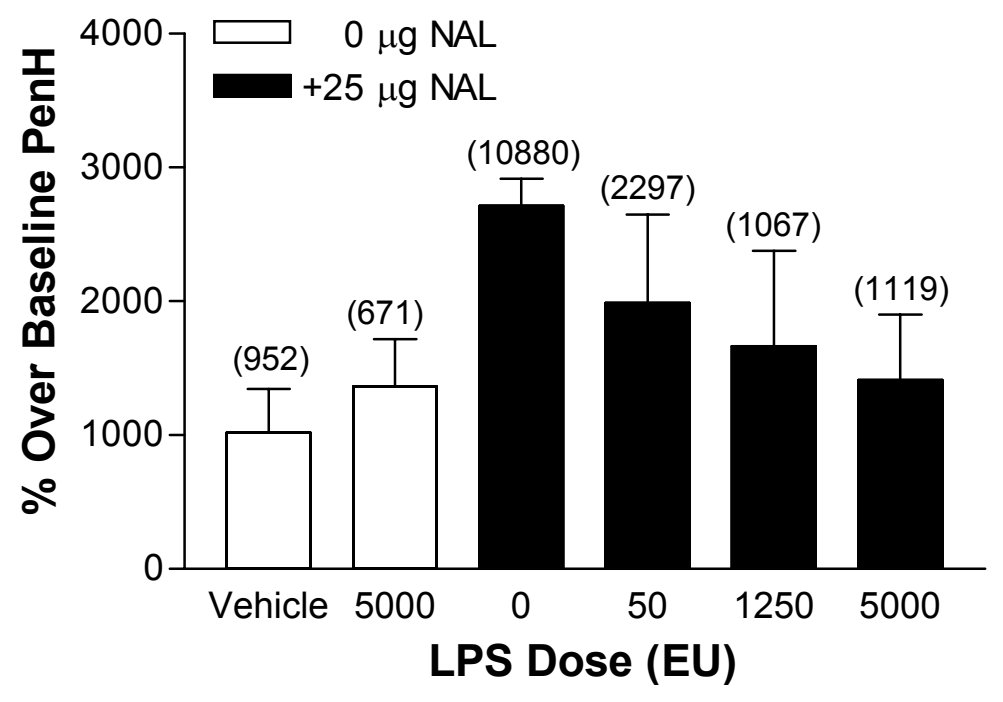

Figure 25. Latex Specific Airway Hyper-reactivity in Mice Exposed to Latex and Increasing Concentrations of Endotoxin. Numbers in parenthesis represent the mean total serum IgE levels on day 66 for each corresponding exposure group. Bars represent means $\pm \mathrm{SE}$ for each group. $\mathrm{n}=5$ for all exposure groups except the vehicle group where $n=4$. Mice concurrently exposed to NAL and endotoxin were compared to animals exposed to NAL alone for statistical significance using a Dunnett's $t$ test. 
Table 8. Histopathological Analysis of the Lung Following Concurrent Exposure to Latex and Increasing Concentrations of Endotoxin from S. tyhphimurium.

\begin{tabular}{|c|c|c|c|c|}
\hline $\begin{array}{l}\text { Exposure } \\
\text { Group }\end{array}$ & $\begin{array}{l}\text { Mucin } \\
\text { Score }^{\text {a }}\end{array}$ & $\begin{array}{c}\# \text { of } \\
\text { Responses }^{b}\end{array}$ & $\begin{array}{c}\text { Hematoxylin \& Eosin } \\
\text { Evaluation }\end{array}$ & $\begin{array}{c}\text { \# of } \\
\text { Responses } \\
\end{array}$ \\
\hline \multirow[t]{3}{*}{ Vehicle } & - & $1 / 4$ & Mild peribronchial alveolitis & $1 / 4$ \\
\hline & + & $3 / 4$ & Moderate peribronchial alveolitis & $2 / 4$ \\
\hline & & & Moderate peribronchial and perivascular alveolitis & $1 / 4$ \\
\hline \multirow[t]{2}{*}{$5,000 \mathrm{EU}$} & - & $2 / 5$ & Multifocal perivascular and peribronchial alveolitis & $5 / 5$ \\
\hline & + & $3 / 5$ & & \\
\hline \multirow[t]{2}{*}{ NAL } & ++ & $2 / 5$ & Multifocal peribronchial and perivascular alveolitis & $5 / 5$ \\
\hline & +++ & $3 / 5$ & & \\
\hline NAL & - & $1 / 5$ & Multifocal peribronchial and perivascular alveolitis & $5 / 5$ \\
\hline \multirow[t]{2}{*}{$\& 50 \mathrm{EU}$} & + & $2 / 5$ & & \\
\hline & ++ & $2 / 5$ & & \\
\hline NAL & - & $1 / 5$ & Multifocal peribronchial and perivascular alveolitis & $5 / 5$ \\
\hline$\& 1,250 \mathrm{EU}$ & + & $4 / 5$ & with areas of diffuse alveolitis & \\
\hline NAL & - & $4 / 5$ & Severe diffuse alveolititis & $5 / 5$ \\
\hline$\& 5,000 \mathrm{EU}$ & + & $1 / 5$ & & \\
\hline
\end{tabular}

\footnotetext{
a Lung sections were scored "_" to “+++" based on the degree of mucin production as visualized by staining with Alcian blue and periodic acid Schiff.

${ }^{b}$ Represents the number of mice in each exposure group with the particular response
} 


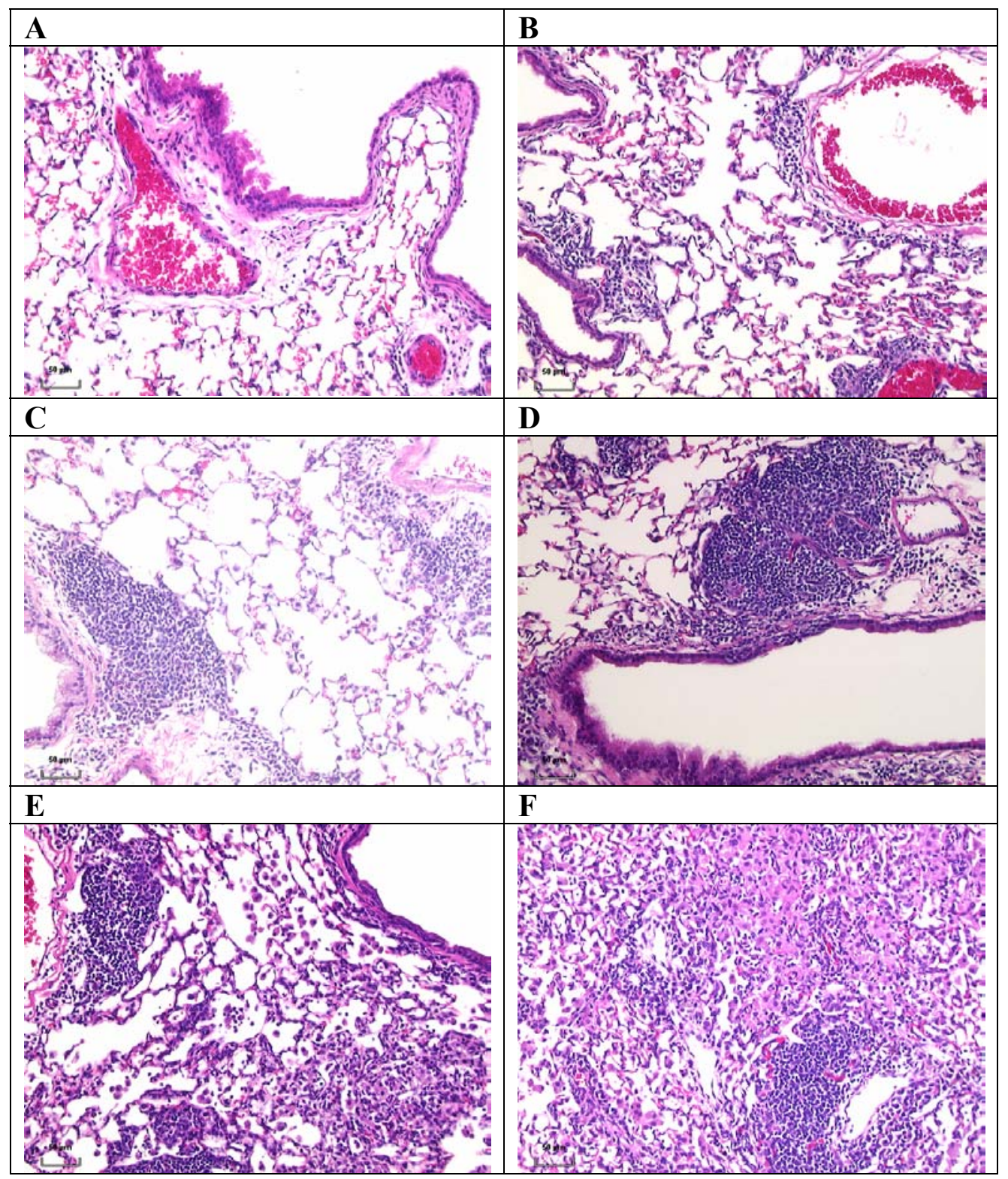

Figure 26. Histopathological Evaluation of Cellular Infiltration Following Concurrent Respiratory Exposure to Latex and Endotoxin from $S$. tyhphimurium. Lungs were excised 24 hours following i.t. challenge with latex proteins and stained with hematoxylin and eosin. Lung sections are representative of mice previously intratracheally exposed to Vehicle (A), 5,000 EU of endotoxin (B), NAL (C), NAL \& 50 EU of endotoxin (D), NAL \& 1,250 EU of endotoxin (E), and NAL \& 5,000 EU of endotoxin (F). Magnification $=20 \mathrm{x}$ and bars represent $50 \mu \mathrm{m}$. 


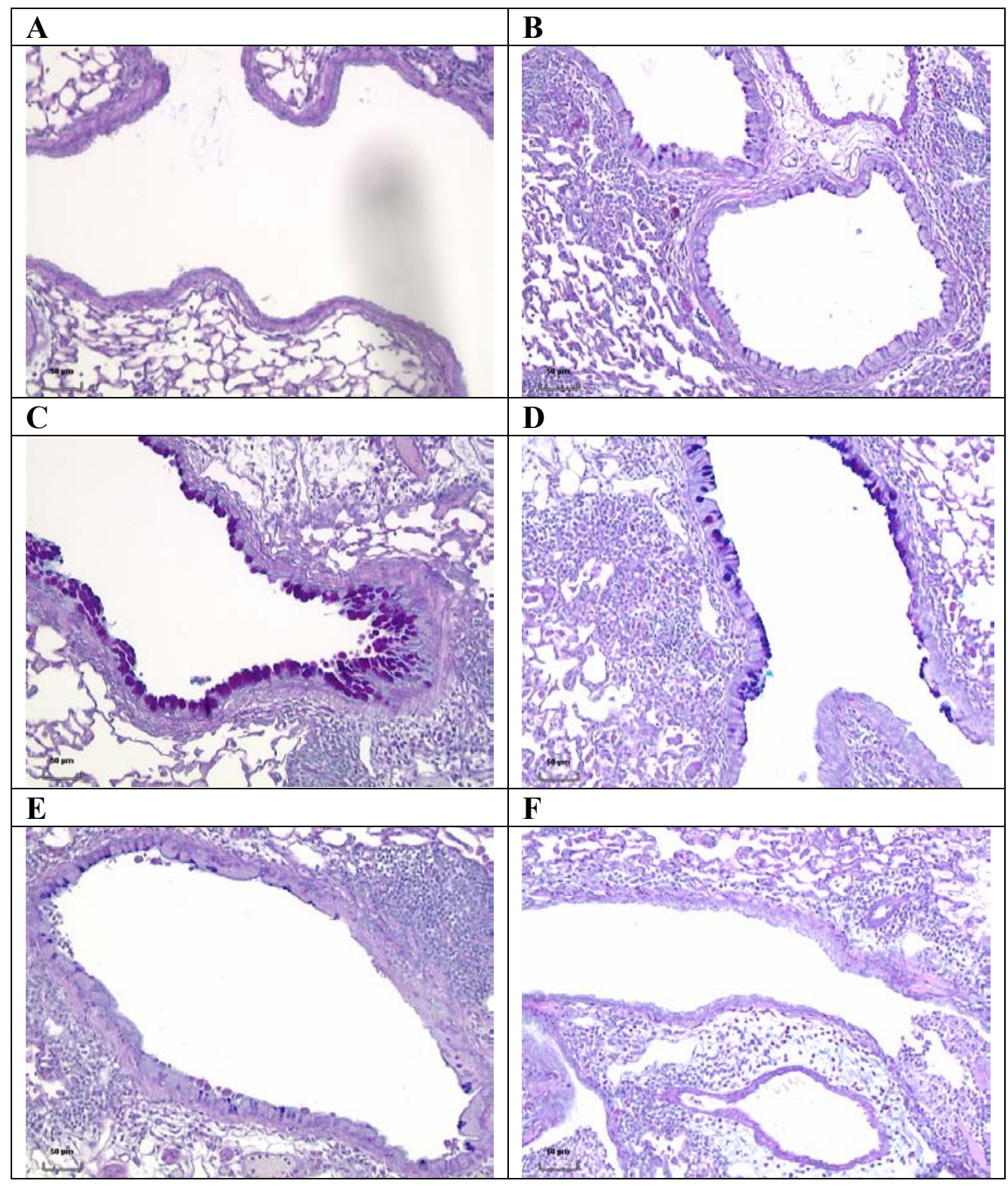

Figure 27. Mucin Production in Mice Following Concurrent Exposure to Latex and Endotoxin from $S$. tyhphimurium. Lungs were excised 24 hours following i.t. challenge with latex proteins and stained with Alcian blue-periodic acid Schiff for visualization of mucin production. Lung sections are representative of mice previously intratracheally exposed to Vehicle (A), 5,000 EU of endotoxin (B), NAL (C), NAL \& 50 EU of endotoxin (D), NAL \& 1,250 EU of endotoxin (E), and NAL \& 5,000 EU of endotoxin $(\mathrm{F})$. Magnification $=20 \mathrm{x}$ and bars represent $50 \mu \mathrm{m}$. 
Cytokine Evaluation. Following the evaluation of airway hyper-reactivity, mice were sacrificed on day 67 and the mediastinal lymph nodes were excised from exposed mice and RNA was isolated to evaluate the message levels of Th1 and Th2 cytokines. Interleukin-4, IL-10, IL-12, and IFN- $\gamma$ messenger RNA levels were evaluated using realtime quantitative polymerase chain reaction. No significant alterations were observed in the levels of IL-4 mRNA of any exposure groups when compared to mice exposed to vehicle alone (Figure 28A). While no alterations in IL-4 message were observed, i.t. administration of endotoxin with or without NAL proteins resulted in at least a 3-fold increase in IL-10 messenger RNA levels (Figure 28B). In contrast, endotoxin exposure induced greater than 50-fold and 8-fold increases in IL-12 and IFN- $\gamma$ mRNA levels, respectively, upon comparison with vehicle levels (Figure 29). Additionally, mice concurrently exposed to NAL and increasing concentrations of endotoxin demonstrated dose responsive increases in IL-12 and IFN- $\gamma$ production, reaching greater than a 40 -fold and 4-fold increase over vehicle levels respectively. 

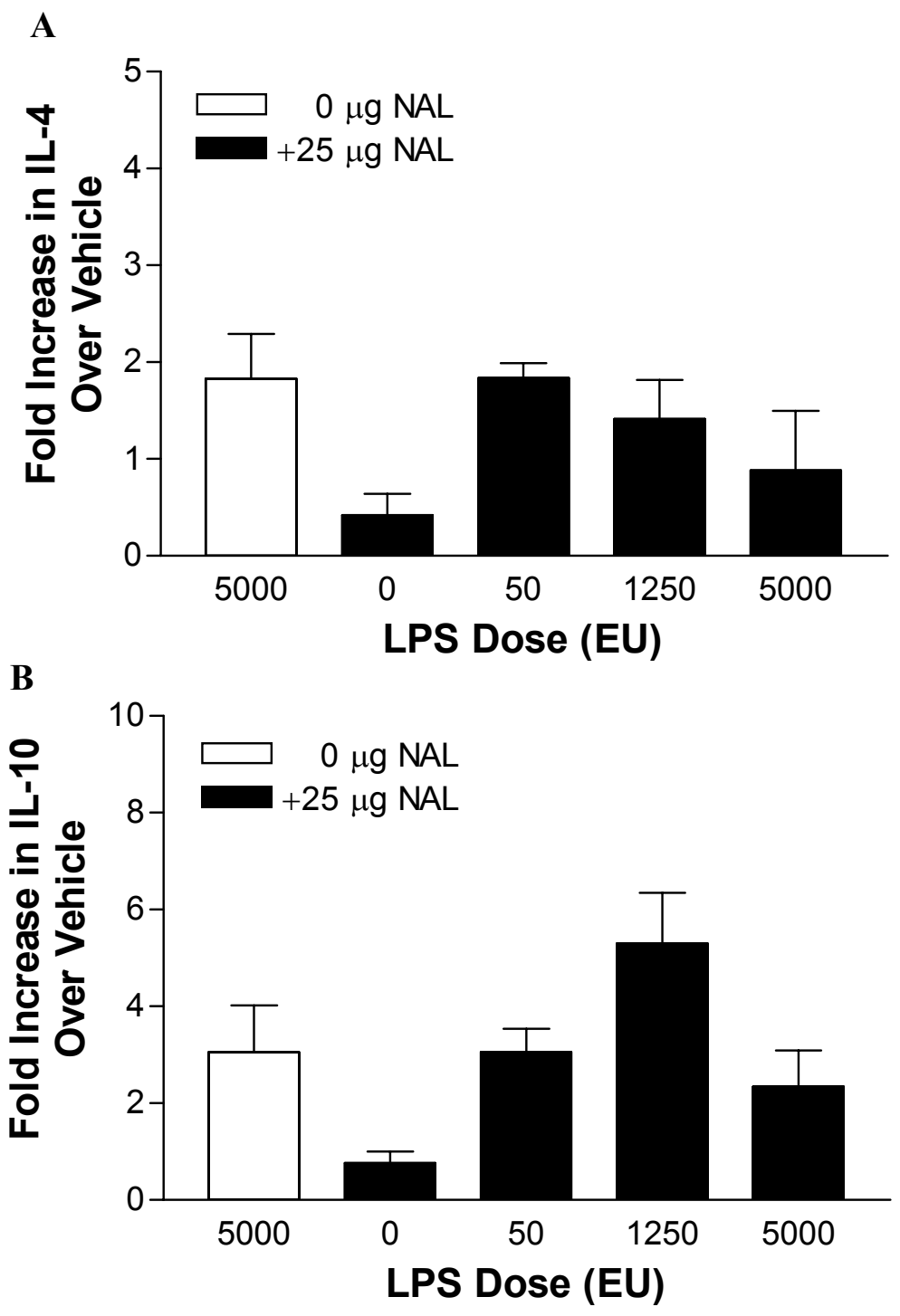

Figure 28. Th2 Cytokine Message Levels in Mice Exposed to Latex and Increasing Concentrations of Endotoxin from $S$. typhimurium. Increases in IL-4 (A) and IL-10 (B) expression were determined for each exposure group by calculating the fold increase over vehicle levels as described in the methods. Bars represent means \pm SE for each group. $\mathrm{n}=5$ for all exposure groups except the vehicle group where $\mathrm{n}=4$. 

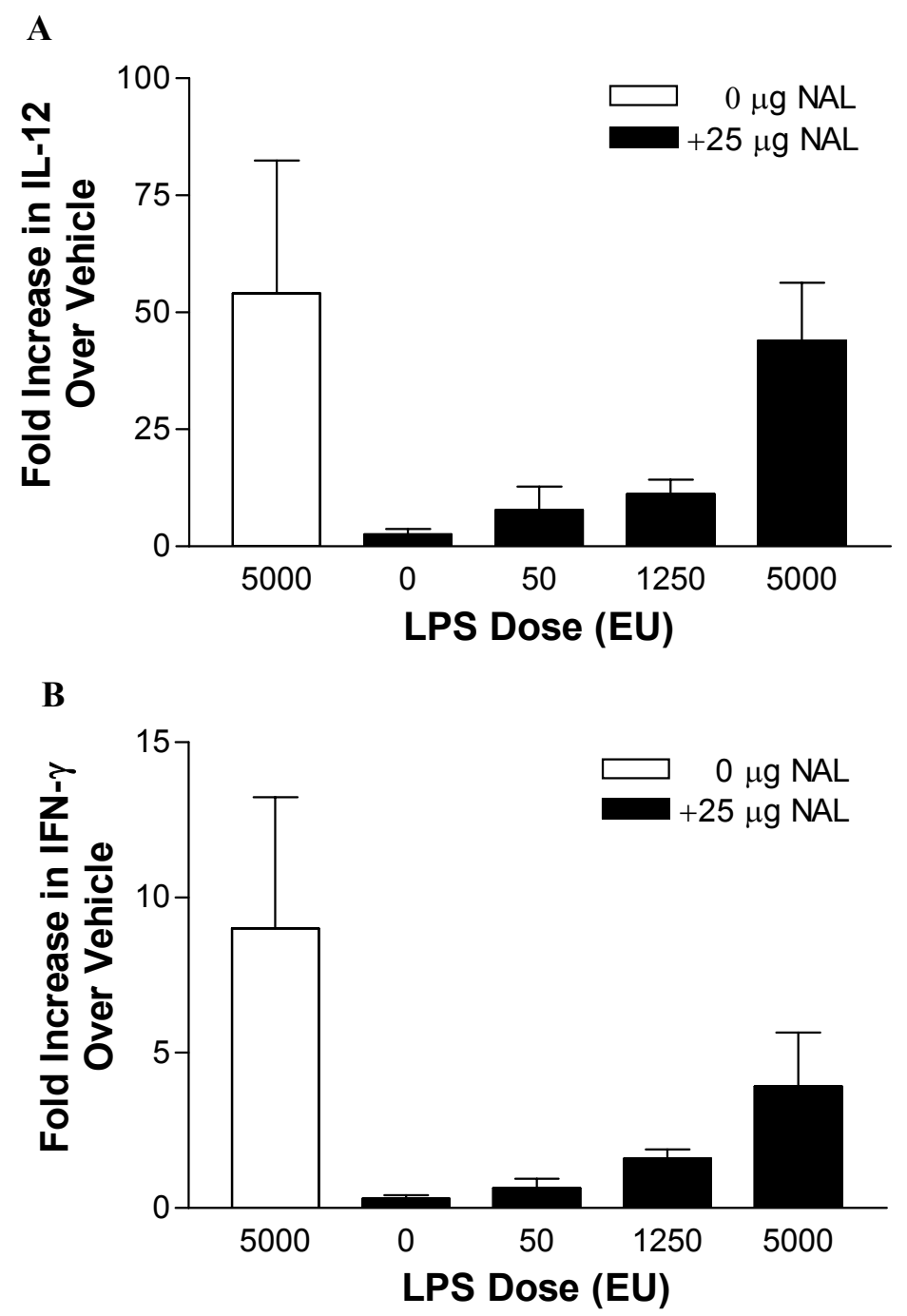

Figure 29. Th1 Cytokine Message Levels in Mice Exposed to Latex and Increasing Concentrations of Endotoxin from S. typhimurium. Increases in IL-12 (A) and IFN- $\gamma$ (B) expression were determined for each exposure group by calculating the fold increase over vehicle levels as described in the methods. Bars represent means \pm SE for each group. $\mathrm{n}=5$ for all exposure groups except the vehicle group where $\mathrm{n}=4$. 


\section{Correlation between Class Switch and Cytokine Response}

Previous studies demonstrated that concurrent exposure to latex and endotoxin results in the development of a predominantly Th1 response characterized by an increase in the levels of latex specific serum IgG2a antibodies and an increase in IL-12 and IFN- $\gamma$ production. Mice were intratracheally exposed to NAL and endotoxin to investigate the relationship between IgG2a and cytokine levels.

Latex Specific IgG2a Antibodies. An initial study was conducted to identify the earliest time point at which latex specific IgG2a was detectable in concurrently exposed mice. Mice were intratracheally exposed to NAL and/or 2,500 EU of S. typhimurium every $5^{\text {th }}$ day for 12,16 , or 20 days. Upon comparison with mice exposed to NAL alone, mice concurrently exposed to NAL and 2,500 EU demonstrated significant elevations ( $p$ $<0.01$ ) in IgG2a levels as early as day 16 (Figure 30).

A subsequent study was conducted to investigate the dose response relationship at day 16. Mice were exposed every $5^{\text {th }}$ day for 16 days and upon sacrifice, blood was collected for analysis of serum IgG2a levels. Levels of IgG2a were dose responsively increased $(p<0.01)$ in mice exposed to NAL and increasing concentrations of endotoxin reaching levels 1000-fold greater than those observed in mice exposed to NAL alone (Figure 31). 


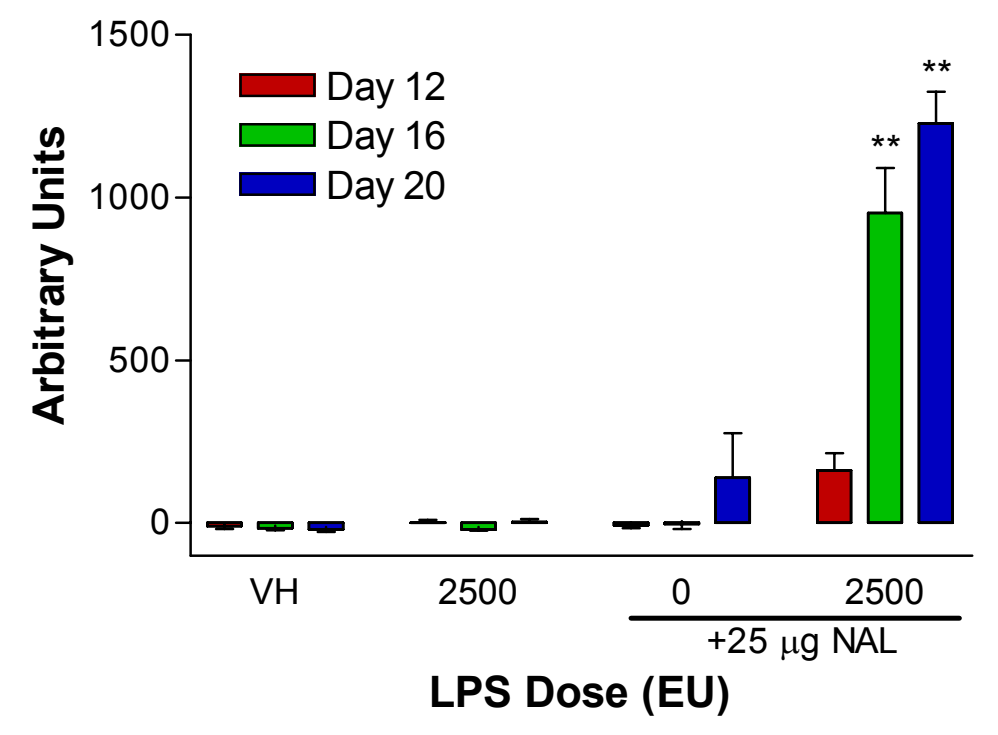

Figure 30. Time Course of Latex Specific Serum IgG2a Levels in Mice Exposed to Latex and 2,500 EU of Salmonella typhimurium. Bars represent means $\pm \mathrm{SE}$ for each group. $\mathrm{n}=5$ for all exposure groups. Statistical significance between mice concurrently exposed and mice exposed to NAL alone was determined using a Dunnett's $t$ test.

$* *$ represents $\mathrm{p}<0.01$.

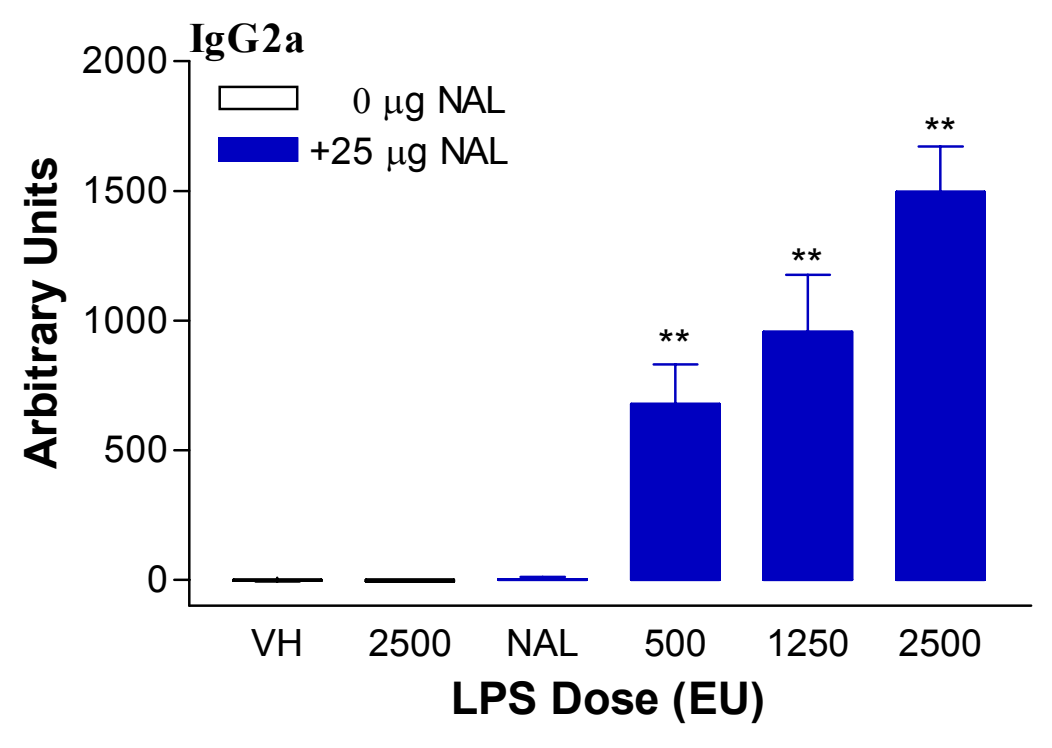

Figure 31. Latex Specific Serum IgG2a Levels on Day 16 in Mice Exposed to Latex and Increasing Concentrations of Endotoxin. Bars represent means \pm SE for each group. $n=5$ for all exposure groups. Statistical significance between mice concurrently exposed and mice exposed to NAL alone was determined using a Dunnett's $t$ test. ${ }^{* *}$ represents $\mathrm{p}<0.01$. 
Th1 Cytokine Message Levels. The previous study demonstrated a dose responsive increase in latex specific serum IgG2a levels in mice concurrently exposed to NAL and increasing concentrations of endotoxin from S. typhimurium. Mediastinal lymph nodes from these animals were excised and evaluated for cytokine message analysis. As was observed in the cytokine levels on day 67, a dose responsive relationship was observed between the levels of IL-12 and concurrent exposure to NAL and increasing concentrations of endotoxin (Figure 32a). Although not dose responsive, levels of IFN- $\gamma$ were increased in animals concurrently exposed to NAL and increasing concentrations of endotoxin, reaching a 4-fold increase over levels in vehicle exposed mice (Figure 32b). As was the case in the Th2 cytokine levels on day 67, IL-4 and IL-10 mRNA levels were not significantly altered in any of the exposure groups (data not shown). 

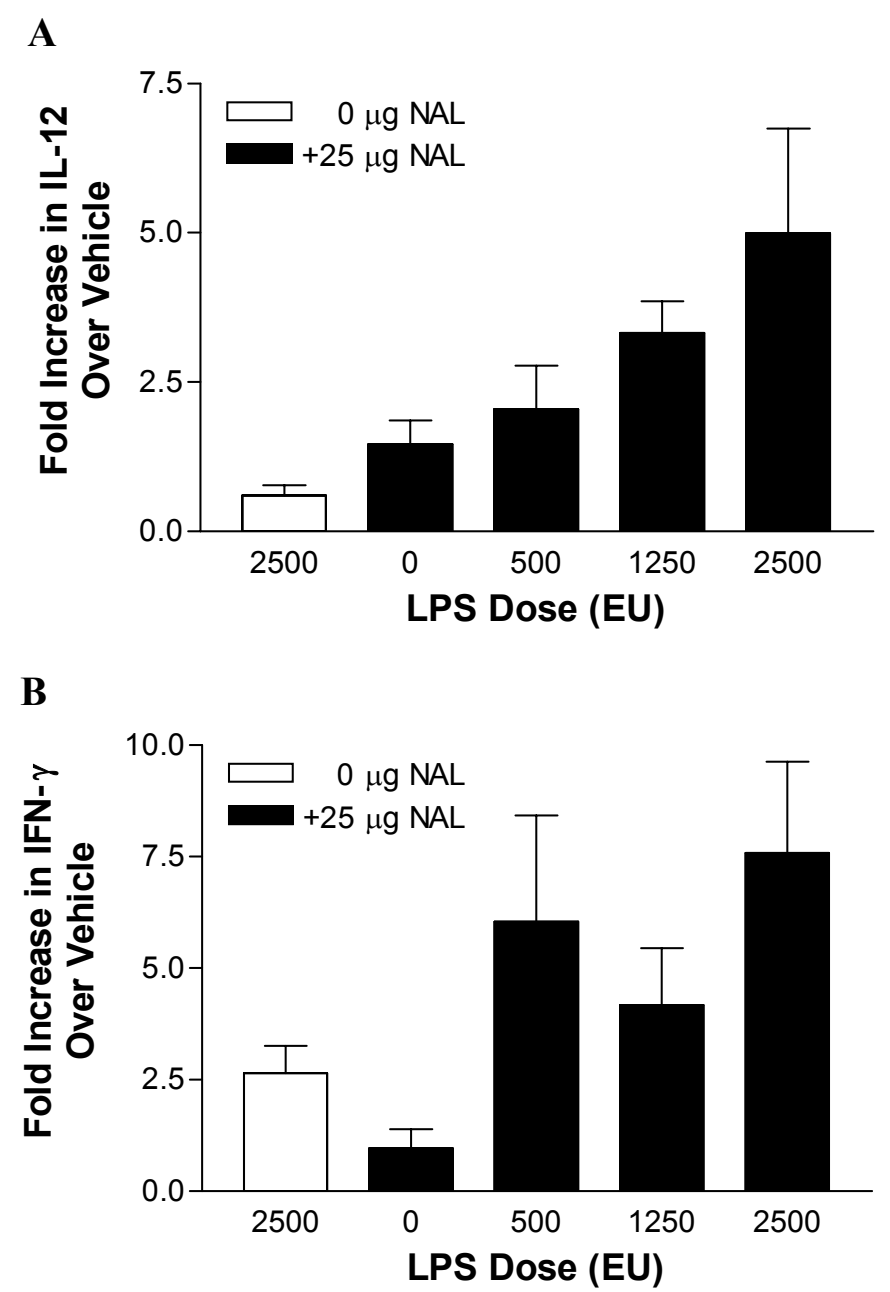

Figure 32. Th1 Cytokine Message Levels in Mice Exposed to Latex and Endotoxin for 16 Days. Increases in IL-12 (A) and IFN- $\gamma$ (B) expression were determined for each exposure group by calculating the fold increase over vehicle levels as described in the methods. Bars represent means $\pm \mathrm{SE}$ for each group. $\mathrm{n}=5$ for all exposure groups. 


\section{Immunomodulatory Role of Glutaraldehyde in the Induction of Latex Specific IgE}

Due to its immunological activity and extensive use within medical care facilities, glutaraldehyde was investigated for the potential to modulate the development of an IgE mediated hypersensitivity response to latex proteins following dermal exposure.

$\underline{\text { Serum IgE Response. }}$ Mice were exposed 5 days a week to NAL and increasing concentrations of glutaraldehyde by first applying the vehicle or glutaraldehyde solution to the clipped dorsal thorax region of mice. Approximately 5 minutes later, NAL proteins were applied to the same site. Due to the irritancy potential of glutaraldehyde, the application site of mice was monitored throughout the studies for the development of skin irritation.

An initial study was conducted investigating concurrent exposure of mice to NAL and concentrations of glutaraldehyde representative of those used in cold sterilant solutions $(0.1,0.5$, and $1 \%)$. Serum IgE levels were monitored bi-weekly throughout the course of the study. Following dermal exposure to solutions containing $1 \%$ glutaraldehyde, skin in exposed mice failed to re-grow hair and appeared to be thickened. Mice exposed to $1 \%$ glutaraldehyde alone demonstrated a time dependent increase in total serum IgE levels, with a significant increase $(\mathrm{p}<0.01)$ over vehicle exposed mice observed as early as day 30 (Figure 33A). While levels of total serum $\operatorname{IgE}$ in mice exposed to glutaraldehyde alone increased to levels greater than $3,000 \mathrm{ng} / \mathrm{ml}$ on day 79 , no significant elevations were observed in any of the other exposure groups. Animals 
exposed concurrently to $1 \%$ glutaraldehyde and NAL had levels of total serum $\operatorname{IgE}$ approximately $50 \%$ lower than those observed in mice exposed to $1 \%$ glutaraldehyde alone (Figure 33B). Latex specific serum IgE levels did not reach levels of significance in any of the exposure groups (Figure 33C). 

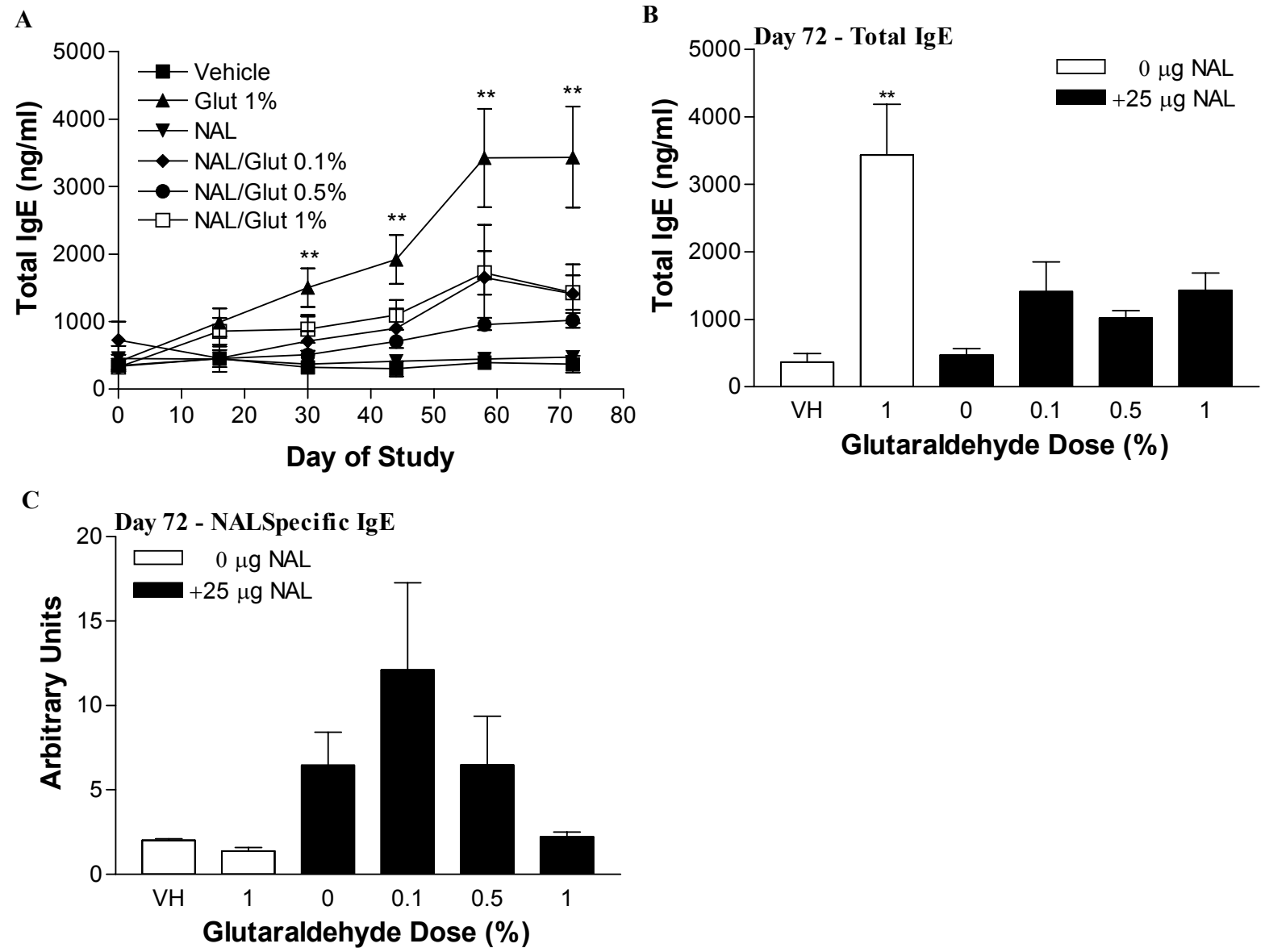

Figure 33. Total and Latex Specific Serum IgE Levels in Mice Concurrently Exposed to Latex and Glutaraldehyde for 72 Days. Time course of total $\operatorname{IgE}(\mathrm{A})$, day 72 total $\operatorname{IgE}(\mathrm{B})$, and day 72 latex specific $\operatorname{IgE}(\mathrm{C})$ levels were evaluated by ELISA in mice concurrently exposed to NAL and concentrations of glutaraldehyde (Glut) ranging from $0.1-1 \%$. Bars or points represent means \pm SE for each exposure group. $\mathrm{n}=5$ for all exposure groups. Statistical significance was determined using a Dunnett's $t$ test. ** represents $\mathrm{p}<0.01$ as compared to vehicle alone. 
Studies were then conducted to evaluate the effect of exposure to lower concentrations of glutaraldehyde ranging from $0.05-1 \mathrm{ppm}$ (values surrounding the permissible exposure limit) on the development of an IgE mediated hypersensitivity response to latex proteins. Data from a representative study is shown in Figure 34 . Throughout the course of the study, no significant elevation in the levels of total serum IgE was observed in animals exposed to NAL alone. A time and dose dependent increase in total serum $\operatorname{IgE}$ was observed in mice concurrently exposed to NAL and concentrations of glutaraldehyde ranging from $0.05-0.75 \mathrm{ppm}$ (Figures $34 \mathrm{~A} \& \mathrm{~B}$ ). No significant elevations in total serum $\operatorname{IgE}$ were observed in mice exposed concurrently to NAL and 1ppm glutaraldehyde throughout the course of the study. Mice exposed concurrently to NAL and $0.75 \mathrm{ppm}$ of glutaraldehyde demonstrated significantly $(\mathrm{p}<$ 0.01 ) elevated levels of total serum $\operatorname{IgE}$ as early as day 58 reaching greater than 3000 $\mathrm{ng} / \mathrm{ml}$ on day 65 . Co-exposure to $0.75 \mathrm{ppm}$ glutaraldehyde augmented the latex specific $\operatorname{IgE}$ response as a 40 -fold increase was observed in comparison with levels from mice exposed to NAL alone (Figure 34C).

A repeat study was conducted to demonstrate the reproducibility of this effect. Mice were again exposed 5 days a week on the dorsal thorax to NAL and up to $1 \mathrm{ppm}$ glutaraldehyde and serum antibody levels were monitored bi-weekly throughout the study. As in the previous study, mice concurrently exposed to NAL and $0.75 \mathrm{ppm}$ of glutaraldehyde demonstrated significant elevations $(\mathrm{p}<0.05)$ in total serum $\operatorname{IgE}$ as early as day 58 following the initial exposure (Figure 35A) reaching levels greater than 2,500 $\mathrm{ng} / \mathrm{ml}$ on day 86 (Figure 35B). Although not statistically significant, increased levels of 
latex specific IgE were observed in mice concurrently exposed to NAL and increasing concentrations of glutaraldehyde reaching 2 -fold higher levels in mice exposed to NAL and $0.75 \mathrm{ppm}$ glutaraldehyde when compared with those from animals exposed to NAL alone (Figure 35C). As in the previous study, animals exposed to NAL and $1 \mathrm{ppm}$ did not demonstrate significant elevations in either total or latex specific IgE. 
A

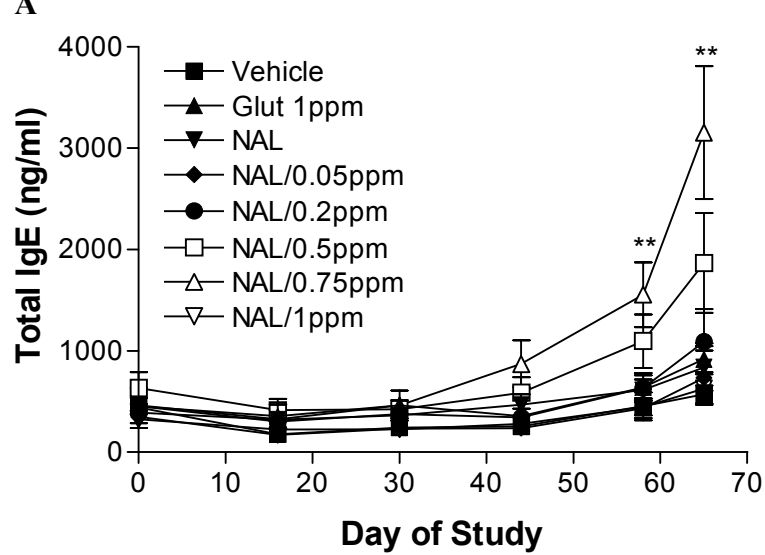

C

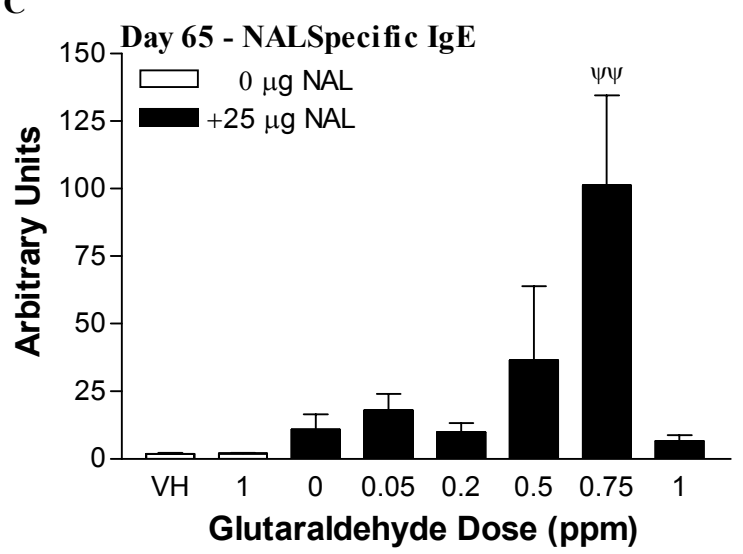

B

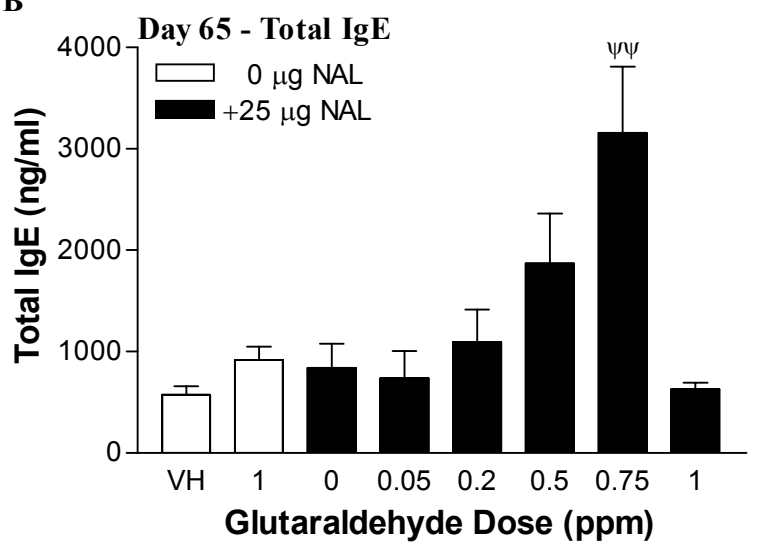

Figure 34. Total and Latex Specific Serum IgE Levels in Mice Concurrently Exposed to Latex and Glutaraldehyde for 65 Days. Time course of total IgE (A), day 65 total IgE (B), and day 65 latex specific IgE (C) levels were evaluated by ELISA in mice concurrently exposed to NAL and concentrations of glutaraldehyde (Glut) ranging from $0.05-1 \mathrm{ppm}$. Points and bars represent means $\pm \mathrm{SE}$ for each exposure group. $\mathrm{n}=5$ for all exposure groups. Statistical significance was determined using a Dunnett's $t$ test. ** represents $\mathrm{p}<0.01$ as compared to vehicle alone. $\psi \psi$ represents $\mathrm{p}<0.01$ as compared to NAL alone. 
A

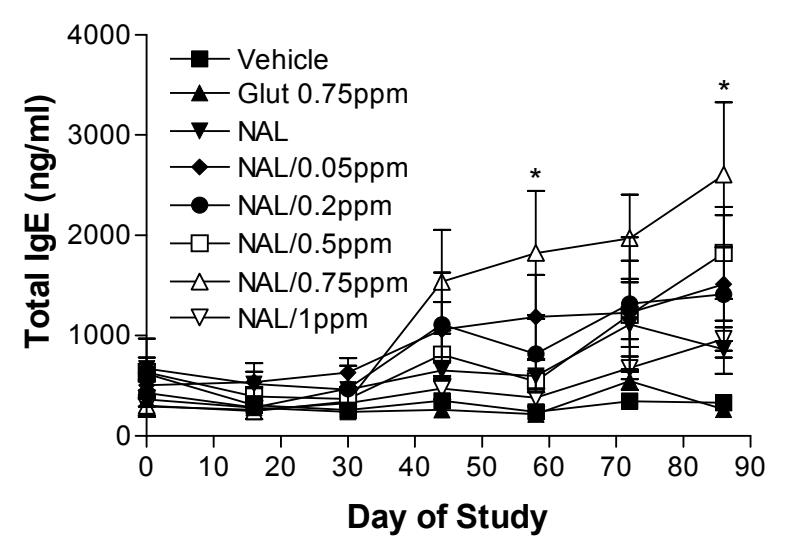

C

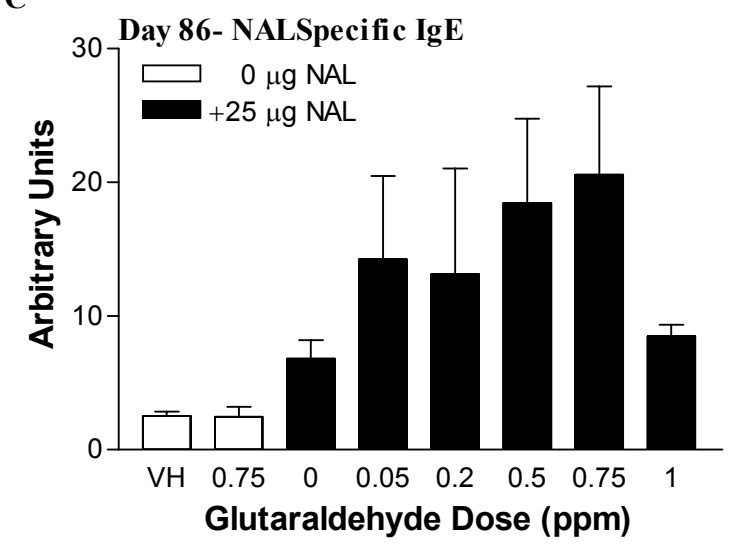

B

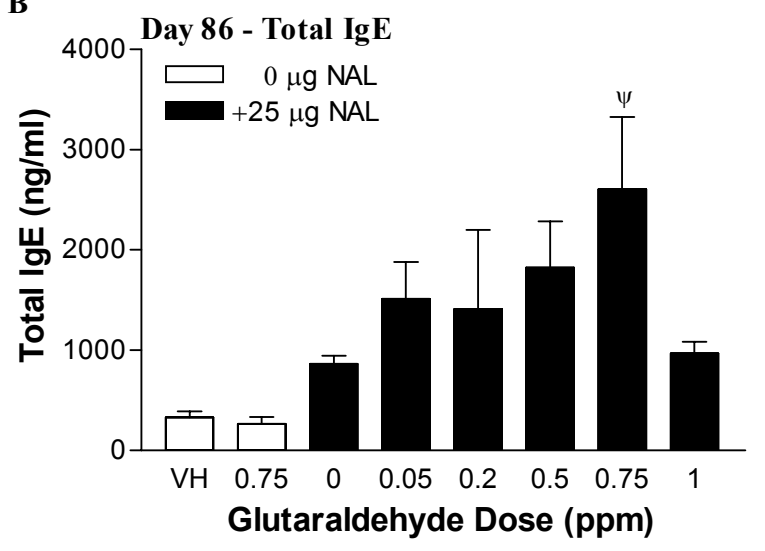

Figure 35. Total and Latex Specific Serum IgE Levels in Mice Concurrently Exposed to Latex and Glutaraldehyde for 86 Days. Time course of total IgE (A), day 86 total $\operatorname{IgE}(\mathrm{B})$, and day 86 latex specific $\operatorname{IgE}(\mathrm{C})$ levels were evaluated by ELISA in mice dermally exposed to NAL and concentrations of glutaraldehyde (Glut) ranging from $0.05-1 \mathrm{ppm}$. Points and bars represent means $\pm \mathrm{SE}$ for each exposure group. $\mathrm{n}=5$ for all exposure groups. Statistical significance was determined using a Dunnett's $\mathrm{t}$ test. * represents $\mathrm{p}<0.05$ as compared to vehicle alone. $\psi$ represents $\mathrm{p}<0.05$ as compared to NAL alone. 


\section{Potential Role for Barrier Disruption}

Given that glutaraldehyde is known to induce dermatitis, these studies tested the hypothesis that disruption of the stratum corneum, due to glutaraldehyde exposure, would allow for enhanced dermal penetration of latex proteins leading to the observed elevations in latex specific IgE.

$\underline{\text { In Vitro Percutaneous Penetration of Latex Proteins. Glutaraldehyde }}$ concentrations of 0.75 and $1 \mathrm{ppm}$ were evaluated for their potential to disrupt the barrier integrity of the skin. Skin from hairless guinea pigs previously exposed to glutaraldehyde ( 0.75 or $1 \mathrm{ppm}$ ) for up to 56 days was tested using a ${ }^{3} \mathrm{H}_{2} \mathrm{O}$-barrier integrity test followed by the evaluation of in vitro percutaneous penetration of radiolabeled NAL proteins.

Every two weeks post initial exposure (days 14, 28, 42, and 56), a pair of hairless guinea pigs were sacrificed and the dorsal lumbar region excised for analysis. Exposure was carried out for up to 56 days due to the initial observation of elevated $\operatorname{IgE}$ levels on day 58 (Figure 34A) in mice concurrently exposed to NAL and $0.75 \mathrm{ppm}$ glutaraldehyde. The percent penetration of radiolabeled NAL protein was compared between skin previously exposed to acetone (the vehicle for glutaraldehyde) or glutaraldehyde (Tables $9 \& 10)$. Upon analysis it was demonstrated that the barrier integrity was conserved in all previously exposed skin samples as the percent of ${ }^{3} \mathrm{H}_{2} \mathrm{O}$ penetration ranged between 0.03 and $0.14 \%$; while the established cutoff for determining barrier disruption is $0.35 \%$ (Bronaugh and Collier, 1991). Additionally, no significant differences in latex protein 
penetration were observed between skin samples exposed to acetone or glutaraldehyde throughout the course of the study (Tables $9 \& 10$ ). Acetone and glutaraldehyde exposed skin samples were found to contain between $0.05 \%$ and $0.30 \%$ of the applied radiolabeled dose, while the percent penetration through the skin and into the receptor fluid ranged from $0.20 \%-0.60 \%$. Radiolabel recovery (mass balance) for all studies was greater than $85 \%$. Additionally, immunohistochemical analysis of the skin samples previously exposed to acetone or glutaraldehyde demonstrated no differences in the stratum corneum integrity, cellular infiltration, or localization of NAL proteins (Figures $36 \& 37)$.

Barrier Integrity in Mice Concurrently Exposed to Latex and Glutaraldehyde. Barrier integrity was also evaluated in the dose response, time course murine study where an elevation in total serum $\operatorname{IgE}$ was observed in mice concurrently exposed to NAL and 0.75ppm glutaraldehyde on day 86 (Figure 35). Upon sacrifice, skin from the dorsal thorax exposure site was excised and subjected to a barrier test. While skin samples for vehicle exposed animals did not demonstrate significant alterations in the barrier integrity $\left(0.30 \%{ }^{3} \mathrm{H}_{2} \mathrm{O}\right.$ penetration); all skin samples previously exposed to NAL and increasing concentrations of glutaraldehyde demonstrated greater than $0.35 \%{ }^{3} \mathrm{H}_{2} \mathrm{O}$ penetration (Figure 38). The percent of ${ }^{3} \mathrm{H}_{2} \mathrm{O}$ penetration in skin previously exposed to NAL and glutaraldehyde ranged between 0.4 and $0.8 \%$, which, although greater than the cutoff for barrier disruption, has been shown to be insufficient to allow enhanced penetration of latex proteins (Hayes et al., 2000). Mass balance for all samples was greater than $90 \%$ (data not shown). 
Table 9. Penetration of Latex Protein through Hairless Guinea Pig Skin Previously Exposed to 0.75ppm Glutaraldehyde.

\begin{tabular}{|c|c|c|c|c|c|}
\hline Time Point & Exposure & ${ }^{3} \mathrm{H}_{2} \mathrm{O}$ Penetration ${ }^{\mathrm{a}}$ & Skin $^{b}$ & Receptor Fluid $^{\text {b }}$ & Mass Balance $^{b}$ \\
\hline \multicolumn{6}{|l|}{ Day 0} \\
\hline & Unexposed & $0.053 \pm 0.005$ & $0.54 \pm 0.04$ & $0.59 \pm 0.05$ & $96.31 \pm 1.24$ \\
\hline & Acetone & $0.037 \pm 0.003$ & $0.25 \pm 0.02$ & $041+0.04$ & $9882+243$ \\
\hline & 0.75 ppm Glutaraldehyde & $0.039 \pm 0.005$ & $0.30 \pm 0.03$ & $0.50 \pm 0.04$ & $97.45 \pm 1.12$ \\
\hline \multicolumn{6}{|l|}{ Day 28} \\
\hline & Acetone & $0.044 \pm 0.008$ & $0.07 \pm 0.01$ & $0.52 \pm 0.28$ & $99.42 \pm 0.77$ \\
\hline & 0.75 ppm Glutaraldehyde & $0.084 \pm 0.030$ & $0.15 \pm 0.05$ & $0.60 \pm 0.34$ & $95.28 \pm 4.11$ \\
\hline \multicolumn{6}{|l|}{ Day 42} \\
\hline \multirow{5}{*}{ Day 56} & Acetone & $0.051 \pm 0.005$ & $0.19 \pm 0.02$ & $0.37 \pm 0.02$ & $108.1 \pm 2.07$ \\
\hline & 0.75 ppm Glutaraldehyde & $0.071 \pm 0.028$ & $0.26 \pm 0.03$ & $0.35 \pm 0.03$ & $103.7 \pm 2.94$ \\
\hline & & & & & \\
\hline & Acetone & $0.051 \pm 0.004$ & $0.16 \pm 0.04$ & $0.39 \pm 0.04$ & $99.91 \pm 1.03$ \\
\hline & 0.75 ppm Glutaraldehyde & $0.143 \pm 0.089$ & $0.14 \pm 0.03$ & $0.55 \pm 0.12$ & $101.6 \pm 1.63$ \\
\hline
\end{tabular}

${ }^{a}$ Values represent the mean percentage \pm SE of the applied ${ }^{3} \mathrm{H}_{2} \mathrm{O}$ dose. $(n=6)$

${ }^{\mathrm{b}}$ Values for the skin, receptor fluid, and mass balance represent the mean percentage \pm SE of the applied ${ }^{125} \mathrm{I}-\mathrm{NAL}$ dose. $(n=6)$ 
Table 10. Percutaneous Penetration of Latex Protein through Hairless Guinea Pig Skin Previously Exposed to 1ppm Glutaraldehyde.

\begin{tabular}{|c|c|c|c|c|c|}
\hline Time Point & Exposure & ${ }^{3} \mathrm{H}_{2} \mathrm{O}$ Penetration ${ }^{\mathrm{a}}$ & Skin $^{\mathrm{b}}$ & Receptor Fluid $^{\mathrm{b}}$ & Mass Balance $^{\mathrm{b}}$ \\
\hline \multicolumn{6}{|l|}{ Day 0} \\
\hline \multirow{3}{*}{ Day 14} & Unexposed & $0.053 \pm 0.005$ & $0.54 \pm 0.04$ & $0.59 \pm 0.05$ & $96.31 \pm 1.24$ \\
\hline & Acetone & $0.052 \pm 0.005$ & $0.05 \pm 0.01$ & $0.20 \pm 0.02$ & $102.5 \pm 1.31$ \\
\hline & 1 ppm Glutaraldehyde & $0.053 \pm 0.006$ & $0.05 \pm 0.01$ & $0.20 \pm 0.03$ & $101.3 \pm 0.47$ \\
\hline \multicolumn{6}{|l|}{ Day 28} \\
\hline & Acetone & $0.030 \pm 0.003$ & $0.10 \pm 0.01$ & $0.27 \pm 0.11$ & $96.78 \pm 1.22$ \\
\hline & 1 ppm Glutaraldehyde & $0.030 \pm 0.004$ & $0.10 \pm 0.01$ & $0.30 \pm 0.04$ & $96.21 \pm 1.13$ \\
\hline \multicolumn{6}{|l|}{ Day 42} \\
\hline & Acetone & $0.108 \pm 0.033$ & $0.07 \pm 0.02$ & $0.41 \pm 0.17$ & $85.58 \pm 14.7$ \\
\hline & 1 ppm Glutaraldehyde & $0.043 \pm 0.011$ & $0.07 \pm 0.01$ & $0.30 \pm 0.08$ & $88.52 \pm 10.3$ \\
\hline Day 0 & Acetone & & $0.25 \pm 0.03$ & $0.32 \pm 0.08$ & $1015 \pm 222$ \\
\hline & 1 ppm Glutaraldehyde & $0.042 \pm 0.003$ & $0.25 \pm 0.02$ & $0.31 \pm 0.03$ & $100.2 \pm 1.30$ \\
\hline
\end{tabular}

${ }^{a}$ Values represent the mean percentage \pm SE of the applied ${ }^{3} \mathrm{H}_{2} \mathrm{O}$ dose. $(n=6)$

${ }^{\mathrm{b}}$ Values for the skin, receptor fluid, and mass balance represent the mean percentage \pm SE of the applied ${ }^{125} \mathrm{I}-\mathrm{NAL}$ dose. $(n=6)$ 

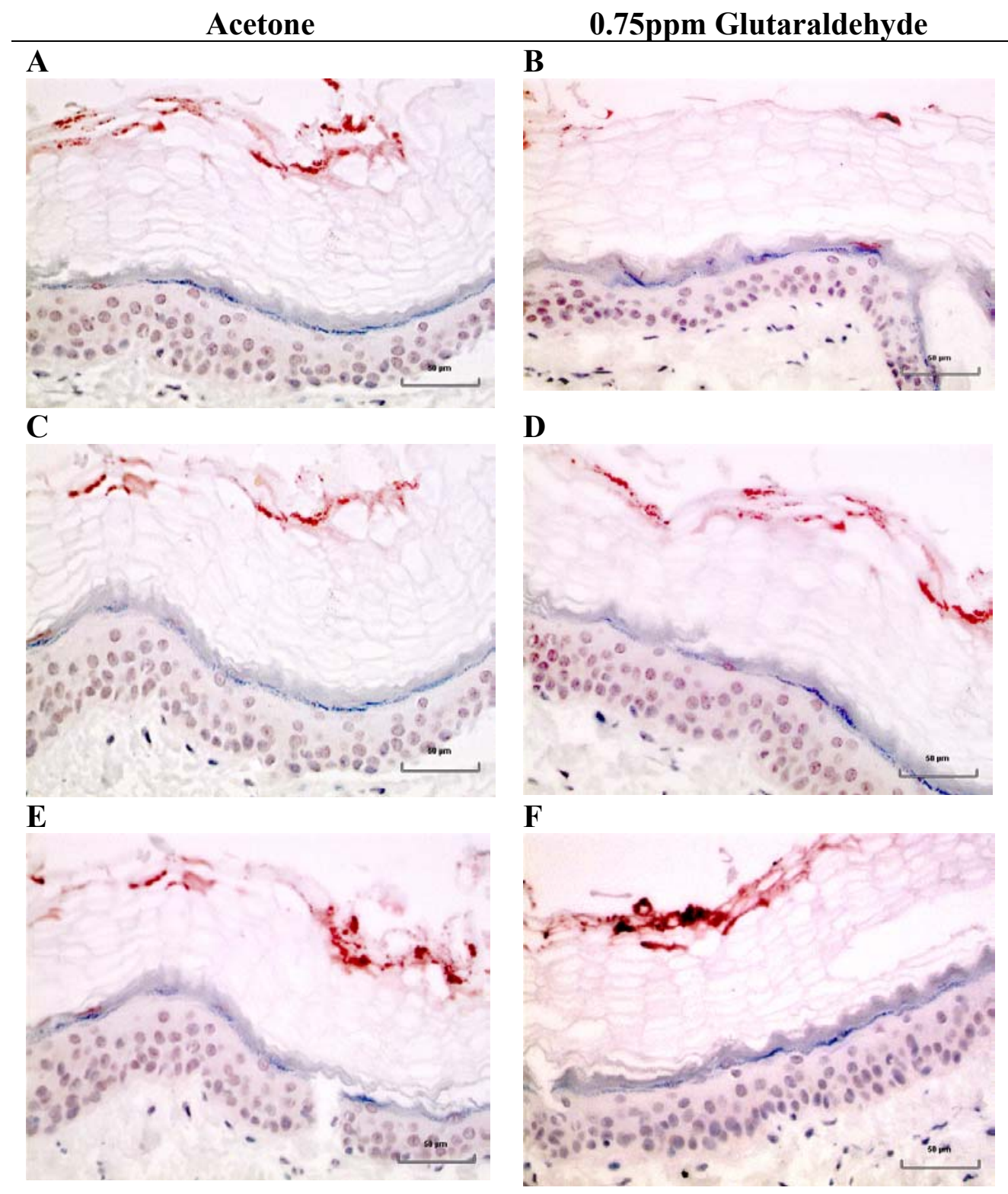

Figure 36. Latex Protein Penetration in Hairless Guinea Pig Skin Exposed to 0.75ppm Glutaraldehyde. Latex protein visualization in the skin of hairless guinea pig skin previously exposed to either acetone or $0.75 \mathrm{ppm}$ of glutaraldehyde for $0(\mathrm{~A}, \mathrm{~B}), 28(\mathrm{C}$, D), and 56 days (E, F). Excised skin was exposed to $100 \mu \mathrm{g}$ of NAL protein for 24 hours and stained using a polyclonal rabbit anti-NAL antibody to visualize the degree of protein penetration. Magnification $=40 \mathrm{x}$ and bars represent $50 \mu \mathrm{m}$. 

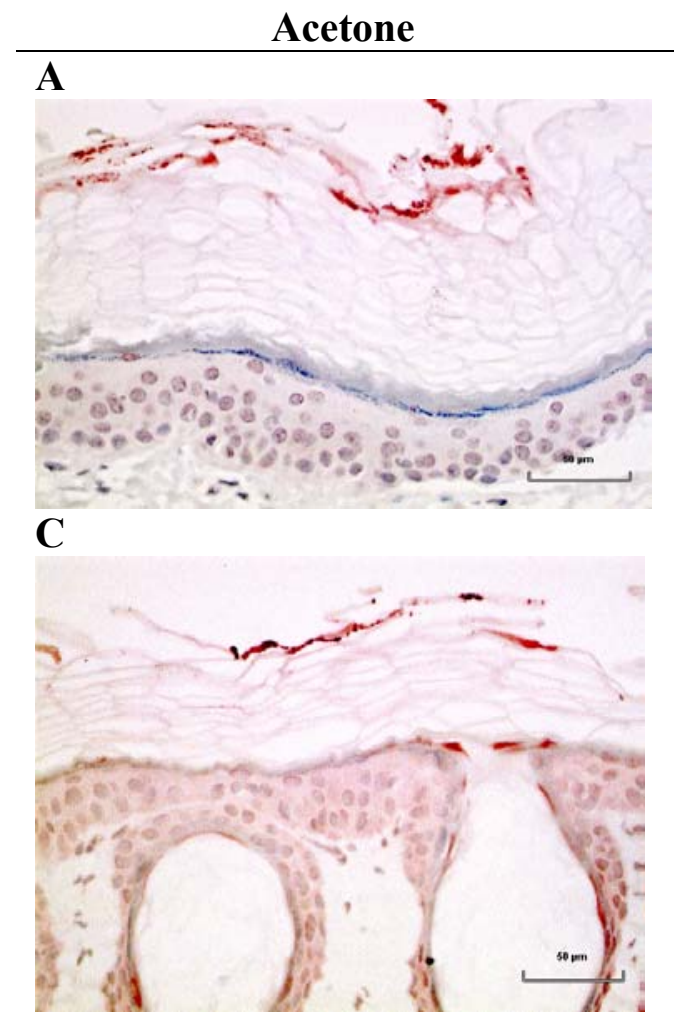

$\mathbf{E}$

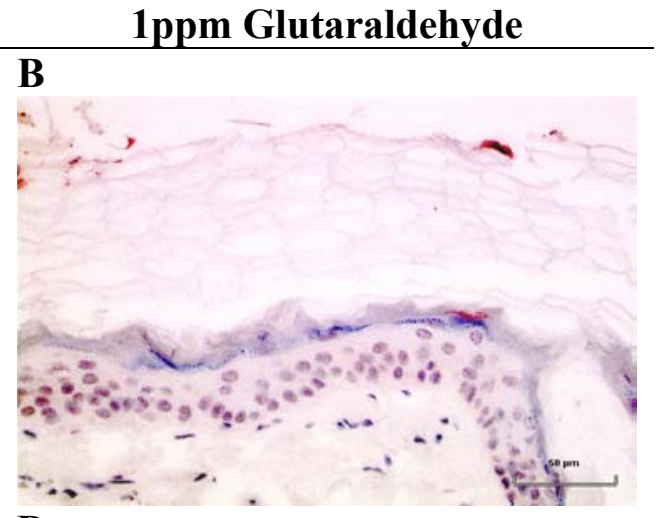

D

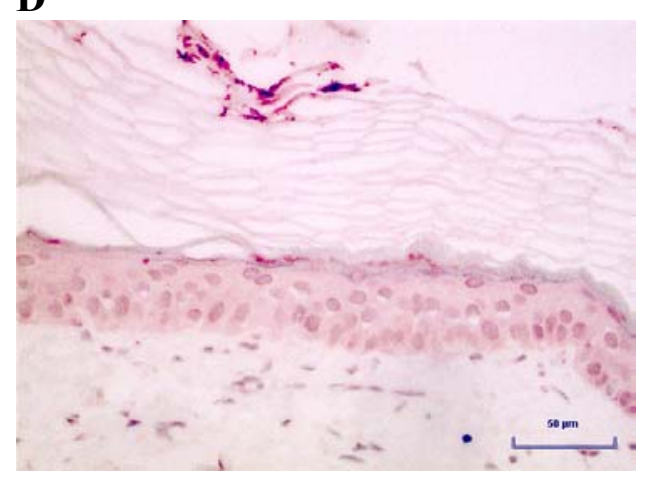

$\mathbf{F}$
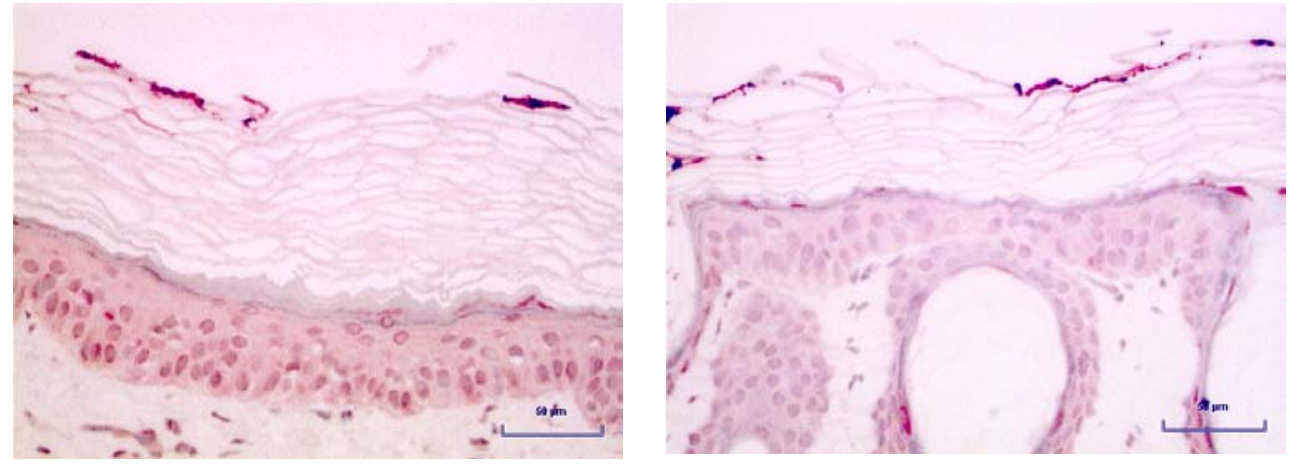

Figure 37. Latex Protein Penetration in Hairless Guinea Pig Skin Exposed to 1ppm Glutaraldehyde. Latex protein visualization in the skin of hairless guinea pig skin previously exposed to either acetone or 1ppm of glutaraldehyde for 0 (A, B), 28 (C, D), and 56 days (E, F). Excised skin was exposed to $100 \mu \mathrm{g}$ of NAL protein for 24 hours and stained using a polyclonal rabbit anti-NAL antibody to visualize the degree of protein penetration. Magnification $=40 \mathrm{x}$ and bars represent $50 \mu \mathrm{m}$. 


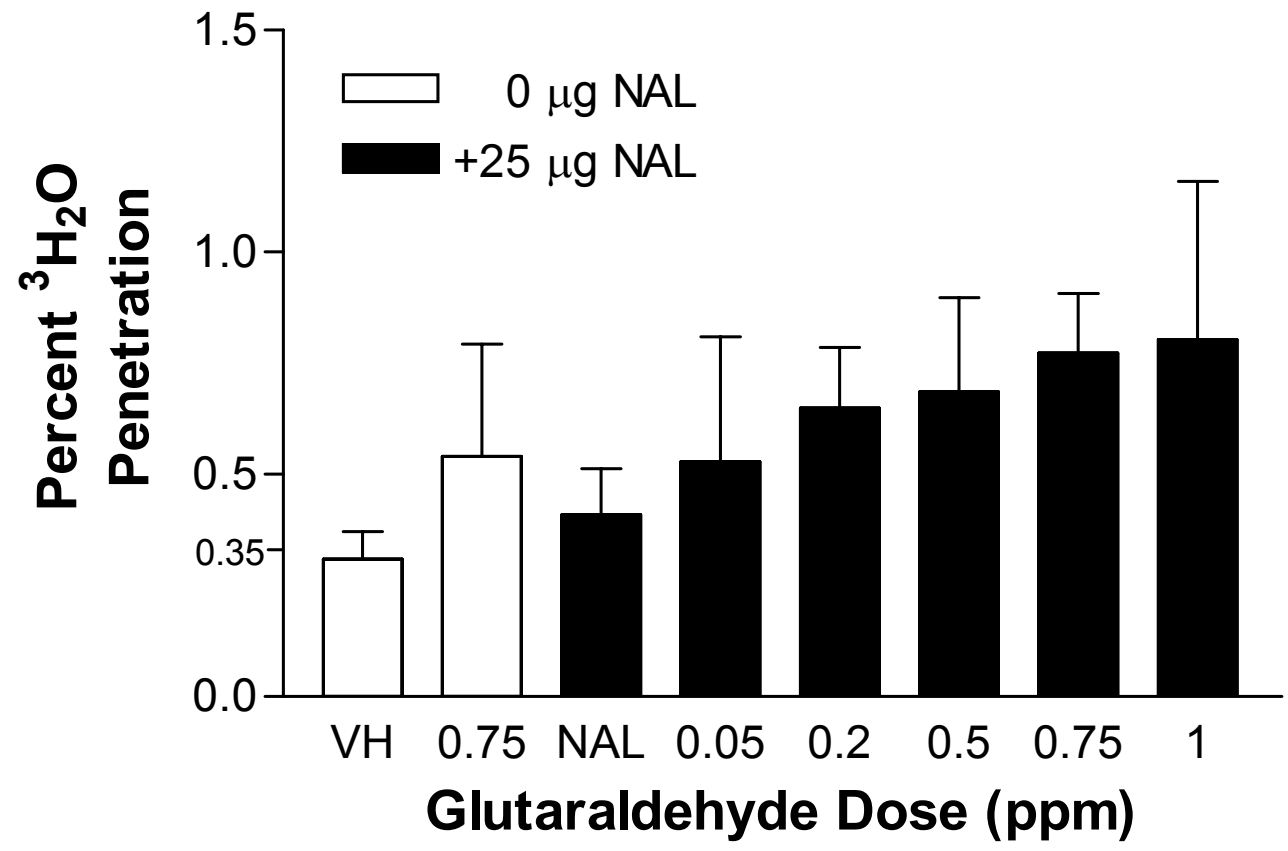

Figure 38. Barrier Integrity in Skin Previously Exposed to Latex and Increasing Concentrations of Glutaraldehyde. Skin from the dorsal thorax exposure region was excised on day 86 from mice previously exposed to NAL with increasing concentrations of glutaraldehyde and subjected to a ${ }^{3} \mathrm{H}_{2} \mathrm{O}$ barrier test. $\mathrm{n}=5$ for all exposure groups. Statistical significance and dose responsive trends were determined using a Dunnett's $t$ test and linear regression, respectively. 


\section{Investigation of the Mechanisms Leading to the Augmented IgE Response in Mice Concurrently Exposed to Latex and Glutaraldehyde}

In order to investigate the mechanism(s) underlying the serum $\operatorname{IgE}$ augmentation following concurrent exposure to NAL and glutaraldehyde, mice were exposed on the dorsal surface of the ear pinna. This site of chemical exposure allows for analysis of multiple endpoints within a given study such as: 1) evaluation of Langerhans' cell activation by the up-regulation of MHC class II expression, 2) phenotypic analysis of the

draining lymph node cells, and 3) characterization of the cytokine microenvironment within the draining lymph node. These studies evaluated the hypothesis that concurrent exposure to glutaraldehyde with NAL would augment the cellular activation by upregulating the expression of MHC class II on Langerhans cells, thereby increasing the potential for APC - T cell interaction in the draining lymph nodes, subsequent $\mathrm{T}$ and $\mathrm{B}$ cell activation through the up-regulation of CD40 and CD86 on B cells and CD28 on T cells, and IgE production through the release of IL-4 by T cells.

Mice were concurrently exposed to glutaraldehyde with latex on the dorsal surface of the ear pinna for 86 days. On day 86 , mice were sacrificed and sera collected from all animals ( $\mathrm{n}=10$ per group). Cervical lymph nodes were excised and five animals per exposure group were used for phenotypic analysis and the other five animals used for cytokine evaluation using real-time RT-PCR. 


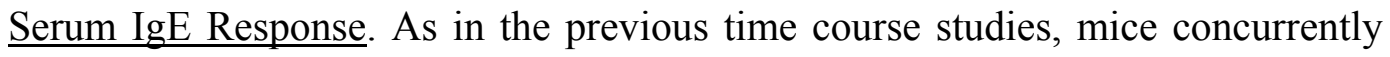
exposed to NAL and $0.75 \mathrm{ppm}$ glutaraldehyde demonstrated elevated levels of total serum IgE reaching approximately $2,000 \mathrm{ng} / \mathrm{ml}$ on day 86 as compared with $\sim 1,000 \mathrm{ng} / \mathrm{ml}$ in mice exposed to NAL alone (Figures 39A \& B). IgE levels were not significantly elevated in mice exposed to NAL alone or mice concurrently exposed to NAL and $1 \mathrm{ppm}$ glutaraldehyde. Mice concurrently exposed to NAL and $0.75 \mathrm{ppm}$ glutaraldehyde demonstrated significantly elevated $(p<0.05)$ levels of latex specific serum $\operatorname{IgE}$ on day 86 reaching greater than a 2 -fold increase over levels in mice exposed to NAL alone (Figure 39C).

Cytokine Micro-Environment in the Draining Lymph Node. Upon activation, dendritic cells, $\mathrm{B}$ cells, and $\mathrm{T}$ cells secrete cytokines that modulate the immune response. To investigate the relationship between local cytokine production and the augmented total serum IgE response, the draining cervical lymph nodes were excised and analyzed for the levels of IL-4, IL-10, IL-12 and IFN- $\gamma$ messenger RNA. No significant alterations in IL-4 message levels were observed in any of the exposure groups (Figure 40A). Concurrent exposure to NAL and either 0.75 or $1 \mathrm{ppm}$ glutaraldehyde resulted in slightly elevated mRNA levels of IL-10 (Figure 40B), IL-12 (Figure 40C), and IFN- $\gamma$ (Figure 40D) in comparison to mice exposed to NAL alone. While these levels were elevated, none of the exposure groups exhibited levels of cytokine message 2-fold greater than the vehicle and therefore are not considered biologically significant. 
Expression of Cell Surface Markers and Co-Stimulatory Molecules. Upon sacrifice, the cervical draining lymph nodes were excised and cells analyzed for the expression of co-stimulatory molecules (CD28, CTLA-4, CD86), activation markers (CD40, MHC class II), cell surface markers (CD4, CD8, B220) and IgE antibody molecules bound to FceRII/CD23 on the B cell.

Mice concurrently exposed to NAL and $0.75 \mathrm{ppm}$ glutaraldehyde demonstrated increased numbers of B220+ cells as evidenced by the increase from $3.31 \times 10^{6}$ (vehicle) to $7.67 \times 10^{6} \mathrm{~B} 220+$ cells (Table 11 ). Mice concurrently exposed to NAL and $0.75 \mathrm{ppm}$ glutaraldehyde also demonstrated an increase in cellular activation and co-stimulation in both MHC class II (Table 12) and CD40 (Table 11) expressing cells as evidenced by an approximate 2-fold increase when compared with vehicle treated mice. In correlation with serum IgE levels, the expression of CD23 and number of B cells with IgE bound to the low affinity receptor were significantly increased $(p<0.05)$ over vehicle exposed animals. Additionally, mice exposed to $0.75 \mathrm{ppm}$ glutaraldehyde alone demonstrated significant increases in the number of both $\mathrm{CD} 4+$ and $\mathrm{CD} 8+\mathrm{T}$ cells in comparison to those levels in mice exposed to the vehicle alone (Table 12). These mice also demonstrated an increase in the number of cells expressing the $\mathrm{T}$ cell co-stimulatory molecule, $\mathrm{CD} 28$, with an approximate increase in cell number 1.5-fold greater than those observed in mice exposed to vehicle (Table 12). With the exception of CD40 expressing cells, mice concurrently exposed to NAL and 1ppm exhibited levels of expression similar to those observed in mice exposed to NAL alone. The B cell co-stimulatory molecule, CD40, however, was significantly $(\mathrm{p}<0.05)$ elevated in these animals (Table 11). 

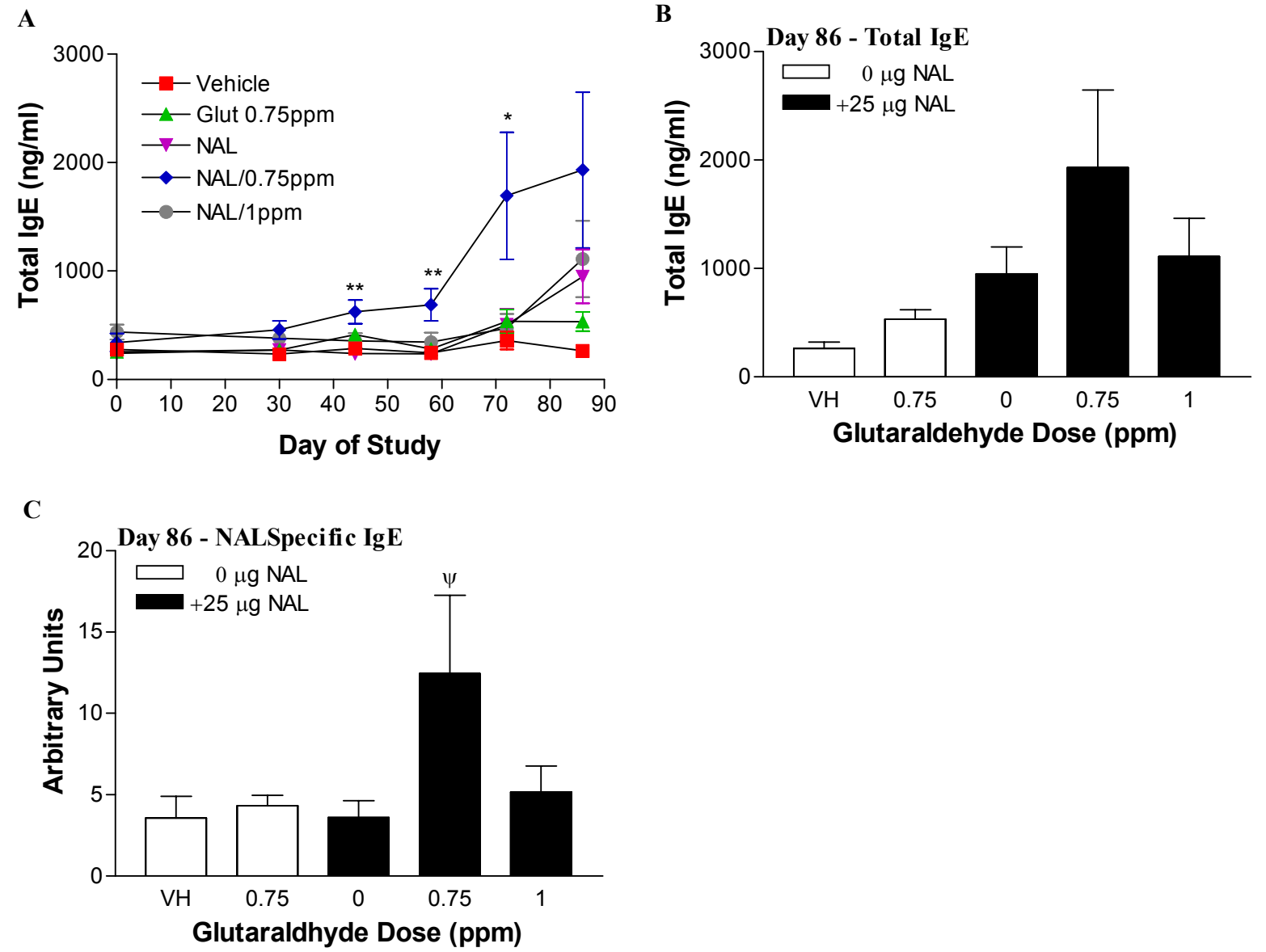

Figure 39. Total and Latex Specific Serum IgE Levels in Mice Dermally Exposed to Latex and Glutaraldehyde on the Ear Pinna. Time course of total $\operatorname{IgE}(\mathrm{A})$, day 86 total $\operatorname{IgE}(\mathrm{B})$, and day 86 latex specific $\operatorname{IgE}(\mathrm{C})$ levels were evaluated by ELISA in mice concurrently exposed to NAL and either 0.75 or $1 \mathrm{ppm}$ glutaraldehyde (Glut). Bars represent means \pm SE for each exposure group. $\mathrm{n}=10$ for all exposure groups. Statistical significance was determined using a Dunnett's $\mathrm{t}$ test. * and $* *$ represents $\mathrm{p}<0.05$ and $\mathrm{p}<0.01$, respectively, as compared to vehicle alone. $\psi$ represents $\mathrm{p}<0.05$ as compared to NAL alone. 
A

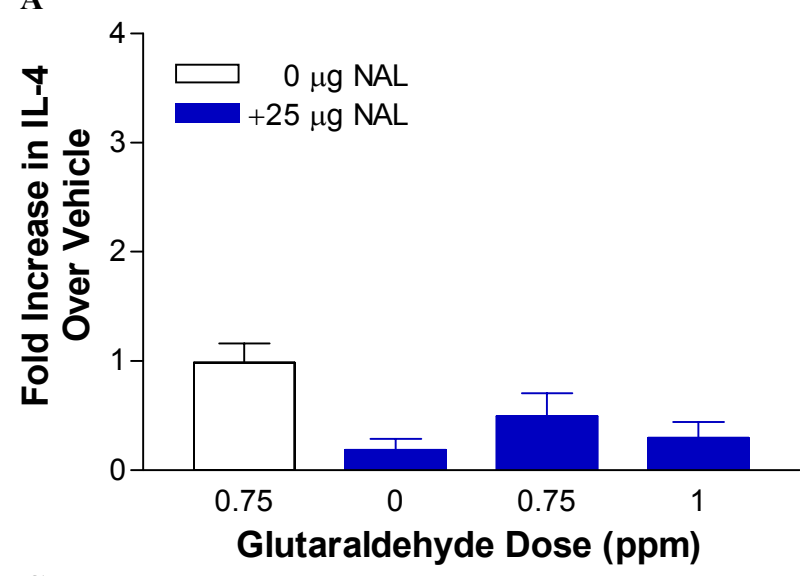

C

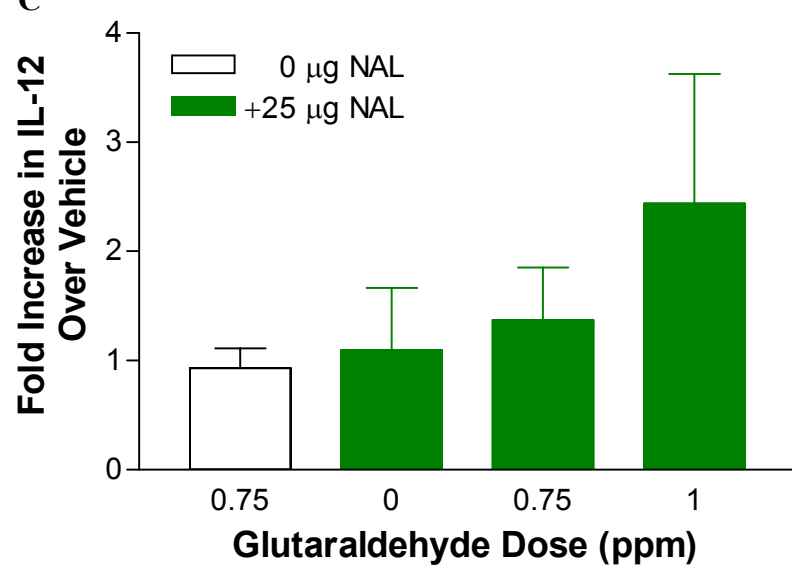

B
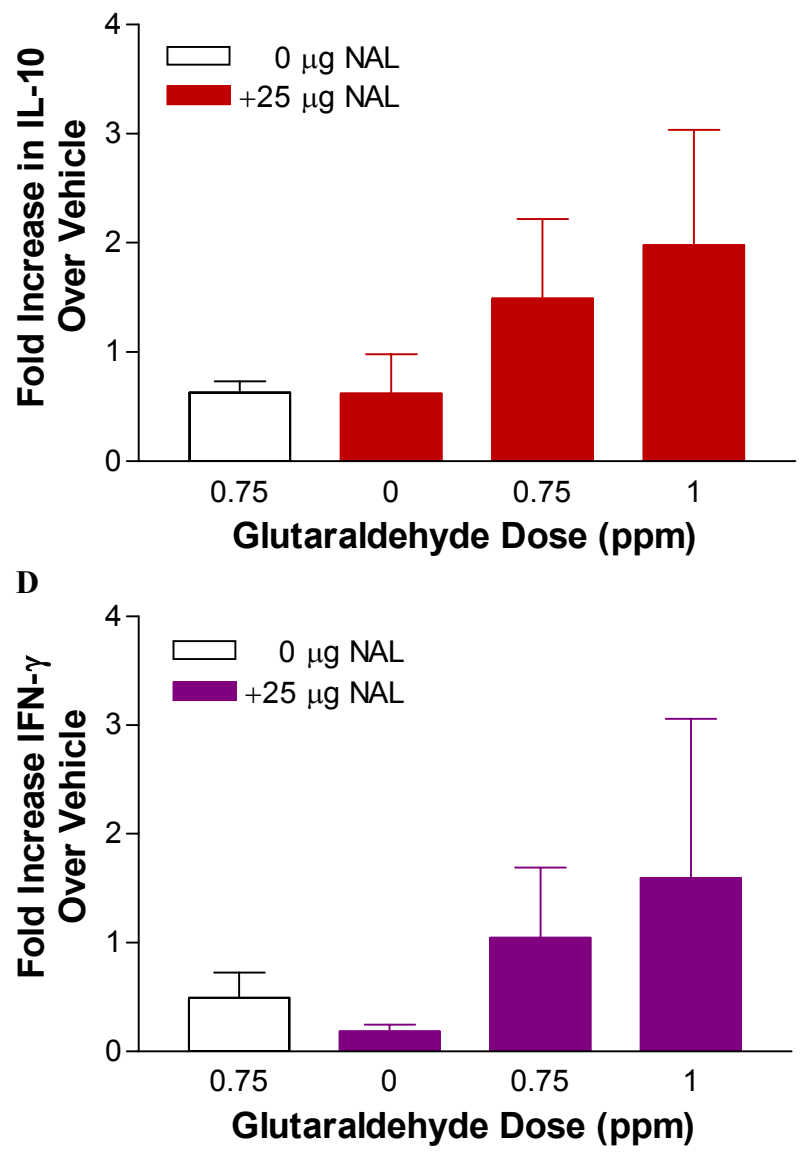

Figure 40. Cytokine Message Levels in Mice Exposed to Latex and Glutaraldehyde for 86 Days. Increases in IL-4 (A), IL-10 (B), IL-12 (C) and IFN- $\gamma$ (D) expression were determined for each exposure group by calculating the fold increase over vehicle levels as described in the methods. Bars represent means $\pm \mathrm{SE}$ for each group. $\mathrm{n}=5$ for all exposure groups. 
Table 11. Modulation of B Cell Markers Upon Concurrent Exposure to Latex and Glutaraldehyde.

\begin{tabular}{lcllll} 
Exposure Group & Cell Count & B220+ & B220+IgE+ & CD40+ & CD23+ \\
\hline & & & & & \\
Vehicle & $8.67 \pm 0.72$ & $3.31 \pm 0.18$ & $0.82 \pm 0.15$ & $2.29 \pm 0.18$ & $2.25 \pm 0.17$ \\
Glut 0.75ppm & $12.61 \pm 0.94^{*}$ & $5.02 \pm 0.71$ & $1.65 \pm 0.36$ & $3.16 \pm 0.33$ & $3.07 \pm 0.32$ \\
25 $\mu \mathrm{g}$ NAL & $9.33 \pm 0.50$ & $6.06 \pm 0.75$ & $2.50 \pm 0.45$ & $3.40 \pm 0.37$ & $3.33 \pm 0.36$ \\
Glut 0.75ppm/NAL & $11.84 \pm 1.10$ & $7.67 \pm 1.18^{* *}$ & $3.28 \pm 0.75^{* *}$ & $3.95 \pm 0.38^{* *}$ & $4.01 \pm 0.43^{*}$ \\
Glut 1ppm/NAL & $11.14 \pm 1.13$ & $5.52 \pm 0.87$ & $1.82 \pm 0.55$ & $3.56 \pm 0.37^{*}$ & $3.43 \pm 0.40$ \\
\hline
\end{tabular}

Note. Values represent mean absolute cell numbers $\left(\mathrm{x} 10^{6}\right)$ for each group $\pm \mathrm{SE} . \mathrm{n}=5$ for all exposure groups.

$*$ and $* *$ represent significant differences of $\mathrm{p}<0.05$ and $\mathrm{p}<0.01$ compared to vehicle exposed animals, as determined by Dunnett's t test

Table 12. Modulation of MHC Class II Expression and T Cell Markers Upon Concurrent Exposure to Latex and Glutaraldehyde.

\begin{tabular}{lcclll} 
Exposure Group & Cell Count & MHC Class II & CD4+ & CD8+ & CD28+ \\
\hline & & & & & \\
Vehicle & $8.67 \pm 0.72$ & $2.77 \pm 0.19$ & $3.81 \pm 0.35$ & $1.59 \pm 0.15$ & $5.29 \pm 0.46$ \\
Glut 0.75ppm & $12.61 \pm 0.94^{*}$ & $3.68 \pm 0.34$ & $5.93 \pm 0.50^{* *}$ & $2.43 \pm 0.21^{*}$ & $7.98 \pm 0.62^{* *}$ \\
25 $\mu$ g NAL & $9.33 \pm 0.50$ & $3.80 \pm 0.42$ & $3.83 \pm 0.16$ & $1.58 \pm 0.08$ & $4.98 \pm 0.23$ \\
Glut 0.75ppm/NAL & $11.84 \pm 1.10$ & $4.50 \pm 0.45^{*}$ & $5.01 \pm 0.58$ & $2.00 \pm 0.21$ & $6.30 \pm 0.85$ \\
Glut 1ppm/NAL & $11.14 \pm 1.13$ & $3.84 \pm 0.44$ & $4.72 \pm 0.44$ & $1.88 \pm 0.25$ & $5.86 \pm 0.59$ \\
\hline
\end{tabular}

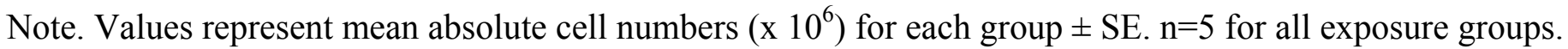

$*$ and $* *$ represent significant differences of $\mathrm{p}<0.05$ and $\mathrm{p}<0.01$ compared to vehicle exposed animals, as determined by Dunnett's t test 
Based on the results from the previous study, it was hypothesized that earlier time points were required to elucidate the cellular events responsible for the increase in total serum IgE levels in mice concurrently exposed to NAL and $0.75 \mathrm{ppm}$ glutaraldehyde. A time course study was designed to evaluate: 1) activation of antigen presenting cells as evidenced by increased MHC class II expression, 2) the expression of co-stimulatory molecules on B and T cells, and 3) level of IgE bound to CD23 on B cells. Mice were exposed on the dorsal surface of the ear pinna for $2,4,6,8,15,22$, or 29 days. Upon sacrifice, the epidermal sheets were removed for MHC class II expression on Langerhans' cells and cervical draining lymph nodes were excised and analyzed by phenotypic analysis.

Langerhans' cells uptake and process antigen for presentation to T cells via MHC class II molecules. The level of Langerhans' cell activation was subjectively evaluated by counting the number of MHC class II positive cells within a specified field of focus (40x magnification) using confocal microscopy. A significant increase $(\sim 70 \%, \mathrm{p}<0.05)$ in the number of MHC class II positive Langerhans' cells was observed on day 2 in mice exposed concurrently to NAL and $0.75 \mathrm{ppm}$ glutaraldehyde as compared to vehicle exposed animals (Figure 41). Although not statistically significant, mice exposed to NAL and 1ppm glutaraldehyde exhibited a greater than $25 \%$ increase in the number of Langerhans' cells expressing MHC class II. No significant elevations in Langerhans' cells were observed by any other exposure groups at any time point during the course of the study, however mice exposed to $0.75 \mathrm{ppm}$ glutaraldehyde with NAL exhibited higher numbers of Langerhans' cells in comparison with mice exposed to NAL alone. 


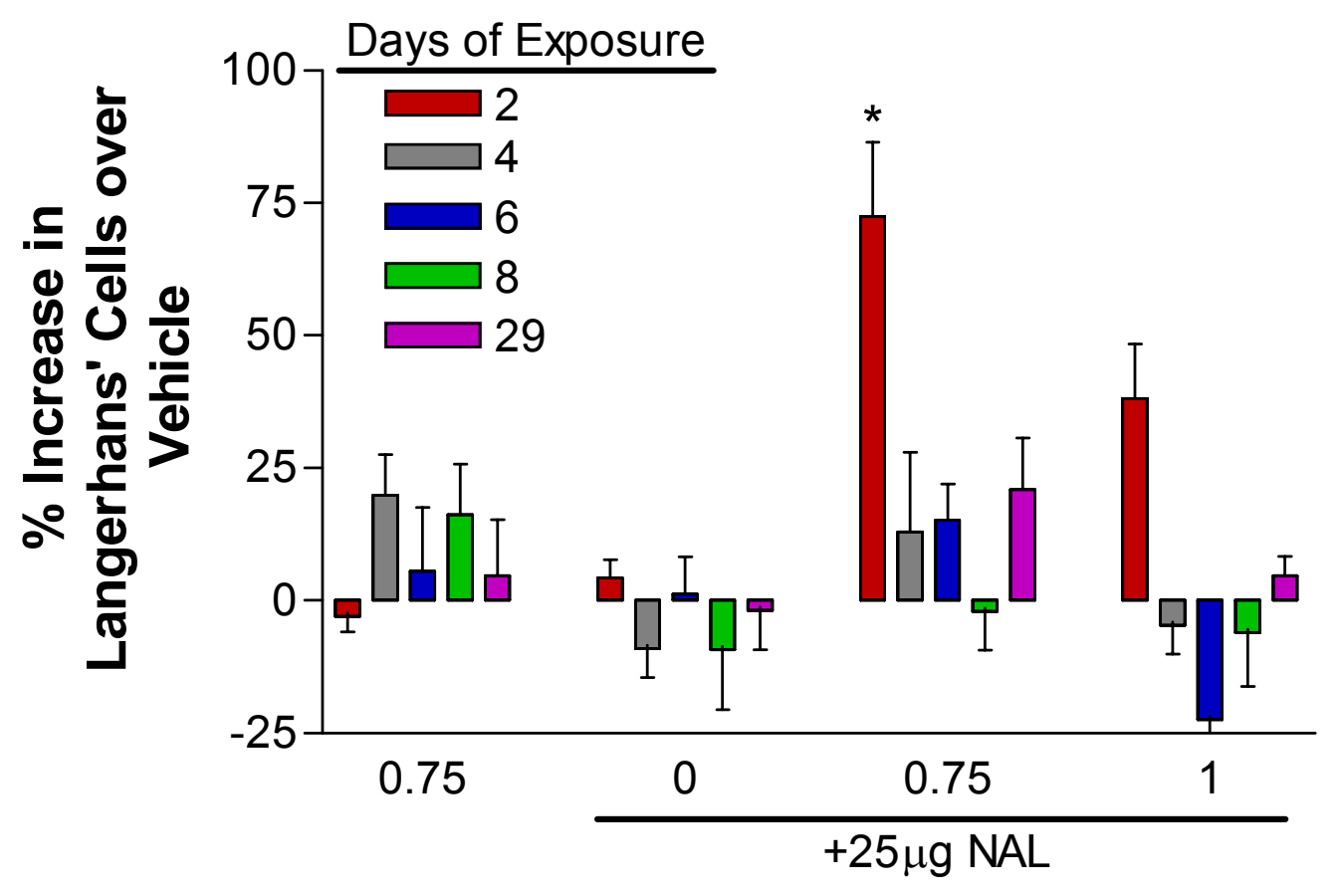

Glutaraldehyde Dose (ppm)

Figure 41. Time Course Evaluation of MHC Class II Expressing Langerhans' Cell Numbers in Mice Concurrently Exposed to Glutaraldehyde with Latex. MHC Class II expressing Langerhans' cells were evaluated by confocal microscopy in mice concurrently exposed to NAL and/or either 0.75 or 1ppm glutaraldehyde. Bars represent means \pm SE for each exposure group. $n=5$ for all exposure groups. Statistical significance was determined using a Dunnett's $\mathrm{t}$ test. * represents $\mathrm{p}<0.05$ as compared to mice exposed to NAL alone. 
Throughout the course of the study, no significant differences in the total number of draining lymph node cells were observed between any of the exposure groups (Table 13). In the previous study, mice concurrently exposed to NAL and $0.75 \mathrm{ppm}$ glutaraldehyde for 86 days demonstrated increases in the number of cells expressing B cell surface and co-stimulatory molecules while mice exposed to $0.75 \mathrm{ppm}$ glutaraldehyde alone exhibited increased numbers of cells expressing $\mathrm{T}$ cell surface markers and costimulatory molecules. At an earlier time point (day 8), mice exposed to $0.75 \mathrm{ppm}$ glutaraldehyde alone in the time course study demonstrated an almost a 2-fold increase in the number of B cells on day 8 when compared to mice exposed to NAL alone (Table 14), however this observation failed to repeat in a subsequent experiment (data not shown). No other elevations in the number of B220+ expressing cells were observed in exposure groups throughout the time course study. The number of cells expressing IgE bound to the low affinity receptor on B cells did not significantly differ between exposure groups at any time point up to 29 days post initial exposure (Table 15). CD86 is a costimulatory molecule expressed on B cells and up-regulated during the activation process. On day 22 , mice exposed to $0.75 \mathrm{ppm}$ glutaraldehyde alone exhibited more than a 6 -fold increase in the number of B cells expressing CD86 as compared to those observed in mice exposed to NAL alone (Table 16). In a subsequent study, this observation failed to repeat (data not shown). Although B cells and CD86 molecules have been shown to be elevated at times during the course of the study, expression of the co-stimulatory molecule CD40 on B cells did not significantly differ between exposure groups (Table 17). Additionally, there were no statistically significant differences between the numbers of CD4+ T cells in mice concurrently exposed to NAL and glutaraldehyde (Table 18). 
Whereas the number of cells expressing the co-stimulatory molecule CD86 was shown to increase in mice exposed to $0.75 \mathrm{ppm}$ glutaraldehyde, there was no observed increase in the number of $\mathrm{T}$ cells expressing the complementary molecule (CD28) in any exposure group during the course of the study (Table 19). Based on the observed increase in MHC class II expression in mice following exposure for 86 days; it was initially hypothesized that the number of antigen presenting cells would be elevated in mice exposed to NAL and $0.75 \mathrm{ppm}$ glutaraldehyde. However, exposure groups did not exhibit statistically significant differences in the number of MHC class II expressing antigen presenting cells in the DLN at any point during the time course (Table 20). 
Table 13. Time Course of DLN Cell Counts in Mice Concurrently Exposed to Latex and Glutaraldehyde.

Cell Counts

Exposure Group

Vehicle

Glut $0.75 \mathrm{ppm}$

$25 \mu \mathrm{g}$ NAL

Glut $0.75 \mathrm{ppm} / \mathrm{NAL}$

Glut 1ppm/NAL

\section{2}

$\begin{array}{rrr}9.44 \pm 1.37 & 8.80 \pm 0.96 & 14.69 \pm 1.61 \\ 10.19 \pm 1.02 & 9.35 \pm 0.39 & 11.71 \pm 1.87 \\ 8.49 \pm 0.68 & 9.09 \pm 0.69 & 10.76 \pm 1.19 \\ 11.20 \pm 1.26 & 10.11 \pm 1.40 & 11.13 \pm 0.48 \\ 8.65 \pm 0.52 & 8.94 \pm 1.51 & 10.27 \pm 1.75\end{array}$

Day of Sacrifice

8

15

22 29

$\begin{array}{rrrr}8.68 \pm 0.70 & 8.63 \pm 1.40 & 10.69 \pm 0.24 & 9.25 \pm 0.56 \\ 12.73 \pm 1.23 & 9.34 \pm 0.27 & 9.79 \pm 0.95 & 12.78 \pm 1.41 \\ 9.04 \pm 0.83 & 10.33 \pm 1.01 & 10.96 \pm 0.96 & 9.48 \pm 1.18 \\ 11.84 \pm 1.10 & 8.87 \pm 1.07 & 9.07 \pm 0.79 & 10.60 \pm 1.10 \\ 11.15 \pm 1.15 & 9.15 \pm 1.23 & 10.09 \pm 1.53 & 9.84 \pm 0.54\end{array}$

Note. Values represent mean absolute cell numbers $\left(\mathrm{x} 10^{6}\right)$ for each group $\pm \mathrm{SE} . \mathrm{n}=5$ for all exposure groups.

Table 14. Time Course of B220 Expression in DLN Cells of Mice Following Concurrent Exposure to Latex and Glutaraldehyde

\begin{tabular}{lccccccc} 
B220 & \multicolumn{7}{c}{ Day of Sacrifice } \\
Exposure Group & $\mathbf{2}$ & $\mathbf{4}$ & $\mathbf{6}$ & $\mathbf{8}$ & $\mathbf{1 5}$ & $\mathbf{2 2}$ & $\mathbf{2 9}$ \\
\hline & & & & & & & \\
Vehicle & $0.98 \pm 0.18$ & $0.94 \pm 0.13$ & $1.70 \pm 0.08$ & $1.99 \pm 0.23$ & $1.99 \pm 0.32$ & $1.07 \pm 0.06$ & $0.91 \pm 0.16$ \\
Glut 0.75ppm & $1.24 \pm 0.20$ & $0.82 \pm 0.14$ & $1.35 \pm 0.28$ & $3.29 \pm 0.43^{*}$ & $2.29 \pm 0.08$ & $2.02 \pm 0.32$ & $1.29 \pm 0.18$ \\
25 $\mu$ g NAL & $0.92 \pm 0.12$ & $0.92 \pm 0.10$ & $0.96 \pm 0.14$ & $1.87 \pm 0.24$ & $2.70 \pm 0.32$ & $1.36 \pm 0.16$ & $0.89 \pm 0.14$ \\
Glut 0.75ppm/NAL & $1.25 \pm 0.20$ & $1.12 \pm 0.25$ & $1.13 \pm 0.10$ & $2.67 \pm 0.37$ & $2.22 \pm 0.36$ & $1.35 \pm 0.17$ & $1.00 \pm 0.18$ \\
Glut 1ppm/NAL & $0.88 \pm 0.14$ & $1.12 \pm 0.25$ & $1.09 \pm 0.29$ & $2.14 \pm 0.40$ & $2.26 \pm 0.29$ & $1.30 \pm 0.19$ & $0.79 \pm 0.15$ \\
\hline
\end{tabular}

Note. Values represent mean absolute cell numbers $\left(\mathrm{x} 10^{6}\right)$ for each group $\pm \mathrm{SE} . \mathrm{n}=5$ for all exposure groups.

Statistical significance was determined using a Dunnett's t test. * represents $\mathrm{p}<0.05$ when compared to mice exposed to NAL alone. 
Table 15. Time Course of IgE Expression on B Cells in the DLN of Mice Concurrently Exposed to Latex and Glutaraldehyde

B220+IgE+

Exposure Group

$2 \quad 4 \quad$ Day of Sacrifice

8

15

22

29

\begin{tabular}{llllllll} 
Vehicle & $0.11 \pm 0.06$ & $0.05 \pm 0.02$ & $0.30 \pm 0.09$ & $0.30 \pm 0.14$ & $0.49 \pm 0.11$ & $0.05 \pm 0.02$ & $0.02 \pm 0.02$ \\
Glut 0.75ppm & $0.17 \pm 0.10$ & $0.08 \pm 0.03$ & $0.09 \pm 0.05$ & $0.32 \pm 0.09$ & $0.37 \pm 0.09$ & $0.23 \pm 0.10$ & $0.10 \pm 0.04$ \\
25 $\mu$ g NAL & $0.05 \pm 0.02$ & $0.06 \pm 0.02$ & $0.14 \pm 0.06$ & $0.18 \pm 0.05$ & $0.45 \pm 0.17$ & $0.13 \pm 0.03$ & $0.03 \pm 0.01$ \\
Glut 0.75ppm/NAL & $0.16 \pm 0.08$ & $0.13 \pm 0.05$ & $0.28 \pm 0.05$ & $0.20 \pm 0.08$ & $0.41 \pm 0.11$ & $0.18 \pm 0.05$ & $0.02 \pm 0.01$ \\
Glut 1ppm/NAL & $0.10 \pm 0.04$ & $0.21 \pm 0.06$ & $0.08 \pm 0.03$ & $0.27 \pm 0.08$ & $0.47 \pm 0.10$ & $0.04 \pm 0.01$ & $0.05 \pm 0.02$ \\
\hline
\end{tabular}

Note. Values represent mean absolute cell numbers $\left(\mathrm{x}_{10}{ }^{6}\right)$ for each group $\pm \mathrm{SE} . \mathrm{n}=5$ for all exposure groups.

Table 16. Time Course of CD86 Expression on B Cells in Mice Concurrently Exposed to Latex and Glutaraldehyde

\begin{tabular}{lccccccc} 
B220+CD86+ & \multicolumn{9}{c}{ Day of Sacrifice } \\
Exposure Group & $\mathbf{2}$ & $\mathbf{4}$ & $\mathbf{6}$ & $\mathbf{8}$ & $\mathbf{1 5}$ & $\mathbf{2 2}$ & $\mathbf{2 9}$ \\
\hline & & & & & & \\
Vehicle & N.D. ${ }^{\psi}$ & $0.02 \pm 0.01$ & $0.04 \pm 0.01$ & $0.09 \pm 0.02$ & $0.07 \pm 0.01$ & $0.03 \pm 0.01$ & $0.00 \pm 0.01$ \\
Glut 0.75ppm & $0.00 \pm 0.01$ & $0.02 \pm 0.01$ & $0.01 \pm 0.01$ & $0.13 \pm 0.03$ & $0.10 \pm 0.01$ & $0.16 \pm 0.05^{* *}$ & $0.01 \pm 0.02$ \\
25 $\mu$ g NAL & N.D. ${ }^{\psi}$ & $0.01 \pm 0.01$ & $0.02 \pm 0.01$ & $0.09 \pm 0.01$ & $0.10 \pm 0.02$ & $0.02 \pm 0.01$ & $0.02 \pm 0.01$ \\
Glut 0.75ppm/NAL & $0.00 \pm 0.01$ & $0.03 \pm 0.02$ & $0.02 \pm 0.01$ & $0.13 \pm 0.03$ & $0.08 \pm 0.01$ & $0.03 \pm 0.01$ & $0.01 \pm 0.01$ \\
Glut 1ppm/NAL & N.D. ${ }^{\psi}$ & $0.02 \pm 0.01$ & $0.01 \pm 0.01$ & $0.08 \pm 0.02$ & $0.09 \pm 0.02$ & $0.02 \pm 0.00$ & $0.01 \pm 0.01$ \\
\hline
\end{tabular}

Note. Values represent mean absolute cell numbers $\left(\mathrm{x} 10^{6}\right)$ for each group $\pm \mathrm{SE} . \mathrm{n}=5$ for all exposure groups.

${ }^{\psi}$ represents that levels of cells were non-detectable

Statistical significance was determined using a Dunnett's t test. ** represents $\mathrm{p}<0.01$ when

compared to mice exposed to NAL alone. 
Table 17. Time Course of CD40 Expressing B Cells in the DLN of Mice Concurrently Exposed to Latex and Glutaraldehyde

\begin{tabular}{lccccccc}
$\begin{array}{l}\text { B220 }+ \text { CD40+ } \\
\text { Exposure Group }\end{array}$ & $\mathbf{2}$ & $\mathbf{4}$ & $\mathbf{6}$ & $\mathbf{8}$ & $\mathbf{1 5}$ & $\mathbf{2 2}$ & $\mathbf{2 9}$ \\
\hline & & & & & & & \\
Vehicle & $0.85 \pm 0.16$ & $0.79 \pm 0.16$ & $1.23 \pm 0.08$ & $1.46 \pm 0.17$ & $1.89 \pm 0.30$ & $0.78 \pm 0.07$ & $0.64 \pm 0.08$ \\
Glut 0.75ppm & $1.03 \pm 0.16$ & $0.59 \pm 0.11$ & $1.05 \pm 0.19$ & $2.49 \pm 0.38$ & $1.99 \pm 0.05$ & $1.32 \pm 0.17$ & $1.19 \pm 0.25$ \\
25 $\mu$ g NAL & $0.81 \pm 0.15$ & $0.67 \pm 0.08$ & $0.94 \pm 0.16$ & $1.67 \pm 0.31$ & $2.46 \pm 0.30$ & $0.98 \pm 0.12$ & $0.68 \pm 0.12$ \\
Glut 0.75ppm/NAL & $0.93 \pm 0.21$ & $0.95 \pm 0.19$ & $0.89 \pm 0.08$ & $2.55 \pm 0.41$ & $2.02 \pm 0.32$ & $1.01 \pm 0.15$ & $0.82 \pm 0.14$ \\
Glut 1ppm/NAL & $0.83 \pm 0.16$ & $0.84 \pm 0.16$ & $0.90 \pm 0.24$ & $1.58 \pm 0.42$ & $2.06 \pm 0.26$ & $0.95 \pm 0.12$ & $0.67 \pm 0.12$ \\
\hline
\end{tabular}

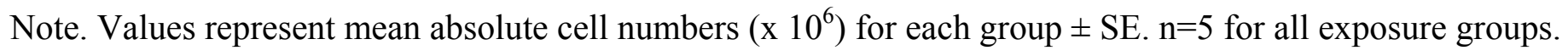

Table 18. Time Course of CD4+ T Cells in the DLN of Mice Concurrently Exposed to Latex and Glutaraldehyde.

\begin{tabular}{lccccccc} 
CD4+ \\
Exposure Group & $\mathbf{2}$ & $\mathbf{4}$ & $\mathbf{6}$ & $\mathbf{8}$ & $\mathbf{1 5}$ & $\mathbf{2 2}$ & $\mathbf{2 9}$ \\
\hline & & & & & & \\
Vehicle & $4.58 \pm 0.74$ & $4.72 \pm 0.48$ & $7.08 \pm 0.62$ & $4.64 \pm 0.42$ & $4.39 \pm 0.74$ & $5.26 \pm 0.36$ & $3.91 \pm 0.05$ \\
Glut 0.75ppm & $5.09 \pm 0.48$ & $4.22 \pm 0.71$ & $5.85 \pm 1.01$ & $6.65 \pm 0.64$ & $4.68 \pm 0.23$ & $4.77 \pm 0.64$ & $5.98 \pm 0.72$ \\
25 $\mu$ g NAL & $4.27 \pm 0.35$ & $5.14 \pm 0.40$ & $5.60 \pm 0.55$ & $4.57 \pm 0.40$ & $5.18 \pm 0.60$ & $5.29 \pm 0.57$ & $5.00 \pm 0.63$ \\
Glut 0.75ppm/NAL & $5.86 \pm 0.59$ & $5.16 \pm 0.68$ & $5.38 \pm 0.35$ & $5.99 \pm 0.68$ & $4.30 \pm 0.47$ & $4.43 \pm 0.37$ & $5.08 \pm 0.62$ \\
Glut 1ppm/NAL & $4.31 \pm 0.20$ & $4.51 \pm 0.75$ & $4.92 \pm 0.57$ & $5.22 \pm 0.91$ & $4.47 \pm 0.54$ & $5.16 \pm 0.81$ & $4.56 \pm 0.18$ \\
\hline
\end{tabular}

Note. Values represent mean absolute cell numbers $\left(\mathrm{x} 10^{6}\right)$ for each group $\pm \mathrm{SE} . \mathrm{n}=5$ for all exposure groups. 
Table 19. Time Course of CD28+ Expressing CD4+ T Cells in Mice Concurrently Exposed to Latex and Glutaraldehyde

\begin{tabular}{lccccccc}
$\begin{array}{l}\text { CD4+CD28+ } \\
\text { Exposure Group }\end{array}$ & $\mathbf{2}$ & $\mathbf{4}$ & $\mathbf{6}$ & $\mathbf{8}$ & $\mathbf{1 5}$ & $\mathbf{2 2}$ & $\mathbf{2 9}$ \\
\hline & & & & & & \\
Vehicle & $4.34 \pm 0.42$ & $4.20 \pm 0.44$ & $6.45 \pm 0.59$ & $4.34 \pm 0.42$ & $4.26 \pm 0.72$ & $4.95 \pm 0.42$ & $3.75 \pm 0.49$ \\
Glut 0.75ppm & $6.23 \pm 0.55$ & $3.85 \pm 0.68$ & $5.22 \pm 0.88$ & $6.23 \pm 0.55$ & $4.57 \pm 0.24$ & $4.72 \pm 0.52$ & $5.78 \pm 0.71$ \\
25 $\mu$ g NAL & $4.36 \pm 0.37$ & $4.56 \pm 0.34$ & $5.04 \pm 0.53$ & $4.36 \pm 0.37$ & $4.99 \pm 0.59$ & $4.97 \pm 0.49$ & $4.77 \pm 0.53$ \\
Glut 0.75ppm/NAL & $5.68 \pm 0.64$ & $4.70 \pm 0.62$ & $4.87 \pm 0.32$ & $5.68 \pm 0.64$ & $4.21 \pm 0.45$ & $4.25 \pm 0.39$ & $4.76 \pm 0.63$ \\
Glut 1ppm/NAL & $4.97 \pm 0.86$ & $4.08 \pm 0.72$ & $4.55 \pm 0.59$ & $4.97 \pm 0.86$ & $4.39 \pm 0.53$ & $5.05 \pm 0.83$ & $4.31 \pm 0.15$ \\
\hline
\end{tabular}

Note. Values represent mean absolute cell numbers $\left(\mathrm{x} 10^{6}\right)$ for each group $\pm \mathrm{SE} . \mathrm{n}=5$ for all exposure groups.

Table 20. Time Course of DLN Cells Expressing MHC Class II in Mice Concurrently Exposed to Latex and Glutaraldehyde.

\begin{tabular}{lccccccc}
$\begin{array}{l}\text { MHC Class II+ } \\
\text { Exposure Group }\end{array}$ & $\mathbf{2}$ & $\mathbf{4}$ & $\mathbf{6}$ & $\mathbf{8}$ & $\mathbf{1 5}$ & $\mathbf{2 2}$ & $\mathbf{2 9}$ \\
\hline & & & & & & \\
Vehicle & $1.99 \pm 0.30$ & $1.63 \pm 0.23$ & $2.64 \pm 0.20$ & $1.44 \pm 0.11$ & $2.12 \pm 0.38$ & $1.31 \pm 0.08$ & $1.53 \pm 0.19$ \\
Glut 0.75ppm & $2.59 \pm 0.39$ & $1.47 \pm 0.24$ & $2.44 \pm 0.43$ & $2.39 \pm 0.28$ & $2.25 \pm 0.05$ & $1.83 \pm 0.18$ & $2.62 \pm 0.30$ \\
25 $\mu$ g NAL & $1.86 \pm 0.19$ & $1.64 \pm 0.22$ & $1.98 \pm 0.25$ & $1.60 \pm 0.15$ & $2.83 \pm 0.34$ & $1.74 \pm 0.21$ & $1.72 \pm 0.25$ \\
Glut 0.75ppm/NAL & $2.49 \pm 0.32$ & $2.05 \pm 0.41$ & $2.14 \pm 0.12$ & $1.94 \pm 0.20$ & $2.17 \pm 0.30$ & $1.80 \pm 0.19$ & $2.13 \pm 0.31$ \\
Glut 1ppm/NAL & $1.97 \pm 0.21$ & $1.94 \pm 0.36$ & $2.17 \pm 0.56$ & $1.29 \pm 0.26$ & $2.19 \pm 0.27$ & $1.91 \pm 0.29$ & $1.71 \pm 0.29$ \\
\hline
\end{tabular}

Note. Values represent mean absolute cell numbers $\left(\mathrm{x} 10^{6}\right)$ for each group $\pm \mathrm{SE} . \mathrm{n}=5$ for all exposure groups. 


\section{DISCUSSION}

In the health care environment there are many factors which affect the development of an IgE mediated hypersensitivity response to latex proteins including the length of exposure, route of exposure, and other chemicals or contaminants encountered within the health care environment that may modulate the immune response. Understanding the role of these factors in the development of adverse reactions to latex proteins will allow the development of more effective intervention strategies.

Due to ethical limitations and regulations on conducting research with human subjects, numerous animal models have been used to investigate the development of $\operatorname{IgE}$ mediated hypersensitivity. The murine model has been extensively used in the evaluation of IgE mediated hypersensitivity responses following both chemical (Dearman et al., 1996; Dearman et al., 1998) and allergen exposure (Spergel et al., 1998; Thakker et al., 1999; Woolhiser et al., 2000; Nelde et al., 2001). Current studies utilized the BALB/c strain of mouse due to its predominant Th2 phenotype and high IgE production following allergen exposure (Hilton et al., 1994; Kurup et al., 1994; Saloga et al., 1994; Robinson et al., 1996). Studies using the BALB/c strain to understand the development of latex allergy have demonstrated increased latex specific $\operatorname{IgE}$, non-specific and latex specific airway hyper-reactivity, eosinophilia in the lungs, and cellular infiltration in the lung upon exposure to latex proteins (Kurup et al., 1994; Thakker et al., 1999; Woolhiser et al., 2000). 
While studies have demonstrated the development of a latex specific IgE response following intranasal (Kurup et al., 1994; Thakker et al., 1999), dermal, intratracheal, and subcutaneous (Woolhiser et al., 2000) exposures; the use of different exposure routes and dosing regimens has not allowed for comparison of the timing or intensity of the response between the exposure routes. The present studies were designed to address this issue by comparing the rates of induction following dermal, intranasal, intratracheal, or subcutaneous exposure to latex proteins using a uniform dosing regimen. Current studies demonstrated that exposure to latex proteins via intratracheal aspiration or dermal application induces similar levels of latex specific IgE. In a recent study evaluating the induction of IgE mediated hypersensitivity to low molecular weight chemicals, Warbrick et al. (Warbrick et al., 2002) demonstrated similar trimellitic anhydride specific IgE following either inhalation or dermal exposure. While intratracheal and dermal exposure resulted in similar levels of latex specific IgE in our studies, mice subcutaneously exposed to latex proteins demonstrated higher elevations in total and latex specific IgE at an earlier time point in the study as compared to mice dermally or intratracheally exposed. In contrast, mice intranasally exposed to latex proteins failed to demonstrate significantly increased levels of $\operatorname{IgE}$ when compared to the other exposure routes.

These studies demonstrate the importance of bioavailability in the induction of the response as the level of total serum $\operatorname{IgE}$ and the timing required for induction correlate with the bioavailability by each route of exposure. It is presumed that $100 \%$ of an applied dose is bio-available following subcutaneous administration and therefore may explain the higher levels and shorter time frame of development in subcutaneously 
sensitized mice. In contrast, it has been shown that bioavailability following dermal exposure is largely dependent on the condition of the skin. Recent studies using hairless guinea pigs have demonstrated that approximately $30-50 \%$ of the applied dose of latex proteins penetrates into or through the skin following dermal application to disrupted skin (Hayes et al., 2000; Howell et al., 2002a). Following intratracheal aspiration it has been shown that greater than $75 \%$ of the applied intratracheal dose reaches the lungs and is therefore available for induction of an immune response (Ann Hubbs, personal communication). Using an Evan's blue solution, it was demonstrated that a large portion of the intranasally applied dosing solution reaches the stomach resulting in less of a respiratory tract exposure. In addition to less respiratory exposure, studies have demonstrated the potential for latex desensitization following oral administration of latex proteins, which may explain the lower levels of IgE in intranasally exposed animals (Toci et al., 2002). In addition to bio-availability, differences in the antigen presenting cells Langerhans' cells in the skin, dendritic cells and macrophages in the lung - and the cytokine microenvironment at the site of administration may contribute to differences in the degree of the $\operatorname{IgE}$ response following different routes of exposure (Knop and Enk, 1995).

The route of exposure was determined to not only influence the intensity of the IgE response, but also influence the class of antibody produced. Latex specific IgE was induced following all routes of exposure. Whereas no significant elevations were observed in the levels of $\operatorname{IgG} 2 \mathrm{a}$ or $\operatorname{IgA}$ in mice dermally exposed to latex proteins; respiratory tract exposure via the intranasal or intratracheal routes resulted in increased 
levels of serum IgG2a and IgA. While the induction of IgG2a is not associated with any one particular site of exposure, IgA is the major immunoglobulin molecule produced at mucosal sites. IgA antibodies may potentially bind antigen at the mucosal surface and thereby inhibit further development of an IgE mediated hypersensitivity response (Frazer and Capra, 1999). In the current studies, mice intranasally exposed to latex exhibited significant increases in the levels of latex specific IgA which may contribute to the lower IgE response observed in comparison to mice exposed via the dermal and intratracheal routes.

Airway hyper-reactivity is a hallmark of an IgE mediated pulmonary response and therefore, both invasive and non-invasive methods have been developed to evaluate airway hyper-reactivity in sensitized mice following non-specific (cholinergic) and antigen specific challenges. Invasive measurements of airway hyper-reactivity require the intratracheal cannulation of mice to measure pulmonary changes. Upon cannulation, a tube is inserted in to the esophagus and connected to a transducer to measure pleural pressure. This setup allows for the measurement of the pressure and volume for each breath. These measurements are then used to calculate the compliance, resistance, respiration frequency, and tidal volume (Drazen et al., 1999; Thakker et al., 1999). While effective in evaluating airway hyper-reactivity; the invasive measurement of pulmonary function by intratracheal cannulation is limited by the need for anesthesia and the necessity of sacrificing the animals upon completion of the measurements. This terminal act prevents the evaluation of airway hyper-reactivity over a time course and does not allow for the evaluation of both non-specific and specific airway hyper- 
reactivity in the same animals. Whole body plethysmography has the advantage of being non-invasive and therefore allowing for repeated evaluation of airway hyper-reactivity in exposed animals. Whole body plethysmograph chambers consist of an upper, reference chamber and a lower, animal chamber. During inspiration, air is warmed as it enters the trachea and lungs; heated air expands and the resulting increase in pressure due to volume expansion is reflected in a pressure change within the chamber. Each breath results in a change in pressure in the animal chamber as compared to the reference chamber and is detected via a transducer. The frequency, magnitude and timing of pressure changes are measured and used to determine such parameters as breathing frequency, tidal volume, peak expiratory flow, peak inspiratory flow, relaxation time, flow rates or relaxation times. Using these parameters, enhanced pause $(\mathrm{PenH})$ is calculated as an indicator of bronchoconstriction (Hamelmann et al., 1997; Drazen et al., 1999).

These studies used whole body plethysmography to measure both non-specific and specific airway hyper-reactivity in mice exposed to latex proteins by different routes. Mice dermally exposed to latex proteins in current studies demonstrated an increase in both non-specific and antigen specific airway hyper-reactivity upon respiratory challenge with methacholine and latex proteins, respectively. While similar elevations in latex specific airway hyper-reactivity have been previously observed (Woolhiser et al., 2000), this is the first reported observation of increased non-specific airway hyper-reactivity following dermal sensitization to latex proteins. 
Mice intratracheally exposed in the current studies demonstrated increased nonspecific airway hyper-reactivity upon methacholine challenge, but failed to exhibit increased airway hyper-reactivity upon respiratory challenge with latex proteins. The lack of significance is potentially due to elevated levels of airway hyper-reactivity in vehicle-exposed mice. Upon comparison with mice dermally and intranasally exposed to the vehicle, levels of latex specific airway hyper-reactivity in intratracheally exposed vehicle mice were approximately 7 fold higher. Upon comparison with control animals from the study evaluating intratracheal exposure to endotoxin with latex, mice intratracheally exposed to the vehicle (PBS) demonstrated comparable levels of airway hyper-reactivity and baseline levels of alveolitis. It is speculated that the infiltration of macrophages and neutrophils following i.t. administration of PBS contributed to the increased baseline levels of airway hyper-reactivity following latex specific challenge. Contrary to the latex specific airway hyper-reactivity response observed in these studies, Woolhiser et al. (Woolhiser et al., 2000) demonstrated elevated levels of airway hyperreactivity in mice intratracheally exposed to latex proteins. Mice in the Woolhiser study and the current study were exposed using similar dosing regimens and exhibited similar levels of total serum IgE, however, different sources of latex proteins were used for subsequent respiratory challenge. While Woolhiser et al. (Woolhiser et al., 2000) used proteins which had been prepared from a glycerol free non-ammoniated latex extract, proteins used in the current studies were precipitated from a non-ammoniated latex extract prepared in Goodyear preservative which contains glycerol. Glycerol is known to irritate the mucosa areas (Material Safety and Data Sheet) and, although precipitated, small amounts may remain in the dosing solution which could potentially irritate the 
respiratory tract and alter the pulmonary response to latex proteins. It is speculated that this may have been partially responsible for the differences in latex specific airway hyper-reactivity between mice in the current study and those in the study by Woolhiser et al. (Woolhiser et al., 2000).

Mice intranasally exposed in the current studies failed to exhibit an elevation in either non-specific or latex specific airway hyper-reactivity. Contrary to the response observed in these studies, Thakker et al. (Thakker et al., 1999) demonstrated an increase in both non-specific and latex specific airway hyper-reactivity in mice intranasally sensitized with latex proteins. The difference in airway hyper-reactivity may be explained in part by the 25 -fold higher levels of total serum IgE in intranasally sensitized mice in the study reported by Thakker et al.. Additionally, several other differences in the study designs may account for the differences in airway hyper-reactivity. Different exposure regimens were used between the two studies and may play a role in the degree of latex sensitization. While mice in the current studies were exposed to up to $25 \mu \mathrm{g}$ of latex proteins and challenged via the respiratory tract with either methacholine or latex proteins; Thakker et al. intranasally exposed mice to $30 \mu \mathrm{g}$ of latex proteins and subsequently challenged sensitized mice with either an intraperitoneal injection of methacholine or intravenous injection of latex.

These studies have demonstrated the important contribution of both dermal and respiratory exposure in the development of latex allergy. Subsequent studies evaluated the effect of concurrent respiratory exposure to endotoxin with latex or dermal exposure 
to glutaraldehyde with latex on the development of $\operatorname{IgE}$ mediated response to latex proteins.

Endotoxin is ubiquitous in nature and exposure has been shown to induce irritation, fever, rhinoconjunctivitis, and asthma (Morrison and Ryan, 1979; Lantz et al., 1985; Rylander and Beijer, 1987; Michel et al., 1991; Sandstrom et al., 1992; Sandstrom et al., 1994; Milton et al., 1995; Lefort et al., 1998). Many of these same symptoms have also been reported in individuals exposed to natural rubber latex products (Meding and Fregert, 1984; Tomazic et al., 1992; Weytjens et al., 1999; Tarlo, 2001). Due to the overlapping symptomology, it has been speculated that many of the symptoms attributed to latex exposure are actually due to endotoxin found within latex gloves (Williams and Halsey, 1997). Our studies investigated both the effect of endotoxin on the development of latex specific IgE and the inflammatory effect of endotoxin on the development of airway hyper-reactivity.

Conflicting studies have been published reporting both the ability of endotoxin to enhance (Mizoguchi et al., 1986) or inhibit (Gerhold et al., 2002) the development of an IgE mediated response to allergens. The effect of endotoxin on the development of an IgE mediated hypersensitivity response has been shown to be dependent on a number of factors including route of exposure, timing of endotoxin administration in relation to allergen exposure, and quantity of allergen or endotoxin exposure. Whereas Mizoguchi et al. (Mizoguchi et al., 1986) observed augmented allergen specific serum IgE levels in mice exposed via aerosolization of LPS and ovalbumin simultaneously, Gerhold et al. 
(Gerhold et al., 2002) observed a down-regulation of the $\operatorname{IgE}$ response when mice were pre-exposed systemically to LPS prior to intraperitoneal ovalbumin exposure. In comparing the designs of these studies (Mizoguchi et al. vs Gerhold et al.), additional differences identified were: 1) different concentrations of ovalbumin (50 mg vs. $20 \mu \mathrm{g}$ ), 2) different routes of exposure (aerosol vs. i.p. injection), 3) different concentration of LPS ( $1 \mathrm{mg}$ in aerosol vs. $0.5 \mathrm{mg} / \mathrm{kg}$ injections), 4) different strains of mice (SMA, C57BL/6, and CBA vs. BALB/c), and 5) different bacterial strains of endotoxin (E. coli 055:B5 vs. E. coli 0111:B4). For these studies, concurrent exposure to endotoxin with latex was carried out in female BALB/c due to their predominantly Th2 phenotype and the historical use of this strain in evaluating the development of an $\operatorname{IgE}$ mediated hypersensitivity response to allergen. Glove powder has been shown to be contaminated with endotoxin and has also been shown to serve as a carrier molecule for latex (Tomazic et al., 1994; Sussman and Beezhold, 1995). Upon donning and removing powdered latex gloves, $\mathrm{HCW}$ are potentially exposed to both endotoxin and latex via inhalation. Mice in these studies were concurrently exposed to endotoxin with latex via the respiratory tract to mimic the possible occupational exposure from NRL gloves. Additionally, endotoxin differs between bacterial strains due to differences in the makeup of LPS. Multiple bacterial strains of endotoxin (E. coli 0111:B4, S. typhimurium, S. typhosa) were used in these studies to compare the different immunomodulatory activities for each strain.

Upon concurrent intranasal administration of $10 \mu \mathrm{g}$ of endotoxin from Escherichia coli serotype 0111:B4 and $10 \mu \mathrm{g}$ of $\mathrm{rHev}$ b 5, Slater et al. (Slater et al., 1998) demonstrated elevated levels of rHev b 5 specific IgE, IgG1, and IgG2a. In 
contrast, concurrent exposure to NAL and endotoxin by the intranasal or intratracheal routes in current studies down regulated the latex specific serum IgE response. Whereas cellular infiltration in the lungs was not observed on either day 51 or 73 in mice exposed to rHev b 5 (Slater et al., 1998), mice exposed to 5,000 EU of endotoxin alone (5 $\mu \mathrm{g})$ or NAL alone exhibited peribronchial and perivascular alveolitis, characterized by macrophage and neutrophil infiltration, which increased in severity in mice concurrently exposed to latex and increasing concentrations of endotoxin in our studies. Using Alcian blue and periodic acid Schiff staining, no mucin production was observed in mice exposed to Hev b 5 alone (Slater et al., 1998), however, using the same histological stain, mice exposed to NAL alone in the current studies demonstrated an increase in mucin production, as compared to vehicle controls, which was reduced by co-exposure with endotoxin. There are several possible explanations for the differing allergen specific serum IgE responses observed in our studies and those observed by Slater et al. (Slater et al., 1998). In the previously reported study, mice were intranasally exposed every other day for 10 days ( 6 doses), rested for 6 weeks, and then exposed 3 more times on alternate days. In our studies mice were either intranasally exposed 5 days a week for up to 10 weeks, or intratracheally exposed every $5^{\text {th }}$ day (Mon - Fri - Wed) for up to 11 weeks. Hev b 5 is a single potent latex allergen with $6 \mathrm{IgE}$ binding epitopes (Beezhold et al., 1999), whereas non-ammoniated latex is an extract of greater than 100 proteins (Figure 3A). To date 11 allergens have been identified and characterized from latex extracts, however numerous other proteins have been shown to be immunogenic and the relative allergenicity of NAL is not known (Czuppon et al., 1993). Therefore exposure to $10 \mu \mathrm{g}$ of Hev b 5 may pose a more potent allergenic exposure than $25 \mu \mathrm{g}$ of NAL proteins. 
Additionally, Slater et al. (Slater et al., 1998) evaluated the histopathology in mice 2 weeks following the final endotoxin exposure, whereas mice in these studies were sacrificed 24 hours following NAL respiratory challenge (6 days following the final endotoxin exposure). A recent study by Yanagihara et al. (Yanagihara et al., 2001) demonstrated peak mucin production in the lungs 4 days following endotoxin challenge and resolution by day 7. Therefore the differences in mucin staining between these studies may be accounted for by the time of histopathological evaluation post final exposure.

Increases in serum IgE levels are often attributed to increases in IL-4 production as it has been shown that Th2 cytokines drive the development of an IgE mediated hypersensitivity response. Following repeated intranasal exposure to $30 \mu \mathrm{g}$ of latex proteins, Kurup et al. (Kurup et al., 1994) demonstrated elevated IL-4 and IL-5 mRNA levels in the spleens of mice which correlated with an increase in latex specific serum IgE in the same animals. In the current study, no significant alteration in IL-4, IL-10, IL-12 or IFN- $\gamma$ message was observed in the mediastinal lymph nodes (the lymphatic tissue draining the site of exposure) of mice intracheally exposed to latex alone. Mice intratracheally exposed to endotoxin with latex demonstrated elevated levels of IFN- $\gamma$ and IL-12 message which corresponded with increased levels of IgG2a and IgA and an increase in the severity of macrophage and neutrophil infiltration in the lungs. Previous literature has described the down regulatory role of IFN- $\gamma$ and IL-12 in the development of IgE (Snapper and Paul, 1987; Morris et al., 1994; Metzger et al., 1996; Schwarze et al., 1998a). IL-12 produced by macrophages indirectly down regulates the IgE response 
by inducing IFN- $\gamma$ production by natural killer cells and T cells (Morris et al., 1994; Metzger et al., 1996) and this up-regulation of IFN- $\gamma$ acts directly by inhibiting germ-line $\varepsilon$ chain transcription and inducing a class switch to IgG2a (Berton et al., 1989). In our studies, mice intratracheally exposed to endotoxin with latex demonstrated increased levels of latex specific serum IgG2a and increased IFN- $\gamma$ and IL-12 mRNA levels as early as day 16. This suggests a strong relationship between the induction of a Th1 cytokine response following endotoxin exposure and the subsequent down regulation of the latex specific IgE response.

Upon subsequent latex specific pulmonary challenge, animals sensitized by i.t. exposure to NAL alone demonstrated an increase in airway hyper-reactivity. However, as compared to animals sensitized to latex alone, decreased airway hyper-reactivity was observed in animals which had been previously sensitized by concurrent exposure to NAL with endotoxin. In addition to down-regulating the allergen specific IgE response, IFN- $\gamma$ and IL-12 have been shown to inhibit the development of allergen specific airway hyper-reactivity (Gavett et al., 1995; Huang et al., 2001; Tang et al., 2001). In a study by Huang et al. (Huang et al., 1999), Brown Norway rats treated with exogenous IFN- $\gamma$ prior to ovalbumin sensitization demonstrated a significant reduction in airway hyperreactivity with decreases in IL-4, IL-5 and IL-10 mRNA levels upon aerosol challenge with ovalbumin. Schwarze et al. (Schwarze et al., 1998b) demonstrated that local administration of IL-12 reduces the airway hyper-reactivity response and Th2 cytokine production (IL-4, IL-5) in previously ovalbumin sensitized mice. Gerhold et al. (Gerhold et al., 2002) observed a decrease in ovalbumin specific airway hyper-reactivity upon 
sensitization with ovalbumin and endotoxin which could be reversed upon administration of a neutralizing IL-12 antibody. Mice concurrently exposed to latex and increasing concentrations of endotoxin in these studies demonstrated decreased airway hyperreactivity responses which coincided with increases in both IL-12 and IFN- $\gamma$ mRNA levels, as well as IgG2a and IgA antibody levels. The increased levels of IgA may also play a modulatory role in the decreased airway hyper-reactivity as was previously discussed that antigen specific IgA has been shown to down-regulate the antigen specific airway response upon subsequent respiratory challenge (Schwarze et al., 1998a).

Unlike allergen specific airway hyper-reactivity, non-specific airway hyperreactivity can occur in both sensitized and non-sensitized individuals. Following chronic exposure to endotoxin, Vernooy et al. (Vernooy et al., 2002) demonstrated the development of chronic lung inflammation with increased numbers of macrophages and lymphocytes to the peribronchial regions of the lung. Lung inflammation has been proposed to play a role in the development of non-specific airway hyper-reactivity. Macrophages recruited to the site of exposure have been shown to release excessive amounts of nitric oxide (NO) upon chronic exposure to endotoxin. While nitric oxide is traditionally thought to trigger bronchodilation, excessive NO production reacts with superoxide anions forming peroxynitrite which induces contraction of the smooth muscle resulting in bronchoconstriction (Toward and Broadley, 2001). Additionally, Lefort et al. (Lefort et al., 2001) demonstrated a positive relationship between non-specific airway hyper-reactivity to methacholine and the influx of neutrophils into the lungs following endotoxin exposure. In our studies, mice concurrently exposed to 5,000 EU of endotoxin 
and latex exhibited increased levels of non-specific airway hyper-reactivity which correlated with an increase in the mixed cellular alveolitis (i.e. macrophages and neutrophils).

Glutaraldehyde was chosen for the evaluation of its modulatory effects on the development of latex allergy following dermal exposure due to its extensive use in the health care environment. While the allergic potential of glutaraldehyde is well documented, the potential immunodulatory role of glutaraldehyde in the development of latex allergy has not been previously investigated. While no significant modulation of latex specific IgE was observed upon co-exposure to concentrations of glutaraldehyde surrounding those used in cold sterilant solutions $(0.1-1 \%)$, an augmented total and latex specific IgE response was observed in mice concurrently exposed to latex and concentrations of glutaraldehyde surrounding the aerosol permissible exposure limit $(0.05$ $-0.75 \mathrm{ppm})$. Mice concurrently exposed to latex and $1 \mathrm{ppm}$ of glutaraldehyde did not demonstrate elevations in total serum or latex specific IgE. This trend was reproduced in subsequent studies which verified the dose responsive augmentation of the $\operatorname{IgE}$ response in animals exposed to latex and concentrations of glutaraldehyde up to $0.75 \mathrm{ppm}$ and a lack of a response in animals exposed concurrently to latex and 1ppm of glutaraldehyde.

Studies have demonstrated the adjuvancy of particulates and proteolytically active allergens in the development of an IgE mediated hypersensitivity response. Numerous studies with diesel exhaust particles (DEP) have demonstrated an augmentation of the development of an IgE mediated hypersensitivity response upon concurrent exposure 
with allergen (Suzuki et al., 1996; Lovik et al., 1997; Miyabara et al., 1998; Wang et al., 1999; Heo et al., 2001). A study by Heo et al. (Heo et al., 2001) demonstrated that intraperitoneal injection of DEP and ovalbumin on the same day resulted in the augmentation of ovalbumin specific IgE levels 56 days following initial exposure. It was further shown that altering the administration of DEP either one day before or after administration of ovalbumin diminished the immunomodulatory effect. In a separate study, concurrent intranasal exposure of mice to DEP and dust mite allergen weekly for at least 3 weeks, was shown to augment the development of dust mite specific IgE and IgG1 (Suzuki et al., 1996). Upon analysis of other immunologically active agents, coinjection of mice with polystyrene particles was shown to augment the development of ovalbumin specific IgE responses (Granum et al., 2001); and increased levels of ovalbumin specific IgE have been observed upon co-injection with OVA and a proteolytically active dust mite allergen (Gough et al., 2001). While the mechanism behind the augmentation is not understood, it was speculated in each of these previous studies that the agent acted to "prime" the cellular response for allergen exposure. It was speculated that the immunological activity induced by glutaraldehyde exposure would also stimulate the induction of latex specific $\operatorname{IgE}$ upon concurrent exposure to latex proteins.

Given the irritant nature of glutaraldehyde, one hypothesized mechanism of its role in the augmentation of the $\operatorname{IgE}$ response to latex was disruption of the stratum corneum. It has previously been shown that disruption of the skin barrier allows enhanced penetration of latex proteins into and through the skin with the potential of 
reaching the systemic circulation (Hayes et al., 2000) and inducing an IgE response in a shorter time period than is required when exposure is to intact skin (Woolhiser et al., 2000). In an initial study, in vitro percutaneous penetration of latex proteins was evaluated using skin from hairless guinea pigs which were exposed to glutaraldehyde for up to 56 days. The determination for the 56 day time point was due to the observed elevation in serum IgE levels in mice concurrently exposed to latex and $0.75 \mathrm{ppm}$ glutaraldehyde on day 51. These studies demonstrated no significant alterations in hairless guinea pig skin permeability following exposure to either 0.75 or $1 \mathrm{ppm}$ of glutaraldehyde for up to 56 days. Although the hairless guinea pig model has been shown to be a good surrogate for human tissue in evaluating latex penetration (Hayes et al., 2000), studies have not been conducted comparing the penetration of latex proteins through the skin of the hairless guinea pig and mouse. At the European Centre for the Validation of Alternative Methods Workshop in 1996, skin sources for in vitro percutaneous penetration experiments were ranked based on their relevance to human physiology. While guinea pigs are thought to be a good model for human exposure, proteins penetrate more readily through mouse skin due to physiological differences in the skin (Howes et al., 1996). Therefore, to confirm that the elevated IgE levels in mice concurrently exposed to latex and $0.75 \mathrm{ppm}$ was not due to alterations in barrier function, a second study was conducted to evaluate the effects of glutaraldehyde on the percutaneous penetration in mice. At the time of sacrifice, following 86 days of exposure when mice were shown to exhibit increased levels of total and latex specific IgE (Figure 33), skin from the dorsal thorax of mice concurrently exposed to latex and glutaraldehyde was subjected to a barrier integrity test. Bronaugh and Collier (Bronaugh and Collier, 
1991) previously determined, based on penetration, water partition coefficients and skin permeability constants, that skin samples permitting greater than $0.35 \%{ }^{3} \mathrm{H}_{2} \mathrm{O}$ penetration demonstrated sufficient disruption of the barrier function to be considered abraded. Although exposure to latex and increasing concentrations of glutaraldehyde sufficiently disrupted the barrier integrity to allow up to $1 \%{ }^{3} \mathrm{H}_{2} \mathrm{O}$ penetration, the amount of permeability required to allow significant latex penetration is unknown in mice. Studies conducted by Hayes et al. (Hayes et al., 2000) using a hairless guinea pig model, have demonstrated, however, that significant penetration of latex proteins did not occur unless skin was abraded to the point that $8 \%{ }^{3} \mathrm{H}_{2} \mathrm{O}$ penetrated through the skin.

Glutaraldehyde exposure did not induce significant perturbations in the stratum corneum; however other immunological factors within the epidermis may contribute to the elevation in total serum IgE levels observed in mice concurrently exposed to latex and glutaraldehyde. Several studies have demonstrated an up-regulation in MHC class II expression on Langerhans' cells during the induction of a contact hypersensitivity response. While studies have not investigated the relationship between MHC class II expression on antigen presenting cells and the initiation of IgE mediated responses; it is speculated that the mechanism of antigen up-take and presentation is similar to that of contact hypersensitivity. Cumberbatch et al. (Cumberbatch et al., 1992) demonstrated an increase in Langerhans' cell number, as evidenced by an increase in MHC class II expressing cells in the epidermal sheets of mice exposed to the contact sensitizer, 1chloro-2, 4-dinitrobenzene (DNCB). Becker et al. (Becker et al., 1992) used a polyclonal antibody to the MHC class II molecule to demonstrate an increase in Langerhans' cells in 
mice exposed to either DNCB, 2,4-dinitroflourobenzene (DNFB), oxazolone, or potassium dichromate for 3 hours. In addition to demonstrating an increase in Langerhans' cell number in the epidermal sheets of mice exposed to DNFB, Tsuruta et al. (Tsuruta et al., 1999) also demonstrated an increase in the dendritic processes of activated Langerhans cells. Based on these previous studies, it was hypothesized that concurrent exposure to glutaraldehyde with latex would increase the expression of MHC class II expression on Langerhans' cells and would thereby enhance the antigen presentation to $\mathrm{T}$ cells in the draining lymph node. Upon comparison with vehicle exposed animals, mice concurrently exposed to $0.75 \mathrm{ppm}$ glutaraldehyde with latex demonstrated a significant $(\mathrm{p}<0.05) \quad 15$-fold increase in Langerhans' cell number following 2 days of exposure on the dorsal surface of the ear. While not reaching statistical significance, increased Langerhans' cell numbers were observed throughout the time course study in mice concurrently exposed to $0.75 \mathrm{ppm}$ glutaraldehyde with NAL, suggesting a role for increased antigen presenting cell activity in the augmented latex specific IgE response.

Upon activation, Langerhans' cells migrate to the draining lymph node to interact with $\mathrm{T}$ cells and initiate an $\operatorname{IgE}$ or $\mathrm{T}$ cell mediated hypersensitivity response (Cumberbatch et al., 2000). Upon interacting with the antigen presenting cells and to facilitate activation, co-stimulatory molecules are up-regulated on $\mathrm{T}$ and $\mathrm{B}$ cells. Following activation, $\mathrm{T}$ and $\mathrm{B}$ cells differentiate and proliferate. Phenotypic analysis of the draining lymph node cells has been previously shown to be an effective tool in the evaluation of the hypersensitivity response following chemical exposure (Sikorski et al., 
1996; Gerberick et al., 1997; Manetz and Meade, 1999; Howell et al., 2000; Gerberick et al., 2002). It was hypothesized in these studies that concurrent exposure to latex and glutaraldehyde would induce the up-regulation of MHC class II expression on dendritic cells and B cell co-stimulatory molecules (B7.2, CD40) resulting in increased cellular activation and proliferation. Exposure to glutaraldehyde at concentrations representative of those used in cold sterilant solutions has been shown to induce both cellular proliferation and a Th2 cytokine profile (Dearman et al., 1999). Additionally, recent studies have suggested divergent hypersensitivity responses following glutaraldehyde exposure with higher concentrations inducing an IgE mediated response and lower concentrations inducing a $T$ cell mediated response (Azadi et al., 2002). In comparison to vehicle controls, mice concurrently exposed, in these studies, to latex and $0.75 \mathrm{ppm}$ of glutaraldehyde for 86 days demonstrated increases in B cell proliferation and CD40 expression whereas no significant increase was observed in animals exposed to $0.75 \mathrm{ppm}$ glutaraldehyde or NAL alone. Upon comparison with mice concurrently exposed to latex and $0.75 \mathrm{ppm}$ of glutaraldehyde, decreased numbers of B cells were observed in mice concurrently exposed to latex and 1ppm of glutaraldehyde. While the exact role of CD40 in the development of an IgE mediated hypersensitivity response is unknown and under investigation, previous studies have demonstrated the requirement for CD40 in the development of IgE (Hermes et al., 1997; Jeppson et al., 1998; Lazaar et al., 1998; Oettgen, 2000). In contrast to mice concurrently exposed to $0.75 \mathrm{ppm}$ glutaraldehyde with latex, mice exposed to $0.75 \mathrm{ppm}$ of glutaraldehyde alone demonstrated an increase in $\mathrm{T}$ cell proliferation and CD28. CD28 plays a critical role by providing a secondary signal for $\mathrm{T}$ cell activation. This dichotomy of cell type and number suggests the ability of co- 
exposure to latex with low concentrations of glutaraldehyde to prime the immune system for a B cell response. No significant elevations in the expression of MHC class II in the draining lymph node cells were observed in any of the exposure groups. Evaluation at earlier time points (days $2-29$ ) in a time course study demonstrated no significant increases in the expression of any of the cell surface markers or co-stimulatory molecules.

Upon activation, antigen presenting cells (i.e. Langerhans cells, macrophages, dendritic cells), as well as $\mathrm{T}$ and $\mathrm{B}$ cells, produce and secrete cytokines to direct the immune response. Previous studies have demonstrated the association between chemical exposure leading to IgE mediated hypersensitivity response and the production of IL-4 (Kurup et al., 1994; Thakker et al., 1999; Xia et al., 1999). Whereas IL-4 is associated with increased IgE production, IL-12 and IFN- $\gamma$ act to down-regulate the IgE response by inhibiting IL-4 production (Manetti et al., 1993; Yoshimoto et al., 1998). Following dermal exposure to glutaraldehyde, mice have been shown to demonstrate increased levels of both IL-4 and IL-10 protein in the draining lymph node cells (Dearman et al., 1999). It was hypothesized in our studies that concurrent exposure to latex and glutaraldehyde would up-regulate the messenger RNA levels of IL-4 and IL-10 while down-regulating the expression of IL-12 and IFN- $\gamma$. Contrary to our hypothesis, no significant alterations in cytokine message levels were observed in the draining lymph node cells of mice exposed to latex and glutaraldehyde for 86 days. 
While it has been predominantly thought that respiratory exposure results in pulmonary complications, and that dermal exposure results in cutaneous complications; these studies demonstrate that dermal and respiratory exposure to latex proteins result in the induction of similar levels of latex specific IgE and lead to increased airway hyperreactivity. Additionally, these studies demonstrated that other agents encountered in the health care environment may modulate the development of a latex specific IgE mediated hypersensitivity response. Mice concurrently exposed to latex and increasing concentrations of endotoxin demonstrated a reduction in latex specific IgE levels and antigen specific airway hyper-reactivity when compared to mice exposed to latex alone. It was further determined that while $\operatorname{IgE}$ was down-regulated, concurrent exposure to endotoxin with latex induced increased levels of IFN- $\gamma$ and IL-12 mRNA in the draining lymph nodes and an immunoglobulin class switch to latex specific IgG2a and IgA production. The large number of macrophages recruited upon repeated exposure to endotoxin and latex are speculated to serve as the primary source for IL-12 which stimulates IFN- $\gamma$ production in $\mathrm{T}$ cells and NK cells. The increased inflammatory response in the lungs of mice concurrently exposed to endotoxin with latex is thought to be responsible for the increase in non-specific airway hyper-reactivity in these groups.

Exposure to glutaraldehyde at concentrations surrounding the PEL was shown to augment the $\operatorname{IgE}$ response to latex proteins through an as yet undetermined mechanism. While latex gloves are extensively used by health care workers as a protective barrier against pathogens, studies have shown that glutaraldehyde penetrates through latex 
gloves within an hour. These studies raise the concern that co-exposure to glutaraldehyde with latex may augment the induction of latex sensitization.

These studies demonstrate the importance of understanding the role of concurrent environmental or occupational exposures in the development of $\operatorname{IgE}$ responses to allergens and clinical observations attributed to allergic diseases. Understanding the mechanism by which mixed exposures modulate the development of allergic responses will allow for improved design, development, and implementation of intervention strategies. 


\section{LITERATURE CITED}

Abbott, L. (1995). The Use and Effects of Glutaraldehyde: A Review. Occupational Health 47, 238-239.

Akdis, C. A., Akdis, M., Simon, H. U., and Blaser, K. (1999). Regulation of Allergic Inflammation by Skin-Homing T Cells in Allergic Eczema. Int Arch Allergy Immunol 118, $140-144$.

Akdis, M., Akdis, C. A., Wieigl, L., Disch, R., and Blaser, K. (1997). Skin-Homing, CLA+ Memory T Cells are Activated in Atopic Dermatitis and Regulate IgE by an IL13-Dominated Cytokine Patter: IgG4 Counter-Regulationn by CLA-Memory T Cells. $J$ Immunol 159, 4611-4619.

Alenius, H., Turjanmaa, K., Makinen-Kiljunen, S., Reunala, T., and Palosuo, T. (1994). IgE Immune Response to Rubber Proteins in Adult Patients with Latex Allergy. J Allergy Clin Immunol 93, 859-863.

Alessio, L., Baruffini, A., Biscaldi, G., Cirla, A. M., Cortona, G., Crippa, M., Franco, G., Marcer, G., Moscato, G., and Toffoletto, F. (1997). Allergic and Irritant Glove-Related Diseases in Health Care Workers and Their Prevention. International Journal of Occupational and Environmental Health 3, 300-303.

Andersson, J., Felchers, F., Galanos, C., and Luderitz, O. (1973). The Mitogenic Effect of Lipopolysaccharide on Bone Marrow-Derived Mouse Lymphocytes. J Exp Med 137, 943-953.

Arellano, R., Bradley, J., and Sussman, G. (1992). Prevalence of Latex Sensitization Among Hospital Physicians Occupationally Exposed to Latex Gloves. Anesthesiology 77, 905-908.

Arts, J. H. E., Kuper, C. F., Spoor, S. M., and Bloksma, N. (1998). Airway Morphology and Function of Rats Following Dermal Sensitization and Respiratory Challenge with Low Molecular Weight Chemicals. Toxicol Appl Pharmacol 152, 66-76.

Axelsson, J. G. K., Johansson, S. G. O., and Wrangsjo, K. (1987). IgE-Mediated Anaphylactoid Reactions to Rubber. Allergy 42, 46-50.

Azadi, S., Butterworth, L. F., and Meade, B. J. (2002). Divergent Immunological Responses Following Glutaraldehyde Exposure. Toxicologist 66, 384.

Baur, X., Chen, Z., and Allmers, H. (1998). Can a Threshold Limit Value for Natural Rubber Latex Airborne Allergens be Defined. J Allergy Clin Immunol 101, 24-27. 
Baur, X., Chen, Z., Allmers, H., Beckmann, U., and Walther, J. W. (1995). Relevance of Latex Aeroallergen for Healthcare Workers. Allergology International 20, 105-111.

Beauchamp, R. O., St. Clair, M. G., Fennell, T. R., Clarke, D. O., Morgan, K. T., and Kari, F. W. (1992). A Critical Review of the Toxicology of Glutaraldehyde. Critical Reviews in Toxicology 22, 143-174.

Becker, D., Mohamadzadeh, M., Reske, K., and Knop, J. (1992). Increased Level of Intracellular MHC Class II Molecules in Murine Langerhans Cells Following In Vivo and In Vitro Administration of Contact Allergens. J Invest Derm 99, 545-549.

Becker, S., Soukup, J. M., Gilmour, M. I., and Devlin, R. B. (1996). Stimulation of Human and Rat Alveolar Macrophages by Urban Air Particulates: Effects on Oxidant Radical Generation and Cytokine Production. Toxicol Appl Pharmacol 84, 484-491.

Beezhold, D., Kostyal, D., and Wiseman, J. (1994). The Transfer of Protein Allergens from Latex Gloves. AORN J 59, 605-613.

Beezhold, D., Pugh, B., Liss, G., and Sussman, G. (1996). Correlation of Protein Levels with Skin Prick Test Reactions in Patients Allergic to Latex. J Allergy Clin Immunol 98, 1097-1102.

Beezhold, D. H. (1992). LEAP: Latex ELISA for Antigenic Proteins. Guthrie Journal 61, 77-81.

Beezhold, D. H., Hickey, V. L., Slater, J. E., and Sussman, G. L. (1999). Human IgEBinding Epitopes of the Latex Allergen Hev b 5. J Allergy Clin Immunol 103, 1166-1172.

Benson, W. G. (1984). Exposure to Glutaraldehyde. Journal of Soc Occupational Medicine 34, 63-64.

Berton, M. T., Uhr, J. W., and Vitetta, E. S. (1989). Synthesis of Germ-line $\gamma 1$ Immunoglobulin Heavy-Chain Transcripts in Resting B Cells: Induction by Interleukin 4 and Inhibition by Interferon $\gamma$. Proc. Natl. Acad. Sci. 86, 2829-2833.

Bessler, W. G., Cox, M., Lex, A., Suhr, B., Wiesmuller, K. H., and Jung, G. (1985). Synthetic Lipopeptide Analogs of Bacterial Lipoprotein are Potent Polyclonal Activators for Murine B Lymphocytes. J Immunol 135, 1900-1905.

Boivin, A., and Mesrobeanu, L. (1935). Recherche Sur Les Antigenes Somatiques et Sur Les Endotoxines des Bacteries. I. Rev Immunol Paris 1, 553-569.

Bos, J. D., and Kapsenberg, M. L. (1993). The Skin Immune System: Progress in Cutaneous Biology. Immunology Today 14, 75-78.

Bowes, J. H., and Cater, C. W. (1968). The Interaction of Aldehydes with Collagen. Biochim Biophys Acta 168, 341-352. 
Brehler, R., Rutter, A., and Kutting, B. (2002). Allergenicity of Natural Rubber Latex Gloves. Contact Dermatitis 46, 65-71.

Bronaugh, R., and Collier, S. (1991). Preparation of Human and Animal Skin. In In Vitro Percutaneous Absorption: Principles, Fundamentals, and Applications (R. Bronaugh, and H. Maibach, Eds.), pp. 1-6. CRC Press, Inc., Boca Raton, FL.

Buck, D., Michael, T., Wahn, U., and Niggemann, B. (2000). Ventricular Shunts and the Prevalence of Sensitization and Clinically Relevant Allergy to Latex in Patients with Spina Bifida. Pediatric Allergy Immunology 11, 111-115.

Burge, P. S. (1989). Occupational Risks of Glutaraldehyde. British Medical Journal 299, 342.

Burnham, K., Robb, L., Scott, C. L., O'Keefe, M., and Shortman, K. (2000). Effect of Granulocyte-Macrophage Colony-Stimulating Factor on the Generation of Epidermal Langerhans Cells. Journal of Interferon and Cytokine Research 20, 1071-1076.

Burrell, R. (1990). Immunomodulation by Bacterial Endotoxin. Crit. Rev. Microbiol 17, 189-208.

Carrillo, T., Cuevas, M., Munoz, T., Hinojosa, M., and Moneo, I. (1986). Contact urticaria and rhinitis from latex surgical gloves. Contact Dermatitis 15, 69-72.

CDC (1987). Recommendations for prevention of HIV transmission in health-care settings. Centers for Disease Control and Prevention.

CDC (1988). Update: Universal precautions for prevention of transmission of human immunodeficiency virus, hepatitis B virus, and other blood borne pathogens in healthcare settings.

CDC (1989). Guidelines for prevention of transmission of human immunodeficiency virus and hepatitis B virus to health-care and public-safety wrokers. Centers for Disease Control and Prevention.

Charous, B. L., Hamilton, R. G., and Yunginger, J. W. (1994). Occupational Latex Exposure: Characteristics of Contact and Systemic Reactions in 47 Workers. J Allergy Clin Immunol 94, 12-18.

Chen, Z., Cremer, R., Posch, A., Raulf-Heimsoth, M., Rihs, H., and Baur, X. (1997). On the Allergenicity of Hev b 1 Among Health Care Workers and Patients with Spina Bifida Allergic to Natural Rubber Latex. J Allergy Clin Immunol 100, 684-693.

Coates, A. (1987). The commerce in rubber: The first 250 years. Oxford University Press, Oxford.

Cohen, D. E., Scheman, A., Stewart, L., Taylor, J., Pratt, M., Trotter, K., Prawer, S., Warshaw, E., Rietschel, R., Watsky, K., Shama, S., Godwin, L., Kosann, M. K., and 
Wilson, B. A. (1998). American Academy of Detmatology's position paper on latex allergy. Journal of the American Acadamy of Dermatology 39, 98-106.

Collier, S., Skeikh, N., Sakr, A., Lichtin, J., Stewart, R. and Bronaugh, R. (1989). Maintenance of Skin Viability During In Vitro Percutaneous Absorption/Metabolism Studies. Toxicol Appl Pharmacol 99, 522-533.

Conde-Salazar, L., del-Rio, E., Guimaraens, D., and Domingo, A. G. (1993). Type IV allergy to rubber additives: A 10-year study of 686 cases. Journal of the American Acadamy of Dermatology 29, 176-180.

Corrado, O. J., Osman, J., and Davies, R. J. (1986). Asthma and Rhinitis after Exposure to Glutaraldehyde in Endoscopy Units. Human Toxicology 5, 325-327.

Cremer, R., Hoppe, A., Korsch, E., Kleine-Diepenbruck, U., and Blaker, F. (1998). Natural Rubber Latex Allergy: Prevalence and Risk Factors in Patients with Spina Bifida Compared with Atopic Children and Controls. European Journal of Pediatrics 157, 1316.

Crippa, M., and Pasolini, G. (1997). Allergic Reactions due to Glove-Lubricant-Powder in Health-Care Workers. International Archives of Occupational and Environmental Health 70, 399-402.

Cui, Z. H., Sjostrand, M., Pullerits, T., Andius, P., Skoogh, B. E., and Lotvall, J. (1997). Bronchial Hyperresponsiveness, Epithelial Damage, and Airway Eosinophilia After Single and Repeated Allergen Exposure in a Rat Model of Anhydride-Induced Asthma. Allergy 52, 739-746.

Cumberbatch, M., Dearman, R. J., Griffiths, C. E., and Kimber, I. (2000). Langerhans Cell Migration. Clinical and Experimental Dermatology 25, 413-418.

Cumberbatch, M., Gould, S. J., Peters, S. W., Basketter, D. A., Dearman, R. J., and Kimber, I. (1992). Influence of Topical Exposure to Chemical Allergens on Murine Langerhans Cells. Comparison of 2,4-Dinitrochlorobenzene with Trimellitic Anhydride. J. Clin. Lab. Immunol. 37, 65-81.

Czuppon, A. B., Chen, Z., Rennert, S., Engelke, T., Meyer, H. E., Heber, M., and Baur, X. (1993). The Rubber Elongation Factor of Rubber Trees (Hevea brasiliensis) is the Major Allergen in Latex. J Allergy Clin Immunol 92, 690-697.

Danneman, P. J., and Michael, J. G. (1976). Adjuvant and Immunogenic Properties of Bacterial Lipopolysaccharide in IgE and IgG1 Antibody Formation in Mice. Cell. Immunol. 22, 128-139.

Dasic, G., Juillard, P., Graber, P., Herren, S., Angell, T., Knowles, R., Bonnefoy, J., Kosco-Vilbois, M. H., and Chvatchko, Y. (1999). Critcal Role of CD23 in AllergenInduced Bronchoconstriction in a Murine Model of Allergic Asthma. European Journal of Immunology 29, 2957-2967. 
Dearman, R. J., Basketter, D. A., Blaikie, L., Clark, E. D., Hilton, J., House, R. V., Ladics, G. S., Loveless, S. E., Mattis, C., Sailstad, D. M., Sarlo, K., Selgrade, M. K., and I. Kimber, I. (1998). The Mouse IgE Test: Interlaboratory Evaluation and Comparison of BALB/c and C57BL/6 Strain Mice. Toxicology Methods 8, 69-85.

Dearman, R. J., Basketter, D. A., Evans, P., and Kimber, I. (1999). Comparison of Cytokine Secretion Profiles Provoked in Mice by Glutaraldehyde and Formaldehyde. Clin Exp Allergy 29, 124-132.

Dearman, R. J., Basketter, D. A., and Kimber, I. (1996). Characterization of Chemical Allergens as a Function of Divergent Cytokine Secretion Profiles Induced in Mice. Toxicol Appl Pharmacol 138, 308-316.

DHHS (1997). Preventing Allergic Reactions to Natural Rubber Latex in the Workplace, pp. 11. National Institute for Occupational Safety and Health, Cincinnati, OH.

DHHS (1999). Medical Glove Guidance Manual, pp. 226. Center for Devices and Radiological Health/ Food and Drug Administration, Bethesda, MD.

Doran, J. E. (1992). Biological Effects of Endotoxin. Current Studies in Hematology and Blood Transfusion 59, 66-99.

Drazen, J. M., Finn, P. W., and De Sanctis, G. T. (1999). Mouse models of airway responsiveness: physiological basis of observed outcomes and analysis of selected examples using these outcome indicators. In Annual Review of Physiology (J. F. Hoffman, and P. D. Weer, Eds.), pp. 593-625. Annual Reviews, Palo Alto.

Edelstam, G., Arvanius, L., and Karlsson, G. (2002). Glove Powder in the Hospital Environment - Consequences for Healthcare Workers. International Archives of Occupational and Environmental Health 75, 267-271.

Elmets, C. A., Trefzer, U., and Mukhtar, H. (1994). Immunotoxicology and Immunopharmacology of the Skin Immune System. In Immunotoxicology and Immunopharmacology (J. H. Dean, M. I. Luster, A. E. Munson, and I. Kimber, Eds.), pp. 761. Raven Press, Ltd., New York.

Fisher, A. A. (1990). Allergic Contact Dermatitis of the Hands from Sporocidin (Glutaraldehyde-phenate) Used to Disinfect Endoscopes. Cutis 45, 227-228.

Forstrom, L. (1980). Contact Urticaria from Latex Surgical Gloves. Contact Dermatitis 6, 33-34.

Fowler, J. F. (1989). Allergic Contact Dermatitis from Glutaraldehyde Exposure. Journal of Occupational Medicine 31, 852-853.

Frazer, J. K., and Capra, J. D. (1999). Immunoglobulins: Structure and Function. In Fundamental Immunology (W. E. Paul, Ed.), pp. 37-74. Lippincott-Raven Publishers, Philadelphia. 
Friedman, H., Blanchard, D. K., Newton, C., Klein, T., Stewart, W., Keler, T., and Nowotny, A. (1987). Distinctive Immunomodulatory Effects of Endotoxin and NonToxic Lipopolysaccharide Derivatives in Lymphoid Cell Cultures. Journal of Biological Response Modifiers 6, 664-677.

Frosch, P. J., Wahl, R., Bahmer, F. A., and Maasch, H. J. R. n. (1986). Contact urticaria to rubber gloves is IgE-mediated. Contact Dermatitis 14, 241-245.

Galanos, C., Lehmann, V., Luderitz, O., Rietschel, E. T., Brade, H., Brade, L., Feudenberg, M., Hansen-Hagge, T., Luderitz, O., McKenzie, G., Shchade, U., Strittmaker, W., Tanamoto, K., Zahringer, U., Imoto, M., Yoshimura, H., Yamamoto, M., Shimamoto, T., Kusumoto, S., and Shiba, T. (1984). Endotoxic Properties of Synthetic Lipid A Part Structures. Comparison of Synthetic Lipid A Precursor and Synthetic Analogues with Biosynthetic Lipid A Precursor and Free Lipid A. European Journal of Biochemistry 140, 221-227.

Galli, S. J., and Lantz, C. S. (1999). Allergy. In Fundamental Immunology (W. E. Paul, Ed.), pp. 1127-1174. Lippincott-Raven Publishers, Philadelphia, PA.

Galobardes, B., Quliquini, A. M., Roux, N., Taramarcaz, P., Schira, J. C., Berstein, M., Morabia, A., and Hauser, C. (2001). Influence of Occupational Exposure to Latex on the Prevalence of Sensitization and Allergy to Latex in a Swiss Hospital. Dermatology 203, 226-232.

Gannon, P. F. G., Bright, P., Campbell, M., O'Hickey, S. P. O., and Burge, P. S. (1995). Occupational Asthma Due to Glutaraldehyde and Formaldehyde in Endoscopy and X Ray Departments. Thorax 50, 156-159.

Garabrant, D. H., Roth, H. D., Parsad, R., Ying, G., and Weiss, J. (2001). Latex Sensitization in Health Care Workers and in the US General Population. American Journal of Epidemiology 153, 515-522.

Gavett, S. H., O'Hearn, D. J., Li, X., Huang, S. K., Finkelman, F. D., and Wills-Karp, M. (1995). Interleukin 12 Inhibits Antigen-Induced Airway Hyperresponsiveness, Inflammation, and Th2 Cytokine Expression in Mice`. J Exp Med 182, 1527-1536.

Gawchik, S. (1998). The Role of Organizations. The 1998 National Latex Allergy Conference.

Gerberick, G. F., Cruse, L. W., Miller, C. M., Sikorski, E. E., and Ridder, G. M. (1997). Selective Modulation of T Cell Memory Markers CD62L and CD44 on Murine Draining Lymph Node Cells Following Allergen and Irritant Treatment. Toxicol Appl Pharmacol 146, $1-10$.

Gerberick, G. F., Cruse, L. W., Ryan, C. A., Hulette, B. C., Chaney, J. G., Skinner, R. A., Dearman, R. J., and Kimber, I. (2002). Use of a B Cell Marker (B220) to Discriminate between Allergens and Irritants in the Local Lymph Node Assay. Tox Sci 68, 420-428. 
Gerhold, K., Blumchen, K., Bock, A., Seib, C., Stock, P., Kallinich, T., Lohning, M., Wahn, U., and Hamelmann, E. (2002). Endotoxins Prevent Murine IgE Production, Th2 Immune Responses, and Development of Airway Eosinophilia but not Airway Hyperreactivity. J Allergy Clin Immunol 110, 110-116.

Germolec, D. R., Woolhiser, M. R., and Meade, B. J. (1999). Allergy to Natural Rubber Latex. Chemical and Health Safety 6, 44-48.

Ginanni, R., Michel, O., Sergysels, R., and Duchateau, J. (1991). Characteristics of the Bronchial Obstructive Response Induced by Inhalation of Endotoxins. European Respiratory Journal 4, 251-252.

Giulietti, A., Overbergh, L., Valckx, D., Decallonne, B., Bouillon, R., and Mathieu, C. (2001). An Overview of Real-Time Quantitative PCR: Applications to Quantify Cytokine Gene Expression. Methods 25, 386-401.

Goncalo, S., Brandao, F. M., Pecegueiro, M., Moreno, J. A., and Sousa, I. (1984). Occupational Contact Dermatitis to Glutaraldehyde. Contact Dermatitis 10, 183-184.

Gorman, S. P., and Scott, E. M. (1980). Antimicrobial Activity, Uses and Mechanism of Action of Glutaraldehyde. Journal of Applied Bacteriology 48, 161-190.

Gough, L., Sewell, H. F., and Shakib, F. (2001). The Proteolytic Activity of the Major Dust Mite Allergen Der p 1 Enhances the IgE Antibody Response to a Bystander Antigen. Clin Exp Allergy 31, 1594-1598.

Granum, B., Gaarder, P. I., and Lovik, M. (2001). IgE Adjuvant Effect Caused by Particles - Immediate and Delayed Effects. Toxicology 156, 149-159.

Gross, E. A., Mellick, P. W., Kari, F. W., Miller, F. J., and Morgan, K. T. (1994). Histopathology and Cell Replication Responses in the Respiratory Tract of Rats and Mice Exposed by Inhalation to Glutaraldehyde for Up to 13 Weeks. Fund. Appl. Toxicol. 23, 348-362.

Grzybowski, M., Ownby, D. R., Peyser, P. A., Johnson, C. C., and Schork, M. A. (1996). The Prevalence of Anti-Latex IgE Antibodies Among Registered Nurses. J Allergy Clin Immunol 98, 535-544.

Haas, H., Falcone, F. H., Holland, M. J., Schramm, G., Haisch, K., Gibbs, B. F., Bufe, A., and Schlaak, M. (1999). Early Interleukin-4: Its Role in the Switch Towards a Th2 Response and IgE-Mediated Allergy. Int Arch Allergy Immunol 119, 86-94.

Hamelmann, E., Scwarze, J., Takeda, K., Oshiba, A., Larsen, G. L., Irvin, C. G., and Gelfand, E. W. (1997). Noninvasive Measurement of Airway Responsiveness in Allergic Mice Using Barometric Plethysmography. American Journal of Respiratory and Critical Care Medicine 156, 766-775. 
Hamilton, R. G., and Adkinson, N. F. (1996). Natural Rubber Latex Skin Testing Reagents: Safety and Diagnostic Accuracy of Nonammoniated Latex, Ammoniated Latex, and Latex Rubber Glove Extracts. J Allergy Clin Immunol 98, 872-883.

Harries, C. D., and Tank, L. (1908). Conversion of Cyclopentene into the Mono- and DiAldehydes of Glutaric Acid. Berichte 41, 1701-1711.

Hayes, B. B., Afshari, A., Millecchia, L., Willard, P. A., Povoski, S. P., and Meade, B. J. (2000). Evaluation of the Percutaneous Penetration of Latex Proteins. Tox Sci 56, 262270.

Hayes, J. P., Lotvall, J. O., Barniuk, J., Daniel, R., Barnes, P. J., Taylor, A. J. N., and Chung, K. F. (1992). Bronchoconstriction and Airway Microvascular Leakage in Guinea Pigs Sensitized with Trimellitic Anhydride. Am Rev Resp Dis 146, 1306-1310.

Henricson, B. E., Benjamin, W. R., and Vogel, S. N. (1990). Differential Cytokine Induction by Doses of Lipopolysaccharide and Monophosphoryl Lipid A that Result in Equivalent Early Endotoxin Tolerance. Infection and Immunity 58, 2429-2437.

Heo, Y., Saxon, A., and Hankinson, O. (2001). Effect of Diesel Exhaust Particles and Their Components on the Allergen-Specific IgE and IgG1 Response in Mice. Toxicology 159, 143-158.

Hermes, B., Worm, M., Nowak, F., Kroczek, R. A., Stein, H., and Henz, B. M. (1997). Upregulation of CD40 and CD40 Ligand Expression in IgE-Associated Cutaneous Disease. Acta Derm Venereol 77, 441-445.

Hilton, J., Dearman, R. J., Basketter, D. A., and Kimber, I. (1994). Serological Responses Induced in Mice by Immunogenic Proteins and by Protein Respiratory Allergens. Toxicol Lett 73, 43-53.

Hilton, J., Dearman, R. J., Harvey, P., Evans, P., Basketter, D. A., and Kimber, I. (1998). Estimation of Relative Skin Sensitizing Potential Using the Local Lymph Node Assay: A Comparison of Formaldehyde with Glutaraldehyde. American Journal of Contact Dermatitis 9, 29-33.

Hoefer (1994). Protein electrophoresis: application guide.

Hopwood, D., Callen, C. R., and McCabe, M. (1970). The Reactions Between Glutaraldehyde and Various Proteins. An Investigation of Their Kinetics. Histochemical Journal 2, 137-150.

Howell, M. D., Hayes, B. B., and Meade, B. J. (2002a). Populational Differences in Prevalence to Hev b 1 or Hev b 6.02 are not Dependent on Dermal Penetration. Journal of Toxicology - Cutaneous and Ocular Toxicology 21: 293-305.

Howell, M. D., Manetz, T. S., and Meade, B. J. (2000). Comparison of Murine Assays for the Identification of Chemical Sensitizers. Toxicology Methods 10, 1-15. 
Howell, M. D., Weissman, D. N., and Meade, B. J. (2002b). Latex Sensitization by Dermal Exposure Can Lead to Airway Hyper-Reactivity. Int Arch Allergy Immunol 128, 204-211.

Howes, D., Guy, R., Hadgraft, J., Heylings, J., Hoeck, U., Kemper, F., Maibach, H., Marty, J.-P., Merk, H., Parra, J., Rondelli, I., Schaefer, H., Tauber, U., and Verbiese, N. (1996). ECVAM Workshop Report 13: Methods for assessing percutaneous absorption. ATLA 24, 81-106.

Huang, T., MacAry, P. A., Eynott, P., Moussavi, A., Daniel, K. C., Askenase, P. W., Kemeny, D. M., and Chung, K. F. (2001). Allergen-Specific Th1 Cells Counteract Efferent Th2 Cell-Dependent Bronchial Hyperresponsiveness adn Eosinophilic Inflammation Partly Via IFN- $\gamma$. J Immunol 166, 207-217.

Huang, T., MacAry, P. A., Wilke, T., Kemeny, D. M., and Chung, K. F. (1999). Inhibitory Effects of Endogenous and Exogenous Interferon-gamma on Bronchial Hyperresponsiveness, Allergic Inflammation, and T-Helper 2 Cytokines in BrownNorway Rats. Immunology 98, 280-288.

Jachuck, S. J., Bound, C. L., Steel, J., and Blain, P. G. (1989). Occupational Hazard in Hospital Staff Exposed to 2 Percent Glutaraldehyde in an Endoscopy Unit. J. Soc. Occup. Medicine 39, 69-71.

Jacob, J.-L., d'Auzac, J., and Prevot, J.-C. R. n. (1993). The Composition of Natural Latex from Hevea brasiliensis. Clinical Reviews in Allergy 11, 325-337.

Jacobs, R. R. (1997). Analyses of Endotoxins. International Journal of Occupational and Environmental Health 3, S42 -S48.

Jaeger, D., Kleinhans, D., Czuppon, A. B., and Baur, X. (1992). Latex-Specific Proteins Causing Immediate-Type Cutaneous, Nasal, Bronchial, and Systemic Reactions. $J$ Allergy Clin Immunol 89, 759-768.

Jaworsky, C., Taylor, J. S., Evey, P., and Handel, D. (1987). Allergic Contact Dermatitis to Glutaraldehyde in a Hair Conditioner. Cleveland Clinical Journal of Medicine 54, 443444.

Jeppson, J. D., Patel, R. R., Sakata, N., Domenico, J., Terada, N., and Gelfand, E. W. (1998). Requirement for Dual Signals by Anti-CD40 and IL-4 for the Induction of Nuclear Factor-кB, IL-6, and IgE in Human B Lymphocytes. J Immunol 161, 1738-1742.

Jordan, S. L., Stowers, M. F., Trawick, E. G., and Theis, A. B. (1996). Glutaraldehyde Permeation: Choosing the Proper Glove. Am J Infect Control 24, 67-69.

Kagy, L., and Blaiss, M. S. (1998). Anaphylaxis in Children. Pediatric Annals 27, 727734. 
Kattan, H., Harfi, H. A., and Tipirneni, P. (1999). Latex Allergy in Saudi Children with Spina Bifida. Allergy 54, 70-73.

Kelly, A. E., Chen, B., Woodward, E. C., and Conrad, D. H. (1998). Production of a Chimeric Form of CD23 That Is Oligomeric and Blocks IgE Binding to the FceRI. $J$ Immunol 161, 6696-6704.

Kelso, J. M. (1998). Latex Allergy. Pediatric Annals 27, 736-739.

Kiener, P. A., Marek, F., Rodgers, G., Lin, P., Warr, G., and Desiderio, J. (1988). Induction of Tumor Necrosis Factor, IFN-gamma, and Acute Lethality in Mice by Toxic and Non-Toxic Forms of Lipid A. J Immunol 141, 870-874.

Kleinhans, D. (1984). Contact urticaria to rubber gloves. Contact Dermatitis 10, 124-125.

Knop, J., and Enk, A. H. (1995). Cellular and Molecular Mechanisms in the Induction Phase of Contact Sensitivity. Int. Arch Allergy Immunol 107, 231-232.

Kotani, S., Takada, H., Tsujimoto, M., Ogawa, T., Harada, K., Mori, Y., Kawasaki, A., Tanaka, A., Nagao, S., Tanaka, S., Shiba, T., Kusumoto, S., Imoto, M., Yoshimura, H., Yamamoto, M., and Shimamoto, T. (1984). Immunobiologically Active Lipid A Analogs Synthesized According to a Revised Structural Model of Natural Lipid A. Infection and Immunity 45, 293-296.

Kujala, V. M., and Reijula, K. E. (1995). Glove-Induced Dermal and Respiratory Symptoms Among Health Care Workers in One Finnish Hospital. Am J Ind Med 28, 8998.

Kurup, V., Kumar, A., Choi, H., Murali, P. S., Resnick, A., Kelly, K. J., and Fink, J. N. (1994). Latex Antigens Induce IgE and Eosinophils in Mice. Int Arch Allergy Immunol 103, 370-377.

Laemmli, U. K. R. n. (1970). Cleavage of Structural Proteins during the Assembly of the Head of Bacteriophage T4. Nature 227, 680-685.

Lagier, F., Vervloet, D., Lhermet, I., Poyen, D., and Charpin, D. (1992). Prevalence of Latex Allergy in Operating Room Nurses. J Allergy Clin Immunol 90, 319-322.

Landwehr, L. P., and Boguniewicz, M. (1996). Current perspectives on latex allergy. Journal of Pediatrics 128, 305-312.

Lantz, R. C., Birch, K., Hinton, D. E., and Burrell, R. (1985). Morphometric Changes of the Lung Induced by Inhaled Bacterial Endotoxin. Experimental and Molecular Pathology 43, 305-320.

Lastbom, L., Boman, A., Camner, P., and Ryrfeldt, A. (2000). Increased Airway Responsiveness after Skin Sensitization to 3-Carene, Studied in Isolated Guinea Pig Lungs. Toxicology 147, 209-214. 
Lazaar, A. L., Amrani, Y., Hsu, J., Panettieri, R. A., Fanslow, W. C., Albelda, S. M., and Pure, E. (1998). CD40-Mediated Signal Transduction in Human Airway Smooth Muscle. J Immunol 161, 3120-3127.

Lefort, J., Motreff, L., and Vargaftig, B. B. (2001). Airway Administration of Escherichia coli Endotoxin to Mice Induces Glucocorticosteroid-Resistant and Vasopermeation. American Journal of Respiratory Cell and Molecular Biology 24, 345351.

Lefort, J., Singer, M., Leduc, D., Renesto, P., Nahori, M. A., Huerre, M., Creminon, C., Chignard, M., and Vargaftig, B. B. (1998). Systemic Administration of Endotoxin Induces Bronchopulmonary Hyperreactivity Dissociated from TNF- $\alpha$ Formation and Neutrophil Sequestration into the Murine Lungs. J Immunol 161, 474-480.

Lehman, P. A., Franz, T. J., and Guin, J. D. (1994). Penetration of Glutaraldehyde Through Glove Material: Tactylon Versus Natural Rubber Latex. Contact Dermatitis 30, 176-177.

Leinster, P., Baum, J. M., and Baxter, P. J. (1993). An Assessment of Exposure to Glutaraldehyde in Hospitals: Typical Exposure Levels and Recommended Control Measures. British Journal of Industrial Medicine 50, 107-111.

Levy, D. A., Charpin, D., Pecquet, C., Leynadier, F., and Vervloet, D. (1992). Allergy to latex. Allergy 47, 579-587.

Liss, G. M., and Sussman, G. L. (1999). Latex sensitization: occupational versus general population prevalence rates. Am J Ind Med 35, 196-200.

Liss, G. M., Sussman, G. L., Deal, K., Brown, S., Cividino, M., Siu, S., Beezhold, D. H., Smith, G., Swanson, M. C., Yunginger, J., Douglas, A., Holness, D. L., Lebert, P., Keith, P., Wasserman, S., and Turjanmaa, K. (1997). Latex Allergy: Epidemiological Study of 1351 Hospital Workers. Occup Environ Med 54, 335-342.

Liu, F. T., Bohn, J. W., Ferry, E. L., Yamamoto, H., Molinaro, C. A., Sherman, L. A., Klinman, N. R., and Katz, D. H. (1980). Monoclonal Dinitrophenyl-Specific Murine IgE Antibody: Preparation, Isolation, and Characterization. J Immunol 124, 2728-2737.

Lovik, M., Hogseth, A., Gaarder, P. I., Hagemann, R., and Eide, I. (1997). Diesel Exhaust Particles and Carbon Black have Adjuvant Activity on the Local Lymph Node Response and Systemic IgE Production to Ovalbumin. Toxicology 121, 165-178.

Luheshi, G., and Rothwell, N. (1996). Cytokines and Fever. Int Arch Allergy Immunol 109, 301-307.

Manetti, R., Parronchi, P., Giudizi, M. G., Piccinni, M., Maggi, E., Trinchieri, G., and Romagnani, S. (1993). Natural Killer Cell Stimulatory Factor (Interleukin 12 [IL-12]) Induces $\mathrm{T}$ Helper Type 1 (Th1)-specific Immune Responses and Inhibits the Development of IL-4-producing Th Cells. J Exp Med 177, 1199-1204. 
Manetz, T. S., and Meade, B. J. (1999). Development of a Flow Cytometry Assay for the Potential Identification and Differentiation of Chemicals Known to Elicit Irritation, IgEmediated, or T cell-mediated Hypersensitivity Responses. Tox Sci 48, 206-217.

Markwell, M. A. K. (1982). A New Solid-State Reagent to Iodinate Proteins: I. Conditions for the Efficient Labeling of Antiserum. Analytical Biochemistry 125, 427432.

Martin, L., Guennoc, B., Machet, L., and Dupin, M. (1997). Non-Occupational Contact Allergy to Glutaraldehyde. Contact Dermatitis 37, 137.

Mattern, T., Thanhauser, A., Reiling, N., Toellner, K., Duchrow, M., Kusumoto, S., Tietschel, E., Ernst, M., Brade, H., Flad, H., and Ulmer, A. J. (1994). Endotoxin and Lipid A Stimulate Proliferation of Human T Cells in the Presence of Autologous Monocytes. J Immunol 153, 2996-3004.

McCracken, S. (1999). Latex Glove Hypersensitivity and Irritation: A Literature Review. Probe 33, 13-15.

Meade, B. J., Weissman, D. N., and Beezhold, D. H. (2002). Latex Allergy: Past and Present. International Immunopharmacology 2, 225-238.

Meding, B., and Fregert, S. (1984). Contact urticaria from natural latex gloves. Contact Dermatitis 10, 52-53.

Melchers, F., Braun, V., and Galanos, C. (1975). The Lipoprotein of the Outer Membrane of Escherichia coli: A B-Lymphocyte Mitogen. J Exp Med 142, 473-482.

Mellstrom, G. A., Lindberg, M., and Boman, A. (1992). Permeation and Destructive Effects of Disinfectants on Protective Gloves. Contact Dermatitis 26, 163-170.

Metzger, D. W., Buchanan, J. M., Collins, J. T., Lester, T. L., Murray, K. S., Van Cleave, V. H., Vogel, L. A., and Dunnick, W. A. (1996). Enhancement of Humoral Immunity by Interleukin-12. Annals of NY Academy of Science 795, 100-115.

Michel, O., Ginanni, R., Duchateau, J., Vertongen, F., Le Bon, B., and Sergysels, R. (1991). Domestic Endotoxin Exposure and Clinical Severity of Asthma. Clin Exp Allergy 21, 441-448.

Michel, O., Kips, J., Duchateau, J., Vertongen, F., Robert, L., Collet, H., Pauwels, R., and Sergysels, R. (1996). Severity of Asthma Is Related to Endotoxin in House Dust. American Journal of Respiratory and Critical Care Medicine 154, 1641-1646.

Milner, E. C. B., Rudbach, J. A., and Voneschen, K. B. (1983). Cellular Responses to Bacterial Lipopolysaccharide: T Cells Recognize LPS Determinants. Scandinavian Journal of Immunology 18, 21-28. 
Milton, D. K., Amsel, J., Reed, C. E., Enright, P. L., Brown, L. R., Aughenbaugh, G. L., and Morey, P. R. (1995). Cross-Sectional Follow-Up of a Flu-Like Respiratory Illness Among Fiberglass Manufacturing Employees: Endotoxin Exposure Associated with Two Distinct Sequelae. Am J Ind Med 28, 469-488.

Miyabara, Y., Takano, H., Ichinose, T., Lim, H., and Sagai, M. (1998). Diesel Exhaust Enhances Allergic Airway Inflammation and Hyperresponsiveness in Mice. American Journal of Respiratory and Critical Care Medicine 157, 1138-1144.

Mizoguchi, K., Nakashima, I., Hasegawa, Y., Isobe, K., Nagase, F., Kawashima, K., Shimokata, K., and Kato, N. (1986). Augmentation of Antibody Responses of Mice to Inhaled Protein Antigens by Simultaneously Inhaled Bacterial Lipopolysaccharides. Immunobiology 173, 63-71.

Morris, S. C., Madden, K. B., Adamovicz, J. J., Gause, W. C., Hubbard, B. R., Gately, M. K., and Finkelman, F. D. (1994). Effects of IL-12 on In Vivo Cytokine Gene Expression and Ig Isotype Selection. J Immunol 152, 1047-1056.

Morrison, D. C., and Ryan, J. L. (1979). Bacterial endotoxins and Host Immune Responses. Advances in Immunology 28, 293-450.

Morrison, D. C., and Ryan, J. L. (1987). Endotoxins and Disease Mechanisms. Annual Reviews of Medicine 38, 417-432.

Nelde, A., Teufel, M., Hahn, C., Duschl, A., Sebald, W., Brocker, E. B., and Grunewald, S. M. (2001). The Impact of the Route and Frequency of Antigen Exposure on the IgE Response in Allergy. Int Arch Allergy Immunol 124, 461-469.

Nethercott, J. R., Holiness, D. L., and Page, E. (1988). Occupational Contact Dermatitis Due to Glutaraldehyde in Health Care Workers. Contact Dermatitis 18, 193-196.

Nettis, E., Assennato, G., Ferrannini, A., and Tursi, A. (2002). Type I Allergy to Natural Rubber Latex and Type IV Allergy to Rubber Chemicals in Health Care Workers with Glove-Related Skin Symptoms. Clin Exp Allergy 32, 441-447.

Norback, D. (1988). Skin and Respiratory Symptoms from Exposure to Alkaline Glutaraldehyde in Medical Services. Scandinavian Journal of Work and Environmental Health 14, 366-371.

NRC (1996). Guide for the Care and Use of Laboratory Animals, pp. 125. National Research Council, Washington, D.C.

Nutter, A. F. (1979). Contact urticaria to rubber. Br J Derm 101, 597-598.

Oettgen, H. C. (2000). Regulation of the IgE Isotype Switch: New Insights on Cytokine Signals and the Functions of $\varepsilon$ Germline Transcripts. Current Opinion in Immunology 12, 618-623. 
Pauluhn, J., and Mohr, U. (1994). Assessment of Respiratory Hypersensitivity in GuineaPigs Sensitized to Diphenylmethane-4-4'-diisocyanate (MDI) and Challenged with MDI, Acetylcholine, or MDI-Albumin Conjugate. Toxicology 92, 53-74.

Payet, M., and Conrad, D. H. (1999). IgE Regulation in CD23 Knockout and Transgenic Mice. Allergy 54, 1125-1129.

Peavy, D. L., Adler, W. H., and Smith, R. T. (1970). The Mitogenic Effects of Endotoxin and Staphylococcal Enterotoxin B on Mouse Spleen Cells and Human Peripheral Lymphocytes. J Immunol 105, 1453-1458.

Peiro, S. A. (1990). Quantitative Determination of Endotoxins on Surgical Gloves. Journal of Hospital Infection 16, 167-172.

Pfaffi, M. W. (2001). A New Mathematical Model for Relative Quantification in RealTime RT-PCR. Nucleic Acids Research 29, 2002-2007.

Phillips, V. L., Goodrich, M. A., and Sullivan, T. J. (1999). Health Care Worker Disability Due to Latex Allergy and Asthma: A Cost Analysis. American Journal of Public Health 89, 1024-1028.

Pisaniello, D. L., Gun, R. T., Tkaczuk, M. N., and Crea, J. (1997). Glutaraldehyde Exposures and Symptoms Among Endoscopy Nurses in South Australia. Applied Occupational and Environmental Hygiene 12, 171-177.

Rattray, N. J., Botham, P. A., Hext, P. M., Woodcock, D. R., Fielding, I., Dearman, R. J., and Kimber, I. (1994). Induction of Respiratory Hypersensitivity to Diphenylmethane4,4'-Diisocyanate (MDI) in Guinea Pigs. Influence of Route of Exposure. Toxicology 88, $15-30$.

Richards, F. M., and Knowles, J. R. (1968). Glutaraldehyde as a Protein Cross-Linkage Reagent. Journal of Molecular Biology 37, 231-233.

Rietschel, E. T., Brade, H., Holst, O., Brade, L., Muller-Loennies, S., Mamat, U., Zahringer, U., Beckmann, F., Seydel, U., Brandenburg, K., Ulmer, A. J., Mattern, H., H., Schletter, J., Loppnow, H., Schonbeck, U., Flad, H. D., Hauschildt, S., Schade, U. F., Di Padova, F., Kusumoto, S., and Schumann, R. R. (1996). Bacterial Endotoxin: Chemical Constitution, Biological Recognition, Host Response, and Immunological Detoxification. Current Topics in Microbiology Immunology 216, 39-81.

Rietschel, E. T., Kirikae, T., Schade, F. U., Mamat, U., Schmidt, G., Loppnow, H., Ulmer, A. J., Zahringer, U., Seydel, U., Padova, F., Schreier, M., and Brade, H. (1994). Bacterial Endotoxin: Molecular Relationships of Structure to Activity and Function. FASEB 8, 217-225.

Riffo-Vasquez, Y., Pitchford, S., and Spina, D. (2000). Murine Models of Inflammation: Role of CD23. Allergy 55, 21-26. 
Robinson, M. K., Babcock, L. S., Horn, P. A., and Kawabata, T. T. (1996). Specific Antibody Responses to Subtilisin Carlsberg (Alcalase) in Mice: Development of an Intranasal Exposure Model. Fund. Appl. Toxicol. 34, 15-24.

Rylander, R., and Beijer, L. (1987). Inhalation of Endotoxin Stimulates Alveolar Macrophage Production of Platelet-Activating Factor. Am Rev Respir Dis 135, 83-86.

Salkowski, C. A., Detore, G. R., and Vogel, S. N. (1997). Lipopolysaccharide and Monophosphoryl Lipid A Differentially Regulate Interleukin-12, Gamma Interferon, and Interleukin-10 mRNA Production in Murine Macrophages. Infection and Immunity 65, 3239-3247.

Saloga, J., Renz, H., Larsen, G. L., and Gelfand, E. W. (1994). Increased Airways Responsiveness in Mice Depends on Local Challenge with Antigen. American Journal of Respiratory and Critical Care Medicine 149, 65-70.

Sandstrom, T., Bjermer, L., and Rylander, R. (1992). Lipopolysaccharide (LPS) Inhalation in Healthy Subjects Increases Neutrophils, Lymphocytes and Fibronectin Levels in Bronchoalveolar Lavage Fluid. European Respiratory Journal 5, 992-996.

Sandstrom, T., Bjermer, L., and Rylander, R. (1994). Lipopolysaccharide (LPS) Inhalation in Healthy Subjects Causes Bronchalveolar Neutrophilia, Lymphocytosis, and Fibronectin Release. Am J Ind Med 25, 103-104.

Schwarze, J., Cieslewicz, G., Joetham, A., Sun, L. K., Sun, W. N., Chang, T. W., Hamelmann, E., and Gelfand, E. W. (1998a). Antigen Specific Immunoglobulin-A Prevents Increased Airway Responsiveness and Lung Eosinophilia after Airway Challenge. American Journal of Respiratory and Critical Care Medicine 158, 519-525.

Schwarze, J., Hamelmann, E., Cieslewicz, G., Tomkinson, A., Joetham, A., Bradley, K., and Gelfand, E. W. (1998b). Local Treatment with IL-12 is an Effective Inhibitor of Airway Hyperresponsiveness and Lung Eosinophilia after Airway Challenge in Sensitized Mice. J Allergy Clin Immunol 102, 86-83.

Sikorski, E., Gerberick, G., Ryan, C., Miller, C., and Ridder, G. (1996). Phenotypic Analysis of Lymphocyte Subpopulations in Lymph Nodes Draining the Ear Following Exposure to Contact Allergens and Irritants. Fund. Appl. Toxicol. 34, 25-35.

Sinha, A., and Harrison, P. V. (1999). The Prevalence of Latex Allergy Among Hospital Employees in North-West England. Br J Derm 140, 567.

Slater, J. E. (1994). Latex Allergy. J Allergy Clin Immunol 94, 139-149.

Slater, J. E., Paupore, E. J., Elwell, M. R., and Truscott, W. (1998). Lipopolysaccharide Augments IgG and IgE Responses of Mice to the Latex Allergen Hev B 5. Journal of Allergy and Clinical Immunology 102, 977-983. 
Snapper, C. M., and Paul, W. E. (1987). Interferon- $\gamma$ and B Cell Stimulatory Factor-1 Reciprocally Regulate Ig Isotype Production. Science 236, 944-947.

Spaner, D., Dolovich, J., Tarlo, S., Sussman, G., and Buttoo, K. (1989). Hypersensitivity to Natural Latex. J Allergy Clin Immunol 83, 1135-1137.

Spergel, J. M., Mizoguchi, E., Brewer, J. P., Martin, T. R., Bhan, A. K., and Geha, R. S. (1998). Epicutaneous Sensitization with Protein Antigen Induces Localized Allergic Dermatitis and Hyperresponsiveness to Methacholine After Single Exposure to Aerosolized Antigen in Mice. J Clin Invest 101, 1614-1622.

Stern, G. (1927). (U)berempfindlochkeit gegen kautschuk als ursache von urticaria und quinckseschem (o)dem. Klinische Wochenschritf 6, 1096-1097.

Stern, M. L., Holsapple, M. P., McCay, J. A., and Munson, A. E. (1989). Contact Hypersensitivity Response to Glutaraldehyde in Guinea Pigs and Mice. Toxicology and Industrial Health 5, 31-43.

Stingeni, L., Lapomarda, V., and Lisi, P. (1995). Occupational Hand Dermatitis in Hospital Environments. Contact Dermatitis 33, 172-176.

Sultzer, B. M., and Goodman, G. W. (1976). Endotoxin Protein: A B-Cell Mitogen and Polyclonal Activator of C3H/HeJ Lymphocytes. J Exp Med 144, 821-827.

Sussman, G. L., and Beezhold, D. H. (1995). Allergy to Latex Rubber. Annals of Internal Medicine 122, 43-46.

Sussman, G. L., Liss, G. M., Deal, K., Brown, S., Cividino, M., Siu, S., Beezhold, D. H., Smith, G., Swanson, M. C., Yunginger, J., Douglas, A., Holness, D. L., Lebert, P., Keith, P., Waserman, S., and Turjanmaa, K. (1998). Incidence of Latex Sensitization Among Latex Glove Users. J Allergy Clin Immunol 101, 171-178.

Sussman, G. L., Tarlo, S., and Dolovich, J. (1991). The Spectrum of IgE-Mediated Responses to Latex. Journal of the American Medical Association 265, 2844-2847.

Suzuki, T., Kanoh, T., Ishimori, M., Ikeda, S., and Ohkuni, H. (1996). Adjuvant Activity of Diesel Exhaust Particulates (DEP) in Production of Anti-IgE and Anti-IgG1 Antibodies to Mite Allergen in Mice. J. Clin. Lab. Immunol. 48, 187-199.

Swanson, M. C., Bubak, M. E., Hunt, L. W., Yunginger, J. W., Warner, M. A., and Reed, C. E. (1994). Quantification of Occupational Latex Aeroallergens in a Medical Center. $J$ Allergy Clin Immunol 94, 445-451.

Szepfalusi, Z., Seidel, R., Bernert, G., Dietrich, W., Spitzauer, S., and Urbanek, R. (1999). Latex Sensitization in Spina Bifida Appears Disease-Associated. Journal of Pediatrics 134, 344-348. 
Tang, C., Inman, M. D., van Rooigen, N., Yang, P., Shen, H., Matsumoto, K., and O'Byrne, P. M. (2001). Th Type 1-Stimulating Activity of Lung Macrophages Inhibits Th2-Mediated Allergic Airway Inflammation by an IFN- $\gamma$-Dependent Mechanism. $J$ Immunol 166, 1471-1481.

Tarlo, S. M. (2001). Natural Rubber Latex Allergy and Asthma. Current Opinion in Pulmonary Medicine 7, 27-31.

Taylor, J. S., and Praditsuwan, P. (1996). Latex Allergy: Review of 44 Cases Including Outcome and Frequent Association with Allergic Hand Eczema. Arch Dermatol 132, 265-271.

Thakker, J. C., Xia, J. Q., Rickaby, D. A., Krenz, G. S., Kelly, K. J., Kurup, V. P., and Dawson, C. A. (1999). A Murine Model of Latex Allergy-Induced Airway Hyperreactivity. Lung 177, 89-100.

Tobias, P. S., Tapping, R. I., and Gegner, J. A. (1999). Endotoxin Interactions with Lipopolysaccharide-Responsive Cells. Clinical Infectious Diseases 28, 476-481.

Toci, G. R., Shah, S. R., Beezhold, D. H., and McGeady, S. J. (2002). Oral Latex Desensitization in Health Care Providers. Canadian Journal of Allergy and Clinical Immunology.

Tomazic, V. J., Shampaine, E. L., Lamanna, A., Withrow, T. J., Adkinson, N. F., and Hamilton, R. G. (1994). Cornstarch Powder on Latex Products is an Allergen Carrier. J Allergy Clin Immunol 93, 751-758.

Tomazic, V. J., Withrow, T. J., Fisher, B. R., and Dillard, S. F. (1992). Latex-Associated Allergies and Anaphylactic Reactions. Clinical Immunology and Immunopathology 64, 89-97.

Tomei, F., Martini, A., Marcellini, L., and Riservato, R. (2000). Latex Allergy. Panminerva Medicine 42, 217-222.

Toraason, M., Sussman, G., Beezhold, D., Meade, J., Biagini, R., and Germolec, D. (2000). Latex Allergy in the Workplace. Tox Sci 58, 5-14.

Toward, T. J., and Broadley, K. J. (2001). Chronic Lipopolysaccharide Exposure on Airway Function, Cell Infiltration, and Nitric Oxide Generation in Conscious Guinea Pigs: Effect of Rolipram and Dexamethasone. Journal of Pharmacology and Experimental Therapeutics 298, 298-306.

Tsuruta, D., Kaneda, K., Teramae, H., and Ishii, M. (1999). In Vivo Activation of Langerhans Cells and Dendritic Cells Epidermal T Cells in the Elicitation Phase of Murine Contact Hypersensitivity. Br J Derm 140, 392-399.

Turjanmaa, K. (1987). Incidence of Immediate Allergy to Latex Gloves in Hospital Personnel. Contact Dermatitis 17, 270-275. 
Turjanmaa, K. (1997). Contact urticaria from latex gloves. In Contact Urticaria Syndrome. (H. Maibach, and A. Lauerma, Eds.), pp. 173-188. CRC Press, Inc., Boca Rotan.

Turjanmaa, K., Laurila, K., Makinen-Kiljunen, S., and Reunala, T. (1988). Rubber Contact Urticaria: Allergenic Properties of 19 Brands of Latex Gloves. Contact Dermatitis 19, 362-367.

Turjanmaa, K., Makinen-Kiljunen, S., Reunala, T., and Palosuo, T. (1996). Natural Rubber Latex Allergy. Allergy 51, 593-602.

Ulevitch, R. J., and Tobias, P. S. (1995). Receptor-Dependent Mechanisms of Cell Stimulation by Bacterial Endotoxin. Annual Reviews in Immunology 13, 437-457.

Vandenplas, O. (1995). Occupational Asthma Caused by Natural Rubber Latex. European Respiratory Journal 8, 1957-1965.

Vernooy, J. H., Dentener, M. A., van Suylen, R. J., Buurman, W. A., and Wouters, E. F. M. (2002). Long-Term Intratracheal Lipopolysaccharide Exposure in Mice Results in Chronic Lung Inflammation and Persistent Pathology. American Journal of Respiratory Cell and Molecular Biology 26, 152-159.

Vogel, S. N., Hilfiker, M. L., and Caulfield, M. J. (1983). Endotoxin-Induced T Lymphocyte Proliferation. J Immunol 130, 1774-1779.

Vyas, A., Pickering, C. A. C., Oldham, L. A., Francis, H. C., Fletcher, A. M., Merrett, T., and Niven, R. M. (2000). Survey of Symptoms, Respiratory Function, and Immunology and Their Relation to Glutaraldehyde and Other Occupational Exposures Among Endoscopy Nursing Staff. Occup Environ Med 57, 752-759.

Walter, D. M., McIntire, J. J., Berry, G., McKenzie, A. N. J., Donaldson, D. D., DeKruyff, R. H., and Umetsu, D. T. (2001). Critical Role for IL-13 in the Development of Allergen-Induced Airway Hyperreactivity. J Immunol 167, 4668-4675.

Wan, G. H., Li, C. S., and Lin, R. H. (2000). Airborne Endotoxin Exposure and the Development of Airway Antigen-Specific Allergic Responses. Clin Exp Allergy 30, 426432.

Wang, M., Saxon, A., and Diaz-Sanchez, D. (1999). Early IL-4 Production Driving Th2 Differentiation in a Human In Vivo Allergic Model is Mast Cell Derived. Clinical Immunology 90, 47-54.

Warbrick, E. V., Dearman, R. J., and Kimber, I. (2002). IgG and IgE Antibody Responses Following Exposure of Brown Norway Rats to Trimellitic Anhydride: Comparison of Inhalation and Topical Exposure. Toxicology 172, 157-168.

Warshaw, E. (1998). Latex allergy. Journal of the American Acadamy of Dermatology 39, 1-24. 
Weinert, G. (1996). Latex Antigen, Glutaraldehyde Trigger Complaints and Solutions. Advance for Medical Laboratory Professionals.

Wetzel, G. D., and Kettman, J. R. (1981). Activation of Murine B Lymphocytes. III. Stimulation of B Lymphocyte Clonal Growth with Lipopolysaccharide and Dextran Sulfate. J Immunol 126, 723-728.

Weytjens, K., Labrecque, M., Malo, J. L., and Cartier, A. (1999). Asthma to Latex in a Seamstress. Allergy 54, 290-291.

Williams, P. B., and Halsey, J. F. (1997). Endotoxin as a Factor in Adverse Reactions to Latex Gloves. Ann Allergy Asthma Immunol 79, 303-310.

Woolhiser, M. R., Munson, A. E., and Meade, B. J. (2000). Immunological Responses of Mice Following Administration of Natural Rubber Latex Proteins by Different Routes of Exposure. Tox Sci 55, 343-351.

Xia, J.-Q., Rickaby, D. A., Kelly, K. J., Choi, H., Dawson, C. A., and Kurup, V. P. (1999). Immune response and airway reactivity in wild and IL-4 knockout mice exposed to latex allergens. Int Arch Allergy Immunol 118, 23-29.

Yanagihara, K., Seki, M., and Cheng, P. (2001). Lipopolysaccharide Induces Mucus Cell Metaplasia in Mouse Lung. American Journal of Respiratory Cell and Molecular Biology 24, 66-73.

Yoshimoto, T., Nagai, N., Ohkusu, K., Ueda, H., Okamura, H., and Nakanishi, K. (1998). LPS-stimulated SJL macrophages produce IL-12 and IL-18 that inhibit IgE production in vitro by induction of IFN-(g) production from CD3(int)IL-2Rbeta $(+)$ T cells. $J$ Immunol 161, 1483-1492.

Zak, H. N., Kaste, L. M., Schwarzenberger, K., Barry, M. J., and Galbraith, G. M. P. (2000). Health-Care Workers and Latex Allergy. Archives of Environmental Health 55, 336-346.

Zissu, D., Bonnet, P., and Binet, S. (1998). Histopathological Study in B6C3F1 Mice Chronically Exposed by Inhalation to Glutaraldehyde. Toxicol Lett 95, 131-139.

Zissu, D., Gagnaire, F., and Bonnet, P. (1994). Nasal and Pulmonary Toxicity of Glutaraldehyde in Mice. Toxicol Lett 71, 53-62. 


\section{Appendix 1}

Composition of One Liter of HEPES Balanced Hanks Salt Solution

Reagent

Calcium Chloride $\left(\mathrm{CaCl}_{2}\right)$, Anhydrous

Dextrose

$\operatorname{HEPES}\left(\mathrm{C}_{8} \mathrm{H}_{18} \mathrm{~N}_{2} \mathrm{O}_{4} \mathrm{~S}\right)$

Magnesium Sulfate $\left(\mathrm{MgSO}_{4} \cdot 7 \mathrm{H}_{2} \mathrm{O}\right)$

Potassium Chloride

Potassium Phosphate $\left(\mathrm{KH}_{2} \mathrm{PO}_{4}\right)$, monobasic

Sodium Bicarbonate $\left(\mathrm{NaHCO}_{3}\right)$

Sodium Chloride

Sodium Phosphate $\left(\mathrm{Na}_{2} \mathrm{HPO}_{4}\right)$, dibasic

Gentamicin sulfate
Concentration (mg/L)

1,000

5,960

200

400

60

320

7,000

50

50 


\section{Appendix 2: \\ Body Weights of Mice Exposed to Latex Proteins}

Table A.

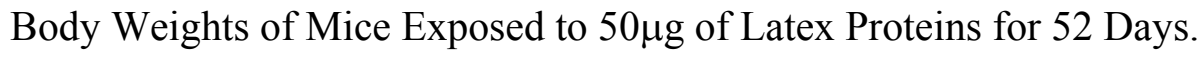

\begin{tabular}{lccc}
\hline Exposure Group & Pre-Exposure & Day 52 & Weight Change \\
\hline Naïve & $16.9 \pm 0.8$ & $19.3 \pm 0.5$ & $1.7 \pm 0.3$ \\
Vehicle & $17.2 \pm 0.4$ & $19.1 \pm 0.4$ & $1.7 \pm 0.1$ \\
Topical 1 & $17.2 \pm 0.4$ & $19.8 \pm 0.4$ & $2.7 \pm 0.2$ \\
Topical 2 & $17.4 \pm 0.5$ & $19.9 \pm 0.6$ & $2.5 \pm 0.6$ \\
Subcutaneous & $17.0 \pm 0.5$ & $19.5 \pm 0.6$ & $2.6 \pm 0.4$ \\
Intranasal & $17.2 \pm 0.3$ & $18.7 \pm 0.3$ & $1.5 \pm 0.3$ \\
Intratracheal & $17.2 \pm 0.3$ & $18.3 \pm 0.2$ & $0.9 \pm 0.2$ \\
\hline
\end{tabular}

Data presented is representative of the initial time course latex study comparing the sensitization rates following exposure to latex via different routes. Values represent the exposure group mean body weights (grams) \pm SE. Mice were weighed prior to initial exposure (Pre-Exposure) and on day 52. Statistical significance from vehicle exposed animals was calculated using a Dunnett's $t$ test. 
Table B.

Body Weights in Mice Dermally Exposed to Increasing Concentrations of Latex for 93 Days

\begin{tabular}{lccc}
\hline Exposure Group & Pre-Exposure & Day 88 & Weight Change \\
\hline Vehicle & $18.6 \pm 0.4$ & $21.7 \pm 0.3$ & $3.1 \pm 0.2$ \\
$6.25 \mu \mathrm{g}$ NAL & $18.7 \pm 0.5$ & $21.1 \pm 0.4$ & $2.4 \pm 0.3$ \\
$12.5 \mu \mathrm{g}$ NAL & $18.2 \pm 0.3$ & $19.5 \pm 0.2$ & $1.5 \pm 0.1$ \\
$25 \mu \mathrm{g}$ NAL & $18.7 \pm 0.6$ & $21.5 \pm 0.8$ & $3.0 \pm 0.6$ \\
\hline
\end{tabular}

Values represent the group mean weights (grams) \pm standard error in mice dermally exposed to latex proteins 5 days a week for 93 days. Mice weights were obtained prior to initial exposure and on day 88 of the study. The weight change was calculated as the difference in body weight between pre-exposure and day 88 . Statistical significance from vehicle exposed animals was calculated using a Dunnett's t test.

Table C.

Body Weights in Mice Intranasally Exposed to Increasing Concentrations of Latex for 51 Days

\begin{tabular}{lccc}
\hline Exposure Group & Pre-Exposure & Day 51 & Weight Change \\
\hline Vehicle & $18.5 \pm 0.6$ & $19.9 \pm 0.8$ & $1.4 \pm 0.3$ \\
$6.25 \mu$ g NAL & $18.9 \pm 0.6$ & $19.9 \pm 0.9$ & $1.1 \pm 0.5$ \\
12.5 $\mu$ g NAL & $18.3 \pm 0.3$ & $19.2 \pm 0.4$ & $0.9 \pm 0.4$ \\
$25 \mu$ NAL & $19.0 \pm 0.4$ & $20.1 \pm 0.6$ & $1.1 \pm 0.3$ \\
\hline
\end{tabular}

Values represent the group mean weights (grams) \pm standard error in mice intranasally exposed to latex proteins 5 days a week for 51 days. Mice weights were obtained prior to initial exposure and on day 51 of the study. The weight change was calculated as the difference in body weight between pre-exposure and day 51. Statistical significance from vehicle exposed animals was calculated using a Dunnett's t test. 
Table D.

Body Weights in Mice Intratracheally Exposed to Increasing Concentrations of Latex for 79 Days

\begin{tabular}{lccc}
\hline Exposure Group & Pre-Exposure & Day 79 & Weight Change \\
\hline Vehicle & $18.2 \pm 0.5$ & $20.7 \pm 0.4$ & $3.0 \pm 0.2$ \\
$6.25 \mu \mathrm{g}$ NAL & $17.2 \pm 0.4$ & $19.8 \pm 0.4$ & $2.6 \pm 0.2$ \\
$12.5 \mu \mathrm{g}$ NAL & $17.8 \pm 0.3$ & $20.0 \pm 0.7$ & $2.2 \pm 0.4$ \\
$25 \mu \mathrm{g}$ NAL & $17.5 \pm 0.4$ & $19.8 \pm 0.4$ & $2.3 \pm 0.1$ \\
\hline
\end{tabular}

Values represent the group mean weights (grams) \pm standard error in mice intratracheally exposed to latex proteins 5 days a week for 79 days. Mice weights were obtained prior to initial exposure and on day 79 of the study. The weight change was calculated as the difference in body weight between pre-exposure and day 79. Statistical significance from vehicle exposed animals was calculated using a Dunnett's t test. 
Table E.

Body Weights in Mice Intranasally Exposed to Latex and 5,000 - 50,000 EU of Endotoxin from Salmonella typhimurium.

\begin{tabular}{lccc}
\hline Exposure Group & Pre-Exposure & Day 72 & Weight Change \\
\hline Vehicle & $18.9 \pm 0.3$ & $20.0 \pm 0.4$ & $1.1 \pm 0.2$ \\
NAL & $19.3 \pm 0.5$ & $20.3 \pm 0.6$ & $1.0 \pm 0.2$ \\
& & & \\
S. typhimurium & & & \\
50,000 EU & $19.3 \pm 0.5$ & $20.7 \pm 0.5$ & $1.4 \pm 0.2$ \\
5,000 EU \& NAL & $19.4 \pm 0.4$ & $20.5 \pm 0.5$ & $1.1 \pm 0.2$ \\
12,500 EU \& NAL & $19.3 \pm 0.9$ & $20.7 \pm 1.0$ & $1.4 \pm 0.3$ \\
25,000 EU \& NAL & $19.0 \pm 0.4$ & $20.0 \pm 0.6$ & $1.0 \pm 0.3$ \\
37,500 EU \& NAL & $18.9 \pm 0.4$ & $20.2 \pm 0.4$ & $1.3 \pm 0.2$ \\
50,000 EU \& NAL & $19.4 \pm 0.4$ & $20.6 \pm 0.6$ & $1.2 \pm 0.3$ \\
\hline
\end{tabular}

Values represent the group mean weights (grams) \pm standard error in mice intranasally exposed to latex proteins and increasing concentrations of endotoxin $(5,000-50,000 \mathrm{EU})$ 5 days a week for 72 days. Mice weights were obtained prior to initial exposure and on day 72 of the study. The weight change was calculated as the difference in body weight between pre-exposure and day 72. Statistical significance from vehicle exposed animals was calculated using a Dunnett's $t$ test. 
Table F.

Body Weights of Mice Intranasally Exposed to Latex and Three Strains of Bacterial Endotoxin for 65 Days

\begin{tabular}{lccc}
\hline Exposure Group & Pre-Exposure & Day 65 & Weight Change \\
\hline Vehicle & $18.2 \pm 0.4$ & $20.2 \pm 0.3$ & $2.0 \pm 0.1$ \\
NAL & $18.1 \pm 0.3$ & $20.3 \pm 0.4$ & $2.3 \pm 0.2$
\end{tabular}

\section{S. typhimurium \\ $25000 \mathrm{EU}$}

50 EU \& NAL

500 EU \& NAL

1,250 EU \& NAL

2,500 EU \& NAL

5,000 EU \& NAL

25,000 EU \& NAL

E. coli

$25000 \mathrm{EU}$

50 EU \& NAL

500 EU \& NAL

1,250 EU \& NAL

2,500 EU \& NAL

5,000 EU \& NAL

25,000 EU \& NAL

$\begin{array}{lll}18.2 \pm 0.3 & 20.5 \pm 0.4 & 2.3 \pm 0.2 \\ 17.5 \pm 0.4 & 20.4 \pm 0.4 & 2.6 \pm 0.2 \\ 18.2 \pm 0.5 & 21.1 \pm 0.5 & 2.4 \pm 0.2 \\ 18.1 \pm 0.6 & 20.2 \pm 0.8 & 2.1 \pm 0.3 \\ 18.6 \pm 0.7 & 20.9 \pm 0.4 & 1.6 \pm 0.2 \\ 17.7 \pm 0.5 & 19.8 \pm 0.2 & 1.7 \pm 0.2 \\ 18.5 \pm 0.5 & 20.7 \pm 0.7 & 2.2 \pm 0.3\end{array}$

$17.8 \pm 0.3 \quad 19.8 \pm 0.2 \quad 2.0 \pm 0.1$

$18.1 \pm 0.5 \quad 20.3 \pm 0.6 \quad 2.2 \pm 0.3$

$17.3 \pm 0.4 \quad 19.0 \pm 0.7 \quad 1.7 \pm 0.5$

$17.6 \pm 0.3 \quad 19.7 \pm 0.4 \quad 2.1 \pm 0.4$

$18.0 \pm 0.4 \quad 19.5 \pm 0.3 \quad 1.5 \pm 0.3$

$18.6 \pm 0.1 \quad 20.5 \pm 0.3 \quad 1.9 \pm 0.2$

$17.7 \pm 0.2 \quad 19.4 \pm 0.2 \quad 1.7 \pm 0.1$

\section{S. typhosa}

$25000 \mathrm{EU}$

50 EU \& NAL

500 EU \& NAL

1,250 EU \& NAL

2,500 EU \& NAL

$$
18.4 \pm 0.3
$$

$20.5 \pm 0.3$

$2.1 \pm 0.1$

$18.1 \pm 0.4$

$20.4 \pm 0.7$

$2.3 \pm 0.2$

$17.8 \pm 0.4$

$19.6 \pm 0.4$

$1.9 \pm 0.2$

$17.5 \pm 0.6$

$19.4 \pm 0.7$

$1.9 \pm 0.3$

5,000 EU \& NAL

$18.2 \pm 0.3$

$21.1 \pm 0.4$

$2.6 \pm 0.3$

25,000 EU \& NAL

$18.7 \pm 0.3$

$21.0 \pm 0.5$

$2.0 \pm 0.3$

$17.1 \pm 0.3$

$19.4 \pm 0.2$

$2.3 \pm 0.3$

Values represent the group mean weights (grams) \pm standard error in mice intranasally exposed to latex proteins and increasing concentrations of endotoxin $(50-25,000 \mathrm{EU}) 5$ days a week for 65 days. Mice weights were obtained prior to initial exposure and on day 65 of the study. The weight change was calculated as the difference in body weight between pre-exposure and day 65. Statistical significance from vehicle exposed animals was calculated using a Dunnett's t test. 
Table G.

Body Weights of Mice Intratracheally Exposed to Latex and Endotoxin for 67 Days

\begin{tabular}{lccc}
\hline Exposure Group & Pre-Exposure & Day 67 & Weight Change \\
\hline Vehicle & $17.7 \pm 0.2$ & $18.7 \pm 0.5$ & $1.0 \pm 0.6$ \\
NAL & $17.9 \pm 0.5$ & $19.2 \pm 0.6$ & $1.4 \pm 0.2$
\end{tabular}

\section{S. typhimurium} $5000 \mathrm{EU}$

50 EU \& NAL

$$
17.6 \pm 0.2 \quad 20.0 \pm 0.5
$$

$2.4 \pm 0.6$

500 EU \& NAL

$17.4 \pm 0.6$

$18.0 \pm 0.3$

$0.6 \pm 0.4$

1,250 EU \& NAL

$18.0 \pm 0.4$

$21.1 \pm 0.3$

$3.1 \pm 0.4$

$2,500 \mathrm{EU} \& \mathrm{NAL}$

$18.1 \pm 0.4$

$20.2 \pm 0.5$

$2.0 \pm 0.2$

$5,000 \mathrm{EU} \& \mathrm{NAL}$

$18.0 \pm 0.5$

$20.8 \pm 0.5$

$2.8 \pm 0.3$

$17.8 \pm 0.5$

$18.2 \pm 0.2$

$0.4 \pm 0.5$

Values represent the group mean weights (grams) \pm standard error in mice intranasally exposed to latex proteins and increasing concentrations of endotoxin $(50-5,000 \mathrm{EU}) 5$ days a week for 67 days. Mice weights were obtained prior to initial exposure and on day 67 of the study. The weight change was calculated as the difference in body weight between pre-exposure and day 67. Statistical significance from vehicle exposed animals was calculated using a Dunnett's t test. 
Table H.

Body Weights in Mice Concurrently Exposed to Latex and Concentrations of Glutaraldehyde Found in Cold Sterilant Solutions $(0.1-1 \%)$

\begin{tabular}{lccc}
\hline Exposure Group & Pre-Exposure & Day 72 & Weight Change \\
\hline Vehicle & $18.9 \pm 0.4$ & $21.1 \pm 0.6$ & $2.2 \pm 0.3$ \\
NAL & $18.9 \pm 0.4$ & $21.8 \pm 0.2$ & $3.0 \pm 0.5$ \\
Glutaraldehyde & & & \\
1.0\% & $19.1 \pm 0.6$ & $22.3 \pm 0.7$ & $3.2 \pm 0.4$ \\
$\quad 0.1 \%$ \& NAL & $19.0 \pm 0.5$ & $21.5 \pm 0.4$ & $2.6 \pm 0.2$ \\
$0.5 \%$ \& NAL & $19.4 \pm 0.5$ & $21.1 \pm 0.6$ & $1.7 \pm 0.3$ \\
$1.0 \%$ \& NAL & $19.0 \pm 0.6$ & $21.6 \pm 0.3$ & $2.6 \pm 0.5$ \\
\hline
\end{tabular}

Values represent the group mean weights (grams) \pm standard error in mice intranasally exposed to latex proteins and increasing concentrations of glutaraldehyde $(0.1-1 \%) 5$ days a week for 72 days. Mice weights were obtained prior to initial exposure and on day 72 of the study. The weight change was calculated as the difference in body weight between pre-exposure and day 72. Statistical significance from vehicle exposed animals was calculated using a Dunnett's t test. 
Table I.

Body Weights in Mice Concurrently Exposed to Latex and Concentrations of Glutaraldehyde Surround the Permissible Exposure Limit (0.05 - 1ppm) for 65 Days

\begin{tabular}{lccc}
\hline Exposure Group & Pre-Exposure & Day 65 & Weight Change \\
\hline Vehicle & $18.9 \pm 0.6$ & $19.6 \pm 0.7$ & $0.7 \pm 0.2$ \\
NAL & $19.3 \pm 0.3$ & $20.0 \pm 0.3$ & $0.7 \pm 0.2$ \\
Glutaraldehyde & & & \\
$\quad$ 0.75ppm & $19.0 \pm 0.5$ & $19.2 \pm 0.3$ & $0.2 \pm 0.2$ \\
0.05ppm \& NAL & $19.2 \pm 0.4$ & $19.9 \pm 0.4$ & $0.7 \pm 0.2$ \\
0.2ppm \& NAL & $19.0 \pm 0.7$ & $19.9 \pm 0.7$ & $0.9 \pm 0.2$ \\
0.5ppm \& NAL & $19.2 \pm 0.6$ & $19.7 \pm 0.8$ & $0.5 \pm 0.2$ \\
0.75ppm \& NAL & $19.3 \pm 0.2$ & $20.2 \pm 0.3$ & $1.0 \pm 0.2$ \\
1.0ppm \& NAL & $19.3 \pm 0.5$ & $19.9 \pm 0.4$ & $0.6 \pm 0.2$ \\
\hline
\end{tabular}

Values represent the group mean weights (grams) \pm standard error in mice intranasally exposed to latex proteins and increasing concentrations of glutaraldehyde $(0.05-1 \mathrm{ppm})$ 5 days a week for 65 days. Mice weights were obtained prior to initial exposure and on day 65 of the study. The weight change was calculated as the difference in body weight between pre-exposure and day 65. Statistical significance from vehicle exposed animals was calculated using a Dunnett's t test. 
Table J.

Body Weights in a Repeat Study with Mice Concurrently Exposed to Latex and Concentrations of Glutaraldehyde Surround the Permissible Exposure Limit (0.05 $1 \mathrm{ppm})$ for 86 Days

\begin{tabular}{lccc}
\hline Exposure Group & Pre-Exposure & Day 86 & Weight Change \\
\hline Vehicle & $18.0 \pm 0.4$ & $21.5 \pm 0.4$ & $3.4 \pm 0.3$ \\
NAL & $19.0 \pm 0.5$ & $21.4 \pm 0.8$ & $2.4 \pm 0.7$ \\
Glutaraldehyde & & & \\
$\quad$ 0.75ppm & $19.2 \pm 0.4$ & $22.4 \pm 0.2$ & $3.5 \pm 0.2$ \\
0.05ppm \& NAL & $18.1 \pm 0.4$ & $21.2 \pm 0.5$ & $3.0 \pm 0.8$ \\
0.2ppm \& NAL & $18.4 \pm 0.5$ & $21.2 \pm 0.2$ & $2.8 \pm 0.4$ \\
0.5ppm \& NAL & $19.2 \pm 0.5$ & $23.8 \pm 0.5$ & $4.6 \pm 0.2$ \\
0.75ppm \& NAL & $18.4 \pm 0.6$ & $21.8 \pm 1.0$ & $3.3 \pm 0.4$ \\
1.0ppm \& NAL & $18.6 \pm 0.3$ & $22.7 \pm 0.5$ & $4.2 \pm 0.4$ \\
\hline
\end{tabular}

Values represent the group mean weights (grams) \pm standard error in mice intranasally exposed to latex proteins and increasing concentrations of glutaraldehyde $(0.05-1 \mathrm{ppm})$ 5 days a week for 86 days. Mice weights were obtained prior to initial exposure and on day 86 of the study. The weight change was calculated as the difference in body weight between pre-exposure and day 86 . Statistical significance from vehicle exposed animals was calculated using a Dunnett's t test. 
Table K.

Body Weights in Mice Concurrently Exposed on the Ear Pinna to Latex and Glutaraldehyde for 86 Days

\begin{tabular}{lccc}
\hline Exposure Group & Pre-Exposure & Day 86 & Weight Change \\
\hline Vehicle & $19.9 \pm 0.2$ & $22.0 \pm 0.3$ & $2.2 \pm 0.3$ \\
NAL & $20.3 \pm 0.4$ & $22.7 \pm 0.5$ & $2.4 \pm 0.2$ \\
Glutaraldehyde & & & \\
$\quad$ 0.75ppm & $19.6 \pm 0.2$ & $22.4 \pm 0.4$ & $2.8 \pm 0.2$ \\
0.75ppm \& NAL & $19.5 \pm 0.3$ & $21.7 \pm 0.4$ & $2.2 \pm 0.3$ \\
$\quad$ 1.0ppm \& NAL & $20.2 \pm 0.4$ & $22.6 \pm 0.6$ & $2.4 \pm 0.4$ \\
\hline
\end{tabular}

Values represent the group mean weights (grams) \pm standard error in mice intranasally exposed to latex proteins and either 0.75 or $1 \mathrm{ppm}$ glutaraldehyde 5 days a week on the dorsal surface of the ear pinna for 86 days. Mice weights were obtained prior to initial exposure and on day 86 of the study. The weight change was calculated as the difference in body weight between pre-exposure and day 86. Statistical significance from vehicle exposed animals was calculated using a Dunnett's t test. 


\title{
Vita
}

Michael David Howell was born on May 30, 1976 in Binghamton, New York. He received his Bachelor of Science degree in Biology from Messiah College (Grantham, PA) in May of 1997. In the fall of 1997, Michael entered the Department of Microbiology, Immunology, and Cell Biology in the School of Medicine at West Virginia University (Morgantown, WV) to further his scientific career.

\section{Career Experience}

Research Fellow

June 1998 - August 2002

Agriculture and Immunotoxicology Group

National Institute for Occupational Safety \& Health (NIOSH)

Office of the Director

Morgantown, West Virginia

Graduate Student

August 1997 - August 2002

Department of Microbiology, Immunology, and Cell Biology

West Virginia University

School of Medicine

Morgantown, West Virginia

\section{Publications}

Howell, Michael D., Benjamin B. Hayes, and B. Jean Meade. 2002. Population Differences in Prevalence to Hev b 1 or Hev b 6.02 is Not Dependent on Dermal Penetration. Journal of Toxicology: Ocular and Cutaneous Toxicology 21: 293-305.

Howell, Michael D., David N. Weissman, and B. Jean Meade. 2002. Latex Sensitization by Dermal Exposure Can Lead to Airway Hyper-Reactivity. International Archives of Allergy and Immunology 128: 204-211.

Howell, Michael D., T. Scott Manetz, and B. Jean Meade. 2000. Comparison of Murine Assays for the Identification of Chemical Sensitizers. Toxicology Methods 10: 1-15.

\begin{abstract}
s
Howell, Michael D. and B. Jean Meade. 2001. Modulation of the IgE Response to Natural Rubber Latex Proteins by Glutaraldehyde. Toxicology 164: 114.

Howell, Michael D., Vesna Tomazic-Jezic, Wava Truscott, Tina Leakakos, Claud M. Johnson, and B. Jean Meade. 2001. Immunomodulation of the IgE Response to Natural Rubber Latex Proteins by Endotoxin and Glutaraldehyde. Toxicologist 58: 830.

Howell, Michael D., Vesna Tomazic-Jezic, Wava Truscott, Tina Leakakos, and B. Jean Meade. 2000. Immunomodulatory Effects of Glutaraldehyde on the Development of IgE
\end{abstract}


in Response to Dermal Exposure to Natural Rubber Latex Proteins. American Association of Immunologists and Clinical Immunology Society Joint Annual Meeting; Seattle, WA.

Howell, Michael D., Benjamin B. Hayes, Harri Alenius, B. Jean Meade. 2000. Skin Penetration by the Natural Rubber Latex Proteins, Hevein, and Rubber Elongation Factor. Toxicologist 54: 727.

Howell, Michael D., Benjamin B. Hayes, Steven P. Povoski, and B. Jean Meade. 1999. Skin Penetration by Latex Proteins. Foundations of Immunotoxicology Meeting; Morgantown, WV.

Howell, Michael D., T. Scott Manetz, and B. Jean Meade. 1999. Comparison of Murine Models in the Identification of Potential Chemical Sensitizers. Toxicologist 48: 1480.

Valosen, John M., Ben B. Hayes, Michael D. Howell, T. Scott Manetz, Michael R. Woolhiser, and B. Jean Meade. 1999. Evaluation of Human Irritants and Weak to Moderate Sensitizers Using a Modified LLNA and an Irritancy/Phenotyping Assay. Toxicologist 48: 1478.

Olenchock, Ben O., Michael D. Howell, John M. Valosen, and B. Jean Meade. 1999. The Role of Endotoxin in the Development of Latex Allergy. Toxicologist 48: 1485.

\section{Platform Presentations}

Howell, Michael D. and B. Jean Meade. 2002. Immunomodulatory Roles of Endotoxin and Glutaraldehyde in the Development of Latex Allergy. Presented to the Inflammation Interest Group at NIOSH, Morgantown, WV.

Howell, Michael D. and B. Jean Meade. 2002. Immunomodulation of the IgE Mediated Response to Natural Rubber Latex Proteins Upon Concurrent Chemical Exposure. Van Liere Research Convocation: Morgantown, WV.

Howell, Michael D. and B. Jean Meade. 2001. Latex Allergy: Effects of Concurrent Exposure to Endotoxin or Glutaraldehyde. Van Liere Research Convocation: Morgantown, WV.

Howell, Michael D., Michael R. Woolhiser, and B. Jean Meade. 1999. Variables Effecting the Outcome of the LLNA (Mouse Strain, Sex, Exposure Duration). Experimental Contact Dermatitis Research Group Meeting; Cincinnati, $\mathrm{OH}$. 